\title{
Pre and Post Blast Chemical Comparison of the Intra- and Inter- Variability of Metal Pipes Commonly Used in Pipe Bombs
}

\author{
Mandi Hellested \\ West Virginia University
}

Follow this and additional works at: https://researchrepository.wvu.edu/etd

\author{
Recommended Citation \\ Hellested, Mandi, "Pre and Post Blast Chemical Comparison of the Intra- and Inter-Variability of Metal \\ Pipes Commonly Used in Pipe Bombs" (2012). Graduate Theses, Dissertations, and Problem Reports. \\ 527. \\ https://researchrepository.wvu.edu/etd/527
}

This Thesis is protected by copyright and/or related rights. It has been brought to you by the The Research Repository @ WVU with permission from the rights-holder(s). You are free to use this Thesis in any way that is permitted by the copyright and related rights legislation that applies to your use. For other uses you must obtain permission from the rights-holder(s) directly, unless additional rights are indicated by a Creative Commons license in the record and/ or on the work itself. This Thesis has been accepted for inclusion in WVU Graduate Theses, Dissertations, and Problem Reports collection by an authorized administrator of The Research Repository @ WVU. For more information, please contact researchrepository@mail.wvu.edu. 


\title{
Pre and Post Blast Chemical Comparison of the Intra- and Inter- Variability of Metal Pipes Commonly Used in Pipe Bombs
}

\author{
Mandi Hellested \\ Thesis Submitted to the \\ Eberly College of Arts and Sciences \\ at West Virginia University \\ in partial fulfillment of the requirements \\ for the degree of \\ Master of Science \\ in \\ Forensic and Investigative Science \\ Keith B. Morris, Ph.D., Chair \\ Suzanne Bell, Ph.D. \\ Michael Smith, Ph.D.
}

Forensic and Investigative Science Program

Morgantown, West Virginia

2012

Keywords: Forensic Science; Pipe Bombs; X-ray Analysis; Elemental Composition; Steel 


\begin{abstract}
Pre and Post Blast Chemical Comparison of the Intra- and Inter- Variability of Metal Pipes Commonly Used in Pipe Bombs
\end{abstract}

Mandi Hellested

Pipe bombs are a substantial problem around the world killing and injuring thousands each year. Traditionally explosive used, residues of explosives, and bomb components have been the main source of evidence in the investigation of a located or exploded pipe bomb. This research analyzed the trace elemental compositions of metal pipes to investigate if pipes can be compared. It was found that in a sample set of 37 pipes, of different brands and purchase locations, each pipe was homogenous at trace elemental concentrations. This homogeneity allowed for comparison between pipes. An x-ray tube, as an alternate excitation source, which had been added to a traditional scanning electron microscope - energy dispersive x-ray spectrometry system was used in this research. X-ray excitation versus the electron excitation of traditional SEM was able to detect trace elements in the pipe metal. The method was able to discriminate between $80 \%$ of the total sample set by trace elemental analysis comparison. 


\section{Acknowledgements}

I would like to express my gratitude to my committee members Dr. Keith Morris, Dr. Suzanne Bell and Dr. Michael Smith for their unending patience and support during this research. Your knowledge and guidance was invaluable.

To my wonderful family and friends, who have been with me on the ups, downs and every step of this journey: we survived! Thank you for all of your love, support and cheering at the finish. 


\section{Table of Contents}

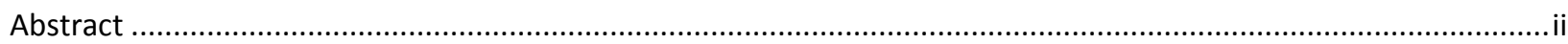

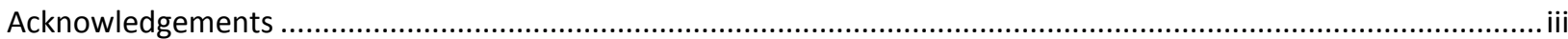

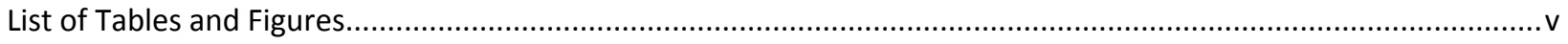

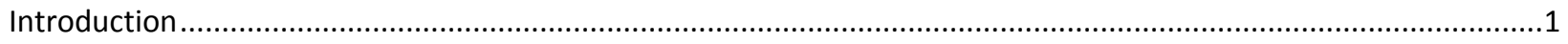

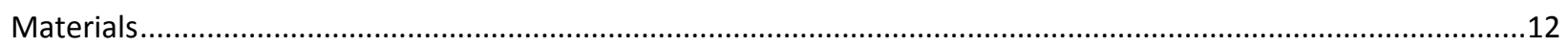

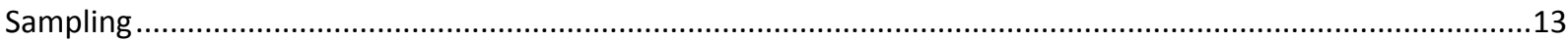

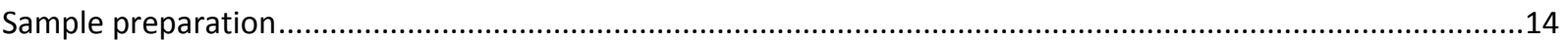

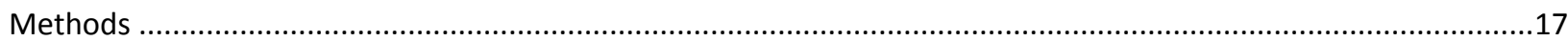

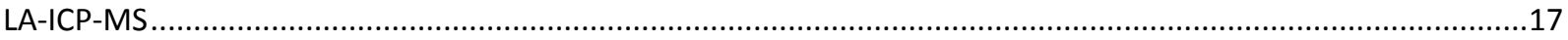

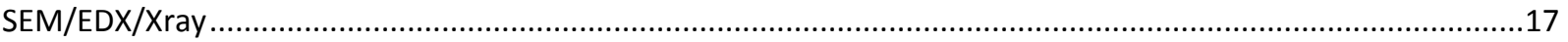

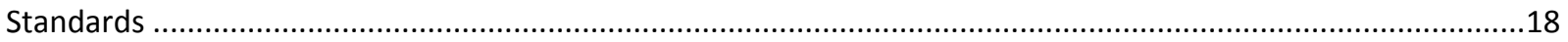

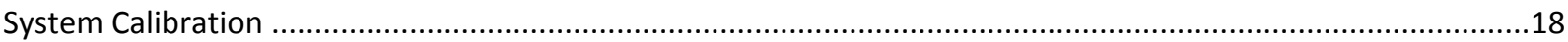

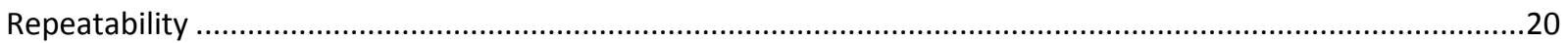

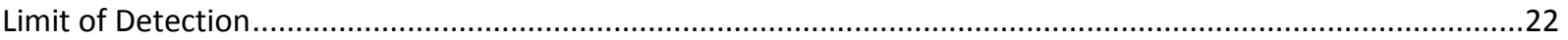

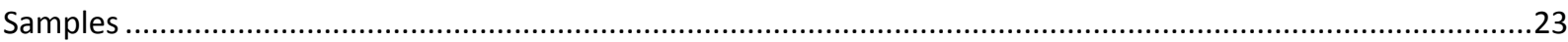

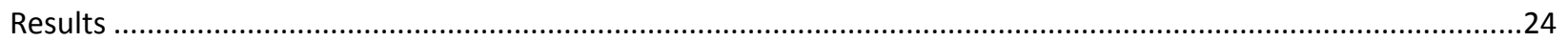

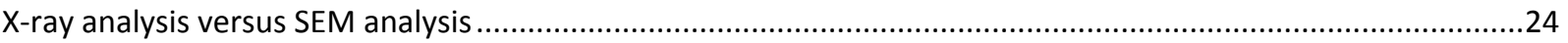

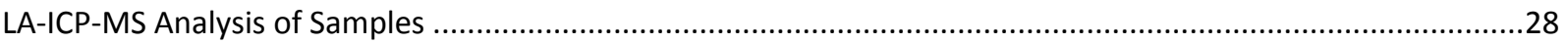

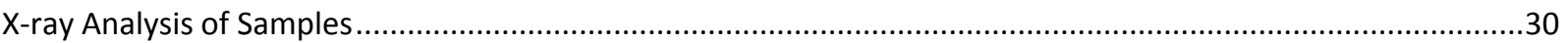

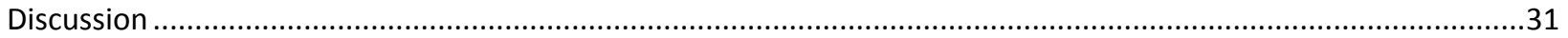

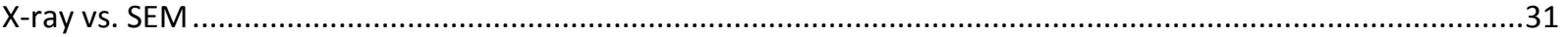

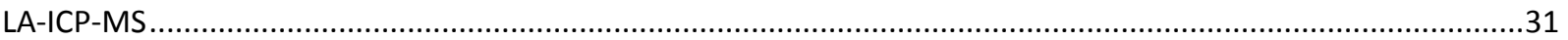

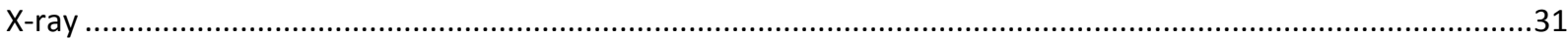

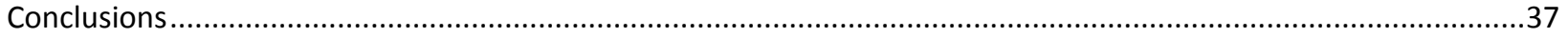

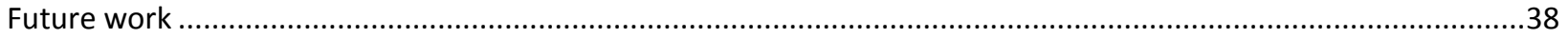

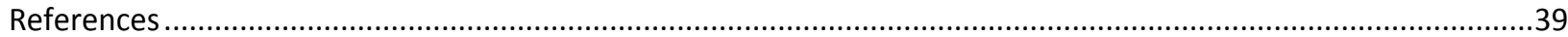

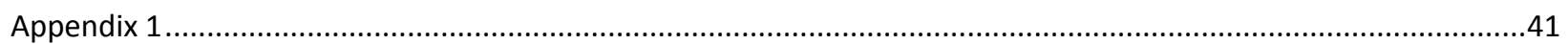

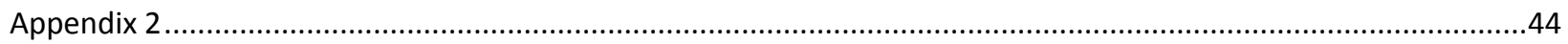

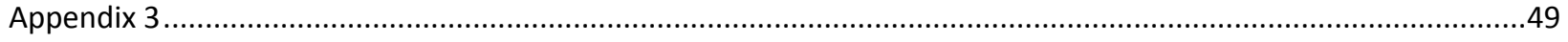

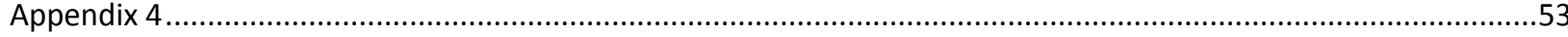

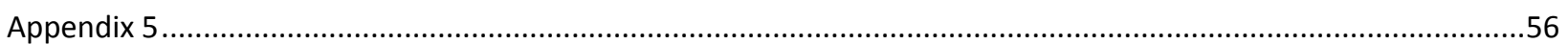

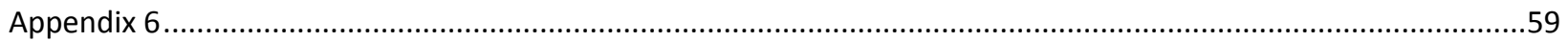

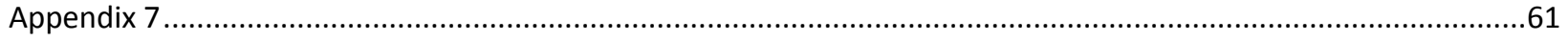

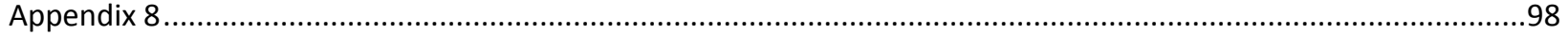




\section{List of Tables and Figures}

Table 1. ASTM maximum chemical composition for furnace-welded pipe $\ldots \ldots \ldots \ldots \ldots \ldots \ldots \ldots \ldots \ldots$

Table 2. Samples highlighted in gray denote samples sent for LA-ICP-MS testing.....................15

Figure 1. Slice from the center of the pipe ................................................... 16

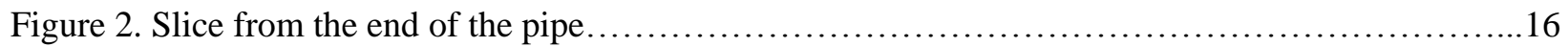

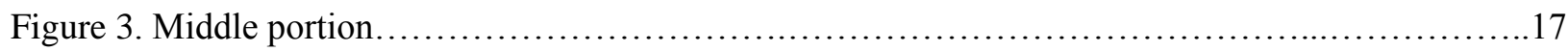

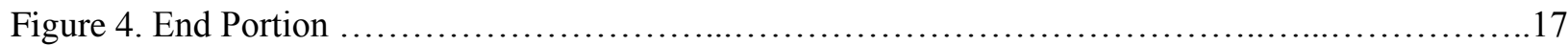

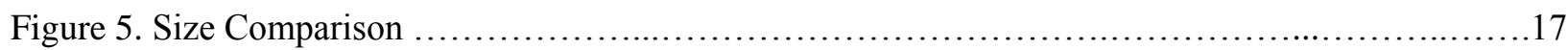

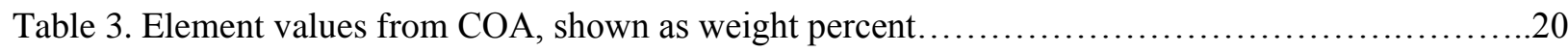

Figure 6. Control Chart for Copper Standard Intensities..........................................21

Figure 7. Control Chart for Copper Standard Energy .............................................21

Table 4. Average and Standard Deviation of 5 replicate BS-41 standards..........................22

Table 5. Average and Standard Deviation of all BS-41 Standards......................................22

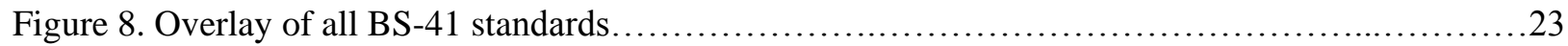

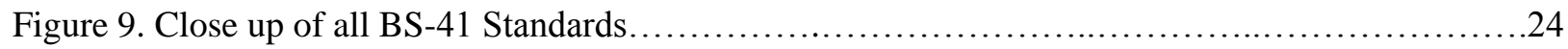

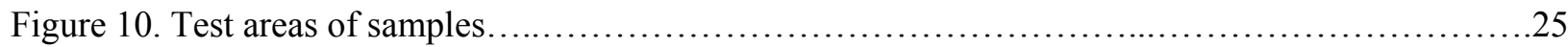

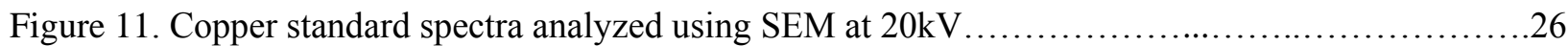

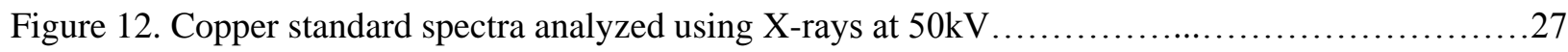

Table 6. Comparison of X-ray and SEM concentrations to BS-41 Standard.........................27

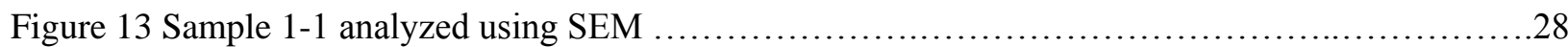

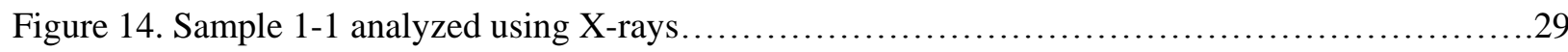

Figure 15 Sample 1-1 analyzed using X-rays, zoomed in on spectrum............................29

Table 7. Averaged Elemental concentrations (ppm) from LA-ICP-MS Analysis..........................33

Figure 16. Comparison of samples by titanium and vanadium....................................

Figure 17. Comparison of samples by copper and tin...............................................

Table 8. Pipes 1 compared for differentiation..................................................... 34

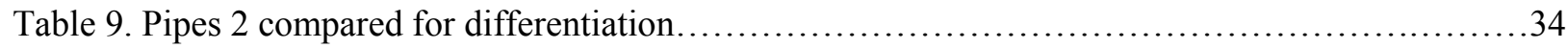

Figure 18. Spectra of samples 5-1 and 5-3 at the titanium peak....................................

Figure 19. Spectra of samples 5-1, 5-2, and 5-3 at the titanium peak................................ 36

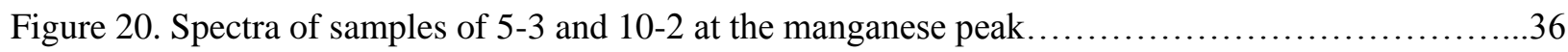

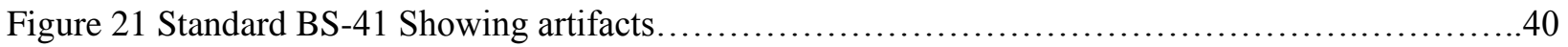




\section{Introduction}

According data collected by the Federal Bureau of Investigation, between the years 1988 and 1997 there were a total of 13,654 actual explosive bombings and 3,728 attempted explosive bombings in the United States (1). Karmy-Jones et al. (2) reviewed data from 1980 to 1990 and found that of 12,216 bombing incidents the majority (53\%) of the devices were pipe bombs. More recent data shows that bombings are still very much a source of concern for law enforcement. According to the U.S. Bomb Data Center, organized by the ATF, between 2004 and 2006 there were 10,957 explosive incidents, with 546 injuries, and 68 fatalities (3). Pipe bombs are by no means at all an issue just for the United States, they are a global problem. The National Counterterrorism Center's 2010 Report on Terrorism states that bombings were the most lethal of all terrorist attacks globally (4). In 2010 there were 4,275 bombings that resulted in 6,595 fatalities (4).

A pipe bomb is a sub-set within improvised explosive devices (IED). Thurman defines an IED as "a combination of items or components that are neither designed nor produced to be used in conjunction with each other and that, when placed together or assembled, constitute a mechanism that has the capability of exploding and causing personal injuries and property damage" (5). The basic components that make up an IED are: initiator, container, electrical components, timing mechanisms, shrapnel, adhesives, fasteners/wire and the explosive (5). The initiator is used to start the detonation; this can be fuses or electric matches. The container, though not used in all IEDs, is used in most for: containing the explosives, concealing the IED, transportation of the IED, or any combination thereof. For IEDs using low explosives, pipes and tubes are the most commonly used containers(5). For IEDs with electrical initiators, electrical components are required. This could include wire, batteries, switches or soldering of wires. According to Thurman, the most common way that IEDs are initiated is by time delay, giving the perpetrator time to place the device and leave before detonation (5). The timing mechanism can either be a mechanically or electrically controlled timer. Mechanical timers are generally windup clocks and watches, while electric timers are battery operated or run by household power. Shrapnel is anything that is added to the IED that is meant to increase its potential to cause 
injury. This can include nuts, bolts, washers, nails, glass, metal and so on (5). Shrapnel can be put within the container of or secured to the outside of the bomb. Adhesives are used to secure the components of the bomb together and prevent accidental dislodge, while fasteners are used in the construction of the bomb (5).

Explosives are chemical mixtures or compounds that react chemically to produce gas, light, and heat. They are most often solid or liquids that are able to rapidly produce a chemical reaction (5). A mixture is two or more chemicals that are merely physically mixed and retain their own properties, while a chemical compound is formed by two or more elements that are combined chemically to form a new substance. From a chemical standpoint, an explosive requires two things to propagate combustion: a fuel to burn and an oxidizer to support the combustion, though it may contain other ingredients. An oxidizer is required due to the fact that the combustion of explosion is so fast that surrounding air cannot feed the reaction with enough oxygen (5).

Explosive materials can react either via deflagration or detonation. Deflagration is a very rapid burning, and expansion of gas, however no pressure wave is formed. Detonation is also a rapid burn, but with more power and pressure that produces a pressure wave. When under pressure, due to containment, deflagration can be forced to detonation. Low explosives are deflagrating explosives that only detonate when confined (6). Confinement, which contains the building pressure of combustion, allows the compression wave produced by the rapid burn of the low explosive to accelerate to become a detonation wave (6). Low explosives burn faster and with more power than when confined than in open air, but still slower and less explosively than high explosives. High explosives can detonate regardless of confinement, however when confined, the speed of reaction increases and can cause greater damage than when unconfined. Pipe bombs most commonly use low explosives (5).

Low explosives are commercially available as propellants, including black and smokeless powders, photo flash powder and Pyrodex ${ }^{\circledR}$. With pipe bombs, the container is a generally a metal pipe with some sort of end cap to hold the explosive and other components in and provide the confined, pressure building, conditions needed for an explosion using a low explosive. The 'classical' pipe bomb is a steel pipe with threaded end caps (7). 
When processing a bombing scene the search for fragments of the device is a priority. The end goal is to recover evidence that can be used to identify a perpetrator. Law enforcement faces a large challenge recovering evidence from a bombing scene. Damage and debris from the explosion can make identification of portions of the bomb difficult. Also, bombs are often on a time delay and the perpetrator leaves behind little physical evidence, making it difficult to identify possible suspects or to link individuals to the device (8). In other types of crimes, the perpetrator is physically present during the commission of that crime. This increases the probability of evidence being left behind. According to Locard's Exchange Principle, the intensity of committing a criminal act leaves behind evidence of that act. For example in a physical assault, there is contact between the perpetrator and the victim. This contact can leave trace evidence such as fibers or hair transferred between both the victim and the perpetrator; fingerprints and DNA can be left behind, as well as eye witnesses. However, with a time delayed bomb, there is no intense activity associated with the setting of the device, thus lessening the chances of trace evidence. The perpetrator can set a concealed bomb and be out of the area hours before it detonates, and evidence left on the bomb itself can be lost or destroyed by the detonation.

All remnants of an exploded IED that are collected are processed as evidence. The discovery of fingerprints or DNA on shrapnel is likely to be the most valuable evidence recovered since it can link a suspect directly to the device. These types of evidence are not commonly found post blast due to the high heat of the explosion which destroys such evidence (8). Residues can be analyzed to determine the types of explosive used in the device. The type of explosive used can possibly be traced back to suppliers in the surrounding area of the bomb, and then further linked to a suspect from purchase records. Black powder substitutes are commonly used in IEDs. These materials have started to replace traditional black powder in commercial retail stores due to less restrictive storage requirements (9).

Routon et al. evaluated the ability to discriminate between the two most common black powder substitutes using Gas Chromatography - Mass Spectrometry (GS-MS) (10). Pyrodex and Triple Seven are similar to black powder but are more stable for storage and transportation(11), (12). Black powder is classified by the Department of Transportation as a Class 1.1 explosive, meaning it has a mass explosion hazard (13), (14). While Pyrodex and Triple Seven are 
considered Class 1.3 explosives which have a minor blast or fire hazard, but not a mass explosion hazard (14). Pyrodex and Triple Seven powders are similar in physical characteristics and their particles cannot be distinguished visually, but they can be differentiated chemically(10). Pyrodex contains sulfur, sodium benzoate, and dicyandiamide. Triple Seven does not contain sulfur, but contains 3-nitrobenzoic acid.

Other researchers analyzed black powder substitutes containing ascorbic acid via Ion Chromatography - Mass Spectrometry (IC/MS) (9). Ascorbic acid is used as a fuel in this group of low explosive black powder substitutes. Ascorbic acid containing powders are becoming more prevalent bombings (9). Ascorbic acid degrades quickly making identification of the black powder substitutes challenging. Their method showed promise which warrants further research.

Kosanke et al. analyzed explosive residues via particle analysis in a Scanning Electron Microscope with Energy Dispersive Spectroscopy detection (SEM/EDX) (15).This study indicated that this technique could discriminate between pyrotechnic residues and unrelated background contamination. It is difficult to distinguish in a bulk chemical analysis of post blast material between residue from the blast and other materials which may have been deposited on the scene by other means. Possible background contamination can come from the soil, weed killer or fertilizer. Using an SEM allows to attribute particles to the blast due to their morphology and size.

Gregory et al. studied the structural changes of pipe bomb fragments caused by various strengths of explosives (16). The strength of an explosive is defined by the amount of heat and volume of gas it produces (6). The explosive index compares the relative power of explosives. This group exploded pipes under controlled conditions and analyzed the fragments using SEM, optical microscopy and microhardness. They were able to correlate the microstructural changes with the relative energy of the smokeless powder used. It was found that higher power propellants resulted in more plastic deformation, or change in shape of the metal, than that of lower powered propellants. Also, higher power propellants produced more work hardening, or strengthening, in the metals as indicated by an increase in microhardness.

Oxley et al. studied the distribution of fragments of pipe bombs, which were detonated under controlled conditions (17). It was found that the number, size and appearance of the 
exploded pipe fragments were correlated to the explosive power of the device. The more powerful explosives produced more and smaller sized pieces than the lower powered explosives. More specifically, for seamless pipes, a high energy explosive destroyed the end caps and tore the pipe into wide strips. While the same energy explosive tore a seamed pipe into thin strips and broke the end caps into a few pieces. Also it was found that very low energy explosives such as black powder tore apart the pipe at its weakest point, which is usually where the pipe and cap meet.

Given the above, current research has focused on the identification of the explosive material used in the device (16), (17). Little, if any, research has been performed on the chemical composition of materials typically used in pipe bombs and its relation to source attribution. However, there has been research on using trace elemental composition of materials for source attribution purposes. It has been shown that very similar samples can be differentiated when comparing relative concentrations of trace elements.

Watling et al. characterized the trace element composition of native gold from three Australian mines using Laser Ablation Inductively Coupled Plasma-Mass Spectrometry (LAICP-MS). This analysis allowed for the creation of a trace element signature or a chemical fingerprint of the samples (18). This research arose due to increased gold theft in Australia, and the need to identify gold which had been melted down. This method was investigated due to the ability of LA-ICP-MS to detect elements at very low levels directly from a solid sample. Watling was able to effectively differentiate three samples of gold from three different mines with different matrices. Due to the samples having different matrices the laser would not couple in the same way to each sample and thus different amounts of material were ablated. These differing amounts would make quantitative comparison impossible. In their study, being able to differentiate between the three different mine samples was a result of each sample having noticeably different combinations of trace elements as well as different relative concentrations. Actual, quantifiable concentrations were of no value in the differentiation between the samples. These findings support the hypothesis that steels can be differentiated in a similar manner since the material in each steel sample originates from various natural mine sources. It is this natural origination that would impart different chemical compositions and concentrations into the ores which make up the steel. 
Later work of Watling and colleagues indicated that it was possible to differentiate between samples of steel using LA-ICP-MS (19). They were able to indicate that a comparison of the inter-element association patterns was distinct enough to differentiate between different glasses and steels from similar objects.

The optimized conditions for LA for the glass and steel samples were quite different. For the glass samples the laser was run in a switched pulse mode, which is better for non-conductive samples. This mode generates ionizing plasma above the sample which then erodes into the sample by vaporizing it. For the steel samples the laser was run in a fixed pulse mode. The energy of the laser is absorbed by the sample causing it to liquefy and then to form an aerosol. The instrument was optimized using a glass standard from NIST. No steel standard was run since continuous ablation of a metal coats the inside of the laser which results in contamination.

For the optimization of the laser for use with glass, voltages from $550 \mathrm{~V}$ to $850 \mathrm{~V}$ in 100 volt increments with repetition of laser shots of 5,10 , and 15 hertz for periods of 30,60 , or 90 seconds were used. It was found that the optimum setting for glass was 750 volts at 15 hertz for 60 seconds.

Similar optimization for steel resulted in using 800 volts with one or two shots gave the most reproducible ablation. Higher energies caused the metal that had become molten to erupt and disperse over too large of an area. It was found that two laser shots per site was optimal due to the first shot heating up the cold metal and the second produced molten metal.

It was possible to differentiate between five different colorless glass samples that had refractive indexes that differed by less than $0.1 \%$. These samples were tested ten different times over a two month period, and indicated very good repeatability of the data.

Their steel sample set included steels from safes, firearm barrels, tools, angle iron, rods, and crowbars. This method was found to be repeatable for steel. It was also possible to differentiate five different safes on three different runs over a three month period.

Watling et al. used ternary plots to compare different trace element ratios of seven different steel samples. Using the various combinations of elements, the relative position of each datum would indicate the similarity of samples. Considering the precision of the method, the 
closer the data were, the more likely they would originate from the same sample. By plotting the same samples using a different combination of trace elements, the differences between samples were easily resolved. The various trace element combinations resulted in varying degrees of differentiation. They also were able to differentiate samples from similar sources when comparing steel from five different safes by using various combinations of trace elements.

The results of Watling's study suggests that it is possible to differentiate between metal pipes using LA-ICP-MS. Commercially available pipes, which are commonly used in pipe bombs, are black iron pipes which are furnace-welded (20). Generally, the properties of pipes are controlled by standards set by the American Society for Testing and Materials (ASTM). The standard for black iron pipes (ASTM A53/A53M) establishes requirements for the chemical compositions of these pipes and also sets maximum allowable amounts for specific elements. ASTM A53/A53M requires furnace-welded black pipes to have a maximum of the following elements (21):

\begin{tabular}{|l|l|l|l|l|l|l|l|l|}
\hline Carbon & Manganese & Phosphorus & Sulfur & Copper & Nickel & Chromium & Molybdenum & Vanadium \\
\hline $0.03 \%$ & $1.20 \%$ & $0.05 \%$ & $0.045 \%$ & $0.40 \%$ & $0.40 \%$ & $0.40 \%$ & $0.15 \%$ & $0.08 \%$ \\
\hline
\end{tabular}

Table 1. ASTM maximum chemical composition for furnace-welded pipe

It is possible for a pipe to contain these elements in lesser amounts. Other elements may be present since they are not controlled under the standard. Considering the standard, it is expected that analysis of these pipes would indicate the presence of the above elements at some level. Since the pipes are steel, it is expected that the main components will be present in about the similar ratios from pipe to pipe. The expected concentrations of elements in steel pipes are mostly iron, with carbon (0.5\%-1.7\%), and manganese (1.67\%) (22). Small amounts of silicon, aluminum, sulfur, oxygen and nitrogen are also expected to be present, as well as chromium and cobalt. It is these lesser present elements that will be used for comparison. Carbon will not be considered as a comparative element, as it is purposefully added to iron to form the alloy that is steel, in order to strengthen and increase the hardness of the steel.

As Watling found with gold (18), mined materials are imparted with trace levels of elements depending on their origin. Steel that is used to make pipes originate as iron ore. Iron ore is mined all over the world, with China as the primary producer in 2004, with Brazil and Canada 
second, followed by India, Russia, and Ukraine (23). The United States was the sixth largest miner of iron ore in 2004 (23). These data show the wide variety of regions producing iron ore which supports the hypothesis that steels pipes can be differentiated as a result of their different origins and trace element compositions. This differentiation of steels has been shown in other materials (19), but not yet with steel pipes.

In the report by the National Research Council on bullet lead evidence, extensive research was done to evaluate the value of the chemical comparison of bullet lead evidence (24). Forensic scientists have compared bullet fragments from a victim to unused cartridges from a suspect. The report found that although the lead in bullets may not be traceable to their origin due variability in the manufacturing process, there is still value in chemical comparison. The report stated that "bullets from the same compositionally indistinguishable volume of lead (CIVL) are more likely to be analytically indistinguishable than bullets from different CIVLs". This chemical analysis can provide a probability that two bullets came from the same volume of lead. The conclusion of this National Research Council report gives further purpose to this research. The aim of analyzing shrapnel from pipe bombs is not to determine the origin of the metal, but to link it back to cuttings or shavings which are associated to a suspect or a site. If the analysis of steel indicates distinguishable differences in the pipes, it may be translated to real forensic investigations, and thus add weight to the probability of steels coming from the same source, or equally as important, from different sources.

The focus of this research was to analyze metal pipe types that are commonly used in pipe bombs through the intra- and inter- variability of the chemical composition of the pipes. First, the research evaluated if each pipes was chemically homogenous throughout the pipe from end to end as well as across the face of each cross section. Secondly, the variability between the pipes was evaluated. This research was done with the aim of finding another tool of evidence analysis in pipe bombings. The chemical composition of shrapnel from a bombing scene may be compared to metal cuttings or shavings found at the location where the bomb was suspected to be made, and either linked or excluded by similar trace element ratios.

Cross sections within one pipe were compared to each other, as well as cross sections between pipes of the same brand from the same retail location. Pipes of the same brand were compared between different retail locations. The purpose of the pipe analysis is to determine if 
pipes can be differentiated by trace elements possibly between brands or batches of pipe, or at best between individual pipes.

The samples were first analyzed using a Laser Ablation Inductively Coupled PlasmaMass Spectrometry (LA- ICP-MS). Laser Ablation ICP-MS was selected for its ability to produce trace element signatures or fingerprints of metals (19). A regular ICP-MS, without laser ablation, requires that metal samples first be dissolved prior to analysis. While LA-ICP-MS uses a laser for initial sample volatilization prior to analysis, eliminating the need for sample dissolution. A LA-ICP-MS uses a laser to volatize the solid sample before it is introduced as an aerosol into the plasma via an argon gas carrier. The plasma is an electrically conductive gas containing charged particles. When atoms of a gas are excited to high energy levels the atoms lose hold of some of their electrons and become ionized, hence producing plasma with electrically charged particles. The ICP produces temperatures of about $8000^{\circ} \mathrm{C}$, which generates ions from the aerosol and then introduces these ions into the Mass Spectrometer (MS). The MS then separates the ions according to their mass-charge ratios identifying the elements. The results from the LA-ICP-MS of what trace elements are in the pipe samples will be used to guide what elements are analyzed using the Scanning Electron Microscope/Energy Dispersive X-ray Spectroscopy (SEM/EDX), due to the LA-ICP-MS having a much lower detection limit than SEM/EDX. If an element is at such low concentrations that it not detected in LA-ICP-MS analyses it will most certainly not be detected with SEM/EDX analyses.

Further comparison was done using a Scanning Electron Microscope/Energy Dispersive X-ray Spectroscopy with an addition of an X-ray tube. The X-ray tube addition was used as an alternate excitation source in attempts to detect elements at or below the limit of detection with electron excitation alone. The scanning electron microscope works by scanning a focused beam of electrons onto a solid sample and interacts with the surface. The electron beam is produced by applying a voltage across a tungsten filament. The anode plate located below the filament forms powerful attractive forces for the electrons, drawing them towards the plate. Some of these electrons accelerate past the anode down the column to the sample. The electrons interact with the sample producing measurable electron energies, secondary electrons and backscattered electrons, which are analyzed to produce a three-dimensional image of the surface of the sample. Both the electrons of the electron beam and X-rays interact with the electrons in the shells 
surrounding the nucleus. Characteristic X-rays result when the beam of electrons or X-rays eject inner shell electrons of the atom. The space left in the shell by the ejected electron is subsequently filled by an electron from an outer electron shell, and thus the extra energy from this transition is emitted as a characteristic X-ray.

While the Energy Dispersive X-ray detector or EDX (also referred to as EDS) analyzes the samples' atomic composition by measuring the element specific energies of characteristic Xray. The primary excitation source for this research is an X-ray tube to analyze elements that would otherwise not be seen with electron excitation alone due to the higher energy of the X-rays versus the electron beam. The higher energy of the X-rays is strong enough to react with heavier elements and at lower concentrations. Being able detect elements at lower concentrations can potentially increase the number of trace elements detected within the sample, thus increasing the number of inter-element combinations possible, in so doing increasing the probability of providing a useful chemical fingerprint for comparison (18).

Little or no sample is actually consumed or destroyed during an analysis using either LAICP-MS or SEM/EDX/X-ray. This property makes either method a perfect fit for forensic applications since the sample is not destroyed and thus can be retained for further testing.

To assure that a method is able to produce reliable data, the accuracy, precision, and repeatability of the method must be assessed. Accuracy is a measure of the closeness of a test result to an accepted reference value. This can be achieved by comparing the results of the analysis of a certified reference material to those values in the certificate of analysis (COA). Precision a measure of the closeness or spread of measured values for a particular measurand. An estimation of precision can be obtained by evaluating the spread of data after repeat analysis of a particular measurement. This was achieved by evaluating the results from five replicate analyses of an iron standard. It is possible to use standard deviation as a measure of spread. This however, requires a relatively large sample set. Since a relatively small sample set is used, a tdistribution will provide for a better estimation of the spread. A confidence interval is a range which, when a new measurement is made, its value will fall within this range with a given probability (typically 95\%) (6). Repeatability is a measure of how well a method will deliver the same result given the same instrument, operator, conditions, etc. over an extended period. 
Limit of detection, or LOD, is typically defined as the level where no significant response can be detected. However for this method, LOD was defined as when the lower value of the confidence intervals is at or below zero. 


\section{Materials}

Lowe's Home Improvement and Home Depot are the two major hardware stores in the United States. Lowes has over 1,745 stores in the United States, Canada and Mexico, while Home Depot has about 2,239 stores in the U.S, Canada and Mexico (25), (26). Kessler Industries, LDR Industries, and Mueller Brands are the three distributors that stock the shelves with pipes for Lowes and Home Depot across the country. Though Ace Hardware is not as numerous or widespread as Lowe's or Home Depot, they still recommend to their franchise owners to buy Mueller. From the variety of Lowe's and Home Depot stores contacted from across the country, the vast majority of the pipes carried were Mueller. Due to the availability of these brands across the country, they can be considered to be common pipes, and hence a good sampling population from which pipe bomb makers might choose their pipes.

Though the exact manufacturer of the three major pipe brands' steel is considered proprietary information, calls to the pipe manufacturer revealed that LDR uses steel made in China and Mueller uses steel made in Mexico (27), (28). The manufacturer of Kessler's pipe steel could not be determined. LDR and Mueller using steel from such distant and different locations adds to the possibility of being able to, at the least, differentiate between brands. Steel is made from mined iron ore. Iron ore, limestone and coke are combined and heated to temperatures over $3000^{\circ} \mathrm{F}$ until it reaches a molten state producing iron (29). The molten iron is either treated in a basic oxygen furnace or an electric arc furnace with scrap, converting the iron into steel (29). Welded pipes are made by pouring the molten steel onto a rolling caster and then rolled into pipes while hot, and then are welded at the seams. It is this melting, and pouring that leads to the hypothesis that the metal will most likely be chemically homogenous throughout.

Iron ore can be of different types depending on location of origin (30). This difference in origin, and hence type, could possibly be reflected in trace levels of impurities, allowing for differentiation between brands. 


\section{Sampling}

Commercially available black iron pipes were purchased from a variety of hardware stores in Pennsylvania, Ohio and West Virginia. A total of thirteen stores, in six different cities, were collected. At each location, if available, the same size and brand of pipe was bought in triplicate. All of the pipes are one inch in diameter, with the majority having lengths of eight inches. Refer to Table 2 for the full sample matrix.

\begin{tabular}{|l|l|l|l|}
\hline \multicolumn{1}{|c|}{ Location } & \multicolumn{1}{c|}{ Store Name } & \multicolumn{1}{c|}{ Brand } & \multicolumn{1}{c|}{ Sample ID } \\
\hline Massillon, OH & Menards & LDR China & $1-1,1-2,1-3$ \\
\hline Massillon, OH & Lowe's & LDR China & $2-1,2-2,2-3$ \\
\hline Washington, PA & Home Depot & LDR China & $3-1,3-2,3-3$ \\
\hline Washington, PA & Lowes & Mueller Proline & $4-1,4-2,4-3$ \\
\hline Robinson, PA & Home Depot & Mueller B\&K & $5-1,5-2,5-3$ \\
\hline Robinson, PA & Lowe's & Mueller Proline & $6-1,6-2,6-3$ \\
\hline Wheeling, WV & Lowe's & Mueller Proline & $7-1,7-2,7-3$ \\
\hline Wheeling, WV & $\begin{array}{l}\text { Northern Panhandle } \\
\text { Pipe and Supply }\end{array}$ & Wheaton & $8-1$ \\
\hline Wheeling, WV & $\begin{array}{l}\text { Northern Panhandle } \\
\text { Pipe and Supply }\end{array}$ & $\begin{array}{l}\text { China } \\
\text { Brand unknown }\end{array}$ & \\
\hline Wheeling, WV & $\begin{array}{l}\text { Northern Panhandle } \\
\text { Pipe and Supply }\end{array}$ & Ukraine & Brand unknown \\
\hline Morgantown, WV & Lowe's & Mueller Proline & $8-3$ \\
\hline Morgantown, WV & Ace Hardware & Wheatland & $10-1,9-2,9-3$ \\
\hline Morgantown, WV & Ace Hardware & Anvil Corp & $10-2,10-3$ \\
\hline Cleveland, OH & Home Depot & Mueller B\&K & $11-1,11-2,11-3$ \\
\hline Cleveland, OH & Lowe's & Mueller Proline & $12-1,12-2,12-3$ \\
\hline Washington, PA & $\begin{array}{l}\text { McKean Plumbing } \\
\text { and Heating }\end{array}$ & Wheaton & $13-1,13-2,13-3$ \\
\hline
\end{tabular}

Table 2. Samples highlighted in gray denote samples sent for LA-ICP-MS testing. 
Northern Panhandle Pipe and Supply did not have multiples of pipes like the larger stores; however they did have more of a variety of pipes. The portions they provided were remainders from larger pipes, and hence were not purchased in triplicate. Ace Hardware in Morgantown only had one long pipe from Wheatland that fit the diameter specifications of one inch. Only one portion of this pipe was bought due to the fact any others would be known to be from the same pipe. Also, Ace Hardware only had two of the Anvil Corp pipes, and hence three were not purchased.

Of the collected pipes, portions of five different brands were sent out for LA-ICP-MS to the Department of Geology at the University of Maryland in College Park, Maryland. These samples are highlighted in green on Table 2.

\section{Sample preparation}

All of the pipes were first cut in half using a liquid-cooled diamond saw, and then a slice was cut from the center. Refer to Figure 1.

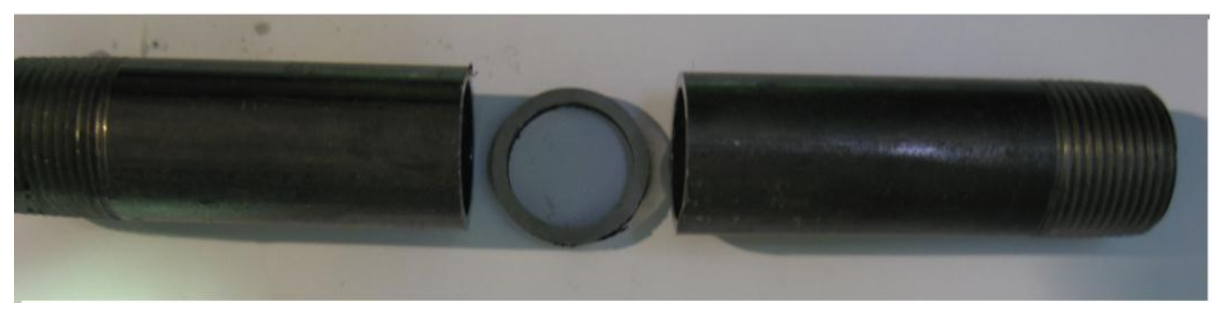

Figure 1 Slice from the center of the pipe

Then a slice was cut from the end of the pipe near the threading.

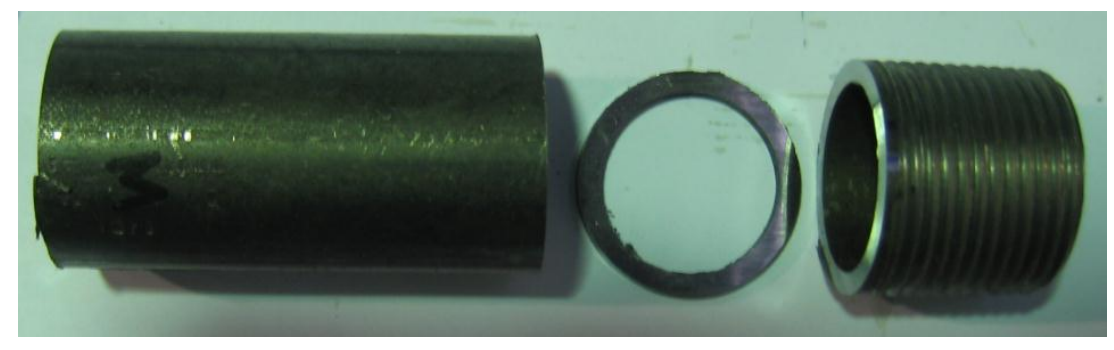

Figure 2 Slice from the end of the pipe 
Each slice had a portion cut out. Portions from the middle slice were purposely cut to be smaller than the portions from the end, to avoid confusion once the samples were mounted.

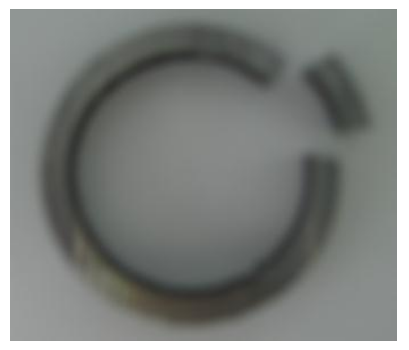

Figure 3 Middle portion

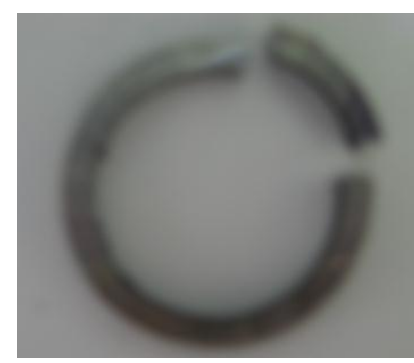

Figure 4 End Portion

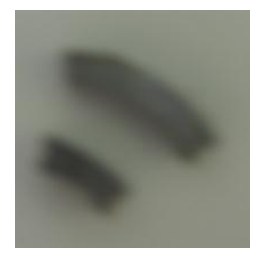

Figure 5 Size Comparison

In naming the samples the end portion is referred to as $\mathrm{A}$ and the middle is referred to as B. For example the first pipe purchased from Menards in Ohio, is 1-1. The end slice from this pipe is 1-1-A, while the slice from the middle is 1-1-B.

All of the pipes were cut using a liquid-cooled diamond blade Buehler Ltd. Cutter 101030.

The portions of pipe were then mounted in Konductmet I (Buehler) using a Buehler SimpliMet 3000 Automatic Mounting Press. The press was run at $4200 \mathrm{psi}$ at $360^{\circ} \mathrm{F}$ for eight minutes, followed by a cool down period of five minutes. The portions were mounted in such a way that the cross-sections of the pipes' diameter was facing outward for analysis.

After mounting, the samples were polished eight at a time using a Buehler Euromet I/Ecomet IV Polisher/Grinder. The samples were polished using successively finer grits starting at 120, 320, 600 and finally 1200 grit sandpaper, run at 35psi and 200rpm for 1.5 minutes. The samples were rinsed thoroughly between each grit level so as to remove residue that might scratch the metal during the next grit level. The samples were then polished one at a time by hand via the paper method using LECO Microid Diamond Compound, first using nine microns and then six microns. The samples were again rinsed between each grade to avoid scratching with a higher grade once moved to a lower grade. After the paper polishing method the samples were polished one at a time by hand on a Buehler Ecomet Variable Speed Grinder/Polisher at three microns using LECO Diamond Dosing stick. To minimize cross contamination between samples, the polishing wheel was cleaned between each sample with running water and scraping 
against the entire wheel while running no less than four times, with rinsing of the scraper between each round of cleaning.

The samples to be sent for LA-ICP-MS, were only cut into the small portions of the slices as described above, and slightly polished to remove any burrs from the cutting process. The samples were rinsed well to eliminate any residue of the coolant used for cutting the metal. The researchers at the LA lab prepared the samples according to their needs.

Photographs of all machines used in the preparation of the samples can be found in Appendix 1 . 


\section{Methods}

\section{LA-ICP-MS}

The five samples highlighted in gray in Table 2. were analyzed using Laser Ablation Inductively Coupled Plasma Mass Spectrometry (LA- ICP-MS) at the University of Maryland's Geology Department. The instrument is a ThermoFinnigan Element 2 sector field mass ICP-MS. The samples were run in low and medium resolution modes. Low resolution provides data on higher mass elements, while medium resolution provides data on low mass elements. Ablation was carried out using a New Wave UP213 laser, which is a frequency quintupled NdYAG, giving $213 \mathrm{~nm}$ UV light. The laser was fired at $7 \mathrm{~Hz}$ with an energy fluence of $2-3 \mathrm{Jcm}^{-2}$. The laser was used to ablate lines perpendicular the edge of the pipe, across the diameter of the slice. The data was processed using LAMTRACE software. NIST standards were run before and after the samples in each of the modes. The standards used were a high nickel steel (SRM 1158) and steel containing chromium and vanadium (SRM 1263a)(31).

\section{SEM/EDX/Xray}

All of the samples, as well as copper and iron standards, were analyzed using a Jeol JSM6490 LV Scanning Electron Microscope with an Oxford INCA X-sight Energy Dispersive X-ray Detector. Also an iXRF Systems Xbeam X-ray tube was used. The data was collected using Iridium Ultra software. All of the samples, copper standards, and iron standards were run with only X-ray excitation at $50 \mathrm{kV}$ at a working distance of $18 \mathrm{~mm}$. This energy produced about 500700 counts per second, giving a total run time on average of 28 minutes for the samples run to a total of one million counts. Also, for comparison, the copper and iron standards, as well as the 5 samples analyzed on LA-ICP-MS were analyzed using the electron gun. The SEM was set at $20 \mathrm{kV}$ with a spot size of 53 , at 500 times magnification and a working distance of $20 \mathrm{~mm}$. This energy produced about 3,000 counts per second, giving a total run time of about 7 minutes when running to one million counts. 


\section{Standards}

Basic copper tape was used as a standard for system calibration. An iron sample containing multiple trace elements was also used. The iron sample (BS-41) is tool steel, certified by Brammer Standard Company, on loan from iXRF Systems. Table 3 shows the trace element values of standard BS-41 as per the Certificate of Analysis(32).

\begin{tabular}{|c|l|l|l|l|l|r|r|r|r|l|}
\hline $\mathrm{Mn}$ & $\mathrm{P}$ & $\mathrm{S}$ & $\mathrm{Si}$ & $\mathrm{Cu}$ & $\mathrm{Ni}$ & $\mathrm{Cr}$ & \multicolumn{1}{l|}{ Mo } & W & V & Fe \\
\hline 0.89 & $\mathbf{0 . 0 1 3}$ & $\mathbf{0 . 0 1 1}$ & 1.02 & $\mathbf{0 . 0 3 8}$ & $\mathbf{0 . 1 5}$ & $\mathbf{0 . 2 2}$ & $\mathbf{0 . 2 3}$ & $\mathbf{0 . 0 3 5}$ & $\mathbf{0 . 0 5}$ & $\mathbf{9 7 . 3 4 3}$ \\
\hline
\end{tabular}

Table 3. Element values from COA, values shown as weight percent

\section{System Calibration}

Copper was used daily as a system calibration check. The copper was run before the iron standard and any samples. The samples and iron standards were run for a total of one million counts, while the copper standards were run to thirty-five thousand counts. The samples and iron standards were collected at higher counts to allow for lower detection of lesser present elements. The copper standards were run to verify that the system was calibrated and that the correct peaks were being identified.

Control charts were calculated for the intensities of the copper peaks as well as the energies of the peaks. The charts show upper limits (UL) and lower limits (LL), using three times the standard deviation, as well as upper warning limits (UWL) and lower warning limits (LWL) using two times the standard deviation (6). In general, with control charts, should the upper or lower limit be breached, the system would be stopped and investigated for what is causing the out of limit reading. If the warning limits are crossed, the system is monitored, but allowed to continue collecting data. As seen in both charts below, there were no standards run that crossed the upper or lower limits. 


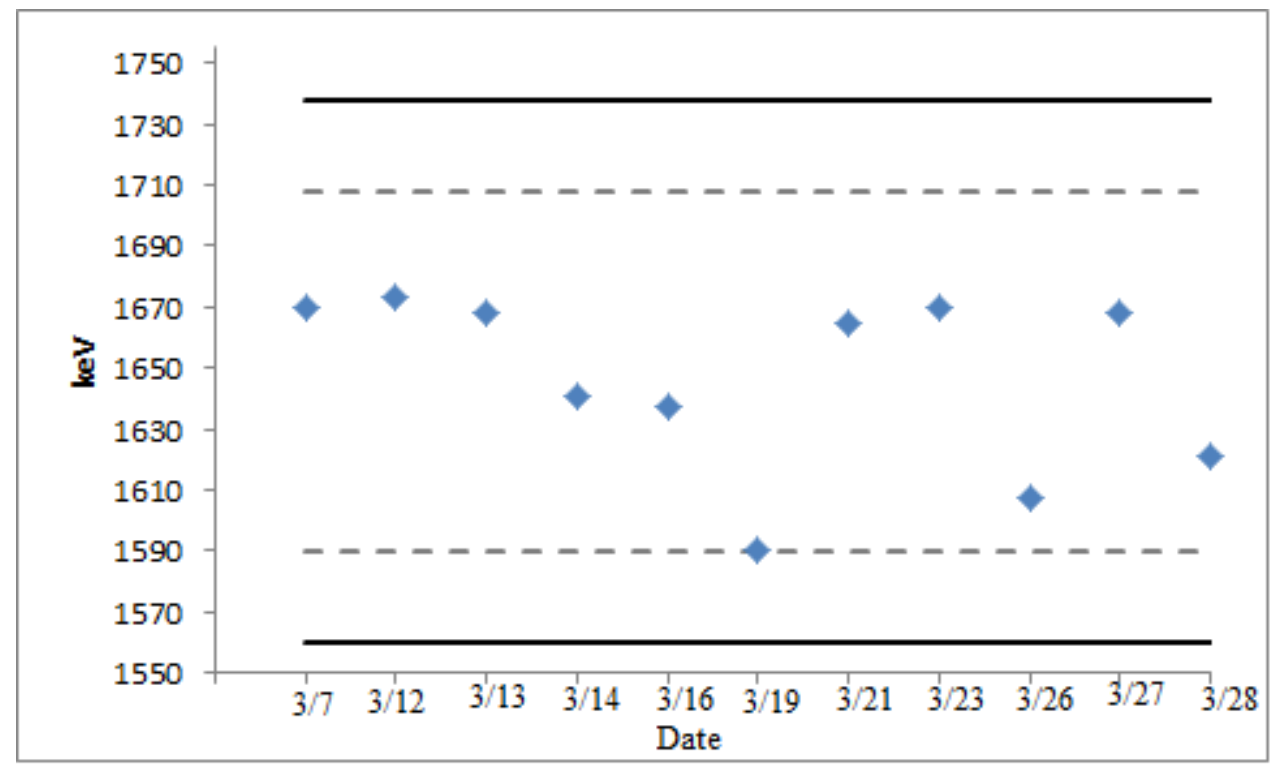

Figure 6. Control Chart for Copper Standard Intensities

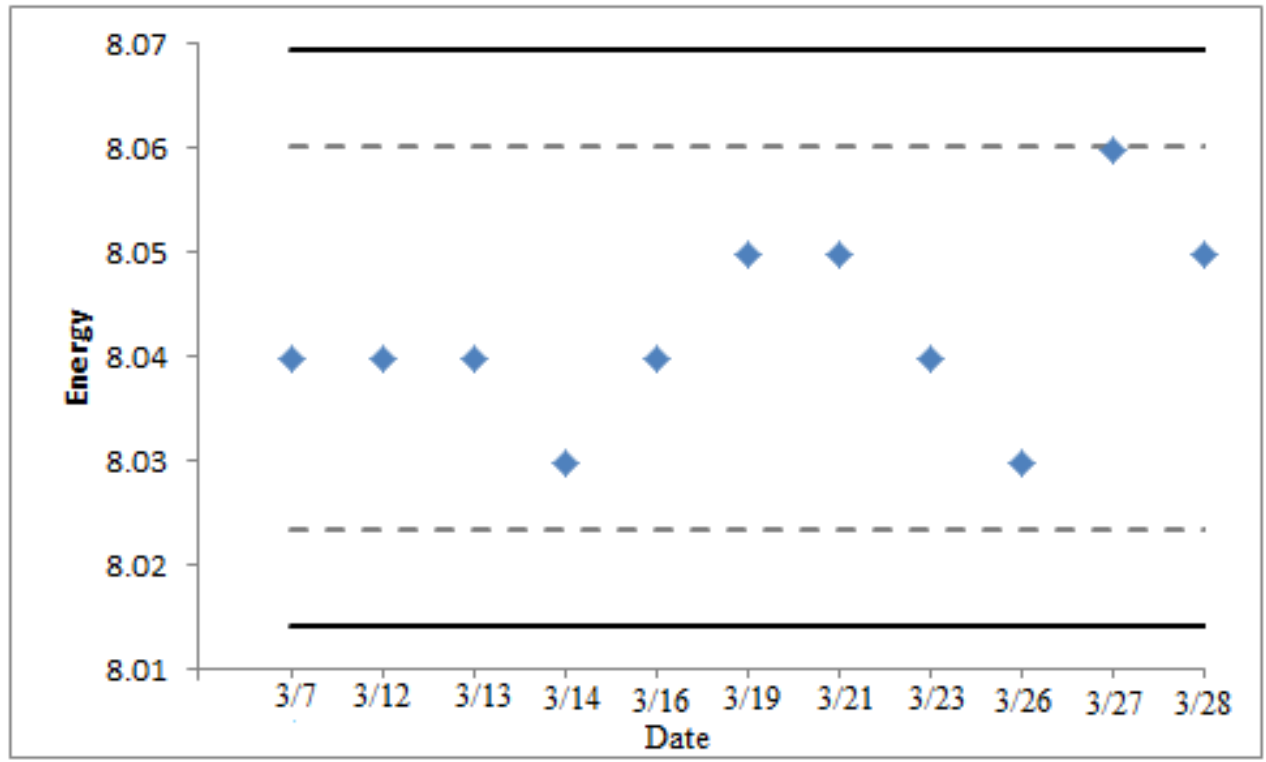

Figure 7. Control Chart for Copper Standard Energy

These charts are visual representations that the system is stable from day to day, is properly calibrated and hence is correctly identifying peaks. 


\section{Repeatability}

To assess the repeatability of the method, five replicate analyses were taken of the iron standard, as well as daily analysis. The five replicate analyses were taken at five different points on the standard disk to also analyze the homogeneity of the disk while testing the method's reproducibility. Daily analyses exhibited the method's repeatability; 11 analyses were taken over 21 days. The averages and confidence intervals for the two sets of standard data were calculated and can be seen in Tables 4 and 5. The spread of the confidence intervals for the 5 replicate standards represents the precision of the analysis, while the spread of the confidence intervals for all of the standards represents the repeatable from day to day.

\begin{tabular}{|l|r|r|r|r|r|r|r|r|r|r|r|}
\hline BS-41 5 Replicates (wt \%) & \multicolumn{1}{l}{ Mn } & P & S & Si & Cu & Ni & Cr & Mo & W & V & Fe \\
\hline Average & 0.89 & 0.00 & 0.01 & 0.10 & 0.01 & 0.07 & 0.16 & 0.02 & 0.05 & 0.08 & 98.61 \\
\hline \multirow{2}{*}{ 95\% Confidence Interval } & 0.86 & 0.00 & 0.00 & 0.09 & 0.01 & 0.06 & 0.14 & 0.00 & 0.04 & 0.07 & 98.56 \\
\cline { 2 - 12 } & 0.92 & 0.00 & 0.02 & 0.11 & 0.02 & 0.08 & 0.17 & 0.04 & 0.07 & 0.09 & 98.66 \\
\hline
\end{tabular}

Table 4. Average and Confidence Intervals of 5 replicate BS-41 standards

\begin{tabular}{|c|c|c|c|c|c|c|c|c|c|c|c|}
\hline All Standards (wt \%) & Mn & $\mathbf{P}$ & $S$ & Si & $\mathrm{Cu}$ & $\mathrm{Ni}$ & $\mathrm{Cr}$ & Mo & $\mathbf{w}$ & $\mathbf{v}$ & $\mathrm{Fe}$ \\
\hline Average & 0.90 & 0.00 & 0.01 & 0.09 & 0.01 & 0.07 & 0.16 & 0.02 & 0.06 & 0.08 & 98.61 \\
\hline \multirow{2}{*}{ 95\% Confidence Interval } & 0.88 & 0.00 & 0.00 & 0.08 & 0.01 & 0.07 & 0.15 & 0.01 & 0.05 & 0.07 & 98.58 \\
\hline & 0.92 & 0.00 & 0.01 & 0.09 & 0.01 & 0.07 & 0.16 & 0.02 & 0.06 & 0.08 & 98.61 \\
\hline
\end{tabular}

Table 5. Average and Confidence Intervals of all BS-41 Standards 
Figure 8 below shows all of the BS-41 standards overlaid, and Figure 9 shows the same spectrum zoomed in to better exemplify the repeatability.

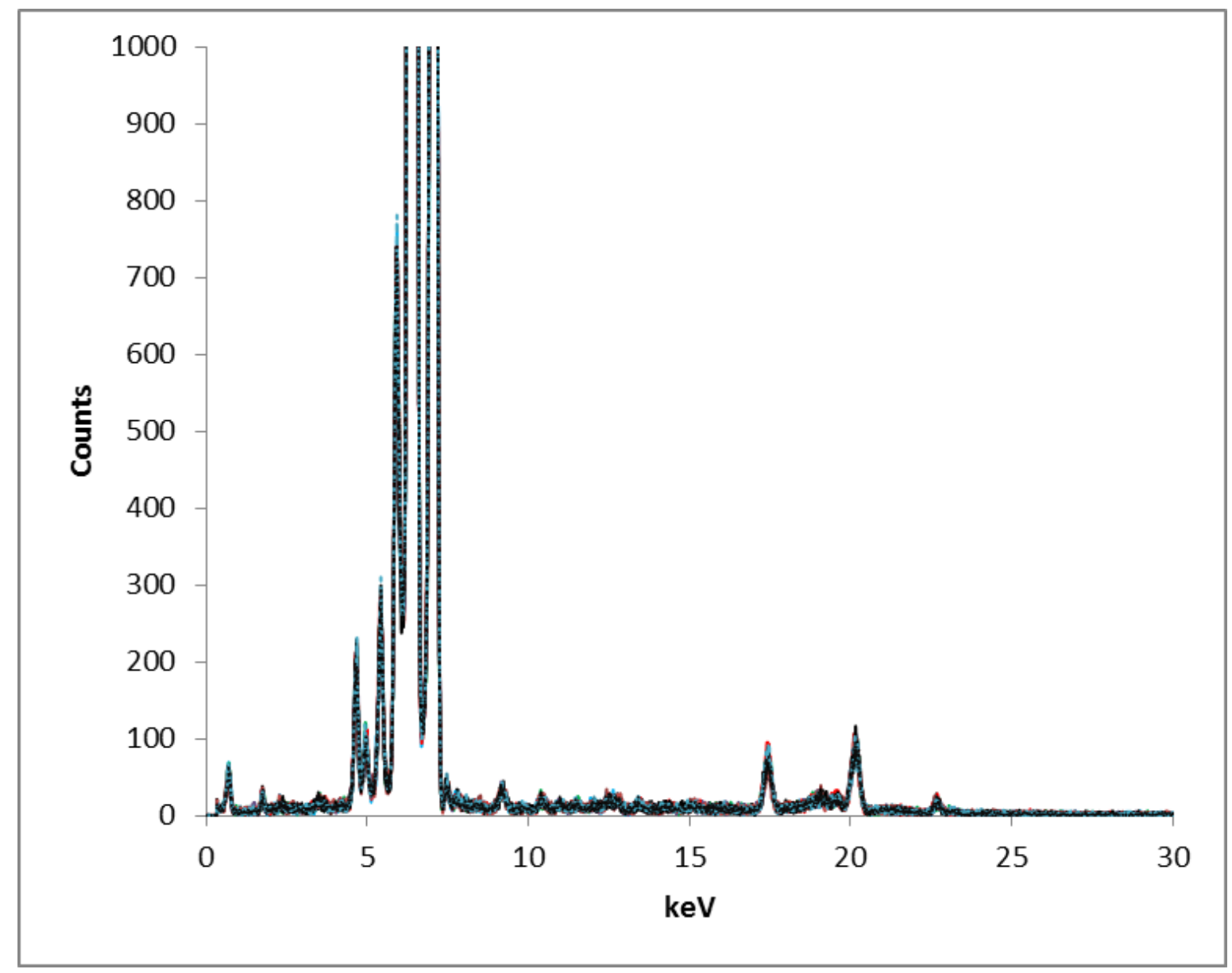

Figure 8. Overlay of all BS-41 standards 


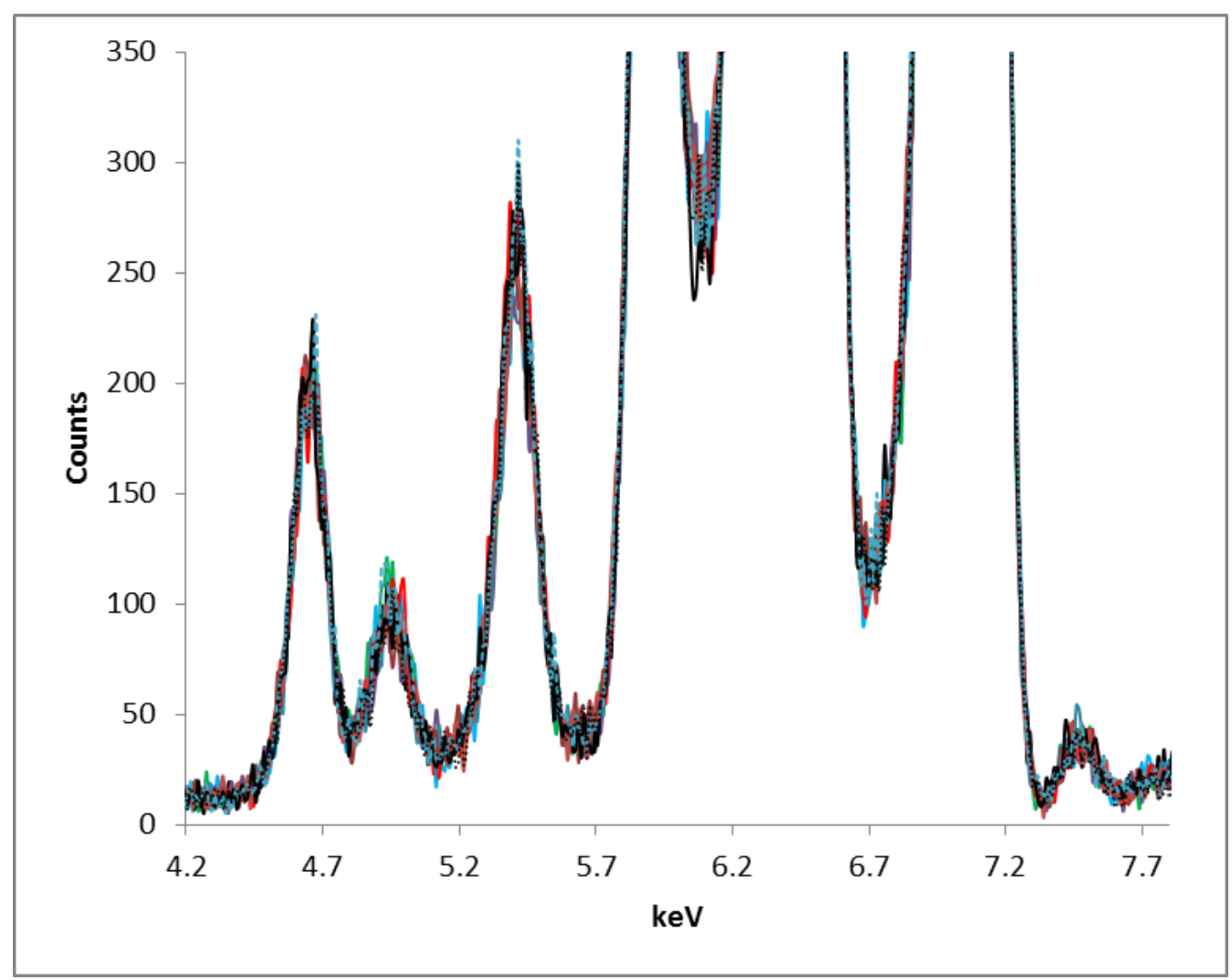

Figure 9. Close up of all BS-41 Standards

\section{Limit of Detection}

The limit of detection was estimated by reviewing the data for all of the sample analyses of individual full pipe comparisons. For example, when reviewing the full pipe data for the samples for Tin and Antimony the calculated lower confidence intervals are at or crossing zero, meaning these values are at or below the limit of detection. These elements were not considered for comparison. The full pipe analysis and related confidence intervals can be seen in Appendix 2. 


\section{Samples}

All of the samples were analyzed at three separate locations across the slice. Slices from the end of the pipe were larger and referred to as "A", while slices from the middle of the pipe were smaller and referred to as "B". As seen in Figure 10, the slices were tested at the top, middle and bottom.

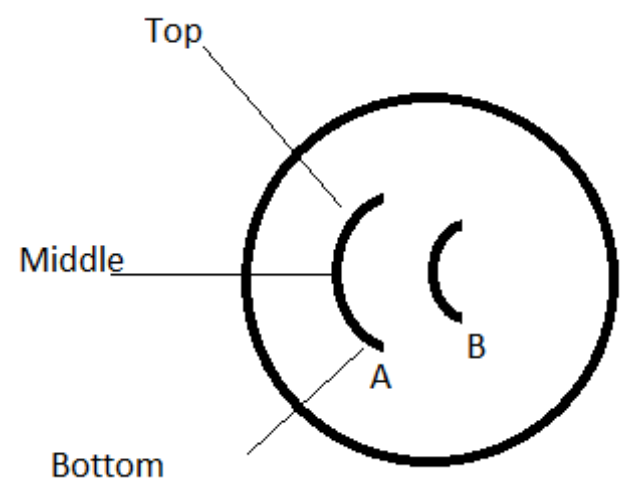

Figure 10. Test areas of samples

The five samples that were sent for LA-ICP-MS were more heavily focused on in terms of sampling. This was done to have a wider range and amount of data for five different brands of pipe. For each of these five samples, each sub sample or slice was consecutively run in duplicate at the same middle spot, as well as the three areas as described above. 


\section{Results}

\section{X-ray analysis versus SEM analysis}

The copper and iron standards as well as the five samples run on LA-ICP-MS were analyzed using the electron beam of the SEM as well as X-rays. This was done to compare the two methods. The SEM analysis showed the broad peak caused by Bremsstrahlung, as well as a copper $\mathrm{K} \alpha$ peak and a smaller copper $\mathrm{K} \beta$ peak. Bremsstrahlung is caused by electrons interacting with the nucleus of the atom instead of the electrons, and loosing energy in the interaction. Bremsstrahlung is an electron generated radiation, and hence it is not present when using X-rays as the excitation (33). The higher energy of the X-ray shows more $\mathrm{K} \beta$, but less $\mathrm{L}$ lines than with SEM. The Copper concentration is the same for both analyses; however it is represented differently because of the energy it is being bombarded with. All of these observations can be seen in Figure 11 and 12 below.

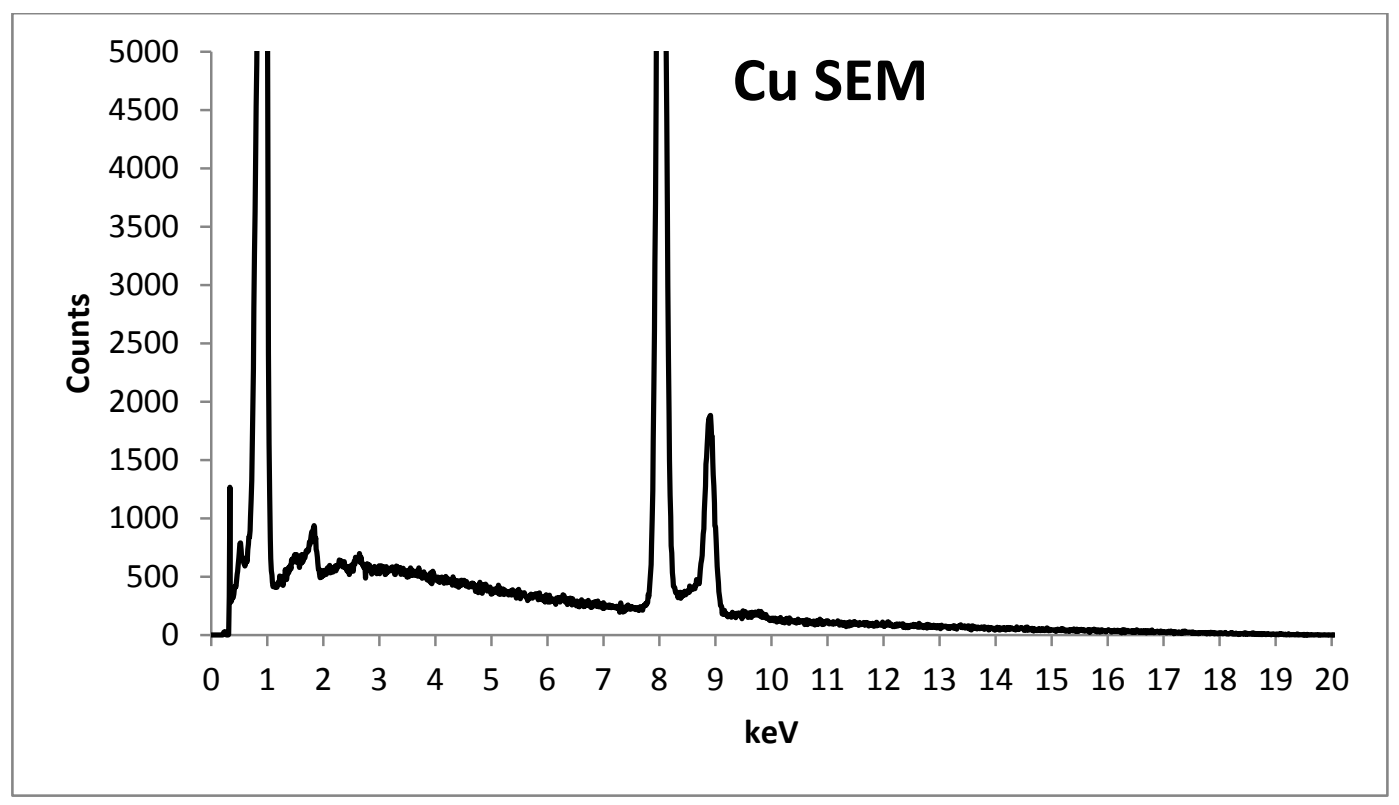

Figure 11. Copper standard spectra analyzed using SEM at 20kV 


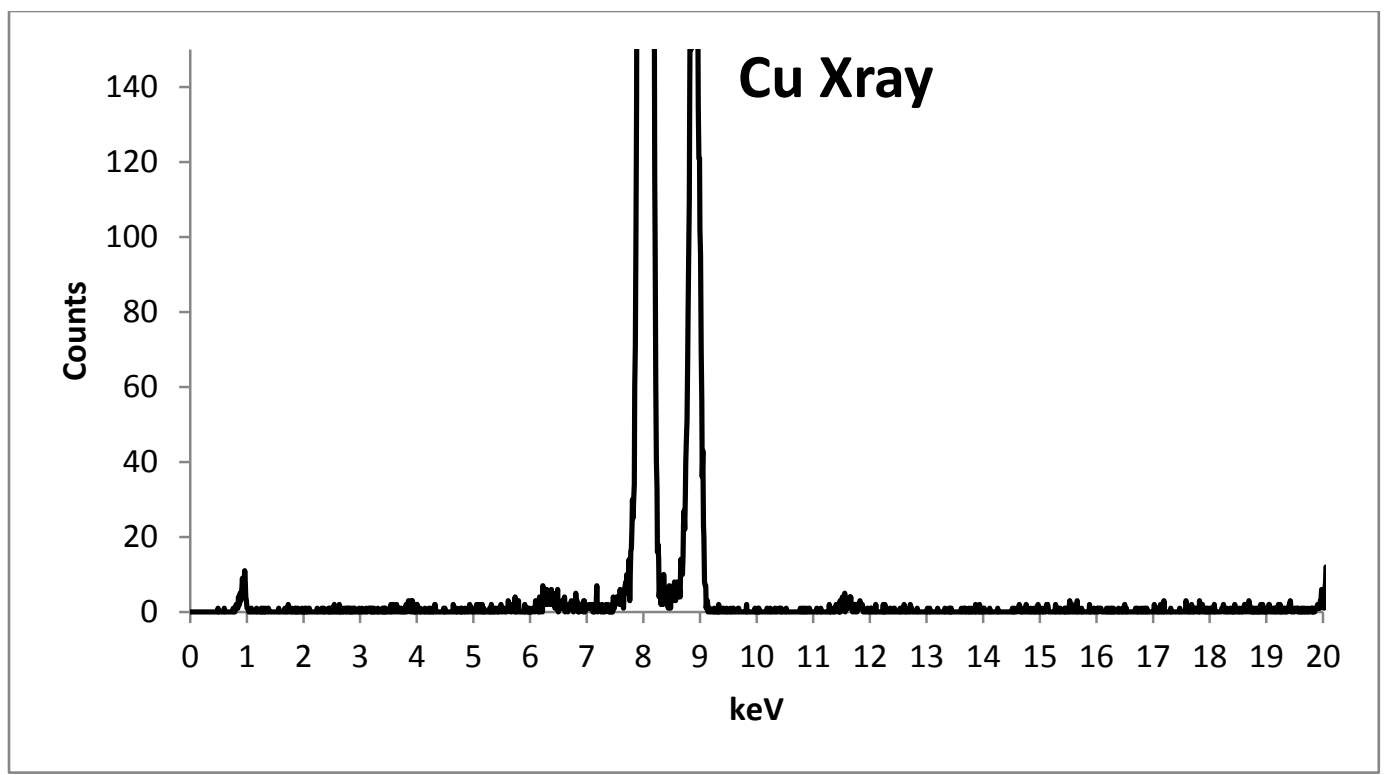

Figure 12. Copper standard spectra analyzed using X-rays at 50kV

The BS-41 standard was also analyzed using both SEM and X-ray excitation. The standard is certified and hence has known concentrations of elements at low levels. It should be noted that the standard was certified using Inductively Coupled Plasma and Atomic Absorption spectrometry, wet chemistry and combustion instrument procedures (34). Certification testing did not include SEM or X-ray analysis. There may be slight differences in calculated elemental concentrations due to the differences in types of analysis. However the focus is to compare differences between SEM and X-ray recoveries as compared to the known values. The closeness of these measured values to the known values of the certified standard used exemplifies the accuracy of the method. This is shown in Table 6.

\begin{tabular}{|l|r|r|r|r|r|r|r|r|r|r|r|}
\hline Elements & Mn & P & S & Si & Cu & Ni & \multicolumn{1}{l|}{ r } & Mo & W & V & Fe \\
\hline Certified (wt \%) & 0.89 & 0.01 & 0.01 & 1.02 & 0.04 & 0.15 & 0.22 & 0.23 & 0.04 & 0.05 & 97.34 \\
\hline Xray & 0.90 & 0.00 & 0.01 & 0.09 & 0.01 & 0.07 & 0.16 & 0.02 & 0.06 & 0.08 & 98.61 \\
\hline SEM & 0.80 & 0.06 & 0.00 & 1.11 & 0.09 & 0.19 & 0.19 & 0.52 & 0.60 & 0.08 & 96.39 \\
\hline
\end{tabular}

Table 6. Comparison of X-ray and SEM concentrations to BS-41 Standard

The differences shown above are not substantial, however it must be taken into consideration that the software (Iridium Ultra) was used to manually select the elements. Due to Bremsstrahlung with electron excitation the recoveries seen above can partially be attributed to 
Bremsstrahlung being counted as characteristic X-rays, artificially raising the percentage. It is also possible that with SEM some of the elements that were calculated may not even be seen visually as actual peaks, but is only background being calculated as a peak.

Sample 1-1 was analyzed using both SEM and X-ray excitation. Figure 13 is a spectrum from the sample analyzed using SEM/EDX. In this spectrum the Bremsstrahlung can be clearly seen. This effect is not visible in Figure 15, where the spectrum was collected using the x-ray tube as the excitation source. These spectra clearly indicate the difference in interaction between $\mathrm{x}$-rays and electrons with the sample.

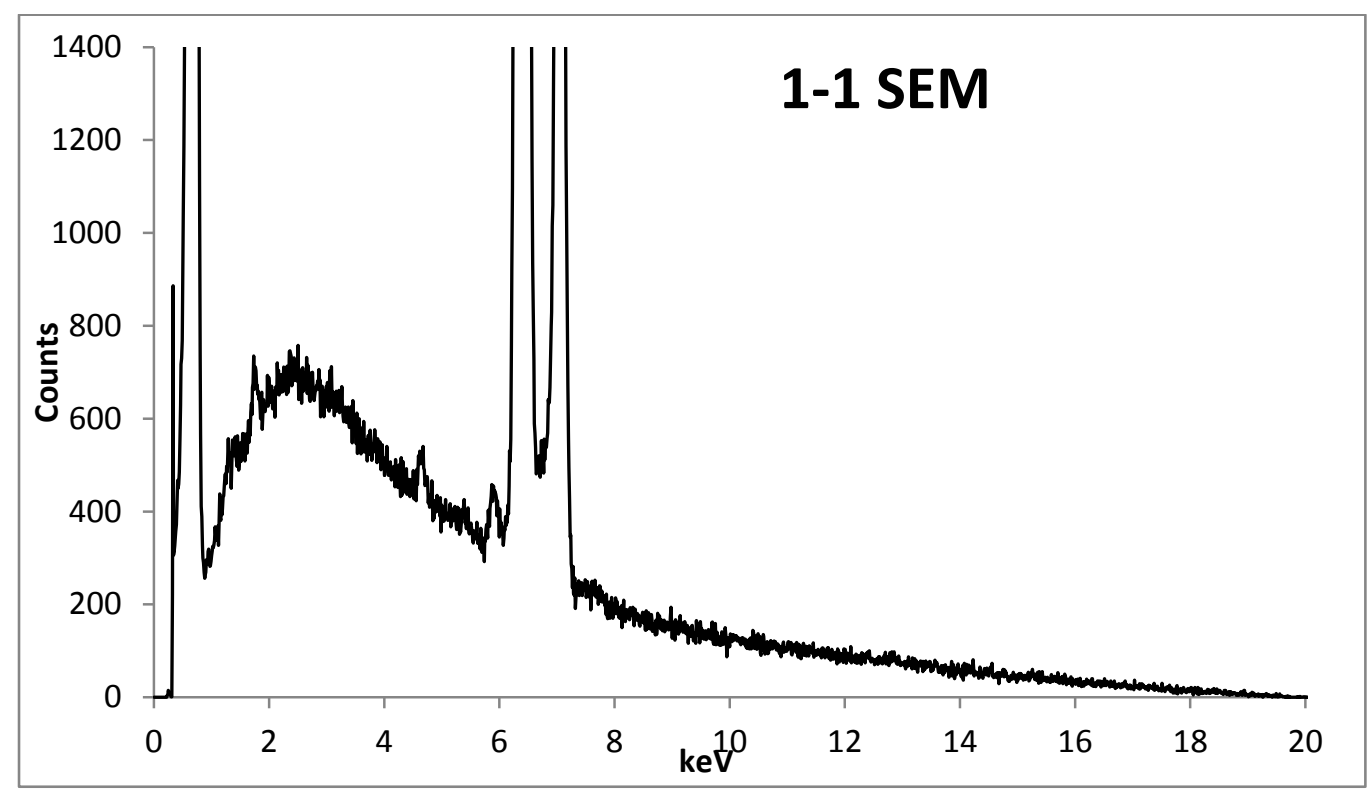

Figure 13. Sample 1-1 analyzed using SEM 


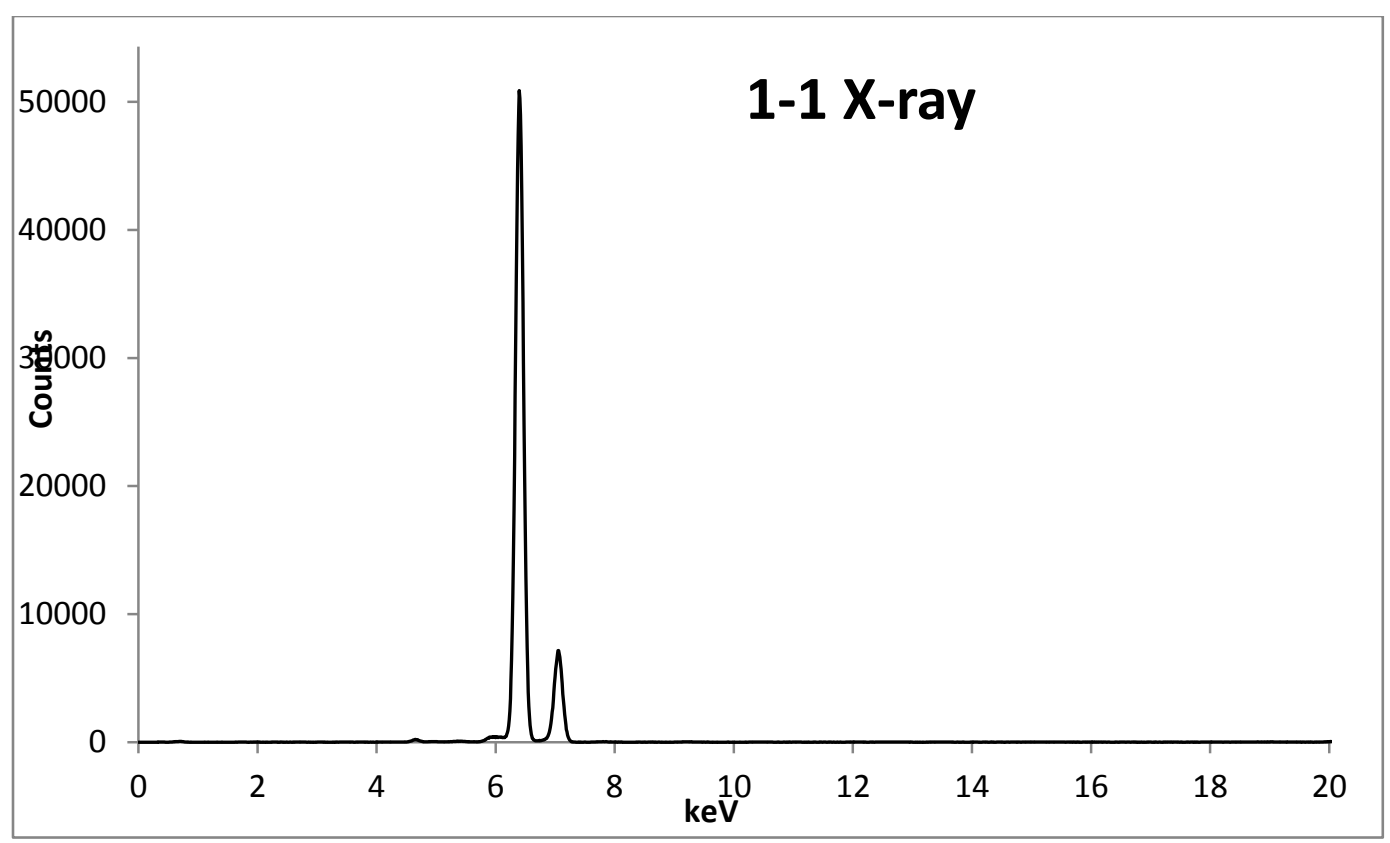

Figure 14. Sample 1-1 analyzed using X-rays, full spectrum

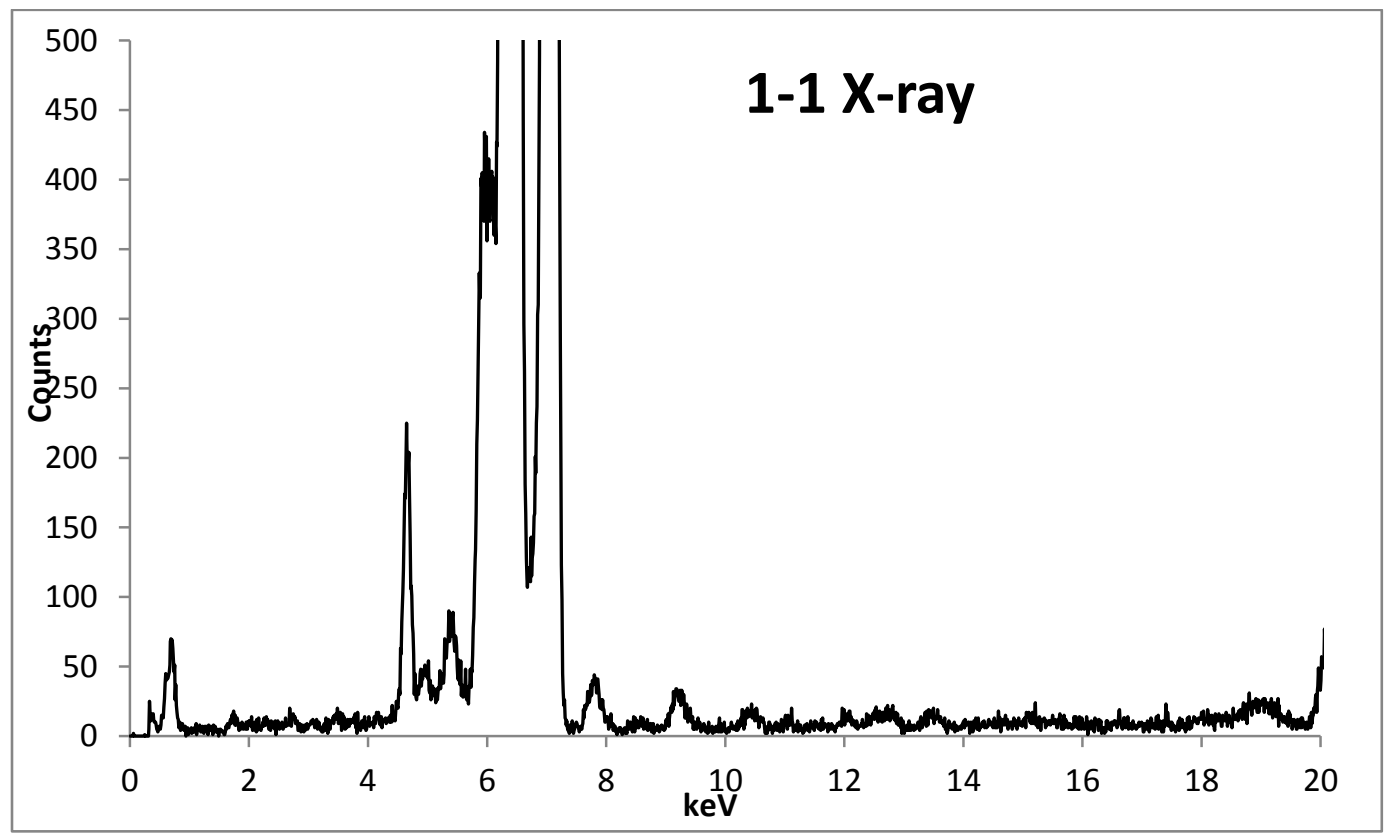

Figure 15. Sample 1-1 analyzed using X-rays, zoomed in on the spectrum 


\section{LA-ICP-MS Analysis of Samples}

The five samples sent for LA-ICP-MS analysis were chosen for their differences in brand and origin anticipating a higher probability to be differentiated from each other. The LA-ICP-MS analyses searched the samples for a total of 25 elements. Refer to Appendix 3 for the entire set of LA-ICP-MS data. The data indicate the presence of elements at concentrations of less than one part per million. After preliminary experiments using SEM with X-rays, it was decided that only a sub-set of the elements identified by LA-ICP-MS would be used in this research due to the very low concentrations of the elements which were excluded. It was determined that if any element, in any of the samples, was present above ten parts per million it would be used in this research. After reviewing the results, it was found that 15 elements were present above the predetermined threshold of 10ppm. Refer to Appendix 4 for an abbreviated version of the LAICP-MS data that only includes the 15 selected elements, at 23 isotopes.

For the five pipe samples tested with LA-ICP-MS, a portion from the end and from the middle were analyzed as single analyses.

Some elements are present in both modes of analysis. The averages of each element present in each sample set, at all modes, were calculated. Due to the data showing that the middle and end portions of the pipe are compositionally the same, they were averaged together and are considered one sample for subsequent LA-ICP-MS data analysis. The averaged counts can be seen in Table 7. These values are used only as a bench mark for what elements to investigate with the SEM/EDX/X-ray analyses due to single analysis on the samples.

\begin{tabular}{|l|l|r|r|l|l|l|l|l|r|r|r|r|r|r|r|}
\hline Sample & $\mathrm{P}$ & \multicolumn{1}{|l|}{$\mathrm{Ti}$} & $\mathrm{V}$ & $\mathrm{Cr}$ & $\mathrm{Mn}$ & $\mathrm{Fe}$ & $\mathrm{Co}$ & $\mathrm{Ni}$ & $\mathrm{Cu}$ & $\mathrm{Ga}$ & $\mathrm{Ge}$ & As & $\mathrm{Mo}$ & $\mathrm{Sn}$ & $\mathrm{Sb}$ \\
\hline 1-1C & 226 & 49 & 29 & 316 & 4041 & 937151 & 66 & 181 & 135 & 22 & 11.5 & 48 & 28 & 8.5 & 14 \\
\hline $4-1 \mathrm{C}$ & 279 & 84 & 32 & 438 & 4362 & 943310 & 36 & 166 & 59 & 16 & 8.6 & 29 & 6.6 & 71 & 4.0 \\
\hline $8-3 \mathrm{C}$ & 188 & 2376 & 7.4 & 488 & 4608 & 964980 & 46 & 423 & 544 & 9.8 & 18.2 & 89 & 45 & 39 & 16 \\
\hline $10-2 \mathrm{C}$ & 138 & 103.01 & 9.8 & 387 & 4475 & 926909 & 16 & 104 & 147 & 4.4 & 33 & 23 & 27 & 16 & 4.4 \\
\hline $13-1 \mathrm{C}$ & 188 & 68.88 & 6 & 298 & 3920 & 947301 & 19 & 154 & 183 & 4.7 & 34 & 31 & 59 & 71 & 8.1 \\
\hline
\end{tabular}

Table 7. Averaged Elemental concentrations (ppm) from LA-ICP-MS Analysis

The table shows that there are differences between some of the elemental values. Similar to the ternary plots of Watling's work, two elements plotted against each other shows distribution of single analyses in Figures 16 and 17. More than one analysis would need to be 
done using LA-ICP-MS to be able to use the data for comparison purposes; however the visual representation gives direction to the SEM/EDX/X-ray work. In the x-ray analyses multiple samples and repeat analyses were performed. The results of these multiple samplings will allow for some comparative interpretation of the LA-ICP-MS data.

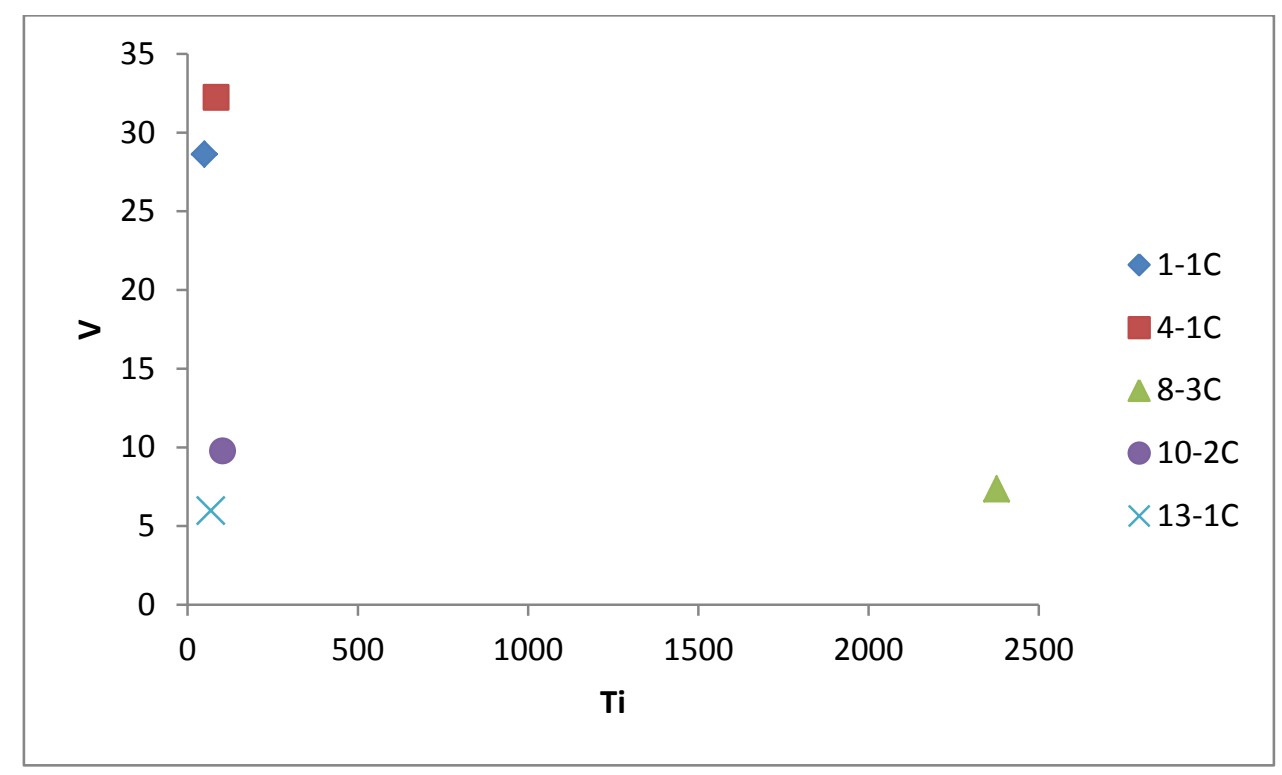

Figure 16. Comparison of samples by titanium and vanadium

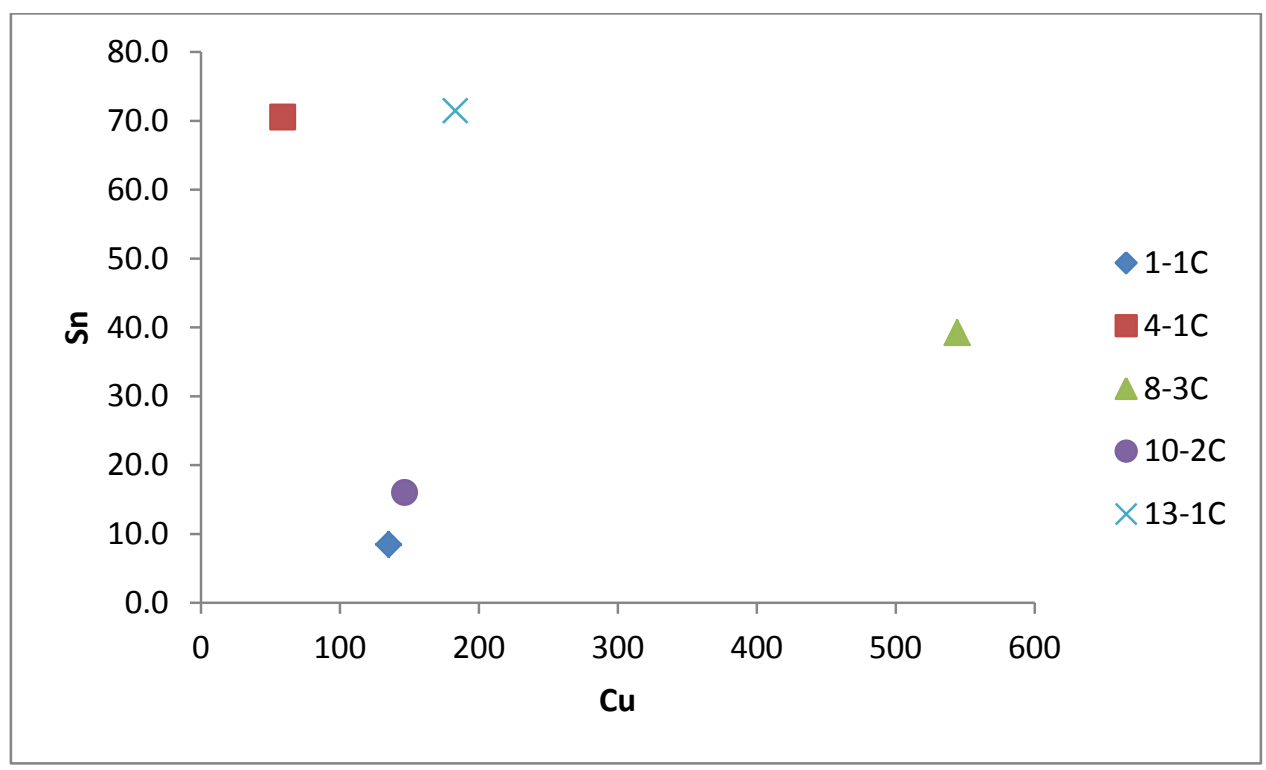

Figure 17. Comparison of samples by copper and tin 
Continuing to combine different elements only further exemplifies the possibility of the value of comparative concentrations for differentiation. Refer to Appendix 5 for more comparisons.

\section{X-ray Analysis of Samples}

All of the samples were analyzed using X-rays as the excitation, and were tested across the pipe as shown in Figure 10. The five samples run on LA-ICP-MS were consecutively run in duplicate at the same middle spot to show repeatability of the measurements. Appendix 6 shows the elemental values for the duplicate analyses by weight percent. The very low standard deviation values show the values are repeatable.

All of the data was analyzed by reviewing the counts at the $\mathrm{kV}$ of the characteristic $\mathrm{X}$ rays for the elements being reviewed. The pipes were compared first for intra-variability. The averages of the counts for the elements were compared for the middle and end slices. This was done by analyzing if there was overlap of the $95 \%$ confidence interval of each element. If the intervals overlap for each element for the end and the middle, the pipes are considered homogenous. According to the data, all of the pipes are homogenous. Appendix 7 shows the calculated $95 \%$ confidence intervals of all of the samples at all elements by counts.

The pipes were then analyzed by pair-wise comparison. Since the pipes are homogeneous, the average value for all analyzed portions each pipe was used. If a significant number of samples were indistinguishable they were rejected for that elemental comparison. This can be seen with Phosphorus which could only four samples could be differentiated. Refer to Appendix 8 for this comparison.

This comparison evaluated, between each sample, if it is possible to differentiate by one element at a time. For example, comparing pipe 1-1 and 2-3, by reviewing their chromium concentrations, these pipes can be differentiated. Appendix 8 shows the pair-wise comparison charts for multiple elements and combinations of elements for all of the samples. On the chart 'yes' means that there is overlap between the confidence intervals and that they cannot be differentiated, while 'no' means that the counts are different, the intervals do not overlap and the samples can be differentiated. Of the 37 total samples compared copper can be used to differentiate 136 or $20 \%$ of the samples, while manganese can differentiate 272 samples or $41 \%$. 
Nickel differentiates 173 samples, or 26\%. Titanium can differentiate 70 samples or $11 \%$.

Chromium was found to be the most discriminating, by differentiating 382 samples or $57 \%$.

However when combining the comparisons a higher number of samples can be differentiated. Comparing chromium, manganese, and copper 517 samples can be differentiated or $78 \%$. Comparing chromium, manganese, copper, nickel and cobalt 532 samples or $80 \%$ can be differentiated.

\section{Discussion}

\section{X-ray vs. SEM}

Electrons from the SEM and X-ray excitation were used to analyze the standards and samples. Though SEM is a valuable technique for bulk analysis, it is not sensitive enough for low level concentrations. Using the higher energy of X-ray allowing for peaks of low concentration elements to be visualized and analyzed. As seen in Spectrum 3 when the same sample is bombarded with X-rays multiple small peaks are able to be seen (Spectrum 4) that were not evident in Spectrum 3.

\section{LA-ICP-MS}

Laser Ablation-ICP-MS is a highly sensitive analytical technique which allows the detection of elements down to less than 1 part per million. The LA-ICP-MS analysis on the five pipes provided benchmark data of suitable elements to be used when applying the X-ray technique. Due to only one sample analysis on each portion of the pipes the LA-ICP-MS data were not used for comparison.

\section{X-ray}

All of the samples' data was analyzed for homogeneity within the pipe. It can be said with $95 \%$ confidence that each pipe tested is homogenous throughout its length given the 
technique applied. Once homogeneity was established it was possible to compare the intervariability of the pipes. Upon the start of this research it was hypothesized that at the very least pipes would be able to be differentiated according to their brand. The research, however, shows that is not the case. The pipes cannot be differentiated solely on their brand, but can be differentiated more specifically by individual pipe. Just one example of this is shown in Table 8 .

\begin{tabular}{|c|c|c|c|}
\hline Sample & $\mathbf{1 - 1}$ & $\mathbf{1 - 2}$ & $\mathbf{1 - 3}$ \\
\hline $1-1$ & - & Differentiated & No \\
\hline $1-2$ & Differentiated & - & Differentiated \\
\hline
\end{tabular}

Table 8. Pipes 1 compared for differentiation

Pipe 2-1, 2-2, and 2-3 are also LDR pipes bought at the same location of each other but a different location than pipes 1-1, 1-2, and 1-3. Pipe 2-1 can be differentiated from 2-2, but not 23. Pipe 2-2 can be differentiated from 2-3.

\begin{tabular}{|c|c|c|c|}
\hline Sample & $\mathbf{2 - 1}$ & $\mathbf{2 - 2}$ & $\mathbf{2 - 3}$ \\
\hline $\mathbf{2 - 1}$ & - & Differentiated & No \\
\hline $\mathbf{2 - 2}$ & Differentiated & - & Differentiated \\
\hline
\end{tabular}

Table 9. Pipes 2 compared for differentiation

Looking at these two examples brand and location has no effect on the differentiation of pipes. These results are reflected throughout the entire sample set.

Furthermore, samples 11-1, 11-2, and 11-3 can be differentiated from all but 2 samples. The pipes in this sample set are all from the same location and are Mueller B\&K brand. This is not an uncommon brand. Sample 5-1 can be differentiated from all other samples. This sample is Mueller B\&K, and also is not an uncommon brand. Also, samples 5-1, 5-2, and 5-3 can all be differentiated from each other. These pipes were all bought at the same location on the same day, from the same box. Mueller B\&K and Proline were brands that were tested from more than one location, adding to the conclusion that brand cannot be correlated to trace elemental composition.

Reviewing the pair-wise comparisons Samples 8-2 and 8-3 can be differentiated from all other pipes. These pipes were of unknown brands from China and Ukraine emphasizing the effect of elemental composition on origin. However, due to the same brands and same store 
location pipes being able to be differentiated, origin cannot be used as a sole discriminating factor.

It was found that just by comparison of titanium, samples 5-1 and 5-3 can be differentiated from all other samples except for each other. Titanium is being identified at $4.505 \mathrm{keV}$.

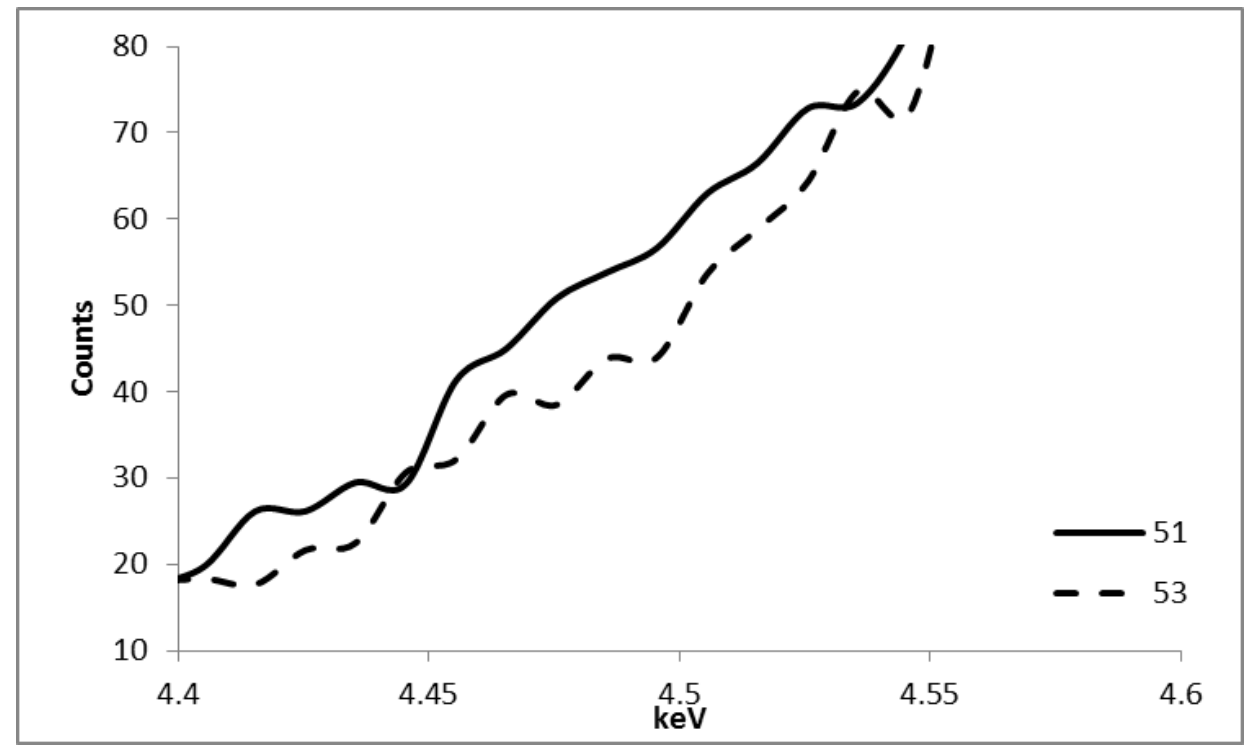

Figure 18. Spectra of Samples 5-1 and 5-3 at the titanium peak

Figure 18 shows the overlap of the confidence intervals in the titanium peaks between samples 51 and 5-3, confirming that the samples cannot be differentiated from each other by this elemental comparison. Figure 19 shows the differentiation between 5-2 and the other two samples. Figure 19 also identifies the confidence intervals of each sample at the titanium peak represented by the vertical lines. The confidence interval for 5-2 does not overlap either interval for 5-1 or 5-3, and thus is differentiated from these samples. 


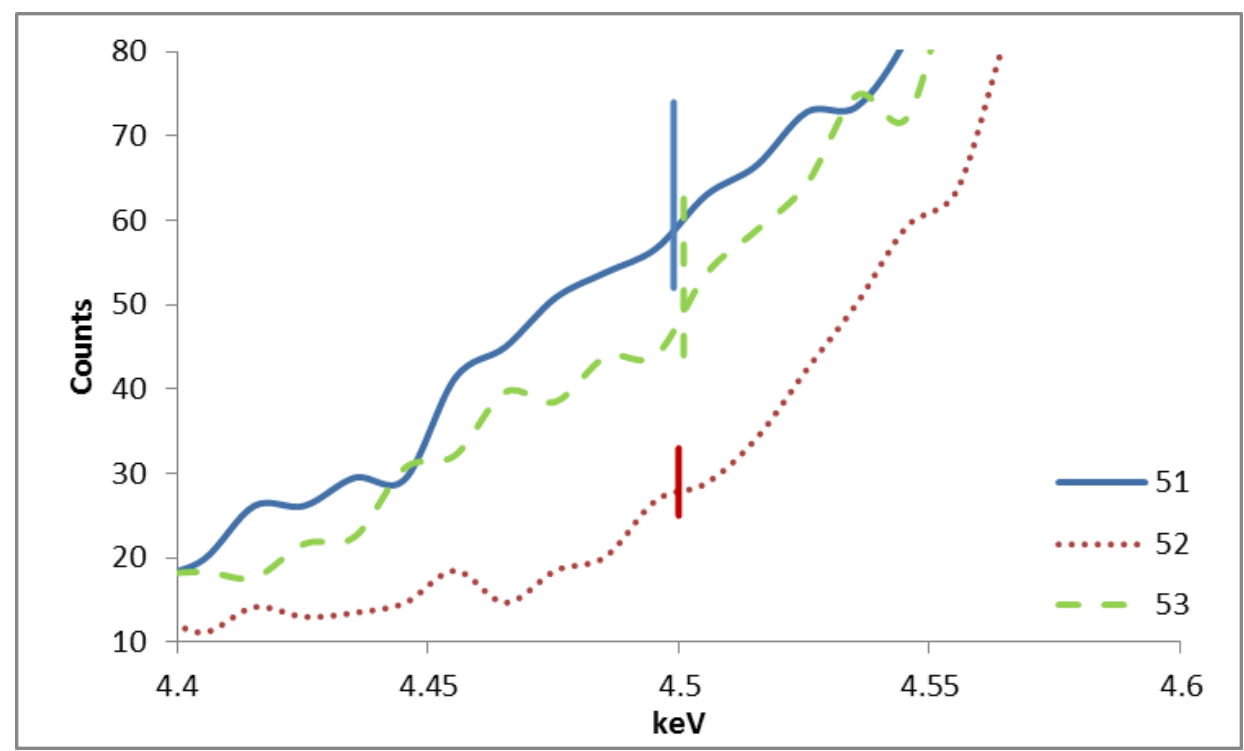

Figure 19. Spectra of Samples 5-1, 5-2 and 5-3 at the titanium peak

Figure 20 exemplifies the comparison of manganese, at energy $5.89 \mathrm{keV}$, for sample 5-3 and 10 2. The confidence intervals of the samples, shown as vertical lines, do not overlap, thus they can be differentiated.

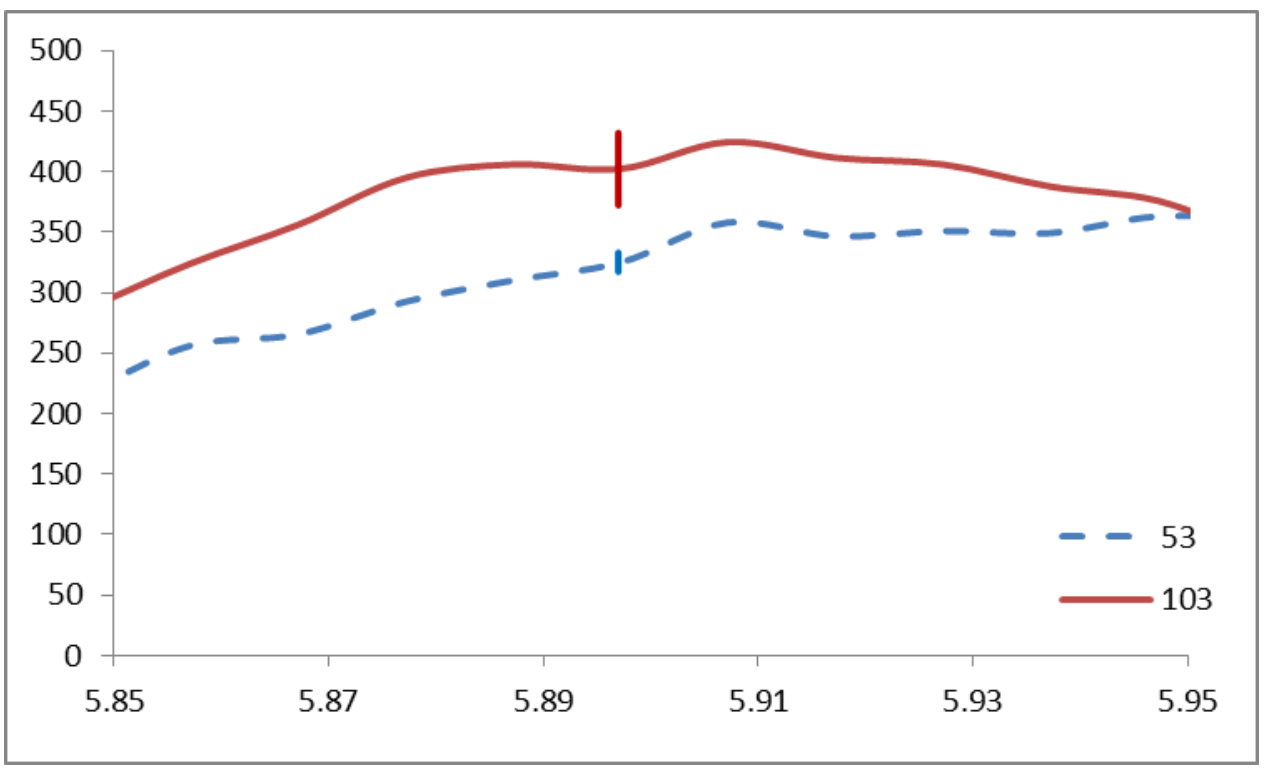

Figure 20. Spectra of samples 5-3 and 10-2 at the manganese peak. 
The method used in this research was able to differentiate $80 \%$ of the total samples, leading to the conclusion that the elemental composition of pipes is not unique between individual pipes. However there is enough variation among pipes to be useful. It would be possible to differentiate between a piece of pipe at a bomb scene and a collected pipe from a suspect's home based on differences of their elemental composition.

Spectra generated using X-ray excitation do not present Bremsstrahlung as present in spectra generated using electron excitation, however the x-ray spectra are not completely free of artifacts.

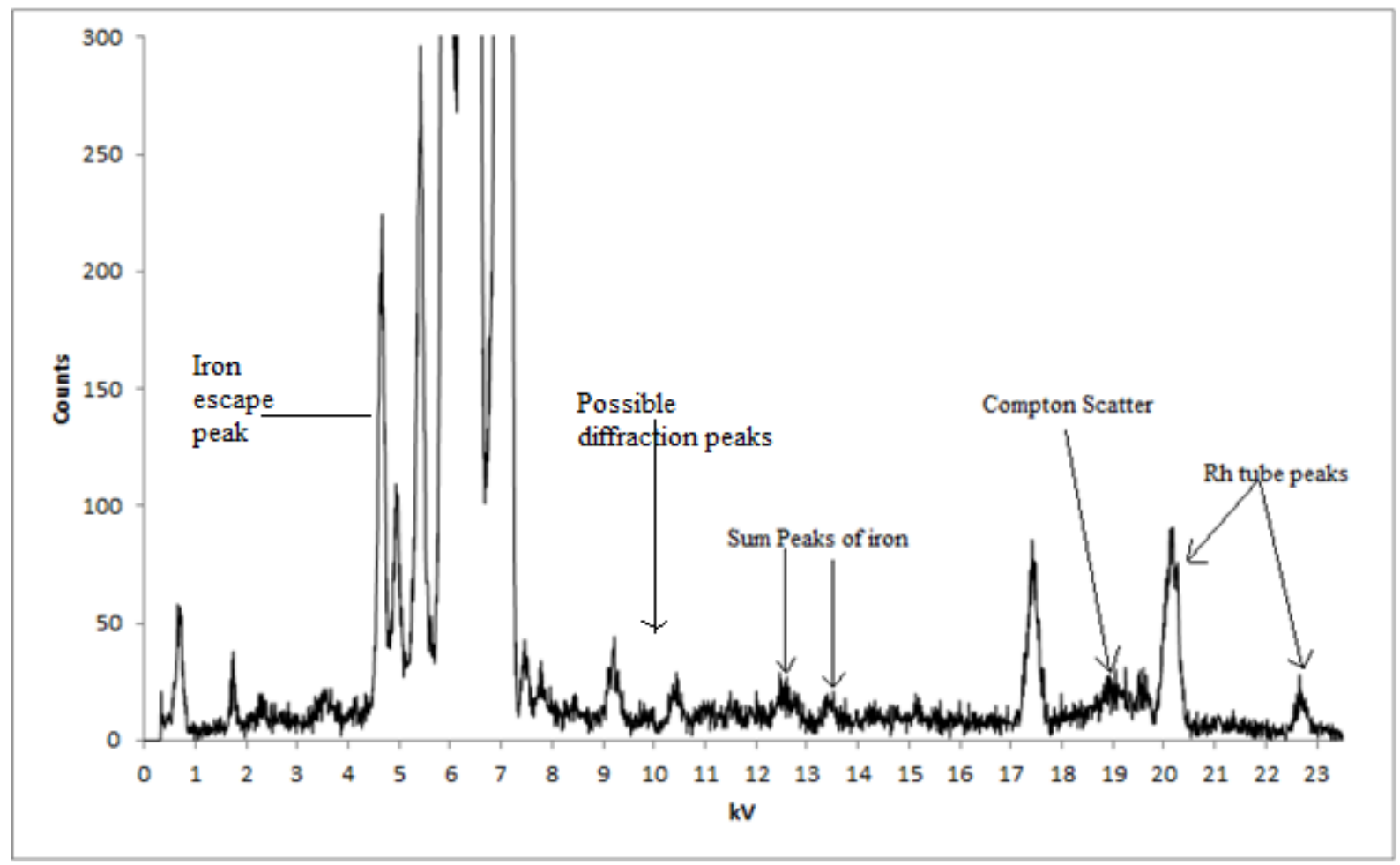

Figure 21. Standard BS-41 showing artifacts

Artifacts in the standard and sample spectra include silicon peaks, tube peaks, Compton scatter, sum peaks, and escape peaks. The iron escape peaks are due to the $\mathrm{X}$-rays interacting with the silicon detector producing peaks that are of the value of an iron $\mathrm{K} \alpha$ photon minus the silicon $\mathrm{K} \alpha$ photon value. The $\mathrm{Rh}$ tube peaks are due to the $\mathrm{X}$-rays generated from the target inside of the $\mathrm{X}$ ray tube, which is made of rhodium. These $\mathrm{x}$-rays are then elastically scattered by the atoms in the sample. This is also referred to as Rayleigh scatter. Compton scatter is the inelastic scatter of 
the Rh tube peaks, which lose a small amount of energy during the interaction. When analyzing standards and samples none of these escape peaks are taken into consideration.

Sum peaks of iron are also present. Sum peaks are a result of two photons arriving at the detector immediately after one another and the detector cannot differentiation between the two. Their values are hence combined. The peak at $12.8 \mathrm{keV}$ is a result of two K $\alpha$ photons $(6.39 * 2=$ 12.8) being counted together. The peak at 13.457 is a result of a $\mathrm{K} \alpha$ and a $\mathrm{K} \beta$ photon hitting the detector immediately following one another $(6.39+7.058=13.457)$. The sum peaks are not counted when calculating concentrations. Also diffraction peaks can be seen in the spectra, these peaks are from the interaction of the x-ray with the crystal structure of the metal. These peaks are not taken into account in this method, as the Giessen-Gordon method (35) is a more appropriate approach to analyzing diffraction and will not be addressed within this research. 


\section{Conclusions}

Using X-rays as an alternate excitation to the electron gun of a SEM is a much more sensitive method and allows for elements of much lower concentrations to be analyzed. Though X-rays increase sensitivity over basic SEM they are not as sensitive as when using LA-ICP-MS for analysis. X-rays are sensitive enough, however, to get useful results. Using this method of Xrays and in comparison to LA-ICP-MS similar data was obtained from both methods in that differentiation of the pipes was possible, leading to the conclusion that using X-ray excitation can be used for trace elemental analysis. This research has shown that it may be in a laboratory's best interest to add an X-ray tube to an existing SEM for trace elemental analysis versus purchasing a much more expensive LA-ICP-MS system.

This method has found that pipes are homogenous throughout and are able to be used for comparison between pipes.

This method has also found that pipes cannot be differentiated by brand, but can to some extent be differentiated by pipe. The method can differentiate a sample set of 37 pipes to $80 \%$. This method cannot link a pipe's trace elemental composition to brand or origin, but can partially differentiate between pipes. This method can be applied to when a pipe bomb is collected and pipe material from a suspect is collected. These pieces of evidence can be compared to each other using this method. This comparison can exclude the possibility that the two came from the same source, or it can add to the weight of evidence that it is possible the two came from the same source. The method cannot state that two pipes are the same as this method does not give $100 \%$ differentiation between pipes. Also since the post-blast pipes were unable to be analyzed before the end of this research project, it cannot be said how pre and post-blast pipe compares. 


\section{Future work}

Though samples were sent to the FBI's Explosives Unit for detonation, scheduling did not allow for these samples to be returned in time for analysis before the defense of this thesis. Once the samples are returned, they will be analyzed according the X-ray method above, and compared to pre-blast portions of the pipe. Portions of the pipes were detonated using the more common low explosives, but also a high explosive. Three brands of pipe were detonated with low explosives, and one duplicate brand was separately exploded with high explosives. Pipes were halved, one half was analyzed pre-blast, and one half was used for an explosion and analyzed post blast to determine if the compositional homogeneity of the pipe changes due to the high heat and pressure of explosion

Future work should also include repeating the analyses of the pipes using $\mathrm{x}$-rays over a variety of energies from $10 \mathrm{keV}$ to $50 \mathrm{keV}$, and not just at $50 \mathrm{keV}$. This is needed to address the difference in the efficiency of excitation at different energies depending on the element of interest, and possibly providing more accurate data.

More extensive research with a larger, more diverse sample set should be pursued to add to the weight of conclusions of this research. More research can be done using X-ray excitation for low level concentrations of elements in other solid samples. This method could potentially be used in glass analysis, concrete, etc. This method could be applied to a variety of fields and not just forensics for the comparison of pipe bombs. 


\section{References}

1. Noji EK, Lee CY, Davis T, Peleg K. Investigation of Federal Bureau of Investigation bomb-related death and injury data in the United States between 1988 and 1997. Military Medicine. 2005 Jul;170(7):595-8.

2. Karmyjones R, Kissinger D, Golocovsky M, Jordan M, Champion HR. BOMB-RELATED INJURIES. Military Medicine. 1994 Jul;159(7):536-9.

3. Bureau of Alcohol T, Firearms and Explosives. ATF Fact Sheet - U.S. Bomb Data Center. In: Division PA, editor.; Sepmtember 2008.

4. 2010 Report on Terrorism. In: Center NC, editor.; 30 April 2011.

5. Thurman JT. Practical Bomb Scene Investigation. Boca Raton, Florida: CRC Press LLC, 2006.

6. Bell S. Forensic Chemistry. 1st Edition ed. Upper Saddle River, New Jersey: Pearson Prentice Hall, 2006.

7. Beveridge A. Forensic Investigation of Explosions. Bristol, Pennsylvania: Taylor \& Francis Ltd, 1998.

8. Foran DR, Gehring ME, Stallworth SE. The Recovery and Analysis of Mitochondrial DNA from Exploded Pipe Bombs. Journal of Forensic Sciences. 2009 Jan;54(1):90-4.

9. Lang G-hL, Boyle KM. The Analysis of Black Powder Substitutes Containing Ascorbic Acid by lon Chromatography/Mass Spectrometry. Journal of Forensic Sciences. 2009 Nov;54(6):1315-22.

10. Routon BJ, Kocher BB, Goodpaster JV. Discriminating Hodgdon Pyrodex (R) and Triple Seven (R) Using Gas Chromatography-Mass Spectrometry. Journal of Forensic Sciences. 2011 Jan;56(1):194-9.

11. Hodgdon. Pyrodex Material Safety Data Sheet. 2009 [updated 2009; cited 03/19/2012]; Available from: http://www.hodgdon.com/PDF/MSDS\%20Files/Muzzleloading/Pyrodex.pdf.

12. Hodgdon. Triple Seven Material Safety Data Sheet. 2009 [updated 2009; cited 03/19/2012]; Available from: http://www.hodgdon.com/PDF/MSDS\%20Files/Muzzleloading/TripleSe7en.pdf.

13. Owen Compliance Services I. Black Powder Material Safety Data Sheet. 2005 [updated 2005; cited 03/19/2012]; Available from: http://web.mit.edu/rocketteam/www/documents/MSDS/Black\%20Powder.pdf.

14. Transportation USDo. Pipeline and Hazardous Materials Safety Administration. [cited 03/19/2012]; Available from: http://www.phmsa.dot.gov/portal/site/PHMSA.

15. Kosanke KL, Dujay RC, Kosanke BJ. Pyrotechnic reaction residue particle analysis. Journal of Forensic Sciences. 2006 Mar;51(2):296-302.

16. Gregory O, Oxley J, Smith J, Platek M, Ghonem H, Bernier E, et al. Microstructural characterization of pipe bomb fragments. Materials Characterization. 2010 Mar;61(3):347-54.

17. Oxley JC, Smith JL, Resende E, Rogers E, Strobel RA, Bender EC. Improvised explosive devices: Pipe bombs. Journal of Forensic Sciences. [Article]. 2001 May;46(3):510-34.

18. Watling RJ, Herbert HK, Delev D, Abell ID. GOLD FINGERPRINTING BY LASER-ABLATION INDUCTIVELY-COUPLED PLASMA-MASS SPECTROMETRY. Spectrochimica Acta Part B-Atomic Spectroscopy. 1994 Feb;49(2):205-19.

19. Watling RJ, Lynch BF, Herring D. Use of laser ablation inductively coupled plasma mass spectrometry for fingerprinting scene of crime evidence. Journal of Analytical Atomic Spectrometry. 1997 Feb;12(2):195-203.

20. Brensing K-H, Sommer B. Steel Tube and Pipe Manufacturing Process. [cited 03/12/2012]; Available from: http://www.smrw.de/downloads/steel tube and _pipe.pdf.

21. Materials ASfTa. Standard Specification for Pipe, Steel, Black and Hot-Dipped, Zinc-Coated, Welded and Seamless (STEEL). Chemical Composition; 2007. 
22. Antaki GA. Piping and Pipeline Engineering: Design, Construction, Maintenance, Integrity and Repair. Boca Raton, Florida: CRC Press LLC, 2003.

23. Jorgenson JD. Mineral Commodity Summaries, Iron Ore. In: Survey USG, editor.; 2005.

24. Weighing Bullet Lead Evidence, Forensic Analysis. Washington, D.C.: National Academies Press, 2004.

25. Lowe's. Company Overview. 2010 [updated 2010; cited 03/20/2012]; Available from: http://media.lowes.com/company+overview/.

26. Depot H. Corporate and Financial Overview. 2011 [updated 2011; cited 03/20/2012]; Available from: https://corporate.homedepot.com/OurCompany/Documents/Corp_Financial_Overview.pdf.

27. LDR. Company Representative. Phone call placed to LDR ed; 2011.

28. Mueller. Company Representative. Phone call placed to Mueller ed; 2011.

29. Euless Co. How is Steel Made. 2003 [updated 2003; cited 03/20/2012]; Available from: http://www.eulesstx.gov/recycling/steel making.htm.

30. Mineral Photos-Iron. Mineral Information Institute; [cited 05/10/2011]; Available from: http://www.mii.org/Minerals/photoiron.html.

31. NIST. Standard Reference Materials Catalog. 2011.

32. Brammer GR. Certificate of Analyses B.S. No. 41. Houston, TX: Brammer Standard Company; 1988 Contract No.: Document Number|.

33. Goldstein J, Newbury D, Joy D, Lyman C, Echlin P, Lifshin E, et al. Scanning Electron Miroscopy and X-Ray Microanalysis. Third ed. New York, New York: Springer Science + Business Media, Inc., 2003. 34. Brammer GR. Certificate of Analyses B.S. No. 41. Houston, TX: Brammer Standard Company; 1988 Contract No.: Document Number|.

35. Bertin EP. Introduction to X-Ray Spectrometric Analysis. New York, NY: Plenum Press, 1978. 
Appendix 1

Sample Preparation Machines Used

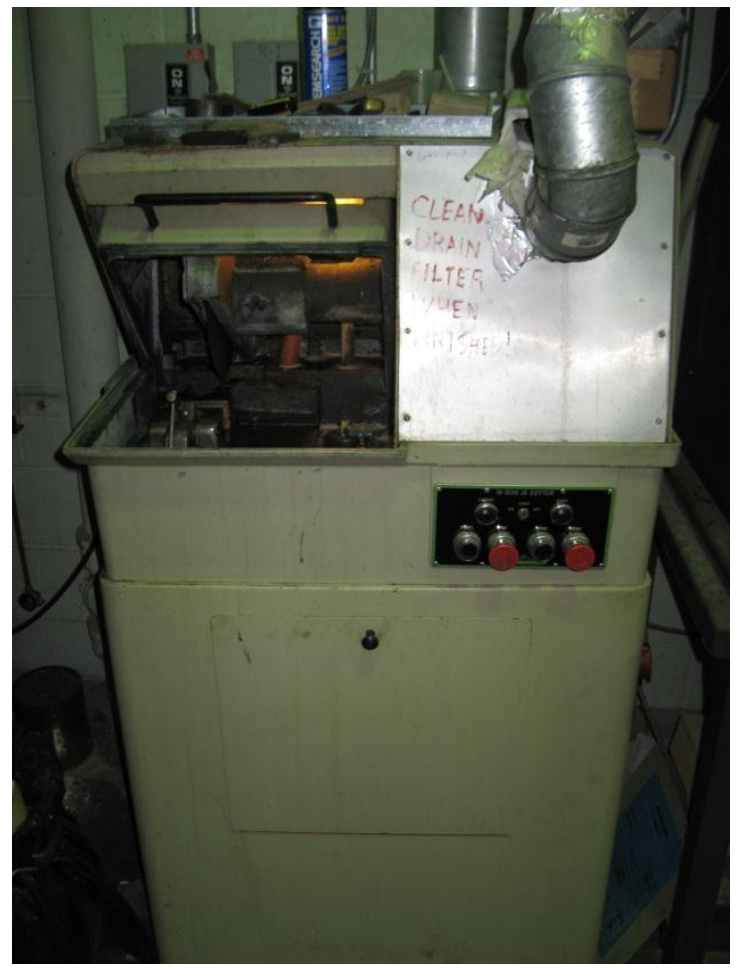

Photo1: Buehler Ltd. Cutter 10-1030

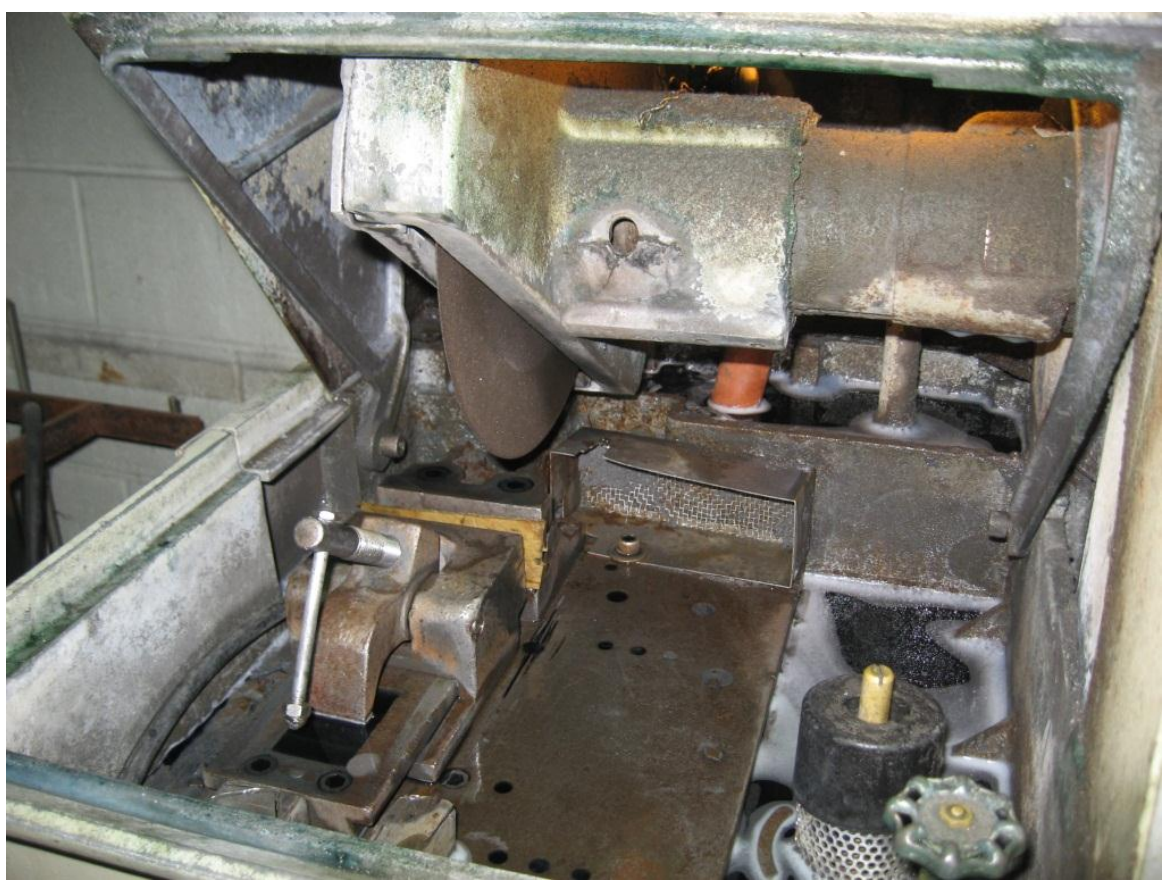

Photo 2: Buehler Ltd. Cutter, inside, cutting blade 


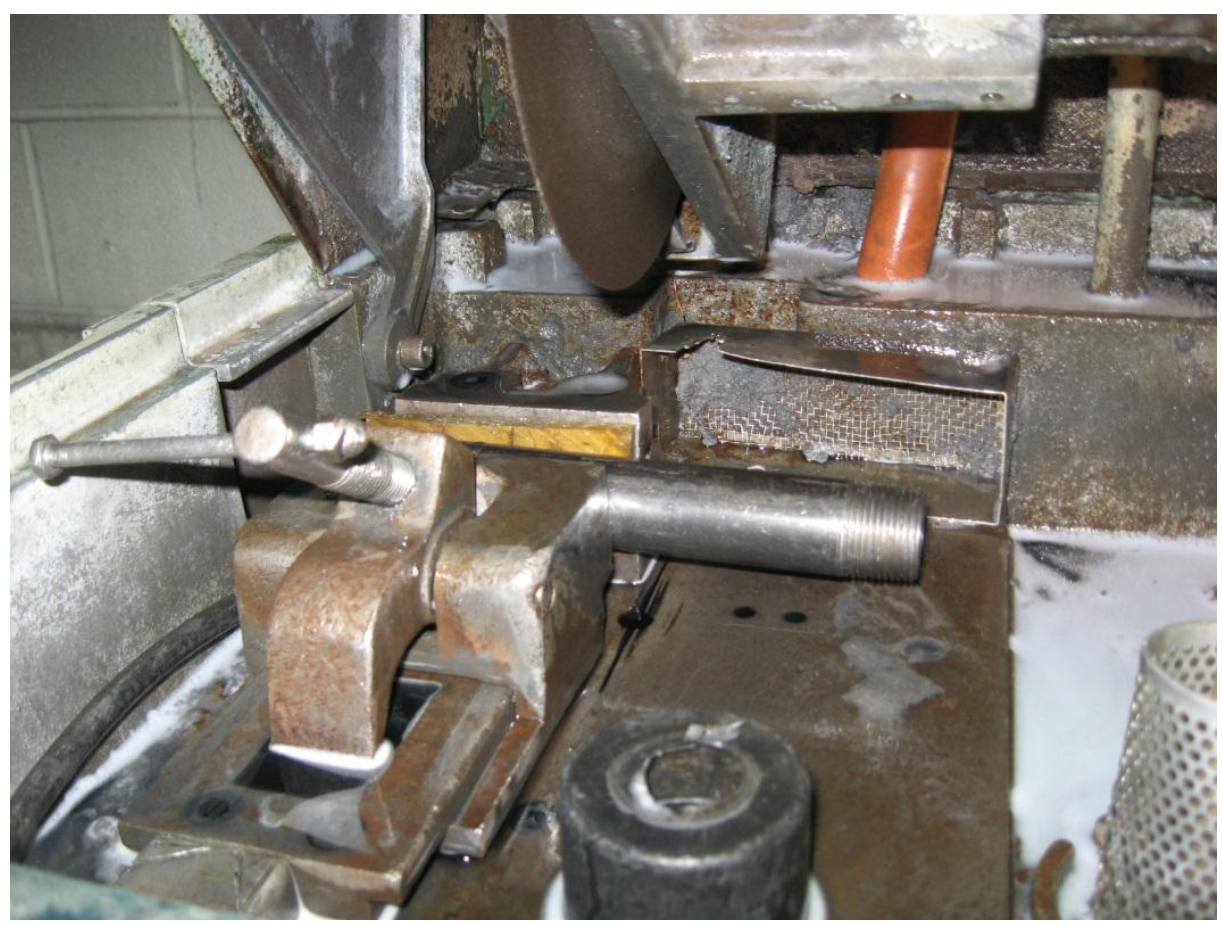

Photo 3: Cutter set to cut a pipe in half

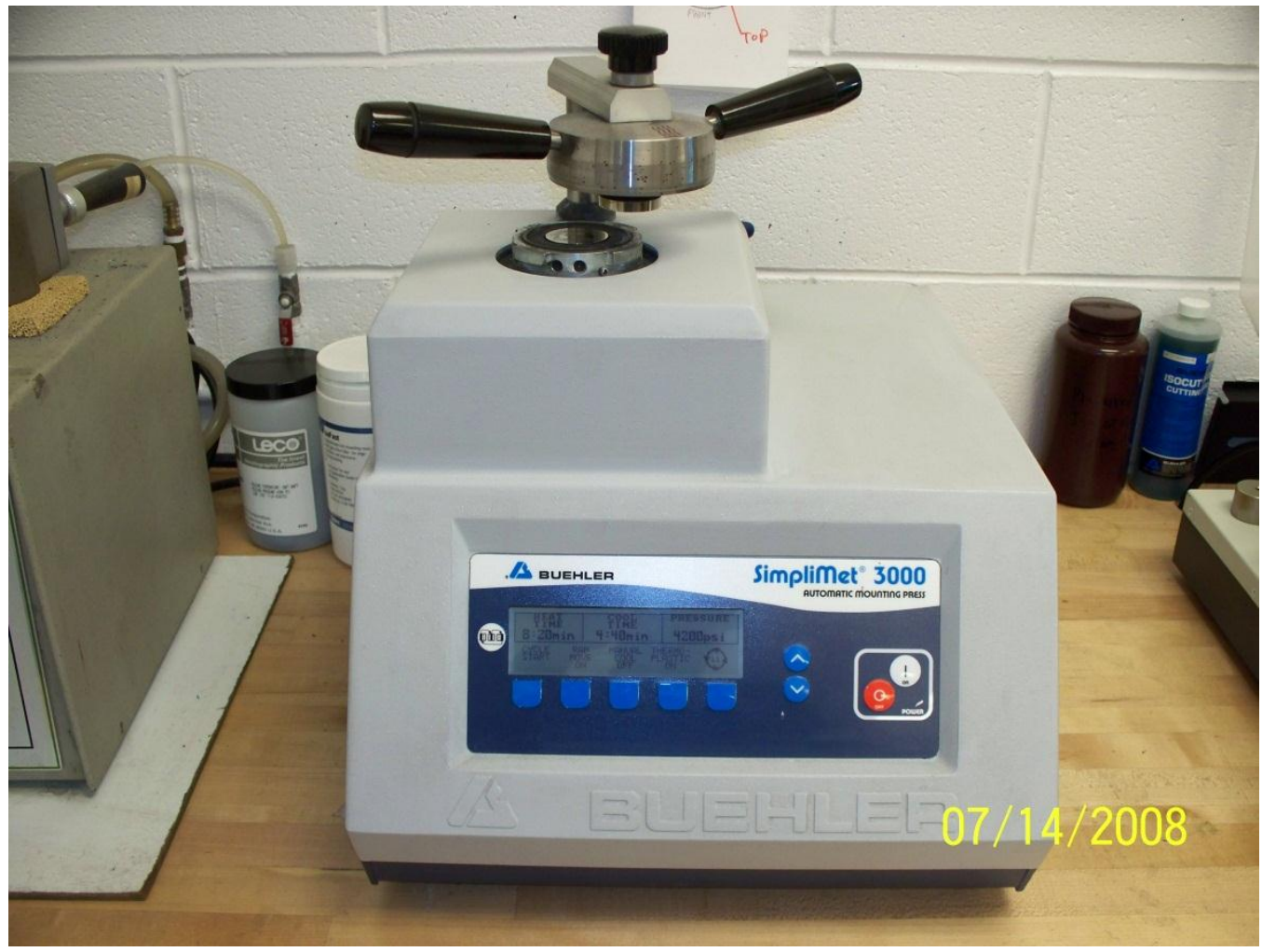

Photo 4: Buehler SimpliMet 3000 Automatic Mounting Press 


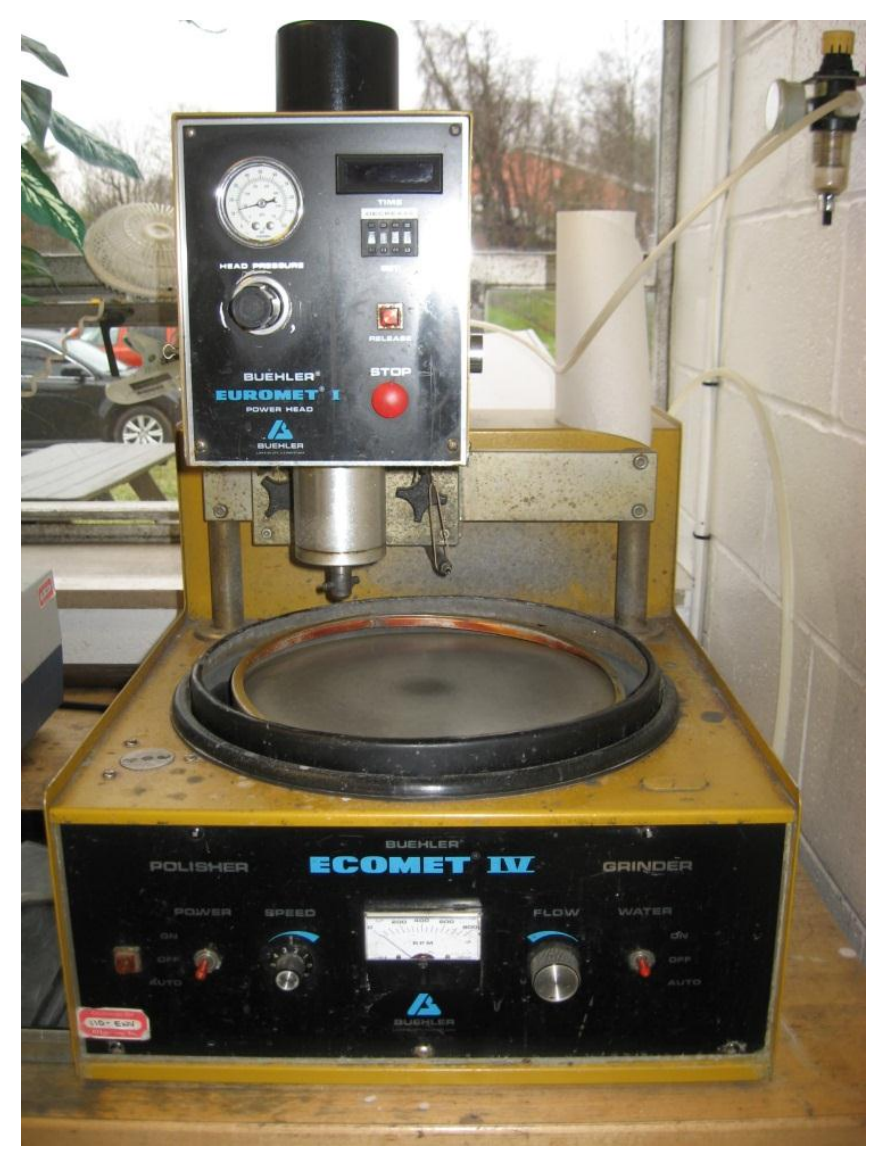

Photo 5: Buehler Euromet I/EcometIV 8-sample polisher/grinder

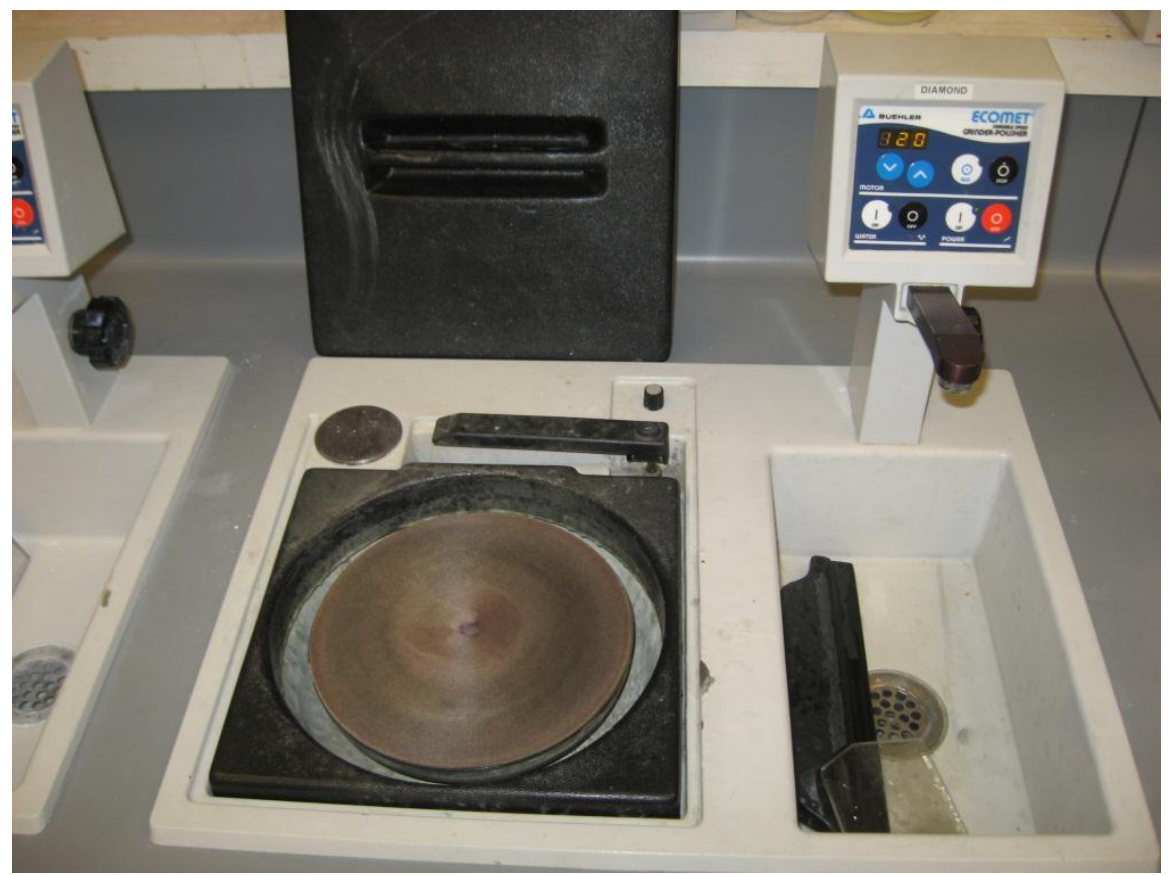

Photo 6: Buehler Ecomet Variable Speed Grinder/Polisher 


\section{Appendix 2}

\begin{tabular}{|c|c|c|c|c|c|c|}
\hline \multicolumn{7}{|l|}{$\mathrm{Ti}$} \\
\hline Row Labels & Average & SD & Low Cl & High Cl & $\#$ analyses $t$ & \\
\hline 11 & 26 & 3.7 & 24 & 29 & 10 & 2.26216 \\
\hline 12 & 29 & 6.8 & 22 & 36 & 6 & 2.57058 \\
\hline 13 & 32 & 2.7 & 29 & 35 & 6 & 2.57058 \\
\hline 21 & 30 & 5.6 & 24 & 36 & 6 & 2.57058 \\
\hline 22 & 33 & 5.6 & 27 & 39 & 6 & 2.57058 \\
\hline 23 & 25 & 6.3 & 18 & 31 & 6 & 2.57058 \\
\hline 31 & 26 & 4.8 & 20 & 31 & 6 & 2.57058 \\
\hline 32 & 25 & 5.7 & 19 & 31 & 6 & 2.57058 \\
\hline 33 & 30 & 6.8 & 23 & 37 & 6 & 2.57058 \\
\hline 41 & 26 & 5.0 & 22 & 29 & 10 & 2.26216 \\
\hline 42 & 28 & 4.4 & 23 & 32 & 6 & 2.57058 \\
\hline 43 & 23 & 9.2 & 14 & 33 & 6 & 2.57058 \\
\hline 51 & 63 & \begin{tabular}{|l|l|} 
& 10.7 \\
\end{tabular} & 52 & 74 & 6 & 2.57058 \\
\hline 52 & 29 & 4.0 & 25 & 33 & 6 & 2.57058 \\
\hline 53 & 54 & 9.3 & 44 & 63 & 6 & 2.57058 \\
\hline 61 & 31 & 7.8 & 23 & 40 & 6 & 2.57058 \\
\hline 62 & 30 & 7.8 & 21 & 38 & 6 & 2.57058 \\
\hline 63 & 27 & 5.8 & 20 & 33 & 6 & 2.57058 \\
\hline 71 & 28 & 5.3 & 22 & 34 & 6 & 2.57058 \\
\hline 72 & 31 & 8.7 & 22 & 40 & 6 & 2.57058 \\
\hline 73 & 27 & 4.2 & 23 & 32 & 6 & 2.57058 \\
\hline 81 & 30 & 3.7 & 26 & 34 & 6 & 2.57058 \\
\hline 82 & 30 & 6.5 & 23 & 37 & 6 & 2.57058 \\
\hline 83 & 29 & 5.8 & 24 & 33 & 10 & 2.26216 \\
\hline 91 & 32 & 3.3 & 29 & 36 & 6 & 2.57058 \\
\hline 92 & 30 & 9.5 & 20 & 40 & 6 & 2.57058 \\
\hline 93 & 30 & 3.7 & 26 & 34 & 6 & 2.57058 \\
\hline 101 & 31 & 7.7 & 22 & 39 & 6 & 2.57058 \\
\hline 102 & 29 & 4.1 & 26 & 32 & 10 & 2.26216 \\
\hline 103 & 32 & 4.6 & 27 & 37 & 6 & 2.57058 \\
\hline 111 & 28 & 4.0 & 24 & 33 & 6 & 2.57058 \\
\hline 112 & 28 & 3.2 & 25 & 32 & 6 & 2.57058 \\
\hline 113 & 33 & 5.7 & 27 & 39 & 6 & 2.57058 \\
\hline 121 & 31 & 5.5 & 26 & 37 & 6 & 2.57058 \\
\hline 122 & 27 & 2.0 & 25 & 29 & 6 & 2.57058 \\
\hline 123 & 29 & 3.3 & 25 & 32 & 6 & 2.57058 \\
\hline 131 & 31 & 5.8 & 26 & 35 & 10 & 2.26216 \\
\hline
\end{tabular}

\begin{tabular}{|r|r|r|r|r|r|r|}
\hline $\mathbf{V}$ & & & & & & \\
Row Labels & Average & SD & Low Cl & High Cl & \# analyses t \\
\hline $\mathbf{1 1}$ & 56 & 17.7 & 43 & 68 & 10 & 2.26216 \\
\hline $\mathbf{1 2}$ & 58 & 19.3 & 37 & 78 & 6 & 2.57058 \\
\hline $\mathbf{1 3}$ & 60 & 17.9 & 41 & 78 & 6 & 2.57058 \\
\hline $\mathbf{2 1}$ & 60 & 15.0 & 44 & 76 & 6 & 2.57058 \\
\hline $\mathbf{2 2}$ & 55 & 10.9 & 44 & 67 & 6 & 2.57058 \\
\hline $\mathbf{2 3}$ & 77 & 35.8 & 40 & 115 & 6 & 2.57058 \\
\hline $\mathbf{3 1}$ & 72 & 11.8 & 59 & 84 & 6 & 2.57058 \\
\hline $\mathbf{3 2}$ & 68 & 15.9 & 51 & 84 & 6 & 2.57058 \\
\hline $\mathbf{3 3}$ & 74 & 11.1 & 62 & 86 & 6 & 2.57058 \\
\hline $\mathbf{4 1}$ & 60 & 11.9 & 52 & 69 & 10 & 2.26216 \\
\hline $\mathbf{4 2}$ & 85 & 29.8 & 54 & 116 & 6 & 2.57058 \\
\hline $\mathbf{4 3}$ & 88 & 34.0 & 53 & 124 & 6 & 2.57058 \\
\hline $\mathbf{5 1}$ & 67 & 3.5 & 63 & 71 & 6 & 2.57058 \\
\hline $\mathbf{5 2}$ & 71 & 23.2 & 46 & 95 & 6 & 2.57058 \\
\hline $\mathbf{5 3}$ & 71 & 7.7 & 63 & 79 & 6 & 2.57058 \\
\hline $\mathbf{6 1}$ & 70 & 15.1 & 54 & 85 & 6 & 2.57058 \\
\hline $\mathbf{6 2}$ & 73 & 17.6 & 54 & 91 & 6 & 2.57058 \\
\hline $\mathbf{6 3}$ & 88 & 18.8 & 68 & 108 & 6 & 2.57058 \\
\hline $\mathbf{7 1}$ & 72 & 18.0 & 53 & 91 & 6 & 2.57058 \\
\hline $\mathbf{7 2}$ & 81 & 21.5 & 58 & 103 & 6 & 2.57058 \\
\hline $\mathbf{7 3}$ & 78 & 30.9 & 46 & 110 & 6 & 2.57058 \\
\hline $\mathbf{8 1}$ & 60 & 15.7 & 44 & 76 & 6 & 2.57058 \\
\hline $\mathbf{8 2}$ & 76 & 23.8 & 51 & 101 & 6 & 2.57058 \\
\hline $\mathbf{8 3}$ & 80 & 29.2 & 59 & 101 & 10 & 2.26216 \\
\hline $\mathbf{9 1}$ & 61 & 15.9 & 44 & 78 & 6 & 2.57058 \\
\hline $\mathbf{9 2}$ & 68 & 20.4 & 47 & 90 & 6 & 2.57058 \\
\hline $\mathbf{9 3}$ & 85 & 37.6 & 45 & 124 & 6 & 2.57058 \\
\hline $\mathbf{1 0 1}$ & 59 & 30.9 & 26 & 91 & 6 & 2.57058 \\
\hline $\mathbf{1 0 2}$ & 67 & 24.1 & 50 & 85 & 10 & 2.26216 \\
\hline $\mathbf{1 0 3}$ & 57 & 52.6 & 2 & 112 & 6 & 2.57058 \\
\hline $\mathbf{1 1 1}$ & 80 & 32.1 & 46 & 113 & 6 & 2.57058 \\
\hline $\mathbf{1 1 2}$ & 75 & 18.4 & 55 & 94 & 6 & 2.57058 \\
\hline 74 & 76 & 19.0 & 59 & 88 & 6 & 2.57058 \\
\hline & & 28.6 & 42 & 102 & 6 & 2.57058 \\
\hline $\mathbf{1 2 1}$ & & 128.8 & 3 & 188 & 10 & 2.57058 \\
\hline & & & 2.57058 \\
\hline
\end{tabular}




\begin{tabular}{|c|c|c|c|c|c|c|}
\hline \multicolumn{7}{|l|}{ Mn } \\
\hline Row Labels & Average & SD & Low Cl & High Cl & \# analyses & $t$ \\
\hline 11 & 375 & 32.7 & 351 & 398 & 10 & 2.26216 \\
\hline 12 & 366 & 26.1 & 338 & 393 & 6 & 2.57058 \\
\hline 13 & 446 & 75.2 & 367 & 525 & 6 & 2.57058 \\
\hline 21 & 377 & 23.4 & 352 & 401 & 6 & 2.57058 \\
\hline 22 & 373 & 10.2 & 362 & 384 & 6 & 2.57058 \\
\hline 23 & 347 & 17.5 & 329 & 365 & 6 & 2.57058 \\
\hline 31 & 368 & 24.8 & 341 & 394 & 6 & 2.57058 \\
\hline 32 & 382 & 50.5 & 329 & 435 & 6 & 2.57058 \\
\hline 33 & 360 & 19.9 & 339 & 381 & 6 & 2.57058 \\
\hline 41 & 372 & 17.6 & 360 & 385 & 10 & 2.26216 \\
\hline 42 & 386 & 53.8 & 329 & 442 & 6 & 2.57058 \\
\hline 43 & 389 & 25.2 & 362 & 415 & 6 & 2.57058 \\
\hline 51 & 351 & 14.8 & 335 & 366 & 6 & 2.57058 \\
\hline 52 & 281 & 14.1 & 266 & 295 & 6 & 2.57058 \\
\hline 53 & 325 & 7.7 & 317 & 333 & 6 & 2.57058 \\
\hline 61 & 311 & 16.3 & 294 & 328 & 6 & 2.57058 \\
\hline 62 & 357 & 15.9 & 340 & 373 & 6 & 2.57058 \\
\hline 63 & 369 & 18.6 & 349 & 388 & 6 & 2.57058 \\
\hline 71 & 349 & 38.6 & 309 & 390 & 6 & 2.57058 \\
\hline 72 & 366 & 27.6 & 337 & 395 & 6 & 2.57058 \\
\hline 73 & 259 & 21.9 & 236 & 282 & 6 & 2.57058 \\
\hline 81 & 367 & 29.9 & 335 & 398 & 6 & 2.57058 \\
\hline 82 & 278 & 25.8 & 251 & 305 & 6 & 2.57058 \\
\hline 83 & 302 & 24.2 & 285 & 320 & 10 & 2.26216 \\
\hline 91 & 297 & 23.0 & 273 & 321 & 6 & 2.57058 \\
\hline 92 & 306 & 36.0 & 269 & 344 & 6 & 2.57058 \\
\hline 93 & 353 & 43.6 & 307 & 399 & 6 & 2.57058 \\
\hline 101 & 424 & 185.8 & 229 & 619 & 6 & 2.57058 \\
\hline 102 & 403 & 27.4 & 383 & 422 & 10 & 2.26216 \\
\hline 103 & 402 & 28.3 & 372 & 432 & 6 & 2.57058 \\
\hline 111 & 226 & 13.2 & 212 & 240 & 6 & 2.57058 \\
\hline 112 & 251 & 32.5 & 217 & 285 & 6 & 2.57058 \\
\hline 113 & 241 & 30.9 & 208 & 273 & 6 & 2.57058 \\
\hline 121 & 304 & 43.8 & 258 & 350 & 6 & 2.57058 \\
\hline 122 & 328 & 35.4 & 291 & 365 & 6 & 2.57058 \\
\hline 123 & 323 & 31.9 & 289 & 356 & 6 & 2.57058 \\
\hline 131 & 379 & 22.6 & 363 & 395 & 10 & 2.26216 \\
\hline
\end{tabular}

\begin{tabular}{|c|c|c|c|c|c|c|}
\hline \multicolumn{7}{|l|}{ Co } \\
\hline Row Labels & Average & SD & Low Cl & High Cl & \# analyses & \\
\hline 11 & 1907 & 68.5 & 1858 & 1956 & 10 & 2.26216 \\
\hline 12 & 1936 & 162.6 & 1765 & 2106 & 6 & 2.57058 \\
\hline 13 & 1872 & $\begin{array}{l}26.5 \\
\end{array}$ & 1802 & 1941 & 6 & 2.57058 \\
\hline 21 & 1904 & 56.0 & 1845 & 1963 & 6 & 2.57058 \\
\hline 22 & 1906 & 38.1 & 1866 & 1946 & 6 & 2.57058 \\
\hline 23 & 1907 & \begin{tabular}{l|l}
7 & 39.8
\end{tabular} & 1865 & 1949 & 6 & 2.57058 \\
\hline 31 & 1915 & 34.9 & 1878 & 1951 & 6 & 2.57058 \\
\hline 32 & 1907 & \begin{tabular}{l|l}
7 & 67.4
\end{tabular} & 1836 & 1978 & 6 & 2.57058 \\
\hline 33 & 1862 & 21.7 & 1839 & 1885 & 6 & 2.57058 \\
\hline 41 & 1865 & \begin{tabular}{|l|l}
5 & 41.7
\end{tabular} & 1835 & 1895 & 10 & 2.26216 \\
\hline 42 & 1869 & 57.8 & 1809 & 1930 & 6 & 2.57058 \\
\hline 43 & 1860 & 61.7 & 1795 & 1925 & 6 & 2.57058 \\
\hline 51 & 1877 & $\begin{array}{l}73.4 \\
\end{array}$ & 1832 & 1923 & 6 & 2.57058 \\
\hline 52 & 1929 & 60.9 & 1865 & 1993 & 6 & 2.57058 \\
\hline 53 & 1888 & $\begin{array}{ll}3 & 60.8\end{array}$ & 1824 & 1952 & 6 & 2.57058 \\
\hline 61 & 1901 & $\begin{array}{l}\mid \\
\end{array}$ & 1863 & 1938 & 6 & 2.57058 \\
\hline 62 & 1885 & 47.4 & 1836 & 1935 & 6 & 2.57058 \\
\hline 63 & 1866 & 71.5 & 1791 & 1941 & 6 & 2.57058 \\
\hline 71 & 1904 & 52.3 & 1849 & 1959 & 6 & 2.57058 \\
\hline 72 & 1857 & 59.6 & 1794 & 1919 & 6 & 2.57058 \\
\hline 73 & 1847 & 19.0 & 1827 & 1867 & 6 & 2.57058 \\
\hline 81 & 1862 & 109.8 & 1746 & 1977 & 6 & 2.57058 \\
\hline 82 & 1852 & 82.1 & 1766 & 1938 & 6 & 2.57058 \\
\hline 83 & 1940 & 62.6 & 1895 & 1985 & 10 & 2.26216 \\
\hline 91 & 1869 & 83.0 & 1782 & 1956 & 6 & 2.57058 \\
\hline 92 & 1921 & 80.0 & 1837 & 2005 & 6 & 2.57058 \\
\hline 93 & 1888 & 83.4 & 1800 & 1975 & 6 & 2.57058 \\
\hline 101 & 1859 & 34.3 & 1823 & 1895 & 6 & 2.57058 \\
\hline 102 & 1936 & 82.8 & 1876 & 1995 & 10 & 2.26216 \\
\hline 103 & 1912 & 73.5 & 1834 & 1989 & 6 & 2.57058 \\
\hline 111 & 1634 & 63.0 & 1568 & 1700 & 6 & 2.57058 \\
\hline 112 & 1759 & 192.8 & 1556 & 1961 & 6 & 2.57058 \\
\hline 113 & 1941 & 127.2 & 1807 & 2074 & 6 & 2.57058 \\
\hline 121 & 1923 & 34.2 & 1887 & 1959 & 6 & 2.57058 \\
\hline 122 & 1910 & 29.7 & 1879 & 1942 & 6 & 2.57058 \\
\hline 123 & 1890 & 73.9 & 1812 & 1967 & 6 & 2.57058 \\
\hline 131 & 1890 & 45.9 & 1857 & 1923 & 10 & 2.26216 \\
\hline
\end{tabular}




\begin{tabular}{|c|c|c|c|c|c|c|}
\hline \multicolumn{7}{|l|}{$\mathrm{Cu}$} \\
\hline Row Labels & Average & SD & Low Cl & High Cl & \# analyses & $t$ \\
\hline 11 & 11 & 3.5 & 9 & 14 & 10 & 2.26216 \\
\hline 12 & 11 & 3.3 & 7 & 14 & 6 & 2.57058 \\
\hline 13 & 13 & 4.8 & 8 & 18 & 6 & 2.57058 \\
\hline 21 & 8 & 2.5 & 5 & 10 & 6 & 2.57058 \\
\hline 22 & 7 & 3.0 & 4 & 10 & 6 & 2.57058 \\
\hline 23 & 6 & 1.3 & 5 & 8 & 6 & 2.57058 \\
\hline 31 & 9 & 2.7 & 6 & 12 & 6 & 2.57058 \\
\hline 32 & 8 & 1.7 & 6 & 10 & 6 & 2.57058 \\
\hline 33 & 11 & 2.1 & 8 & 13 & 6 & 2.57058 \\
\hline 41 & 8 & 2.5 & 6 & 10 & 10 & 2.26216 \\
\hline 42 & 5 & 2.0 & 3 & 7 & 6 & 2.57058 \\
\hline 43 & 7 & 1.8 & 5 & 9 & 6 & 2.57058 \\
\hline 51 & 21 & 7.2 & 14 & 29 & 6 & 2.57058 \\
\hline 52 & 11 & 1.0 & 9 & 12 & 6 & 2.57058 \\
\hline 53 & 19 & 6.4 & 12 & 26 & 6 & 2.57058 \\
\hline 61 & 8 & 3.3 & 4 & 11 & 6 & 2.57058 \\
\hline 62 & 9 & 3.7 & 5 & 13 & 6 & 2.57058 \\
\hline 63 & 8 & 2.0 & 6 & 10 & 6 & 2.57058 \\
\hline 71 & 10 & 3.7 & 6 & 14 & 6 & 2.57058 \\
\hline 72 & 8 & 0.8 & 7 & 9 & 6 & 2.57058 \\
\hline 73 & 13 & 3.3 & 9 & 16 & 6 & 2.57058 \\
\hline 81 & 13 & 2.3 & 10 & 15 & 6 & 2.57058 \\
\hline 82 & 22 & 3.9 & 17 & 26 & 6 & 2.57058 \\
\hline 83 & 26 & 4.3 & 23 & 29 & 10 & 2.26216 \\
\hline 91 & 8 & 2.0 & 6 & 10 & 6 & 2.57058 \\
\hline 92 & 9 & 1.5 & 7 & 10 & 6 & 2.57058 \\
\hline 93 & 9 & 1.9 & 7 & 11 & 6 & 2.57058 \\
\hline 101 & 10 & 3.4 & 7 & 14 & 6 & 2.57058 \\
\hline 102 & 14 & 3.8 & 11 & 17 & 10 & 2.26216 \\
\hline 103 & 12 & 2.9 & 9 & 15 & 6 & 2.57058 \\
\hline 111 & 8 & 3.2 & 5 & 12 & 6 & 2.57058 \\
\hline 112 & 8 & 2.8 & 5 & 11 & 6 & 2.57058 \\
\hline 113 & 7 & 1.0 & 6 & 8 & 6 & 2.57058 \\
\hline 121 & 10 & 4.1 & 6 & 14 & 6 & 2.57058 \\
\hline 122 & 8 & 1.0 & 7 & 9 & 6 & 2.57058 \\
\hline 123 & 8 & 4.2 & 4 & 13 & 6 & 2.57058 \\
\hline 131 & 11 & 4.5 & 8 & 14 & 10 & 2.26216 \\
\hline
\end{tabular}

\begin{tabular}{|c|c|c|c|c|c|c|}
\hline \multicolumn{7}{|l|}{$\mathrm{Ge}$} \\
\hline Row Labels & Average & SD & Low Cl & High Cl & \# analyses & \\
\hline 11 & 8 & 2.8 & 6 & 10 & 10 & 2.26216 \\
\hline 12 & 6 & 3.1 & 3 & 9 & 6 & 2.57058 \\
\hline 13 & 7 & 2.9 & 3 & 10 & 6 & 2.57058 \\
\hline 21 & 6 & 2.3 & 3 & 8 & 6 & 2.57058 \\
\hline 22 & 6 & 3.0 & 3 & 9 & 6 & 2.57058 \\
\hline 23 & 8 & 3.4 & 4 & 11 & 6 & 2.57058 \\
\hline 31 & 9 & 3.9 & 5 & 13 & 6 & 2.57058 \\
\hline 32 & 8 & 3.0 & 4 & 11 & 6 & 2.57058 \\
\hline 33 & 7 & 2.4 & 5 & 9 & 6 & 2.57058 \\
\hline 41 & 7 & 1.6 & 6 & 8 & 10 & 2.26216 \\
\hline 42 & 10 & 3.0 & 7 & 13 & 6 & 2.57058 \\
\hline 43 & 11 & 5.0 & 5 & 16 & 6 & 2.57058 \\
\hline 51 & 19 & 6.0 & 12 & 25 & 6 & 2.57058 \\
\hline 52 & 8 & 2.9 & 5 & 11 & 6 & 2.57058 \\
\hline 53 & 15 & 4.0 & 10 & 19 & 6 & 2.57058 \\
\hline 61 & 10 & 3.7 & 6 & 14 & 6 & 2.57058 \\
\hline 62 & 8 & 2.5 & 6 & 11 & 6 & 2.57058 \\
\hline 63 & 8 & 3.3 & 4 & 11 & 6 & 2.57058 \\
\hline 71 & 9 & 2.3 & 6 & 11 & 6 & 2.57058 \\
\hline 72 & 7 & 3.1 & 4 & 11 & 6 & 2.57058 \\
\hline 73 & 11 & 4.9 & 6 & 16 & 6 & 2.57058 \\
\hline 81 & 7 & 1.7 & 5 & 9 & 6 & 2.57058 \\
\hline 82 & 9 & 2.1 & 7 & 12 & 6 & 2.57058 \\
\hline 83 & 8 & 2.9 & 6 & 10 & 10 & 2.26216 \\
\hline 91 & 7 & 2.9 & 4 & 10 & 6 & 2.57058 \\
\hline 92 & 8 & 3.5 & 4 & 12 & 6 & 2.57058 \\
\hline 93 & 8 & 3.3 & 4 & 11 & 6 & 2.57058 \\
\hline 101 & 6 & 2.6 & 3 & 9 & 6 & 2.57058 \\
\hline 102 & 9 & 3.4 & 7 & 12 & 10 & 2.26216 \\
\hline 103 & 9 & 5.2 & 4 & 15 & 6 & 2.57058 \\
\hline 111 & 8 & 3.3 & 5 & 12 & 6 & 2.57058 \\
\hline 112 & 7 & 1.5 & 6 & 9 & 6 & 2.57058 \\
\hline 113 & 9 & 2.1 & 7 & 11 & 6 & 2.57058 \\
\hline 121 & 10 & 6.0 & 4 & 16 & 6 & 2.57058 \\
\hline 122 & 8 & 3.9 & 4 & 12 & 6 & 2.57058 \\
\hline 123 & 8 & 2.0 & 6 & 10 & 6 & 2.57058 \\
\hline 131 & 9 & 5.6 & 5 & 13 & 10 & 2.26216 \\
\hline
\end{tabular}




\begin{tabular}{|c|c|c|c|c|c|c|}
\hline \multicolumn{7}{|l|}{ Sn } \\
\hline Row Labels & Average & SD & Low Cl & High Cl & $\#$ analyses & $\mathbf{t}$ \\
\hline 11 & 2 & 1.3 & 1 & 3 & 10 & 2.26216 \\
\hline 12 & 2 & 1.2 & 1 & 3 & 6 & 2.57058 \\
\hline 13 & 2 & 1.4 & 0 & 3 & 6 & 2.57058 \\
\hline 21 & 3 & 2.7 & 0 & 5 & 6 & 2.57058 \\
\hline 22 & 3 & 1.2 & 1 & 4 & 6 & 2.57058 \\
\hline 23 & 2 & 0.8 & 1 & 2 & 6 & 2.57058 \\
\hline 31 & 2 & 1.0 & 0 & 3 & 6 & 2.57058 \\
\hline 32 & 1 & 0.8 & 0 & 2 & 6 & 2.57058 \\
\hline 33 & 2 & 2.0 & 0 & 4 & 6 & 2.57058 \\
\hline 41 & 2 & 0.7 & 1 & 2 & 10 & 2.26216 \\
\hline 42 & 1 & 1.0 & 0 & 2 & 6 & 2.57058 \\
\hline 43 & 2 & 2.0 & 0 & 4 & 6 & 2.57058 \\
\hline 51 & 2 & 1.0 & 0 & 3 & 6 & 2.57058 \\
\hline 52 & 2 & 1.5 & 0 & 3 & 6 & 2.57058 \\
\hline 53 & 4 & 1.9 & 2 & 5 & 6 & 2.57058 \\
\hline 61 & 2 & 1.3 & 0 & 3 & 6 & 2.57058 \\
\hline 62 & 2 & 1.0 & 1 & 3 & 6 & 2.57058 \\
\hline 63 & 2 & 1.5 & 0 & 3 & 6 & 2.57058 \\
\hline 71 & 2 & 1.6 & 1 & 4 & 6 & 2.57058 \\
\hline 72 & 2 & 1.0 & 1 & 3 & 6 & 2.57058 \\
\hline 73 & 2 & 1.7 & 0 & 4 & 6 & 2.57058 \\
\hline 81 & 2 & 1.2 & 1 & 3 & 6 & 2.57058 \\
\hline 82 & 3 & 1.2 & 1 & 4 & 6 & 2.57058 \\
\hline 83 & 2 & 1.2 & 1 & 3 & 10 & 2.26216 \\
\hline 91 & 1 & 1.2 & 0 & 2 & 6 & 2.57058 \\
\hline 92 & 1 & 0.8 & 0 & 2 & 6 & 2.57058 \\
\hline 93 & 1 & 0.9 & 0 & 2 & 6 & 2.57058 \\
\hline 101 & 2 & 1.3 & 0 & 3 & 6 & 2.57058 \\
\hline 102 & 2 & 1.5 & 1 & 3 & 10 & 2.26216 \\
\hline 103 & 3 & 1.4 & 1 & 4 & 6 & 2.57058 \\
\hline 111 & 2 & 1.2 & 0 & 3 & 6 & 2.57058 \\
\hline 112 & 2 & 0.8 & 1 & 3 & 6 & 2.57058 \\
\hline 113 & 2 & 1.2 & 1 & 3 & 6 & 2.57058 \\
\hline 121 & 2 & 1.4 & 0 & 3 & 6 & 2.57058 \\
\hline 122 & 2 & 1.2 & 0 & 3 & 6 & 2.57058 \\
\hline 123 & 2 & 0.9 & 1 & 3 & 6 & 2.57058 \\
\hline 131 & 1 & 1.4 & 0 & 2 & 10 & 2.26216 \\
\hline
\end{tabular}

\begin{tabular}{|c|c|c|c|c|c|c|}
\hline \multicolumn{7}{|l|}{$\mathrm{Sb}$} \\
\hline Row Labels & Average & SD & Low Cl & High Cl & \# analyses $t$ & \\
\hline 11 & 3 & 1.6 & 1 & 4 & 10 & 2.26216 \\
\hline 12 & 1 & 0.8 & 0 & 2 & 6 & 2.57058 \\
\hline 13 & 2 & 0.8 & 1 & 3 & 6 & 2.57058 \\
\hline 21 & 2 & 0.8 & 1 & 2 & 6 & 2.57058 \\
\hline 22 & 1 & 0.5 & 1 & 2 & 6 & 2.57058 \\
\hline 23 & 2 & 0.5 & 1 & 2 & 6 & 2.57058 \\
\hline 31 & 1 & 0.8 & 0 & 2 & 6 & 2.57058 \\
\hline 32 & 2 & 1.2 & 0 & 3 & 6 & 2.57058 \\
\hline 33 & 2 & 1.0 & 0 & 3 & 6 & 2.57058 \\
\hline 41 & 2 & 1.4 & 0 & 3 & 10 & 2.26216 \\
\hline 42 & 3 & 1.8 & 1 & 5 & 6 & 2.57058 \\
\hline 43 & 1 & 0.4 & 1 & 2 & 6 & 2.57058 \\
\hline 51 & 1 & 1.4 & 0 & 3 & 6 & 2.57058 \\
\hline 52 & 1 & 0.8 & 0 & 2 & 6 & 2.57058 \\
\hline 53 & 3 & 2.0 & 1 & 5 & 6 & 2.57058 \\
\hline 61 & 2 & 1.0 & 1 & 3 & 6 & 2.57058 \\
\hline 62 & 1 & 1.2 & 0 & 2 & 6 & 2.57058 \\
\hline 63 & 2 & 1.4 & 0 & 3 & 6 & 2.57058 \\
\hline 71 & 1 & 1.0 & 0 & 2 & 6 & 2.57058 \\
\hline 72 & 4 & 1.9 & 2 & 5 & 6 & 2.57058 \\
\hline 73 & 3 & 1.2 & 2 & 4 & 6 & 2.57058 \\
\hline 81 & 2 & 0.8 & 1 & 3 & 6 & 2.57058 \\
\hline 82 & 2 & 1.5 & 1 & 4 & 6 & 2.57058 \\
\hline 83 & 2 & 1.8 & 1 & 3 & 10 & 2.26216 \\
\hline 91 & 2 & 0.8 & 1 & 3 & 6 & 2.57058 \\
\hline 92 & 2 & 1.4 & 0 & 3 & 6 & 2.57058 \\
\hline 93 & 1 & 0.8 & 0 & 2 & 6 & 2.57058 \\
\hline 101 & 2 & 1.3 & 0 & 3 & 6 & 2.57058 \\
\hline 102 & 2 & 1.5 & 1 & 3 & 10 & 2.26216 \\
\hline 103 & 3 & 1.4 & 1 & 4 & 6 & 2.57058 \\
\hline 111 & 2 & 1.2 & 0 & 3 & 6 & 2.57058 \\
\hline 112 & 2 & 0.8 & 1 & 3 & 6 & 2.57058 \\
\hline 113 & 2 & 1.2 & 1 & 3 & 6 & 2.57058 \\
\hline 121 & 2 & 1.4 & 0 & 3 & 6 & 2.57058 \\
\hline 122 & 2 & 1.2 & 0 & 3 & 6 & 2.57058 \\
\hline 123 & 2 & 0.9 & 1 & 3 & 6 & 2.57058 \\
\hline 131 & 1 & 1.4 & 0 & 2 & 10 & 2.26216 \\
\hline
\end{tabular}




\begin{tabular}{|c|c|c|c|c|c|c|}
\hline \multicolumn{7}{|l|}{$\mathbf{P}$} \\
\hline Row Labels & Average & SD & Low Cl & High Cl & \# analyses & \\
\hline 11 & 9 & 2.7 & 7 & 11 & 10 & 2.26216 \\
\hline 12 & 8 & 2.4 & 6 & 11 & 6 & 2.57058 \\
\hline 13 & 10 & 2.2 & 8 & 13 & 6 & 2.57058 \\
\hline 21 & 10 & 1.9 & 8 & 11 & 6 & 2.57058 \\
\hline 22 & 7 & 2.6 & 4 & 10 & 6 & 2.57058 \\
\hline 23 & 9 & 2.8 & 6 & 11 & 6 & 2.57058 \\
\hline 31 & 9 & 2.1 & 6 & 11 & 6 & 2.57058 \\
\hline 32 & 9 & 3.1 & 5 & 12 & 6 & 2.57058 \\
\hline 33 & 8 & 2.4 & 6 & 10 & 6 & 2.57058 \\
\hline 41 & 10 & 2.0 & 8 & 11 & 10 & 2.26216 \\
\hline 42 & 6 & 1.7 & 4 & 8 & 6 & 2.57058 \\
\hline 43 & 8 & 3.2 & 5 & 11 & 6 & 2.57058 \\
\hline 51 & 12 & 3.3 & 8 & 16 & 6 & 2.57058 \\
\hline 52 & 9 & 1.8 & 7 & 11 & 6 & 2.57058 \\
\hline 53 & 10 & 1.9 & 8 & 12 & 6 & 2.57058 \\
\hline 61 & 9 & 1.7 & 7 & 11 & 6 & 2.57058 \\
\hline 62 & 7 & 1.5 & 6 & 9 & 6 & 2.57058 \\
\hline 63 & 8 & 1.8 & 6 & 10 & 6 & 2.57058 \\
\hline 71 & 9 & 5.2 & 3 & 14 & 6 & 2.57058 \\
\hline 72 & 9 & 3.1 & 6 & 12 & 6 & 2.57058 \\
\hline 73 & 11 & 4.7 & 6 & 15 & 6 & 2.57058 \\
\hline 81 & 10 & 2.6 & 7 & 13 & 6 & 2.57058 \\
\hline 82 & 8 & 2.9 & 5 & 11 & 6 & 2.57058 \\
\hline 83 & 10 & 3.3 & 8 & 12 & 10 & 2.26216 \\
\hline 91 & 7 & 2.6 & 4 & 10 & 6 & 2.57058 \\
\hline 92 & 6 & 2.4 & 3 & 8 & 6 & 2.57058 \\
\hline 93 & 6 & 2.9 & 3 & 9 & 6 & 2.57058 \\
\hline 101 & 7 & 1.5 & 5 & 8 & 6 & 2.57058 \\
\hline 102 & 9 & 2.6 & 7 & 11 & 10 & 2.26216 \\
\hline 103 & 8 & 1.5 & 7 & 10 & 6 & 2.57058 \\
\hline 111 & 11 & 1.9 & 9 & 12 & 6 & 2.57058 \\
\hline 112 & 8 & 4.1 & 4 & 12 & 6 & 2.57058 \\
\hline 113 & 9 & 2.4 & 6 & 11 & 6 & 2.57058 \\
\hline 121 & 8 & 3.1 & 5 & 11 & 6 & 2.57058 \\
\hline 122 & 10 & 2.2 & 7 & 12 & 6 & 2.57058 \\
\hline 123 & 6 & 1.9 & 4 & 8 & 6 & 2.57058 \\
\hline 131 & 7 & 2.9 & 5 & 9 & 10 & 2.26216 \\
\hline
\end{tabular}


Appendix 3

\section{All LA-ICP-MS Data}

Results are in Parts per Million

\begin{tabular}{|c|c|c|c|c|c|c|c|c|c|c|}
\hline Low Res 1 & 1-1-C- A & 1-1-C-B & 4-1-C-A & 4-1-C-B & 8-3-C-A & 8-3-C-B & 10-2-C-A & 10-2-C-B & 13-1-C-A & 13-1-C-B \\
\hline $\mathbf{M n}$ & 3946 & 4050 & 4540 & 3975 & 4731 & 4047 & 4404 & 4538 & 3943 & 3837 \\
\hline $\mathbf{F e}$ & 950000 & 950000 & 950000 & 950000 & 950000 & 950000 & 950000 & 950000 & 950000 & 950000 \\
\hline $\mathbf{A s}$ & 40 & 42 & 28 & 26 & 69 & 69 & 22 & 22 & 29 & 29 \\
\hline $\mathbf{Z r}$ & 1.5 & 1.6 & 2.4 & 2.3 & 1.1 & 1.6 & 1.7 & 2.2 & 0.79 & 1.2 \\
\hline $\mathbf{N b}$ & 0.68 & 0.75 & 0.95 & 0.90 & $<0.27$ & $<0.39$ & 1.1 & 1.2 & 0.54 & 0.52 \\
\hline $\mathbf{M o}$ & 24 & 25 & 6.3 & 5.3 & 42 & 40 & 23 & 25 & 53 & 54 \\
\hline $\mathbf{A g}$ & $<0.41$ & $<0.43$ & $<0.40$ & $<0.46$ & 0.57 & 0.49 & $<0.32$ & $<0.45$ & $<0.47$ & $<0.41$ \\
\hline $\mathbf{S n}$ & 8.4 & 8.5 & 77 & 64 & 41 & 37 & 15 & 17 & 72 & 71 \\
\hline $\mathbf{S b}$ & 14 & 15 & 4.4 & 3.7 & 17 & 15 & 4.2 & 4.7 & 8.3 & 7.9 \\
\hline $\mathbf{C e}$ & $<0.02$ & $<0.03$ & $<0.03$ & $<0.04$ & $<0.03$ & 0.035 & $<0.02$ & 0.026 & $<0.03$ & $<0.03$ \\
\hline $\mathbf{W}$ & 1.9 & 1.9 & 5.6 & 4.8 & 20 & 19 & 3.9 & 3.9 & 2.0 & 1.9 \\
\hline $\mathbf{P b ~ 2 0 4}$ & $<4.26$ & $<3.89$ & $<4.79$ & $<4.48$ & $<4.07$ & $<5.69$ & $<3.70$ & $<3.08$ & $<4.65$ & $<3.90$ \\
\hline $\mathbf{P b ~ 2 0 6}$ & 0.29 & 0.27 & 0.33 & 0.34 & 1.0 & 1.4 & 0.42 & 0.55 & 0.51 & 0.63 \\
\hline Pb 207 & 0.27 & 0.29 & 0.33 & 0.33 & 1.1 & 1.5 & 0.41 & 0.54 & 0.49 & 0.71 \\
\hline Pb 208 & 0.30 & 0.35 & 0.35 & 0.35 & 1.1 & 1.4 & 0.39 & 0.55 & 0.52 & 0.65 \\
\hline $\mathbf{B i}$ & $<0.12$ & $<0.10$ & $<0.08$ & $<0.12$ & $<0.09$ & 0.40 & $<0.06$ & $<0.08$ & $<0.08$ & $<0.13$ \\
\hline
\end{tabular}




\begin{tabular}{|c|c|c|c|c|c|c|c|c|c|c|}
\hline Low Res 2 & 1-1-C- A & 1-1-C-B & 4-1-C-A & 4-1-C-B & 8-3-C-A & 8-3-C-B & 10-2-C-A & 10-2-C-B & 13-1-C-A & 13-1-C-B \\
\hline Mn & 4163 & 4264 & 4810 & 4203 & 4927 & 4205 & 4626 & 4756 & 4124 & 4004 \\
\hline Fe & 950000 & 950000 & 950000 & 950000 & 950000 & 950000 & 950000 & 950000 & 950000 & 950000 \\
\hline As & 49 & 51 & 34 & 31 & 86 & 85 & 27 & 27 & 36 & 35 \\
\hline Mo & 30 & 31 & 8.1 & 6.8 & 50 & 47 & 28 & 30 & 65 & 65 \\
\hline Ag & $<0.06$ & $<0.06$ & $<0.06$ & $<0.06$ & 0.10 & 0.097 & $<0.04$ & $<0.06$ & $<0.07$ & $<0.06$ \\
\hline W & 2.0 & 2.0 & 6.0 & 5.1 & 20 & 19 & 4.1 & 4.1 & 2.1 & 1.9 \\
\hline Re & 0.0012 & 0.0047 & $<0.02$ & 0.0039 & 0.0038 & $<0.03$ & $<0.01$ & $<0.03$ & 0.0055 & 0.0035 \\
\hline
\end{tabular}




\begin{tabular}{|c|c|c|c|c|c|c|c|c|c|c|}
\hline Med Res 1 & 1-1-C-A & 1-1-C-B & 4-1-C-A & 4-1-C-B & 8-3-C-A & 8-3-C-B & 10-2-C-A & 10-2-C-B & 13-1-C-A & 13-1-C-B \\
\hline $\mathbf{P}$ & 224 & 228 & 263 & 295 & 135 & 241 & 118 & 158 & 97 & 88 \\
\hline $\mathbf{T i}$ & $<45.38$ & 53 & 49 & 65 & $<68.47$ & 2306 & $<65.37$ & 105 & $<67.98$ & $<51.48$ \\
\hline Ti & $<57.76$ & $<41.40$ & 139 & 83 & $<79.22$ & 2447 & 107 & 135 & $<92.16$ & $<63.54$ \\
\hline V & 27 & 28 & 26 & 34 & 6.0 & $<8.28$ & 8.1 & 11 & $<5.02$ & $<6.48$ \\
\hline Cr 52 & 278 & 293 & 383 & 406 & 440 & 457 & 351 & 365 & 261 & 303 \\
\hline Cr 53 & 287 & 312 & 390 & 444 & 441 & 465 & 363 & 352 & 252 & 286 \\
\hline Mn & 4055 & 3822 & 4358 & 4217 & 4786 & 4693 & 4325 & 4358 & 3758 & 3944 \\
\hline Fe 56 & 950000 & 950000 & 950000 & 950000 & 950000 & 950000 & 950000 & 950000 & 950000 & 950000 \\
\hline Fe 57 & 938020 & 886787 & 934332 & 934750 & 1001131 & 967173 & 928381 & 740709 & 952297 & 918557 \\
\hline Co & 81 & 74 & 42 & 43 & 59 & 50 & 18 & 20 & 22 & 24 \\
\hline Ni 60 & 145 & 138 & 131 & 145 & 405 & 365 & 80 & 93 & 130 & 132 \\
\hline $\mathrm{Ni} 62$ & 210 & 125 & $<137.05$ & 164 & 413 & 351 & 107 & 83 & 146 & 137 \\
\hline $\mathrm{Cu} 63$ & 149 & 138 & 66 & 82 & 799 & 722 & 220 & 247 & 250 & 247 \\
\hline $\mathrm{Cu} 65$ & 257 & 170 & 62 & 96 & 803 & 747 & 225 & 245 & 239 & 277 \\
\hline Zn 66 & 1.2 & 1.3 & 1.6 & 1.8 & 1.2 & 1.4 & 1.0 & 1.6 & 1.3 & 1.3 \\
\hline Zn 67 & 1.3 & 1.5 & 2.3 & 2.5 & 1.3 & 1.3 & 1.1 & 1.9 & $<1.63$ & 1.3 \\
\hline Zn 68 & 1.1 & 1.5 & 1.8 & 1.8 & 1.3 & 1.4 & 1.0 & 1.6 & 1.4 & 1.2 \\
\hline Ga 69 & 20 & 21 & 14 & 16 & 9.3 & 7.9 & 3.9 & 4.3 & 3.6 & 4.1 \\
\hline Ga 71 & 21 & 21 & 15 & 18 & 10 & 9.4 & 4.2 & 4.1 & $<3.76$ & $<6.34$ \\
\hline Ge 72 & 7.3 & $<11.06$ & 7.2 & 7.5 & $<24.65$ & 11 & 26 & 27 & 24 & 26 \\
\hline Ge 73 & 10 & 7.5 & 5.2 & 7.3 & $<16.36$ & 10 & 18 & 26 & 34 & 14 \\
\hline Ge 74 & $<10.59$ & $<7.61$ & 6.1 & 7.4 & 14 & 9.3 & 29 & 31 & 34 & 28 \\
\hline As & 56 & 41 & 29 & 25 & 114 & 84 & 23 & 21 & 30 & 28 \\
\hline Se & 0.31 & 0.31 & 0.46 & 0.44 & 0.66 & 0.22 & 0.16 & 0.83 & 0 & $<11.91$ \\
\hline
\end{tabular}




\begin{tabular}{|c|c|c|c|c|c|c|c|c|c|c|}
\hline Med Res 2 & 1-1-C- A & 1-1-C-B & 4-1-C-A & 4-1-C-B & 8-3-C-A & 8-3-C-B & 10-2-C-A & 10-2-C-B & 13-1-C-A & 13-1-C-B \\
\hline V & 30 & 30 & 30 & 38 & $<6.16$ & $<8.94$ & 8.7 & 11 & $<5.42$ & $<7.00$ \\
\hline Cr 52 & 324 & 342 & 447 & 474 & 513 & 532 & 410 & 425 & 304 & 353 \\
\hline Cr 53 & 330 & 360 & 448 & 511 & 514 & 543 & 419 & 408 & 293 & 333 \\
\hline Mn & 4137 & 3887 & 4474 & 4315 & 4791 & 4684 & 4385 & 4405 & 3786 & 3961 \\
\hline Fe 56 & 950000 & 950000 & 950000 & 950000 & 950000 & 950000 & 950000 & 950000 & 950000 & 950000 \\
\hline Fe 57 & 934270 & 886734 & 923293 & 927351 & 1021083 & 990374 & 932000 & & 963603 & 933154 \\
\hline Co & 56 & 51 & 30 & 30 & 39 & 33 & 12 & 14 & 15 & 16 \\
\hline Ni & 295 & 174 & $<188.19$ & 231 & 545 & 458 & 147 & 113 & 196 & 183 \\
\hline Cu 63 & 77 & 69 & 36 & 44 & 338 & 295 & 106 & 116 & 113 & 108 \\
\hline Cu 65 & 134 & 86 & 35 & 52 & 343 & 308 & 110 & 116 & 109 & 122 \\
\hline Zn 66 & 0.13 & 0.14 & 0.18 & 0.20 & 0.13 & 0.15 & 0.11 & 0.17 & 0.15 & 0.14 \\
\hline Zn 67 & 0.13 & 0.15 & 0.24 & 0.25 & 0.12 & 0.11 & 0.10 & 0.18 & $<0.16$ & 0.12 \\
\hline Zn 68 & 0.12 & 0.16 & 0.21 & 0.20 & 0.14 & 0.15 & 0.11 & 0.17 & 0.15 & 0.13 \\
\hline Ga 69 & 22 & 23 & 16 & 18 & 9.9 & 8.4 & 4.3 & 4.7 & 3.9 & 4.5 \\
\hline Ga 71 & 23 & 23 & 15 & 19 & 12 & 11 & 4.7 & 4.7 & $<4.19$ & $<7.06$ \\
\hline Ge 72 & 11 & $<16.30$ & 11 & 11 & $<36.34$ & 16 & 37 & 39 & 34 & 37 \\
\hline Ge 73 & 19 & 14 & 9.4 & 13 & $<31.04$ & 20 & 34 & 50 & 65 & 28 \\
\hline Ge 74 & $<13.65$ & $<9.81$ & 7.8 & 9.5 & 18 & 12 & 37 & 39 & 43 & 36 \\
\hline As & 59 & 43 & 31 & 27 & 117 & 86 & 24 & 22 & 31 & 29 \\
\hline
\end{tabular}




\section{LA-ICP-MS Data - only relevant elements}

Results are in Parts per Million

\begin{tabular}{|c|c|c|c|c|c|c|c|c|c|c|}
\hline Low Res 1 & 1-1-C-A & 1-1-C-B & 4-1-C-A & 4-1-C-B & 8-3-C-A & 8-3-C-B & 10-2-C-A & 10-2-C-B & 13-1-C-A & 13-1-C-B \\
\hline Mn & 3946 & 4050 & 4540 & 3975 & 4731 & 4047 & 4404 & 4538 & 3943 & 3837 \\
\hline $\mathrm{Fe}$ & 950000 & 950000 & 950000 & 950000 & 950000 & 950000 & 950000 & 950000 & 950000 & 950000 \\
\hline As & 40 & 42 & 28 & 26 & 69 & 69 & 22 & 22 & 29 & 29 \\
\hline Mo & 24 & 25 & 6.3 & 5.3 & 42 & 40 & 23 & 25 & 53 & 54 \\
\hline Sn & 8.4 & 8.5 & 77 & 64 & 41 & 37 & 15 & 17 & 72 & 71 \\
\hline Sb & 14 & 15 & 4.4 & 3.7 & 17 & 15 & 4.2 & 4.7 & 8.3 & 7.9 \\
\hline
\end{tabular}

\begin{tabular}{|c|c|c|c|c|c|c|c|c|c|c|}
\hline Low Res 2 & 1-1-C-A & 1-1-C-B & 4-1-C-A & 4-1-C-B & 8-3-C-A & 8-3-C-B & 10-2-C-A & 10-2-C-B & 13-1-C-A & 13-1-C-B \\
\hline Mn & 4163 & 4264 & 4810 & 4203 & 4927 & 4205 & 4626 & 4756 & 4124 & 4004 \\
\hline $\mathbf{F e}$ & 950000 & 950000 & 950000 & 950000 & 950000 & 950000 & 950000 & 950000 & 950000 & 950000 \\
\hline As & 49 & 51 & 34 & 31 & 86 & 85 & 27 & 27 & 36 & 35 \\
\hline Mo & 30 & 31 & 8.1 & 6.8 & 50 & 47 & 28 & 30 & 65 & 65 \\
\hline
\end{tabular}




\begin{tabular}{|c|c|c|c|c|c|c|c|c|c|c|}
\hline Med Res 1 & 1-1-C- A & 1-1-C-B & 4-1-C-A & 4-1-C-B & 8-3-C-A & 8-3-C-B & 10-2-C-A & 10-2-C-B & 13-1-C-A & 13-1-C-B \\
\hline P & 224 & 228 & 263 & 295 & 135 & 241 & 118 & 158 & 97 & 88 \\
\hline Ti 47 & $<45.38$ & 53 & 49 & 65 & $<68.47$ & 2306 & $<65.37$ & 105 & $<67.98$ & $<51.48$ \\
\hline Ti 49 & $<57.76$ & $<41.40$ & 139 & 83 & $<79.22$ & 2447 & 107 & 135 & $<92.16$ & $<63.54$ \\
\hline V & 27 & 28 & 26 & 34 & 6.0 & $<8.28$ & 8.1 & 11 & $<5.02$ & $<6.48$ \\
\hline Cr 52 & 278 & 293 & 383 & 406 & 440 & 457 & 351 & 365 & 261 & 303 \\
\hline Cr 53 & 287 & 312 & 390 & 444 & 441 & 465 & 363 & 352 & 252 & 286 \\
\hline Mn & 4055 & 3822 & 4358 & 4217 & 4786 & 4693 & 4325 & 4358 & 3758 & 3944 \\
\hline Fe 56 & 950000 & 950000 & 950000 & 950000 & 950000 & 950000 & 950000 & 950000 & 950000 & 950000 \\
\hline Fe 57 & 938020 & 886787 & 934332 & 934750 & 1001131 & 967173 & 928381 & 740709 & 952297 & 918557 \\
\hline Co & 81 & 74 & 42 & 43 & 59 & 50 & 18 & 20 & 22 & 24 \\
\hline Ni 60 & 145 & 138 & 131 & 145 & 405 & 365 & 80 & 93 & 130 & 132 \\
\hline Ni 62 & 210 & 125 & $<137.05$ & 164 & 413 & 351 & 107 & 83 & 146 & 137 \\
\hline Cu 63 & 149 & 138 & 66 & 82 & 799 & 722 & 220 & 247 & 250 & 247 \\
\hline Cu 65 & 257 & 170 & 62 & 96 & 803 & 747 & 225 & 245 & 239 & 277 \\
\hline Ga 69 & 20 & 21 & 14 & 16 & 9.3 & 7.9 & 3.9 & 4.3 & 3.6 & 4.1 \\
\hline Ga 71 & 21 & 21 & 15 & 18 & 10 & 9.4 & 4.2 & 4.1 & $<3.76$ & $<6.34$ \\
\hline Ge 72 & 7.3 & $<11.06$ & 7.2 & 7.5 & $<24.65$ & 11 & 26 & 27 & 24 & 26 \\
\hline Ge 73 & 10 & 7.5 & 5.2 & 7.3 & $<16.36$ & 10 & 18 & 26 & 34 & 14 \\
\hline Ge 74 & $<10.59$ & $<7.61$ & 6.1 & 7.4 & 14 & 9.3 & 29 & 31 & 34 & 28 \\
\hline As & 56 & 41 & 29 & 25 & 114 & 84 & 23 & 21 & 30 & 28 \\
\hline
\end{tabular}




\begin{tabular}{|c|c|c|c|c|c|c|c|c|c|c|}
\hline Med Res 2 & 1-1-C- A & 1-1-C-B & 4-1-C-A & 4-1-C-B & 8-3-C-A & 8-3-C-B & 10-2-C-A & 10-2-C-B & 13-1-C-A & 13-1-C-B \\
\hline V & 30 & 30 & 30 & 38 & $<6.16$ & $<8.94$ & 8.7 & 11 & $<5.42$ & $<7.00$ \\
\hline Cr 52 & 324 & 342 & 447 & 474 & 513 & 532 & 410 & 425 & 304 & 353 \\
\hline Cr 53 & 330 & 360 & 448 & 511 & 514 & 543 & 419 & 408 & 293 & 333 \\
\hline Mn & 4137 & 3887 & 4474 & 4315 & 4791 & 4684 & 4385 & 4405 & 3786 & 3961 \\
\hline Fe 56 & 950000 & 950000 & 950000 & 950000 & 950000 & 950000 & 950000 & 950000 & 950000 & 950000 \\
\hline Fe 57 & 934270 & 886734 & 923293 & 927351 & 1021083 & 990374 & 932000 & - & 963603 & 933154 \\
\hline Co & 56 & 51 & 30 & 30 & 39 & 33 & 12 & 14 & 15 & 16 \\
\hline Ni & 295 & 174 & $<188.19$ & 231 & 545 & 458 & 147 & 113 & 196 & 183 \\
\hline Cu 63 & 77 & 69 & 36 & 44 & 338 & 295 & 106 & 116 & 113 & 108 \\
\hline Cu 65 & 134 & 86 & 35 & 52 & 343 & 308 & 110 & 116 & 109 & 122 \\
\hline Ga 69 & 22 & 23 & 16 & 18 & 9.9 & 8.4 & 4.3 & 4.7 & 3.9 & 4.5 \\
\hline Ga 71 & 23 & 23 & 15 & 19 & 12 & 11 & 4.7 & 4.7 & $<4.19$ & $<7.06$ \\
\hline Ge 72 & 11 & $<16.30$ & 11 & 11 & $<36.34$ & 16 & 37 & 39 & 34 & 37 \\
\hline Ge 73 & 19 & 14 & 9.4 & 13 & $<31.04$ & 20 & 34 & 50 & 65 & 28 \\
\hline Ge 74 & $<13.65$ & $<9.81$ & 7.8 & 9.5 & 18 & 12 & 37 & 39 & 43 & 36 \\
\hline As & 59 & 43 & 31 & 27 & 117 & 86 & 24 & 22 & 31 & 29 \\
\hline
\end{tabular}




\section{Appendix 5}

Elemental comparison of samples using LA-ICP-MS data

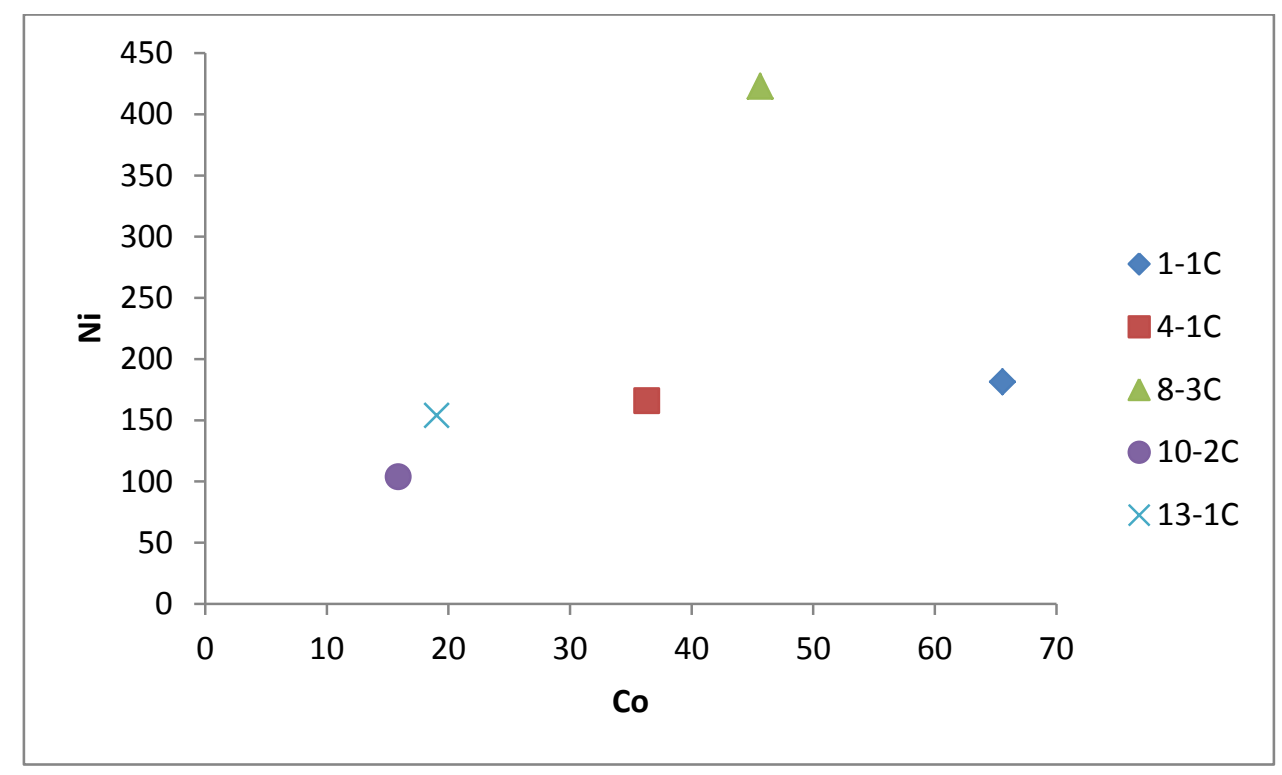

Graph 1. Cobalt versus Nickel

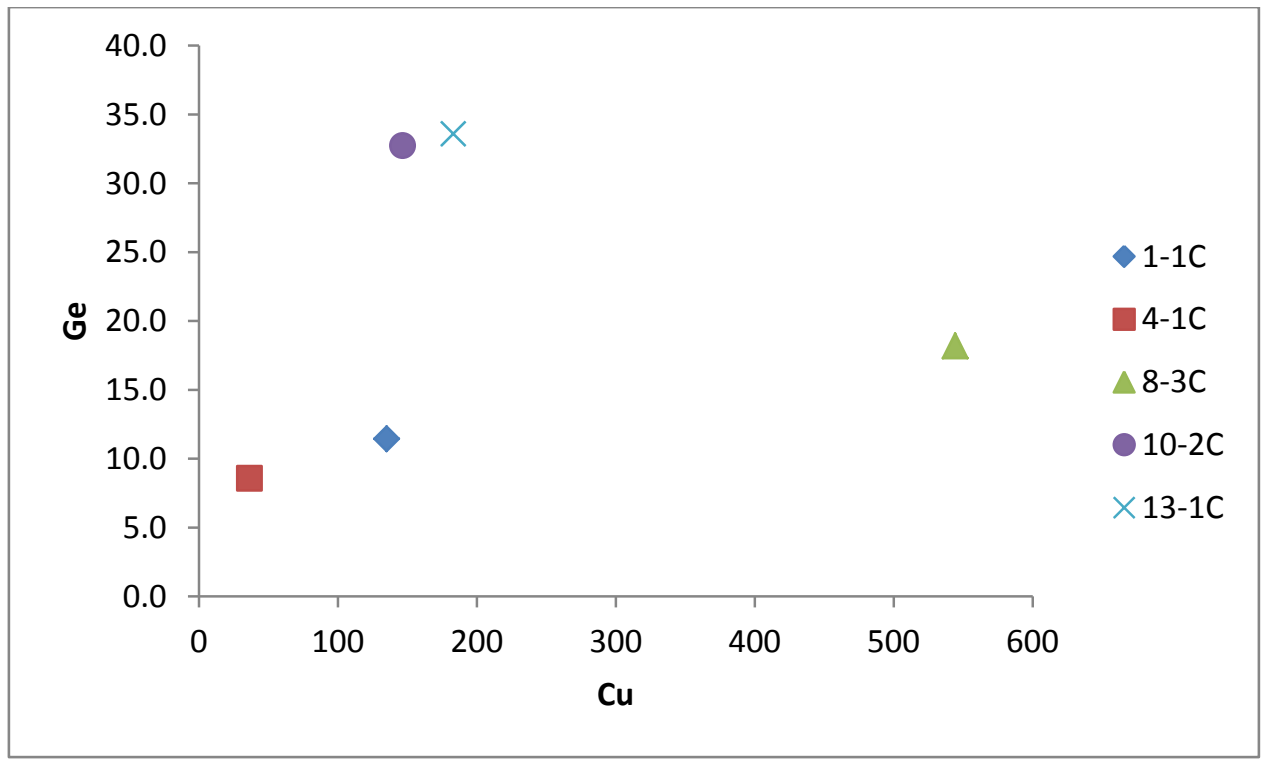

Graph 2. Copper versus Germanium 


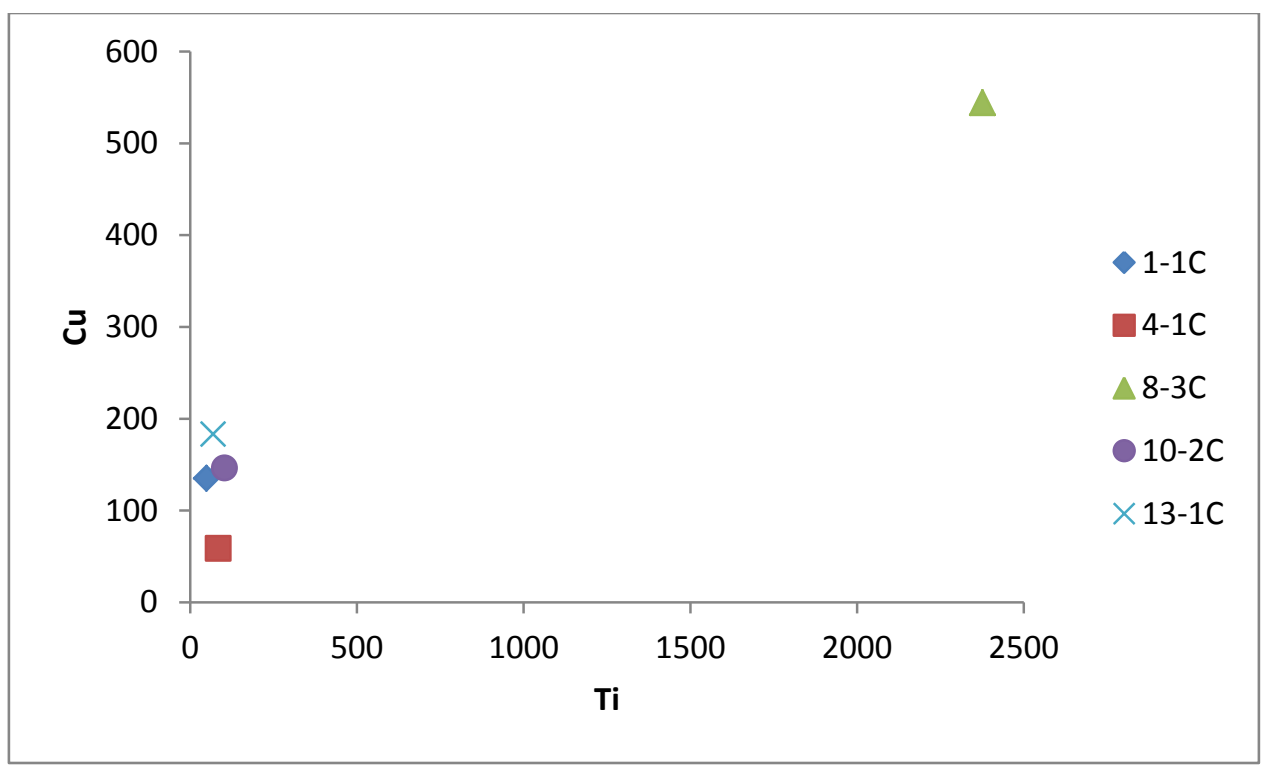

Graph 3. Titanium versus Copper

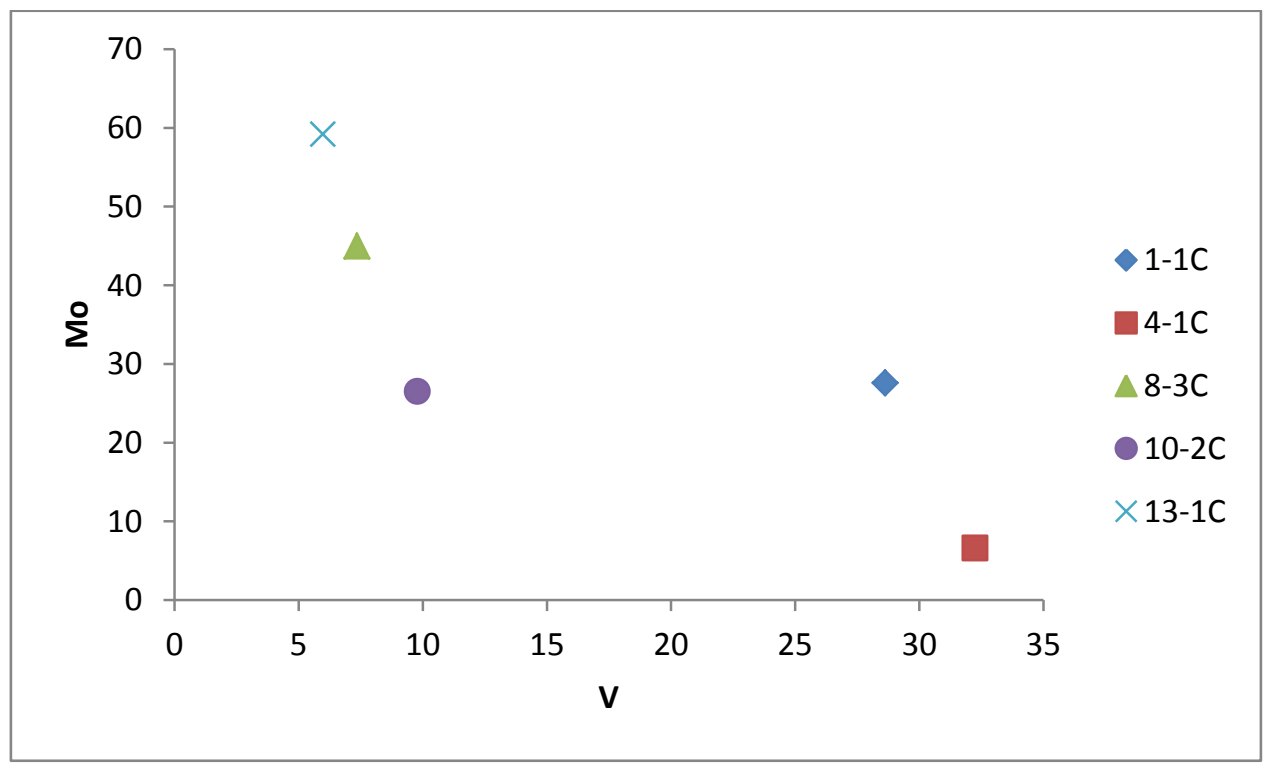

Graph 4. Vanadium versus Molybdenum 


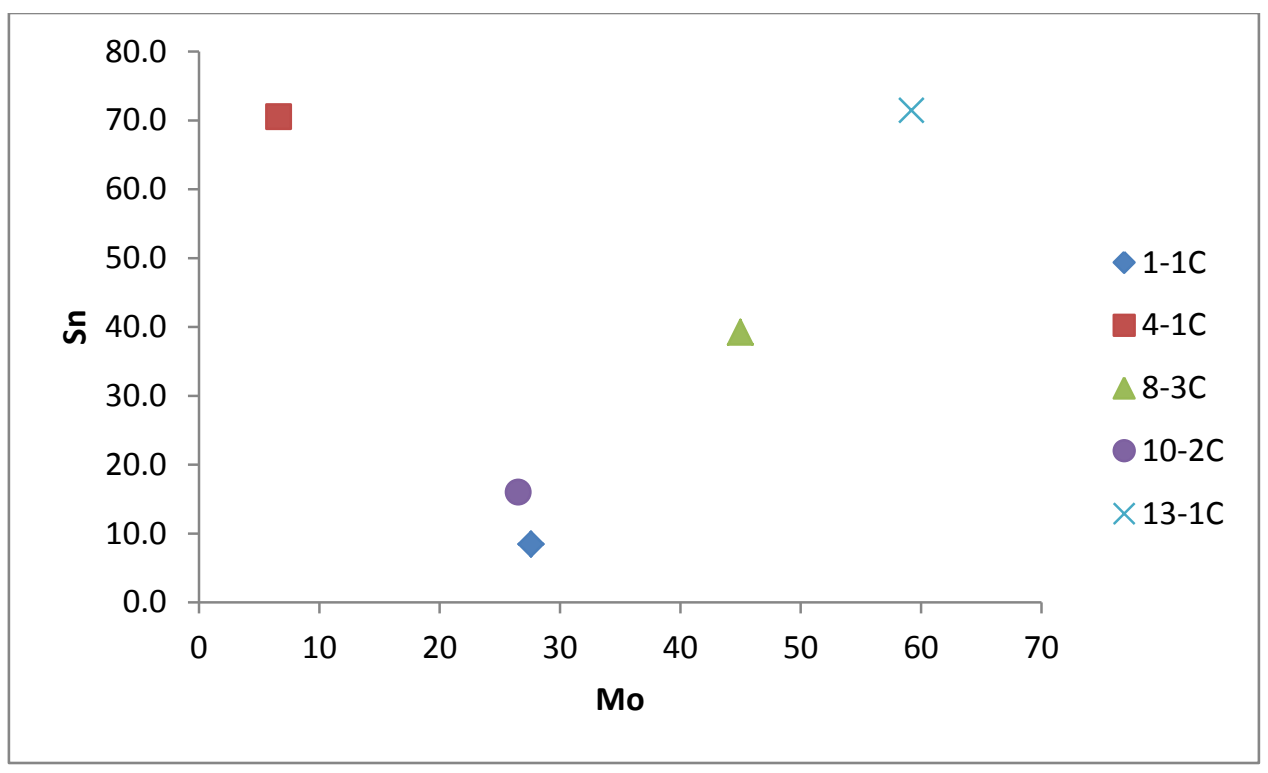

Graph 5. Molybdenum versus Tin

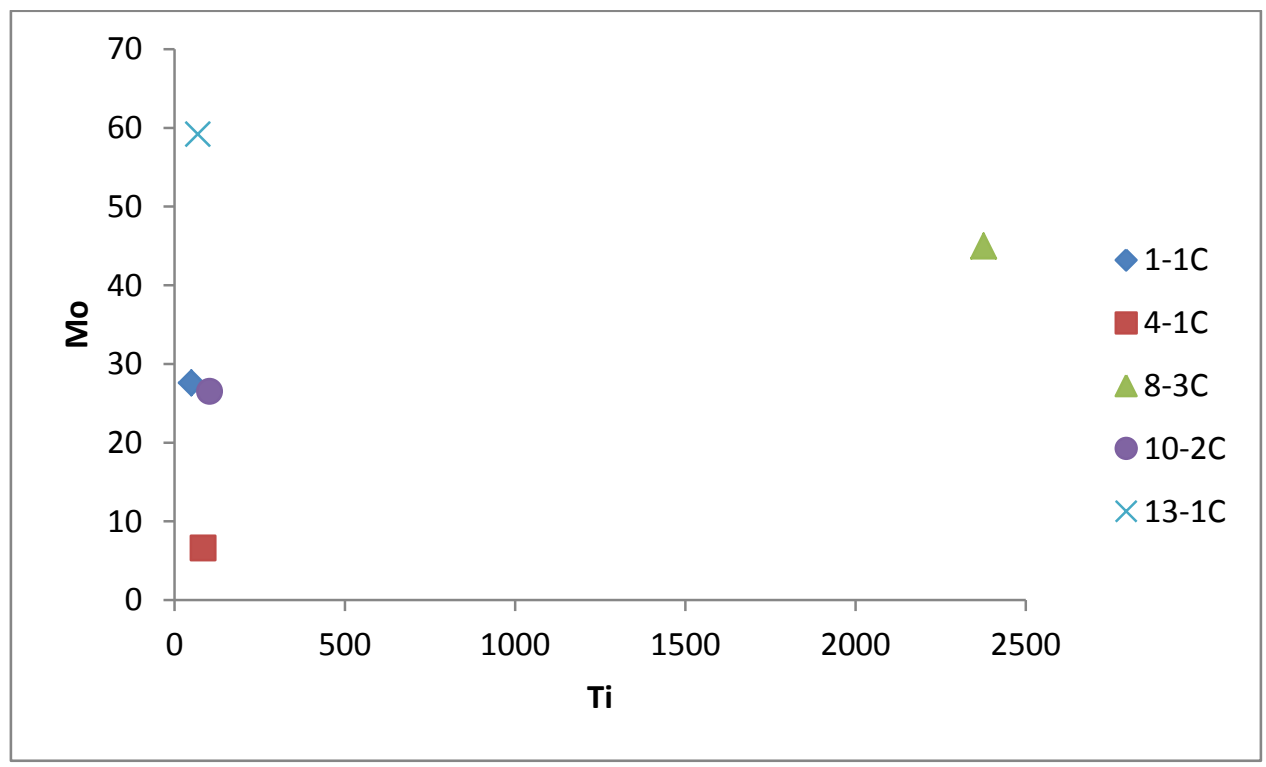

Graph 6. Titanium versus Molybdenum 


\section{Appendix 6}

Duplicate analysis via X-ray on 5 major samples

(shown as weight percent)

\begin{tabular}{|l|r|r|r|r|r|r|r|r|r|r|r|r|r|r|r|r|r|r|r|}
\hline $\mathbf{P}$ & 1-1 Dup 1 & 1-1 Dup 2 & Average StdDev & 1-1 B Dup 1 & 1-1 B Dup 2 & Average & StdDev & 4-1A Dup 1 & 4-1A Dup 2 & Average StdDev & 4-1B Dup 1 & 4-1B Dup 2 & Average StdDev \\
\hline $\mathbf{T i}$ & 0.008 & 0.004 & 0.006 & 0.003 & 0.003 & 0.007 & 0.005 & 0.003 & 0.005 & 0.004 & 0.005 & 0.001 & 0.002 & 0.005 & 0.004 & 0.002 \\
\hline $\mathbf{V}$ & 0.008 & 0.008 & 0.008 & 0.000 & 0.008 & 0.006 & 0.007 & 0.001 & 0.008 & 0.008 & 0.008 & 0.000 & 0.006 & 0.002 & 0.004 & 0.003 \\
$\mathbf{C r}$ & 0.019 & 0.023 & 0.021 & 0.003 & 0.059 & 0.053 & 0.056 & 0.004 & 0.029 & 0.023 & 0.026 & 0.004 & 0.043 & 0.040 & 0.042 & 0.002 \\
\hline $\mathbf{M n}$ & 0.030 & 0.031 & 0.031 & 0.001 & 0.027 & 0.027 & 0.027 & 0.000 & 0.040 & 0.037 & 0.039 & 0.002 & 0.036 & 0.038 & 0.037 & 0.001 \\
\hline $\mathbf{F e}$ & 0.387 & 0.394 & 0.391 & 0.005 & 0.400 & 0.402 & 0.401 & 0.001 & 0.313 & 0.309 & 0.311 & 0.003 & 0.411 & 0.418 & 0.415 & 0.005 \\
\hline $\mathbf{C o}$ & 98.910 & 98.854 & 98.882 & 0.040 & 98.721 & 98.755 & 98.738 & 0.024 & 98.765 & 98.755 & 98.760 & 0.007 & 98.806 & 98.792 & 98.799 & 0.010 \\
\hline $\mathbf{N i}$ & 0.357 & 0.376 & 0.367 & 0.013 & 0.392 & 0.374 & 0.383 & 0.013 & 0.409 & 0.471 & 0.440 & 0.044 & 0.361 & 0.320 & 0.341 & 0.029 \\
\hline $\mathbf{C u}$ & 0.000 & 0.000 & 0.000 & 0.000 & 0.000 & 0.000 & 0.000 & 0.000 & 0.000 & 0.000 & 0.000 & 0.000 & 0.000 & 0.000 & 0.000 & 0.000 \\
\hline $\mathbf{G e}$ & 0.023 & 0.027 & 0.025 & 0.003 & 0.031 & 0.021 & 0.026 & 0.007 & 0.015 & 0.014 & 0.015 & 0.001 & 0.010 & 0.011 & 0.011 & 0.001 \\
\hline $\mathbf{M o}$ & 0.002 & 0.014 & 0.013 & 0.002 & 0.025 & 0.049 & 0.037 & 0.017 & 0.006 & 0.010 & 0.008 & 0.003 & 0.011 & 0.014 & 0.013 & 0.002 \\
\hline $\mathbf{S n}$ & 0.014 & 0.015 & 0.003 & 0.001 & 0.008 & 0.001 & 0.005 & 0.005 & 0.007 & 0.006 & 0.007 & 0.001 & 0.004 & 0.008 & 0.006 & 0.003 \\
\hline $\mathbf{S b}$ & 0.005 & 0.004 & 0.005 & 0.001 & 0.018 & 0.024 & 0.021 & 0.004 & 0.010 & 0.011 & 0.011 & 0.001 & 0.011 & 0.010 & 0.011 & 0.001 \\
\hline
\end{tabular}




\begin{tabular}{|c|c|c|c|c|c|c|c|c|c|c|c|c|c|c|c|c|}
\hline & 8-3 A Dup 1 & 8-3A Dup 2 & Average & StdDev & 8-3B Dup 1 & 8-3B Dup2 & Average & StdDev & 10-2A Dup 1 & 10-2A Dup 2 & Average & StdDev & 10-2B Dup 1 & 10-2B Dup & Average & StdDev \\
\hline $\mathbf{P}$ & 0.000 & 0.005 & 0.003 & 0.004 & 0.014 & 0.004 & 0.009 & 0.007 & 0.003 & 0.008 & 0.006 & ; 0.004 & 0.006 & 0.003 & 0.005 & 0.002 \\
\hline $\mathrm{Ti}$ & 0.012 & 0.003 & 0.008 & 0.006 & 0.008 & 0.005 & 0.007 & 0.002 & 0.017 & 0.005 & 0.011 & 0.008 & 0.008 & 0.008 & 0.008 & 0.000 \\
\hline V & 0.026 & 0.018 & 0.022 & 0.006 & 0.071 & 0.076 & 0.074 & $\quad 0.004$ & 0.041 & 0.037 & 0.039 & 0.003 & 0.049 & 0.052 & 0.051 & 0.002 \\
\hline $\mathrm{Cr}$ & 0.043 & 0.040 & 0.042 & 0.002 & 0.027 & 0.028 & 0.028 & $\begin{array}{l}3 \\
\end{array}$ & 0.032 & 0.037 & 0.035 & 0.004 & 0.025 & 0.033 & 0.029 & 0.006 \\
\hline $\mathrm{Mn}$ & 0.254 & 0.241 & 0.248 & 0.009 & 0.294 & 0.276 & 0.285 & ; 0.013 & 0.440 & 0.436 & 0.438 & 0.003 & 0.389 & 0.485 & 0.437 & 0.068 \\
\hline $\mathrm{Fe}$ & 98.878 & 98.938 & 98.908 & 0.042 & 98.633 & 98.698 & 98.666 & ; 0.046 & 98.745 & 98.845 & 98.795 & 0.071 & 98.700 & 98.629 & 98.665 & 0.050 \\
\hline Co & 0.444 & 0.446 & 0.445 & 0.001 & 0.633 & 0.588 & 0.611 & 0.032 & 0.456 & 0.424 & 0.440 & 0.023 & 0.559 & 0.482 & 0.521 & 0.054 \\
\hline $\mathrm{Ni}$ & 0.000 & 0.000 & 0.000 & 0.000 & 0.000 & 0.000 & 0.000 & 0.000 & 0.000 & 0.000 & 0.000 & 0.000 & 0.000 & 0.000 & 0.000 & 0.000 \\
\hline $\mathrm{Cu}$ & 0.085 & 0.091 & 0.088 & 0.004 & 0.073 & 0.067 & 0.070 & 0.004 & 0.030 & 0.024 & 0.027 & 0.004 & 0.034 & 0.039 & 0.037 & 0.004 \\
\hline $\mathrm{Ge}$ & 0.010 & 0.005 & 0.008 & 0.004 & 0.030 & 0.033 & 0.032 & 0.002 & 0.012 & 0.010 & 0.011 & 0.001 & 0.030 & 0.033 & 0.032 & 0.002 \\
\hline Mo & 0.012 & 0.007 & 0.010 & 0.004 & 0.003 & 0.007 & 0.005 & 0.003 & 0.008 & 0.003 & 0.006 & 0.004 & 0.000 & 0.006 & 0.003 & 0.004 \\
\hline Sn & 0.018 & 0.012 & 0.015 & 0.004 & 0.016 & 0.021 & 0.019 & $\quad 0.004$ & 0.004 & 0.008 & 0.006 & ; 0.003 & 0.015 & 0.016 & 0.016 & 0.001 \\
\hline $\mathrm{Sb}$ & 0.005 & 0.006 & 0.006 & 0.001 & 0.002 & 0.002 & 0.002 & 0.000 & 0.004 & 0.004 & 0.004 & 0.000 & 0.000 & 0.000 & 0.000 & 0.000 \\
\hline
\end{tabular}

\begin{tabular}{|l|c|c|r|r|r|r|r|r|}
\hline $\mathbf{P}$ & 13-1A Dup 1 & 13-A Dup 2 & Average & StdDev & 13-1B Dup 1 & 13-1 Dup 2 & Average StdDev \\
\hline $\mathbf{T i}$ & 0.000 & 0.002 & 0.001 & 0.001 & 0.003 & 0.003 & 0.003 & 0.000 \\
\hline $\mathbf{V}$ & 0.005 & 0.012 & 0.009 & 0.005 & 0.010 & 0.004 & 0.007 & 0.004 \\
\hline $\mathbf{C r}$ & 0.030 & 0.031 & 0.031 & 0.001 & 0.027 & 0.025 & 0.026 & 0.001 \\
\hline $\mathbf{M n}$ & 0.031 & 0.028 & 0.030 & 0.002 & 0.028 & 0.024 & 0.026 & 0.003 \\
\hline $\mathbf{F e}$ & 0.433 & 0.425 & 0.429 & 0.006 & 0.434 & 0.415 & 0.425 & 0.013 \\
\hline $\mathbf{C o}$ & 98.777 & 98.863 & 98.820 & 0.061 & 98.829 & 98.903 & 98.866 & 0.052 \\
\hline $\mathbf{N i}$ & 0.513 & 0.415 & 0.464 & 0.069 & 0.499 & 0.492 & 0.496 & 0.005 \\
\hline $\mathbf{C u}$ & 0.000 & 0.000 & 0.000 & 0.000 & 0.000 & 0.000 & 0.000 & 0.000 \\
\hline $\mathbf{G e}$ & 0.031 & 0.030 & 0.031 & 0.001 & 0.037 & 0.032 & 0.035 & 0.004 \\
\hline $\mathbf{M o}$ & 0.009 & 0.007 & 0.008 & 0.001 & 0.017 & 0.012 & 0.015 & 0.004 \\
\hline $\mathbf{S n}$ & 0.001 & 0.009 & 0.005 & 0.006 & 0.006 & 0.002 & 0.004 & 0.003 \\
\hline $\mathbf{S b}$ & 0.008 & 0.011 & 0.010 & 0.002 & 0.005 & 0.008 & 0.007 & 0.002 \\
\hline
\end{tabular}




\section{Appendix 7}

\section{Confidence intervals for all samples}

\section{(Shown as counts)}

\begin{tabular}{|c|c|c|c|c|c|c|c|c|c|c|c|c|c|c|c|c|c|c|}
\hline Label & 1-1 Dup 1 & 1-1 Dup 2 & 1-1 A Top : & 1-1 A Mid & 1-1 A Bot & & & & & 1-1 B Dup 1 & 1-1 B Dup 2 & 1-1 B Top & 1-1 B Mid & 1-1 B Bot & & & & \\
\hline Store & \multicolumn{5}{|c|}{ Menards } & & & & & \multicolumn{5}{|c|}{ Menards } & & & & \\
\hline Brand & \multicolumn{5}{|c|}{ LDR China } & & & & & \multicolumn{5}{|c|}{ LDR China } & & & & \\
\hline Location & \multicolumn{5}{|c|}{ Masslion, $\mathrm{OH}$} & & & & & \multicolumn{5}{|c|}{ Masslion, $\mathrm{OH}$} & & & & \\
\hline Slice & \multicolumn{5}{|c|}{ end } & & & & & \multicolumn{5}{|c|}{ middle } & & & & \\
\hline Spot & middle & middle & top & middle & bottom & Average & StdDev & $95 \%$ conf $i$ & nterval & middle & middle & top & middle & bottom & Average & StdDev & \multicolumn{2}{|c|}{$95 \%$ Conf Inter } \\
\hline $\mathbf{P}$ & 9 & 5 & 6 & 8 & 10 & 8 & 1.9 & 5 & 10 & 12 & 12 & 6 & 12 & 8 & 10 & 2.5 & 7 & 13 \\
\hline Ti & 33 & 26 & 23 & 20 & 26 & 26 & 4.3 & 20 & 31 & 29 & 26 & 25 & 24 & 30 & 27 & 2.6 & 24 & 30 \\
\hline v & 41 & 43 & 34 & 51 & 52 & 44 & 6.7 & 36 & 52 & 90 & 79 & 66 & 45 & 55 & 67 & 18.0 & 45 & 89 \\
\hline $\mathrm{Cr}$ & 93 & 82 & 83 & 86 & 67 & 82 & 8.5 & 72 & 93 & 87 & 76 & 87 & 74 & 71 & 79 & 7.5 & 70 & 88 \\
\hline Mn & 343 & 416 & 373 & 401 & 375 & 382 & 25.2 & 350 & 413 & 402 & 409 & 360 & 316 & 350 & 367 & 38.5 & 320 & 415 \\
\hline $\mathrm{Fe}$ & 50564 & 50696 & 50639 & 50269 & 50560 & 50546 & 147.2 & 50363 & 50728 & 49992 & 50105 & 50960 & 50617 & 50958 & 50526 & 459.8 & 49955 & 51097 \\
\hline Co & 1952 & 2035 & 1840 & 1852 & 1926 & 1921 & 71.1 & 1833 & 2009 & 1924 & 1975 & 1822 & 1900 & 1846 & 1893 & 61.2 & 1817 & 1969 \\
\hline $\mathrm{Ni}$ & 7 & 11 & 9 & 7 & 4 & 8 & 2.3 & 5 & 10 & 11 & 9 & 8 & 6 & 11 & 9 & 2.1 & 6 & 12 \\
\hline $\mathrm{Cu}$ & 9 & 17 & 13 & 5 & 8 & 10 & 4.2 & 5 & 16 & 14 & 10 & 13 & 14 & 11 & 12 & 1.8 & 10 & 15 \\
\hline Ge & 8 & 10 & 5 & 3 & 5 & 6 & 2.5 & 3 & 9 & 10 & 12 & 7 & 9 & 7 & 9 & 2.1 & 6 & 12 \\
\hline Mo & 8 & 10 & 7 & 10 & 9 & 9 & 1.2 & 7 & 10 & 11 & 13 & 7 & 18 & 8 & 11 & 4.4 & 6 & 17 \\
\hline Sn & 1 & 0 & 3 & 3 & 3 & 2 & 1.3 & 0 & 4 & 0 & 3 & 3 & 2 & 1 & 2 & 1.3 & 0 & 3 \\
\hline Sb & 4 & 4 & 4 & 1 & 1 & 3 & 1.5 & 1 & 5 & 1 & 1 & 1 & 3 & 5 & 2 & 1.8 & 0 & 4 \\
\hline
\end{tabular}




\begin{tabular}{|c|c|c|c|c|c|c|c|c|c|c|c|c|c|c|}
\hline Label & 1-2 A Top & 1-2 A Mid & 1-2 A Bot & & & & & 1-2 B Top & 1-2 B Mid & 1-2 B Bot & & & & \\
\hline Store & \multicolumn{3}{|c|}{ Menards } & & & & & \multicolumn{3}{|c|}{ Menards } & & & & \\
\hline Brand & \multicolumn{3}{|c|}{ LDR China } & & & & & \multicolumn{3}{|c|}{ LDR China } & & & & \\
\hline Location & \multicolumn{3}{|c|}{ Masslion, $\mathrm{OH}$} & & & & & \multicolumn{3}{|c|}{ Masslion, $\mathrm{OH}$} & & & & \\
\hline Slice & \multicolumn{3}{|c|}{ end } & & & & & \multicolumn{3}{|c|}{ middle } & & & & \\
\hline Spot & top & middle & bottom & Average & StdDev & \multicolumn{2}{|c|}{ 95\% Conf Inter } & top & middle & bottom & Average & StdDev & \multicolumn{2}{|c|}{ 95\% Conf Inter } \\
\hline $\mathbf{P}$ & 7 & 5 & 12 & 8 & 3.6 & -1 & 17 & 9 & 9 & 7 & 8 & 1.2 & 5 & 11 \\
\hline $\mathrm{Ti}$ & 33 & 26 & 17 & 25 & 8.0 & 5 & 45 & 30 & 34 & 35 & 33 & 2.6 & 26 & 40 \\
\hline $\mathbf{v}$ & 59 & 47 & 91 & 66 & 22.7 & 9 & 122 & 65 & 35 & 49 & 50 & 15.0 & 12 & 87 \\
\hline $\mathrm{Cr}$ & 154 & 162 & 170 & 162 & 8.0 & 142 & 182 & 157 & 171 & 180 & 169 & 11.6 & 141 & 198 \\
\hline Mn & 342 & 356 & 368 & 355 & 13.0 & 323 & 388 & 409 & 340 & 380 & 376 & 34.6 & 290 & 462 \\
\hline $\mathrm{Fe}$ & 50453 & 50841 & 50428 & 50574 & 231.6 & 49999 & 51149 & 50455 & 50641 & 48993 & 50030 & 902.6 & 47788 & 52272 \\
\hline Co & 1860 & 1916 & 1908 & 1895 & 30.3 & 1819 & 1970 & 1779 & 1899 & 2251 & 1976 & 245.3 & 1367 & 2586 \\
\hline $\mathrm{Ni}$ & 24 & 33 & 22 & 26 & 5.9 & 12 & 41 & 24 & 31 & 26 & 27 & 3.6 & 18 & 36 \\
\hline $\mathrm{Cu}$ & 11 & 11 & 9 & 10 & 1.2 & 7 & 13 & 6 & 16 & 11 & 11 & 5.0 & -1 & 23 \\
\hline Ge & 5 & 8 & 10 & 8 & 2.5 & 1 & 14 & 5 & 7 & 1 & 4 & 3.1 & -3 & 12 \\
\hline Mo & 11 & 9 & 20 & 13 & 5.9 & -1 & 28 & 14 & 8 & 20 & 14 & 6.0 & -1 & 29 \\
\hline Sn & 4 & 1 & 1 & 2 & 1.7 & -2 & 6 & 1 & 2 & 2 & 2 & 0.6 & 0 & 3 \\
\hline Sb & 2 & 0 & 1 & 1 & 1.0 & -1 & 3 & 2 & 1 & 2 & 2 & 0.6 & 0 & 3 \\
\hline
\end{tabular}




\begin{tabular}{|c|c|c|c|c|c|c|c|c|c|c|c|c|c|c|}
\hline Label & 1-3 A Top & 1-3 A Mid & 1-3 A Bot & & & & & 1-3 B Top & 1-3 B Mid & 1-3 B Bot & & & & \\
\hline Store & \multicolumn{3}{|c|}{ Menards } & & & & & \multicolumn{3}{|c|}{ Menards } & & & & \\
\hline Brand & \multicolumn{3}{|c|}{ LDR China } & & & & & \multicolumn{3}{|c|}{ LDR China } & & & & \\
\hline Location & \multicolumn{3}{|c|}{ Masslion, $\mathrm{OH}$} & & & & & \multicolumn{3}{|c|}{ Masslion, $\mathrm{OH}$} & & & & \\
\hline Slice & \multicolumn{3}{|c|}{ end } & & & & & \multicolumn{3}{|c|}{ middle } & & & & \\
\hline Spot & top & middle & bottom & Average & StdDev & $95 \%$ Con & f Inter & top & middle & bottom & Average & StdDev & \multicolumn{2}{|c|}{ 95\% Conf Inter } \\
\hline $\mathbf{P}$ & 14 & 8 & 11 & 11 & 3.0 & 4 & 18 & 10 & 8 & 10 & 9 & 1.2 & 6 & 12 \\
\hline $\mathrm{Ti}$ & 28 & 35 & 31 & 31 & 3.5 & 23 & 40 & 31 & 35 & 33 & 33 & 2.0 & 28 & 38 \\
\hline V & 52 & 60 & 72 & 61 & 10.1 & 36 & 86 & 82 & 62 & 30 & 58 & 26.2 & -7 & 123 \\
\hline $\mathrm{Cr}$ & 79 & 78 & 80 & 79 & 1.0 & 77 & 81 & 87 & 88 & 80 & 85 & 4.4 & 74 & 96 \\
\hline Mn & 399 & 396 & 470 & 422 & 41.9 & 318 & 526 & 370 & 463 & 576 & 470 & 103.2 & 213 & 726 \\
\hline $\mathrm{Fe}$ & 50628 & 50488 & 50195 & 50437 & 221.0 & 49888 & 50986 & 50724 & 50496 & 50424 & 50548 & 156.6 & 50159 & 50937 \\
\hline Co & 1918 & 1825 & 1888 & 1877 & 47.5 & 1759 & 1995 & 1974 & 1807 & 1818 & 1866 & 93.4 & 1634 & 2098 \\
\hline $\mathrm{Ni}$ & 3 & 4 & 13 & 7 & 5.5 & -7 & 20 & 7 & 8 & 8 & 8 & 0.6 & 6 & 9 \\
\hline $\mathrm{Cu}$ & 21 & 13 & 11 & 15 & 5.3 & 2 & 28 & 15 & 9 & 8 & 11 & 3.8 & 1 & 20 \\
\hline Ge & 4 & 5 & 9 & 6 & 2.6 & -1 & 13 & 8 & 10 & 3 & 7 & 3.6 & -2 & 16 \\
\hline Mo & 8 & 14 & 13 & 12 & 3.2 & 4 & 20 & 6 & 5 & 13 & 8 & 4.4 & -3 & 19 \\
\hline Sn & 4 & 1 & 2 & 2 & 1.5 & -1 & 6 & 0 & 1 & 1 & 1 & 0.6 & -1 & 2 \\
\hline Sb & 2 & 3 & 1 & 2 & 1.0 & 0 & 4 & 2 & 2 & 1 & 2 & 0.6 & 0 & 3 \\
\hline
\end{tabular}




\begin{tabular}{|c|c|c|c|c|c|c|c|c|c|c|c|c|c|c|}
\hline Label & 2-1A Top & 2-1 A Mid & 2-1 A Bot & & & & & 2-1 B Top & 2-1 B Mid & 2-1 B Bot & & & & \\
\hline Store & \multicolumn{3}{|c|}{ Lowes } & & & & & \multicolumn{3}{|c|}{ Lowes } & & & & \\
\hline Brand & \multicolumn{3}{|c|}{ LDR China } & & & & & \multicolumn{3}{|c|}{ LDR China } & & & & \\
\hline Location & \multicolumn{3}{|c|}{ Masslion, $\mathrm{OH}$} & & & & & \multicolumn{3}{|c|}{ Masslion, $\mathrm{OH}$} & & & & \\
\hline Slice & \multicolumn{3}{|c|}{ end } & & & & & \multicolumn{3}{|c|}{ middle } & & & & \\
\hline Spot & top & middle & bottom & Average & StdDev & $95 \%$ Con & f Inter & top & middle & bottom & Average & StdDev & \multicolumn{2}{|c|}{ 95\% Conf Inter } \\
\hline $\mathbf{P}$ & 8 & 12 & 9 & 10 & 2.1 & 4 & 15 & 7 & 11 & 10 & 9 & 2.1 & 4 & 15 \\
\hline Ti & 30 & 39 & 34 & 34 & 4.5 & 23 & 46 & 23 & 27 & 28 & 26 & 2.6 & 19 & 33 \\
\hline V & 84 & 57 & 48 & 63 & 18.7 & 16 & 110 & 71 & 56 & 44 & 57 & 13.5 & 23 & 91 \\
\hline $\mathrm{Cr}$ & 57 & 46 & 66 & 56 & 10.0 & 31 & 81 & 56 & 46 & 50 & 51 & 5.0 & 38 & 63 \\
\hline Mn & 357 & 409 & 391 & 386 & 26.4 & 320 & 451 & 377 & 382 & 344 & 368 & 20.6 & 316 & 419 \\
\hline $\mathrm{Fe}$ & 50641 & 50668 & 50244 & 50518 & 237.4 & 49928 & 51107 & 50680 & 50449 & 51029 & 50719 & 292.0 & 49994 & 51445 \\
\hline Co & 1956 & 1928 & 1908 & 1931 & 24.1 & 1871 & 1991 & 1797 & 1934 & 1900 & 1877 & 71.3 & 1700 & 2054 \\
\hline $\mathrm{Ni}$ & 4 & 8 & 9 & 7 & 2.6 & 0 & 14 & 1 & 7 & 5 & 4 & 3.1 & -3 & 12 \\
\hline $\mathrm{Cu}$ & 6 & 10 & 11 & 9 & 2.6 & 2 & 16 & 9 & 6 & 5 & 7 & 2.1 & 1 & 12 \\
\hline Ge & 8 & 8 & 3 & 6 & 2.9 & -1 & 14 & 3 & 7 & 6 & 5 & 2.1 & 0 & 11 \\
\hline Mo & 11 & 11 & 8 & 10 & 1.7 & 6 & 14 & 9 & 11 & 10 & 10 & 1.0 & 8 & 12 \\
\hline Sn & 1 & 1 & 7 & 3 & 3.5 & -6 & 12 & 1 & 1 & 5 & 2 & 2.3 & -3 & 8 \\
\hline $\mathrm{Sb}$ & 2 & 1 & 1 & 1 & 0.6 & 0 & 3 & 1 & 3 & 1 & 2 & 1.2 & -1 & 5 \\
\hline
\end{tabular}




\begin{tabular}{|c|c|c|c|c|c|c|c|c|c|c|c|c|c|c|}
\hline Label & 2-2 A Top & 2-2 A Mid & 2-2 A Bot & & & & & 2-2 B Top & 2-2 B Mid & 2-2 B Bot & & & & \\
\hline Store & \multicolumn{3}{|c|}{ Lowes } & & & & & \multicolumn{3}{|c|}{ Lowes } & & & & \\
\hline Brand & \multicolumn{3}{|c|}{ LDR China } & & & & & \multicolumn{3}{|c|}{ LDR China } & & & & \\
\hline Location & \multicolumn{3}{|c|}{ Masslion, $\mathrm{OH}$} & & & & & \multicolumn{3}{|c|}{ Masslion, $\mathrm{OH}$} & & & & \\
\hline Slice & \multicolumn{3}{|c|}{ end } & & & & & \multicolumn{3}{|c|}{ middle } & & & & \\
\hline Spot & top & middle & bottom & Average & StdDev & $95 \%$ Con & of Inter & top & middle & bottom & Average & StdDev & \multicolumn{2}{|c|}{$95 \%$ Conf Inter } \\
\hline $\mathbf{P}$ & 6 & 4 & 7 & 6 & 1.5 & 2 & 9 & 5 & 11 & 9 & 8 & 3.1 & 1 & 16 \\
\hline $\mathrm{Ti}$ & 38 & 36 & 24 & 33 & 7.6 & 14 & 51 & 39 & 33 & 30 & 34 & 4.6 & 23 & 45 \\
\hline V & 46 & 45 & 56 & 49 & 6.1 & 34 & 64 & 75 & 58 & 52 & 62 & 11.9 & 32 & 91 \\
\hline $\mathrm{Cr}$ & 162 & 147 & 137 & 149 & 12.6 & 117 & 180 & 150 & 168 & 160 & 159 & 9.0 & 137 & 182 \\
\hline$M n$ & 361 & 385 & 365 & 370 & 12.9 & 338 & 402 & 385 & 368 & 375 & 376 & 8.5 & 355 & 397 \\
\hline $\mathrm{Fe}$ & 51459 & 50879 & 50460 & 50933 & 501.7 & 49686 & 52179 & 50928 & 50627 & 51009 & 50855 & 201.3 & 50355 & 51355 \\
\hline Co & 1939 & 1897 & 1916 & 1917 & 21.0 & 1865 & 1970 & 1939 & 1836 & 1910 & 1895 & 53.1 & 1763 & 2027 \\
\hline $\mathrm{Ni}$ & 15 & 19 & 21 & 18 & 3.1 & 11 & 26 & 15 & 27 & 23 & 22 & 6.1 & 6 & 37 \\
\hline $\mathrm{Cu}$ & 3 & 11 & 10 & 8 & 4.4 & -3 & 19 & 7 & 5 & 6 & 6 & 1.0 & 4 & 8 \\
\hline Ge & 5 & 6 & 10 & 7 & 2.6 & 0 & 14 & 8 & 1 & 6 & 5 & 3.6 & -4 & 14 \\
\hline Mo & 15 & 10 & 5 & 10 & 5.0 & -2 & 22 & 15 & 4 & 13 & 11 & 5.9 & -4 & 25 \\
\hline Sn & 1 & 2 & 2 & 2 & 0.6 & 0 & 3 & 3 & 4 & 4 & 4 & 0.6 & 2 & 5 \\
\hline Sb & 1 & 1 & 1 & 1 & 0.0 & 1 & 1 & 1 & 2 & 2 & 2 & 0.6 & 0 & 3 \\
\hline
\end{tabular}




\begin{tabular}{|c|c|c|c|c|c|c|c|c|c|c|c|c|c|c|}
\hline Label & 2-3 A Top & 2-3 A Mid & 2-3 A Bot & & & & & 2-3 B Top & 2-3 B Mid & 2-3 B Bot & & & & \\
\hline Store & \multicolumn{3}{|c|}{ Lowes } & & & & & \multicolumn{3}{|c|}{ Lowes } & & & & \\
\hline Brand & \multicolumn{3}{|c|}{ LDR China } & & & & & \multicolumn{3}{|c|}{ LDR China } & & & & \\
\hline Location & \multicolumn{3}{|c|}{ Masslion, $\mathrm{OH}$} & & & & & \multicolumn{3}{|c|}{ Masslion, $\mathrm{OH}$} & & & & \\
\hline Slice & \multicolumn{3}{|c|}{ end } & & & & & \multicolumn{3}{|c|}{ middle } & & & & \\
\hline Spot & top & middle & bottom & Average & StdDev & \multicolumn{2}{|c|}{ 95\% Conf Inter } & top & middle & bottom & Average $S$ & StdDev & \multicolumn{2}{|c|}{ 95\% Conf Inter } \\
\hline $\mathbf{P}$ & 10 & 5 & 13 & 9 & 4.0 & -1 & 19 & 7 & 7 & 9 & 8 & 1.2 & 5 & 11 \\
\hline $\mathrm{Ti}$ & 16 & 22 & 32 & 23 & 8.1 & 3 & 43 & 32 & 22 & 23 & 26 & 5.5 & 12 & 39 \\
\hline V & 54 & 80 & 146 & 93 & 47.4 & -24 & 211 & 47 & 73 & 63 & 61 & 13.1 & 28 & 94 \\
\hline $\mathrm{Cr}$ & 36 & 44 & 60 & 47 & 12.2 & 16 & 77 & 41 & 52 & 44 & 46 & 5.7 & 32 & 60 \\
\hline Mn & 314 & 350 & 360 & 341 & 24.2 & 281 & 401 & 349 & 363 & 346 & 353 & 9.1 & 330 & 375 \\
\hline $\mathrm{Fe}$ & 51006 & 50470 & 50528 & 50668 & 294.1 & 49937 & 51399 & 50188 & 50508 & 51232 & 50643 & 534.9 & 49314 & 51971 \\
\hline Co & 1901 & 1945 & 1926 & 1924 & 22.1 & 1869 & 1979 & 1946 & 1847 & 1876 & 1890 & 50.9 & 1763 & 2016 \\
\hline $\mathrm{Ni}$ & 5 & 5 & 7 & 6 & 1.2 & 3 & 9 & 4 & 8 & 8 & 7 & 2.3 & 1 & 12 \\
\hline $\mathrm{Cu}$ & 7 & 8 & 6 & 7 & 1.0 & 5 & 9 & 4 & 6 & 6 & 5 & 1.2 & 2 & 8 \\
\hline Ge & 6 & 7 & 14 & 9 & 4.4 & -2 & 20 & 8 & 5 & 5 & 6 & 1.7 & 2 & 10 \\
\hline Mo & 4 & 8 & 13 & 8 & 4.5 & -3 & 20 & 10 & 10 & 11 & 10 & 0.6 & 9 & 12 \\
\hline Sn & 2 & 1 & 1 & 1 & 0.6 & 0 & 3 & 3 & 1 & 1 & 2 & 1.2 & -1 & 5 \\
\hline Sb & 2 & 1 & 2 & 2 & 0.6 & 0 & 3 & 1 & 1 & 2 & 1 & 0.6 & 0 & 3 \\
\hline
\end{tabular}




\begin{tabular}{|c|c|c|c|c|c|c|c|c|c|c|c|c|c|c|}
\hline Label & 3-1 A Top & 3-1 A Mid & 3-1 A Bot & & & & & 3-1 B Top & 3-1 B Mid & 3-1 B Bot & & & & \\
\hline Store & \multicolumn{3}{|c|}{ Home Depot } & & & & & \multicolumn{3}{|c|}{ Home Depot } & & & & \\
\hline Brand & \multicolumn{3}{|c|}{ LDR China } & & & & & \multicolumn{3}{|c|}{ LDR China } & & & & \\
\hline Location & \multicolumn{3}{|c|}{ Washington, PA } & & & & & \multicolumn{3}{|c|}{ Washington, PA } & & & & \\
\hline Slice & \multicolumn{3}{|c|}{ end } & & & & & \multicolumn{3}{|c|}{ middle } & & & & \\
\hline Spot & top & middle & bottom & Average & StdDev & \multicolumn{2}{|c|}{$95 \%$ Conf Inter } & top & middle & bottom & Average & StdDev & \multicolumn{2}{|c|}{$95 \%$ Conf Inter } \\
\hline $\mathbf{P}$ & 6 & 7 & 9 & 7 & 1.5 & 4 & 11 & 12 & 9 & 9 & 10 & 1.7 & 6 & 14 \\
\hline $\mathrm{Ti}$ & 22 & 26 & 25 & 24 & 2.1 & 19 & 30 & 20 & 34 & 26 & 27 & 7.0 & 9 & 44 \\
\hline $\mathbf{V}$ & 86 & 66 & 83 & 78 & 10.8 & 52 & 105 & 61 & 77 & 58 & 65 & 10.2 & 40 & 91 \\
\hline $\mathrm{Cr}$ & 73 & 57 & 63 & 64 & 8.1 & 44 & 84 & 71 & 62 & 66 & 66 & 4.5 & 55 & 78 \\
\hline Mn & 367 & 379 & 327 & 358 & 27.2 & 290 & 425 & 375 & 356 & 401 & 377 & 22.6 & 321 & 433 \\
\hline $\mathrm{Fe}$ & 50964 & 50275 & 50463 & 50567 & 356.2 & 49683 & 51452 & 50633 & 50641 & 50716 & 50663 & 45.8 & 50550 & 50777 \\
\hline Co & 1963 & 1931 & 1913 & 1936 & 25.3 & 1873 & 1999 & 1856 & 1909 & 1916 & 1894 & 32.8 & 1812 & 1975 \\
\hline $\mathbf{N i}$ & 11 & 10 & 8 & 10 & 1.5 & 6 & 13 & 8 & 10 & 8 & 9 & 1.2 & 6 & 12 \\
\hline $\mathrm{Cu}$ & 11 & 9 & 11 & 10 & 1.2 & 7 & 13 & 7 & 5 & 12 & 8 & 3.6 & -1 & 17 \\
\hline Ge & 7 & 6 & 7 & 7 & 0.6 & 5 & 8 & 6 & 16 & 10 & 11 & 5.0 & -2 & 23 \\
\hline Mo & 8 & 10 & 8 & 9 & 1.2 & 6 & 12 & 14 & 9 & 8 & 10 & 3.2 & 2 & 18 \\
\hline Sn & 2 & 0 & 1 & 1 & 1.0 & -1 & 3 & 2 & 3 & 1 & 2 & 1.0 & 0 & 4 \\
\hline Sb & 3 & 1 & 1 & 2 & 1.2 & -1 & 5 & 1 & 1 & 1 & 1 & 0.0 & 1 & 1 \\
\hline
\end{tabular}




\begin{tabular}{|c|c|c|c|c|c|c|c|c|c|c|c|c|c|c|}
\hline Label & 3-2 A Top & 3-2 A Mid & 3-2 A Bot & & & & & 3-2 B Top & 3-2 B Mid & 3-2 B Bot & & & & \\
\hline Store & \multicolumn{3}{|c|}{ Home Depot } & & & & & \multicolumn{3}{|c|}{ Home Depot } & & & & \\
\hline Brand & \multicolumn{3}{|c|}{ LDR China } & & & & & \multicolumn{3}{|c|}{ LDR China } & & & & \\
\hline Location & \multicolumn{3}{|c|}{ Washington, PA } & & & & & \multicolumn{3}{|c|}{ Washington, PA } & & & & \\
\hline Slice & \multicolumn{3}{|c|}{ end } & & & & & \multicolumn{3}{|c|}{ middle } & & & & \\
\hline Spot & top & middle & bottom & Average & StdDev & $95 \%$ Con & If Inter & top & middle & bottom & Average & StdDev & $95 \%$ Con & If Inter \\
\hline $\mathbf{P}$ & 6 & 11 & 13 & 10 & 3.6 & 1 & 19 & 7 & 9 & 5 & 7 & 2.0 & 2 & 12 \\
\hline $\mathrm{Ti}$ & 36 & 24 & 25 & 28 & 6.7 & 12 & 45 & 21 & 25 & 20 & 22 & 2.6 & 15 & 29 \\
\hline V & 94 & 61 & 61 & 72 & 19.1 & 25 & 119 & 78 & 49 & 63 & 63 & 14.5 & 27 & 99 \\
\hline $\mathrm{Cr}$ & 83 & 68 & 68 & 73 & 8.7 & 51 & 95 & 80 & 68 & 66 & 71 & 7.6 & 53 & 90 \\
\hline Mn & 360 & 481 & 388 & 410 & 63.3 & 252 & 567 & 350 & 368 & 347 & 355 & 11.4 & 327 & 383 \\
\hline $\mathrm{Fe}$ & 50154 & 50493 & 50554 & 50400 & 215.5 & 49865 & 50936 & 50711 & 50659 & 50563 & 50644 & 75.1 & 50458 & 50831 \\
\hline Co & 1796 & 1920 & 1979 & 1898 & 93.4 & 1666 & 2130 & 1969 & 1905 & 1872 & 1915 & 49.3 & 1793 & 2038 \\
\hline $\mathrm{Ni}$ & 5 & 10 & 9 & 8 & 2.6 & 1 & 15 & 7 & 7 & 8 & 7 & 0.6 & 6 & 9 \\
\hline $\mathrm{Cu}$ & 7 & 8 & 8 & 8 & 0.6 & 6 & 9 & 5 & 9 & 10 & 8 & 2.6 & 1 & 15 \\
\hline Ge & 9 & 10 & 11 & 10 & 1.0 & 8 & 12 & 6 & 3 & 6 & 5 & 1.7 & 1 & 9 \\
\hline Mo & 6 & 10 & 11 & 9 & 2.6 & 2 & 16 & 10 & 4 & 9 & 8 & 3.2 & 0 & 16 \\
\hline Sn & 0 & 0 & 1 & 0 & 0.6 & -1 & 2 & 2 & 1 & 1 & 1 & 0.6 & 0 & 3 \\
\hline Sb & 3 & 1 & 3 & 2 & 1.2 & -1 & 5 & 0 & 2 & 1 & 1 & 1.0 & -1 & 3 \\
\hline
\end{tabular}




\begin{tabular}{|c|c|c|c|c|c|c|c|c|c|c|c|c|c|c|}
\hline Label & 3-3 A Top & 3-3 A Mid & 3-3 A Bot & & & & & 3-3 B Top & 3-3 B Mid & 3-3 B Bot & & & & \\
\hline Store & \multicolumn{3}{|c|}{ Home Depot } & & & & & \multicolumn{3}{|c|}{ Home Depot } & & & & \\
\hline Brand & \multicolumn{3}{|c|}{ LDR China } & & & & & \multicolumn{3}{|c|}{ LDR China } & & & & \\
\hline Location & \multicolumn{3}{|c|}{ Washington, PA } & & & & & \multicolumn{3}{|c|}{ Washington, PA } & & & & \\
\hline Slice & \multicolumn{3}{|c|}{ end } & & & & & \multicolumn{3}{|c|}{ middle } & & & & \\
\hline Spot & top & middle & bottom & Average & StdDev & \multicolumn{2}{|c|}{ 95\% Conf Inter } & top & middle & bottom & Average & StdDev & \multicolumn{2}{|c|}{ 95\% Conf Inter } \\
\hline $\mathbf{P}$ & 7 & 8 & 5 & 7 & 1.5 & 3 & 10 & 7 & 12 & 9 & 9 & 2.5 & 3 & 16 \\
\hline $\mathrm{Ti}$ & 39 & 27 & 27 & 31 & 6.9 & 14 & 48 & 29 & 37 & 21 & 29 & 8.0 & 9 & 49 \\
\hline V & 59 & 77 & 85 & 74 & 13.3 & 41 & 107 & 65 & 71 & 87 & 74 & 11.4 & 46 & 103 \\
\hline $\mathrm{Cr}$ & 66 & 74 & 60 & 67 & 7.0 & 49 & 84 & 61 & 62 & 75 & 66 & 7.8 & 47 & 85 \\
\hline Mn & 379 & 374 & 360 & 371 & 9.8 & 347 & 395 & 323 & 358 & 367 & 349 & 23.2 & 292 & 407 \\
\hline Fe & 50610 & 50670 & 50445 & 50575 & 116.5 & 50286 & 50864 & 50863 & 50937 & 50260 & 50687 & 371.4 & 49764 & 51609 \\
\hline Co & 1876 & 1840 & 1862 & 1859 & 18.1 & 1814 & 1904 & 1833 & 1889 & 1872 & 1865 & 28.7 & 1793 & 1936 \\
\hline $\mathrm{Ni}$ & 8 & 7 & 9 & 8 & 1.0 & 6 & 10 & 7 & 6 & 6 & 6 & 0.6 & 5 & 8 \\
\hline $\mathrm{Cu}$ & 10 & 10 & 14 & 11 & 2.3 & 6 & 17 & 10 & 8 & 12 & 10 & 2.0 & 5 & 15 \\
\hline Ge & 9 & 5 & 8 & 7 & 2.1 & 2 & 13 & 6 & 10 & 4 & 7 & 3.1 & -1 & 14 \\
\hline Mo & 10 & 14 & 10 & 11 & 2.3 & 6 & 17 & 9 & 6 & 8 & 8 & 1.5 & 4 & 11 \\
\hline Sn & 5 & 3 & 1 & 3 & 2.0 & -2 & 8 & 0 & 1 & 0 & 0 & 0.6 & -1 & 2 \\
\hline $\mathrm{Sb}$ & 1 & 2 & 3 & 2 & 1.0 & 0 & 4 & 1 & 2 & 0 & 1 & 1.0 & -1 & 3 \\
\hline
\end{tabular}




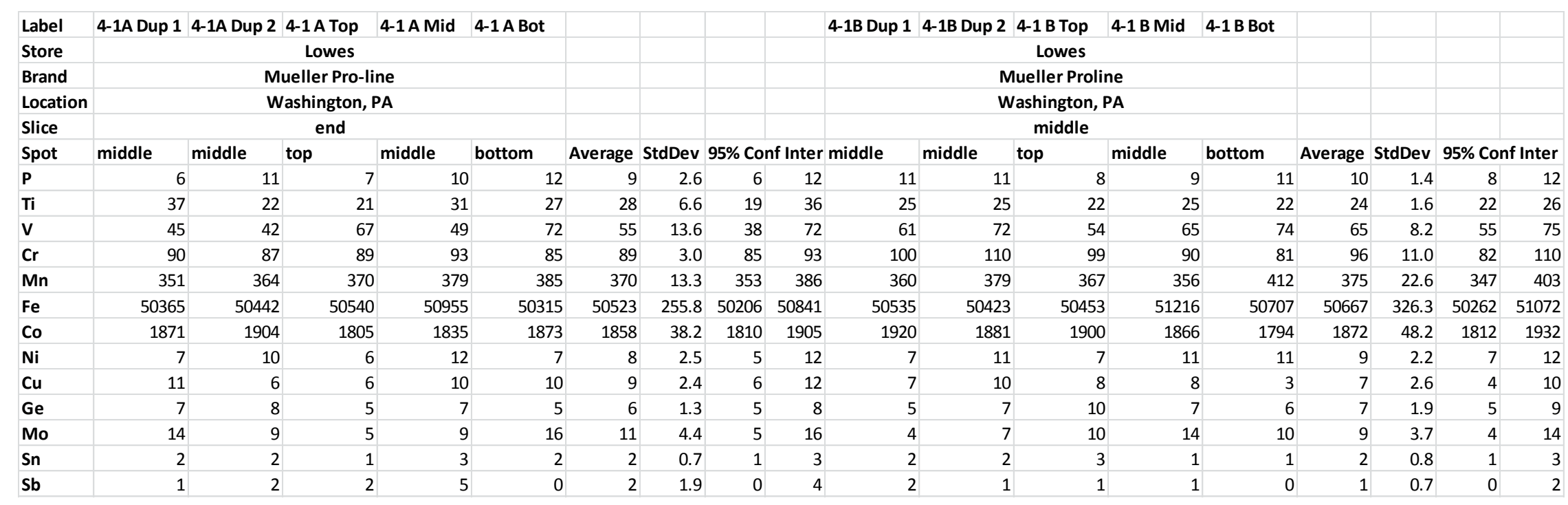




\begin{tabular}{|c|c|c|c|c|c|c|c|c|c|c|c|c|c|c|}
\hline Label & 4-2 A Top & 4-2 A Mid & 4-2 A Bot & & & & & 4-2 B Top & 4-2 B Mid & 4-2 B Bot & & & & \\
\hline Store & \multicolumn{3}{|c|}{ Lowes } & & & & & \multicolumn{3}{|c|}{ Lowes } & & & & \\
\hline Brand & \multicolumn{3}{|c|}{ Mueller Proline } & & & & & \multicolumn{3}{|c|}{ Mueller Proline } & & & & \\
\hline Location & \multicolumn{3}{|c|}{ Washington, PA } & & & & & \multicolumn{3}{|c|}{ Washington, PA } & & & & \\
\hline Slice & \multicolumn{3}{|c|}{ end } & & & & & \multicolumn{3}{|c|}{ middle } & & & & \\
\hline Spot & top & middle & bottom & Average & StdDev & \multicolumn{2}{|c|}{ 95\% Conf Inter } & top & middle & bottom & Average & StdDev & \multicolumn{2}{|c|}{ 95\% Conf Inter } \\
\hline $\mathbf{P}$ & 6 & 7 & 6 & 6 & 0.6 & 5 & 8 & 8 & 5 & 3 & 5 & 2.5 & -1 & 12 \\
\hline $\mathrm{Ti}$ & 21 & 30 & 29 & 27 & 4.9 & 14 & 39 & 34 & 25 & 28 & 29 & 4.6 & 18 & 40 \\
\hline V & 111 & 63 & 81 & 85 & 24.2 & 25 & 145 & 61 & 132 & 63 & 85 & 40.4 & -15 & 186 \\
\hline $\mathrm{Cr}$ & 42 & 59 & 62 & 54 & 10.8 & 28 & 81 & 68 & 58 & 74 & 67 & 8.1 & 47 & 87 \\
\hline Mn & 369 & 339 & 378 & 362 & 20.4 & 311 & 413 & 492 & 374 & 363 & 410 & 71.5 & 232 & 587 \\
\hline $\mathrm{Fe}$ & 50675 & 50882 & 50976 & 50844 & 154.0 & 50462 & 51227 & 50653 & 51236 & 51074 & 50988 & 300.9 & 50240 & 51735 \\
\hline Co & 1887 & 1834 & 1853 & 1858 & 26.9 & 1791 & 1925 & 1969 & 1874 & 1799 & 1881 & 85.2 & 1669 & 2092 \\
\hline $\mathrm{Ni}$ & 6 & 4 & 2 & 4 & 2.0 & -1 & 9 & 9 & 4 & 4 & 6 & 2.9 & -2 & 13 \\
\hline $\mathrm{Cu}$ & 7 & 6 & 7 & 7 & 0.6 & 5 & 8 & 2 & 4 & 4 & 3 & 1.2 & 0 & 6 \\
\hline Ge & 14 & 6 & 9 & 10 & 4.0 & 0 & 20 & 9 & 13 & 9 & 10 & 2.3 & 5 & 16 \\
\hline Mo & 10 & 8 & 6 & 8 & 2.0 & 3 & 13 & 9 & 10 & 9 & 9 & 0.6 & 8 & 11 \\
\hline Sn & 0 & 1 & 3 & 1 & 1.5 & -2 & 5 & 1 & 1 & 2 & 1 & 0.6 & 0 & 3 \\
\hline $\mathrm{Sb}$ & 4 & 5 & 2 & 4 & 1.5 & 0 & 7 & 2 & 0 & 4 & 2 & 2.0 & -3 & 7 \\
\hline
\end{tabular}




\begin{tabular}{|c|c|c|c|c|c|c|c|c|c|c|c|c|c|c|}
\hline Label & 4-3 A Top & 4-3 A Mid & 4-3 A Bot & & & & & 4-3 B Top & 4-3 B Mid & 4-3 B Bot & & & & \\
\hline Store & \multicolumn{3}{|c|}{ Lowes } & & & & & \multicolumn{3}{|c|}{ Lowes } & & & & \\
\hline Brand & \multicolumn{3}{|c|}{ Mueller Pro-line } & & & & & \multicolumn{3}{|c|}{ Mueller Proline } & & & & \\
\hline Location & \multicolumn{3}{|c|}{ Washington, PA } & & & & & \multicolumn{3}{|c|}{ Washington, PA } & & & & \\
\hline Slice & \multicolumn{3}{|c|}{ end } & & & & & \multicolumn{3}{|c|}{ middle } & & & & \\
\hline Spot & top & middle & bottom & Average & StdDev & \multicolumn{2}{|c|}{$\mathbf{9 5 \%}$ Conf Inter } & top & middle & bottom & Average & StdDev & \multicolumn{2}{|c|}{ 95\% Conf Inter } \\
\hline $\mathbf{P}$ & 9 & 6 & 8 & 8 & 1.5 & 4 & 11 & 10 & 3 & 12 & 8 & 4.7 & -3 & 20 \\
\hline $\mathrm{Ti}$ & 28 & 23 & 39 & 30 & 8.2 & 10 & 50 & 19 & 13 & 18 & 17 & 3.2 & 9 & 25 \\
\hline V & 70 & 76 & 145 & 97 & 41.7 & -7 & 201 & 49 & 80 & 110 & 80 & 30.5 & 4 & 155 \\
\hline $\mathrm{Cr}$ & 57 & 70 & 61 & 63 & 6.7 & 46 & 79 & 59 & 57 & 72 & 63 & 8.1 & 42 & 83 \\
\hline Mn & 371 & 393 & 362 & 375 & 15.9 & 336 & 415 & 420 & 370 & 417 & 402 & 28.0 & 333 & 472 \\
\hline $\mathrm{Fe}$ & 50527 & 50761 & 50408 & 50565 & 179.6 & 50119 & 51011 & 50434 & 50601 & 50282 & 50439 & 159.6 & 50043 & 50835 \\
\hline Co & 1848 & 1815 & 1911 & 1858 & 48.8 & 1737 & 1979 & 1893 & 1766 & 1926 & 1862 & 84.5 & 1652 & 2072 \\
\hline $\mathbf{N i}$ & 3 & 3 & 2 & 3 & 0.6 & 1 & 4 & 3 & 6 & 7 & 5 & 2.1 & 0 & 11 \\
\hline $\mathrm{Cu}$ & 8 & 5 & 7 & 7 & 1.5 & 3 & 10 & 5 & 9 & 9 & 8 & 2.3 & 2 & 13 \\
\hline Ge & 7 & 5 & 19 & 10 & 7.6 & -8 & 29 & 11 & 8 & 13 & 11 & 2.5 & 4 & 17 \\
\hline Mo & 3 & 17 & 8 & 9 & 7.1 & -8 & 27 & 6 & 13 & 12 & 10 & 3.8 & 1 & 20 \\
\hline Sn & 1 & 4 & 5 & 3 & 2.1 & -2 & 9 & 3 & 0 & 1 & 1 & 1.5 & -2 & 5 \\
\hline Sb & 1 & 1 & 2 & 1 & 0.6 & 0 & 3 & 1 & 1 & 1 & 1 & 0.0 & 1 & 1 \\
\hline
\end{tabular}




\begin{tabular}{|c|c|c|c|c|c|c|c|c|c|c|c|c|c|c|}
\hline Label & 5-1A Top & 5-1 A Mid & 5-1 A Bot & & & & & 5-1 B Top & 5-1 B Mid & 5-1 B Bot & & & & \\
\hline Store & \multicolumn{3}{|c|}{ Home Depot } & & & & & \multicolumn{3}{|c|}{ Home Depot } & & & & \\
\hline Brand & \multicolumn{3}{|c|}{ Mueller B\&K } & & & & & \multicolumn{3}{|c|}{ Mueller B\&K } & & & & \\
\hline Location & \multicolumn{3}{|c|}{ Robinson, PA } & & & & & \multicolumn{3}{|c|}{ Robinson, PA } & & & & \\
\hline Slice & \multicolumn{3}{|c|}{ end } & & & & & \multicolumn{3}{|c|}{ middle } & & & & \\
\hline Spot & top & middle & bottom & Average & StdDev & \multicolumn{2}{|c|}{ 95\% Conf Inter } & top & middle & bottom & Average & StdDev & \multicolumn{2}{|c|}{ 95\% Conf Inter } \\
\hline $\mathbf{P}$ & 13 & 9 & 14 & 12 & 2.6 & 5 & 19 & 8 & 11 & 17 & 12 & 4.6 & 1 & 23 \\
\hline $\mathrm{Ti}$ & 62 & 74 & 45 & 60 & 14.6 & 24 & 97 & 62 & 61 & 74 & 66 & 7.2 & 48 & 84 \\
\hline $\mathbf{V}$ & 71 & 64 & 65 & 67 & 3.8 & 57 & 76 & 63 & 70 & 70 & 68 & 4.0 & 58 & 78 \\
\hline $\mathrm{Cr}$ & 91 & 89 & 78 & 86 & 7.0 & 69 & 103 & 105 & 156 & 142 & 134 & 26.4 & 69 & 200 \\
\hline Mn & 333 & 353 & 374 & 353 & 20.5 & 302 & 404 & 355 & 353 & 336 & 348 & 10.4 & 322 & 374 \\
\hline $\mathrm{Fe}$ & 50104 & 49853 & 49489 & 49815 & 309.2 & 49047 & 50583 & 49125 & 50060 & 49150 & 49445 & 532.8 & 48122 & 50768 \\
\hline Co & 1891 & 1822 & 1923 & 1879 & 51.6 & 1750 & 2007 & 1925 & 1867 & 1836 & 1876 & 45.2 & 1764 & 1988 \\
\hline $\mathrm{Ni}$ & 26 & 20 & 22 & 23 & 3.1 & 15 & 30 & 26 & 34 & 35 & 32 & 4.9 & 19 & 44 \\
\hline $\mathrm{Cu}$ & 29 & 16 & 21 & 22 & 6.6 & 6 & 38 & 18 & 13 & 31 & 21 & 9.3 & -2 & 44 \\
\hline Ge & 15 & 18 & 15 & 16 & 1.7 & 12 & 20 & 19 & 14 & 30 & 21 & 8.2 & 1 & 41 \\
\hline Mo & 4 & 7 & 15 & 9 & 5.7 & -5 & 23 & 8 & 11 & 14 & 11 & 3.0 & 4 & 18 \\
\hline Sn & 1 & 3 & 2 & 2 & 1.0 & 0 & 4 & 2 & 0 & 1 & 1 & 1.0 & -1 & 3 \\
\hline $\mathrm{Sb}$ & 1 & 1 & 1 & 1 & 0.0 & 1 & 1 & 4 & 0 & 1 & 2 & 2.1 & -4 & 7 \\
\hline
\end{tabular}




\begin{tabular}{|c|c|c|c|c|c|c|c|c|c|c|c|c|c|c|}
\hline Label & 5-2 A Top & 5-2 A Mid & 5-2 A Bot & & & & & 5-2 B Top & 5-2 B Mid & 5-2 B Bot & & & & \\
\hline Store & \multicolumn{3}{|c|}{ Home Depot } & & & & & \multicolumn{3}{|c|}{ Home Depot } & & & & \\
\hline Brand & \multicolumn{3}{|c|}{ Mueller B\&K } & & & & & \multicolumn{3}{|c|}{ Mueller B\&K } & & & & \\
\hline Location & \multicolumn{3}{|c|}{ Robinson, PA } & & & & & \multicolumn{3}{|c|}{ Robinson, PA } & & & & \\
\hline Slice & \multicolumn{3}{|c|}{ end } & & & & & \multicolumn{3}{|c|}{ middle } & & & & \\
\hline Spot & top & middle & bottom & Average & StdDev & \multicolumn{2}{|c|}{$95 \%$ Conf Inter } & top & middle & bottom & Average & StdDev & \multicolumn{2}{|c|}{ 95\% Conf Inter } \\
\hline $\mathbf{P}$ & 7 & 11 & 8 & 9 & 2.1 & 3 & 14 & 11 & 7 & 9 & 9 & 2.0 & 4 & 14 \\
\hline $\mathrm{Ti}$ & 28 & 30 & 23 & 27 & 3.6 & 18 & 36 & 30 & 35 & 27 & 31 & 4.0 & 21 & 41 \\
\hline V & 61 & 73 & 55 & 63 & 9.2 & 40 & 86 & 46 & 76 & 112 & 78 & 33.0 & -4 & 160 \\
\hline $\mathrm{Cr}$ & 49 & 83 & 65 & 66 & 17.0 & 23 & 108 & 67 & 70 & 68 & 68 & 1.5 & 65 & 72 \\
\hline Mn & 279 & 284 & 277 & 280 & 3.6 & 271 & 289 & 282 & 303 & 259 & 281 & 22.0 & 227 & 336 \\
\hline $\mathrm{Fe}$ & 50511 & 50853 & 50647 & 50670 & 172.2 & 50243 & 51098 & 50412 & 50735 & 50687 & 50611 & 174.3 & 50178 & 51044 \\
\hline Co & 1842 & 1966 & 1976 & 1928 & 74.6 & 1743 & 2113 & 1912 & 1997 & 1879 & 1929 & 60.9 & 1778 & 2081 \\
\hline $\mathrm{Ni}$ & 5 & 3 & 5 & 4 & 1.2 & 1 & 7 & 3 & 3 & 9 & 5 & 3.5 & -4 & 14 \\
\hline $\mathrm{Cu}$ & 9 & 10 & 11 & 10 & 1.0 & 8 & 12 & 10 & 12 & 11 & 11 & 1.0 & 9 & 13 \\
\hline Ge & 9 & 11 & 11 & 10 & 1.2 & 7 & 13 & 4 & 6 & 6 & 5 & 1.2 & 2 & 8 \\
\hline Mo & 6 & 10 & 9 & 8 & 2.1 & 3 & 14 & 10 & 5 & 9 & 8 & 2.6 & 1 & 15 \\
\hline Sn & 3 & 0 & 1 & 1 & 1.5 & -2 & 5 & 2 & 4 & 1 & 2 & 1.5 & -1 & 6 \\
\hline $\mathrm{Sb}$ & 2 & 1 & 1 & 1 & 0.6 & 0 & 3 & 1 & 2 & 0 & 1 & 1.0 & -1 & 3 \\
\hline
\end{tabular}




\begin{tabular}{|c|c|c|c|c|c|c|c|c|c|c|c|c|c|c|}
\hline Label & 5-3 A Top & 5-3 A Mid & 5-3 A Bot & & & & & 5-3 B Top & 5-3 B Mid & 5-3 B Bot & & & & \\
\hline Store & \multicolumn{3}{|c|}{ Home Depot } & & & & & \multicolumn{3}{|c|}{ Home Depot } & & & & \\
\hline Brand & \multicolumn{3}{|c|}{ Mueller B\&K } & & & & & \multicolumn{3}{|c|}{ Mueller B\&K } & & & & \\
\hline Location & \multicolumn{3}{|c|}{ Robinson, PA } & & & & & \multicolumn{3}{|c|}{ Robinson, PA } & & & & \\
\hline Slice & \multicolumn{3}{|c|}{ end } & & & & & \multicolumn{3}{|c|}{ middle } & & & & \\
\hline Spot & top & middle & bottom & Average & StdDev & \multicolumn{2}{|c|}{$95 \%$ Conf Inter } & top & middle & bottom & Average & StdDev & \multicolumn{2}{|c|}{ 95\% Conf Inter } \\
\hline $\mathbf{P}$ & 7 & 9 & 10 & 9 & 1.5 & 5 & 12 & 11 & 12 & 12 & 12 & 0.6 & 10 & 13 \\
\hline $\mathrm{Ti}$ & 56 & 54 & 52 & 54 & 2.0 & 49 & 59 & 70 & 47 & 43 & 53 & 14.6 & 17 & 90 \\
\hline V & 76 & 72 & 66 & 71 & 5.0 & 59 & 84 & 65 & 63 & 83 & 70 & 11.0 & 43 & 98 \\
\hline $\mathrm{Cr}$ & 66 & 55 & 69 & 63 & 7.4 & 45 & 82 & 71 & 75 & 75 & 74 & 2.3 & 68 & 79 \\
\hline Mn & 313 & 323 & 325 & 320 & 6.4 & 304 & 336 & 337 & 326 & 325 & 329 & 6.7 & 313 & 346 \\
\hline $\mathrm{Fe}$ & 49670 & 49692 & 50007 & 49790 & 188.5 & 49321 & 50258 & 49835 & 49765 & 49797 & 49799 & 35.0 & 49712 & 49886 \\
\hline Co & 1949 & 1857 & 1898 & 1901 & 46.1 & 1787 & 2016 & 1923 & 1781 & 1920 & 1875 & 81.1 & 1673 & 2076 \\
\hline $\mathrm{Ni}$ & 14 & 13 & 16 & 14 & 1.5 & 11 & 18 & 18 & 14 & 19 & 17 & 2.6 & 10 & 24 \\
\hline $\mathrm{Cu}$ & 25 & 26 & 20 & 24 & 3.2 & 16 & 32 & 19 & 10 & 13 & 14 & 4.6 & 3 & 25 \\
\hline Ge & 12 & 16 & 17 & 15 & 2.6 & 8 & 22 & 19 & 16 & 8 & 14 & 5.7 & 0 & 28 \\
\hline Mo & 12 & 2 & 9 & 8 & 5.1 & -5 & 20 & 7 & 8 & 15 & 10 & 4.4 & -1 & 21 \\
\hline Sn & 4 & 2 & 3 & 3 & 1.0 & 1 & 5 & 7 & 2 & 3 & 4 & 2.6 & -3 & 11 \\
\hline Sb & 4 & 0 & 3 & 2 & 2.1 & -3 & 8 & 6 & 2 & 2 & 3 & 2.3 & -2 & 9 \\
\hline
\end{tabular}




\begin{tabular}{|c|c|c|c|c|c|c|c|c|c|c|c|c|c|c|}
\hline Label & 6-1 A Top & 6-1 A Mid & 6-1 A Bot & & & & & 6-1 B Top & 6-1 B Mid & 6-1 B Bot & & & & \\
\hline Store & \multicolumn{3}{|c|}{ Lowes } & & & & & \multicolumn{3}{|c|}{ Lowes } & & & & \\
\hline Brand & \multicolumn{3}{|c|}{ Mueller Pro-line } & & & & & \multicolumn{3}{|c|}{ Mueller Proline } & & & & \\
\hline Location & \multicolumn{3}{|c|}{ Robinson, PA } & & & & & \multicolumn{3}{|c|}{ Robinson, PA } & & & & \\
\hline Slice & \multicolumn{3}{|c|}{ end } & & & & & \multicolumn{3}{|c|}{ middle } & & & & \\
\hline Spot & top & middle & bottom & Average & StdDev & \multicolumn{2}{|c|}{ 95\% Conf Inter } & top & middle & bottom & Average & StdDev & \multicolumn{2}{|c|}{ 95\% Conf Inter } \\
\hline $\mathbf{P}$ & 7 & 10 & 8 & 8 & 1.5 & 5 & 12 & 9 & 12 & 9 & 10 & 1.7 & 6 & 14 \\
\hline $\mathrm{Ti}$ & 27 & 32 & 32 & 30 & 2.9 & 23 & 38 & 27 & 46 & 24 & 32 & 11.9 & 3 & 62 \\
\hline V & 65 & 83 & 93 & 80 & 14.2 & 45 & 116 & 63 & 58 & 55 & 59 & 4.0 & 49 & 69 \\
\hline $\mathrm{Cr}$ & 58 & 55 & 53 & 55 & 2.5 & 49 & 62 & 55 & 46 & 58 & 53 & 6.2 & 37 & 69 \\
\hline Mn & 318 & 278 & 316 & 304 & 22.5 & 248 & 360 & 316 & 322 & 316 & 318 & 3.5 & 309 & 327 \\
\hline $\mathrm{Fe}$ & 50807 & 50777 & 51066 & 50883 & 158.9 & 50489 & 51278 & 50599 & 50659 & 50831 & 50696 & 120.4 & 50397 & 50995 \\
\hline Co & 1910 & 1913 & 1941 & 1921 & 17.1 & 1879 & 1964 & 1858 & 1925 & 1856 & 1880 & 39.3 & 1782 & 1977 \\
\hline $\mathrm{Ni}$ & 7 & 8 & 4 & 6 & 2.1 & 1 & 12 & 7 & 10 & 5 & 7 & 2.5 & 1 & 14 \\
\hline $\mathrm{Cu}$ & 13 & 6 & 5 & 8 & 4.4 & -3 & 19 & 9 & 4 & 9 & 7 & 2.9 & 0 & 15 \\
\hline Ge & 7 & 12 & 13 & 11 & 3.2 & 3 & 19 & 13 & 9 & 4 & 9 & 4.5 & -3 & 20 \\
\hline Mo & 8 & 7 & 6 & 7 & 1.0 & 5 & 9 & 16 & 7 & 9 & 11 & 4.7 & -1 & 22 \\
\hline Sn & 2 & 1 & 2 & 2 & 0.6 & 0 & 3 & 4 & 0 & 2 & 2 & 2.0 & -3 & 7 \\
\hline Sb & 3 & 1 & 2 & 2 & 1.0 & 0 & 4 & 1 & 1 & 3 & 2 & 1.2 & -1 & 5 \\
\hline
\end{tabular}




\begin{tabular}{|c|c|c|c|c|c|c|c|c|c|c|c|c|c|c|}
\hline Label & 6-2 A Top & 6-2 A Mid & 6-2 A Bot & & & & & 6-2 B Top & 6-2 B Mid & 6-2 B Bot & & & & \\
\hline Store & \multicolumn{3}{|c|}{ Lowes } & & & & & \multicolumn{3}{|c|}{ Lowes } & & & & \\
\hline Brand & \multicolumn{3}{|c|}{ Mueller Proline } & & & & & \multicolumn{3}{|c|}{ Mueller Proline } & & & & \\
\hline Location & \multicolumn{3}{|c|}{ Robinson, PA } & & & & & \multicolumn{3}{|c|}{ Robinson, PA } & & & & \\
\hline Slice & \multicolumn{3}{|c|}{ end } & & & & & \multicolumn{3}{|c|}{ middle } & & & & \\
\hline Spot & top & middle & bottom & Average & StdDev & $95 \%$ Cor & nf Inter & top & middle & bottom & Average & StdDev & \multicolumn{2}{|c|}{ 95\% Conf Inter } \\
\hline $\mathbf{P}$ & 9 & 7 & 8 & 8 & 1.0 & 6 & 10 & 8 & 5 & 6 & 6 & 1.5 & 3 & 10 \\
\hline $\mathrm{Ti}$ & 25 & 24 & 45 & 31 & 11.8 & 2 & 61 & 28 & 27 & 28 & 28 & 0.6 & 26 & 29 \\
\hline V & 93 & 94 & 69 & 85 & 14.2 & 50 & 120 & 66 & 65 & 49 & 60 & 9.5 & 36 & 84 \\
\hline $\mathrm{Cr}$ & 158 & 141 & 129 & 143 & 14.6 & 106 & 179 & 147 & 158 & 156 & 154 & 5.9 & 139 & 168 \\
\hline Mn & 330 & 365 & 349 & 348 & 17.5 & 304 & 392 & 366 & 355 & 375 & 365 & 10.0 & 340 & 390 \\
\hline $\mathrm{Fe}$ & 50556 & 50509 & 49872 & 50312 & 382.1 & 49363 & 51261 & 50715 & 50522 & 50535 & 50591 & 107.9 & 50323 & 50859 \\
\hline Co & 1829 & 1869 & 1960 & 1886 & 67.1 & 1719 & 2053 & 1913 & 1893 & 1848 & 1885 & 33.3 & 1802 & 1967 \\
\hline $\mathrm{Ni}$ & 18 & 9 & 12 & 13 & 4.6 & 2 & 24 & 11 & 10 & 11 & 11 & 0.6 & 9 & 12 \\
\hline $\mathrm{Cu}$ & 14 & 12 & 7 & 11 & 3.6 & 2 & 20 & 8 & 4 & 7 & 6 & 2.1 & 1 & 12 \\
\hline Ge & 11 & 8 & 6 & 8 & 2.5 & 2 & 15 & 5 & 8 & 11 & 8 & 3.0 & 1 & 15 \\
\hline Mo & 6 & 2 & 7 & 5 & 2.6 & -2 & 12 & 8 & 14 & 9 & 10 & 3.2 & 2 & 18 \\
\hline Sn & 0 & 1 & 2 & 1 & 1.0 & -1 & 3 & 2 & 3 & 2 & 2 & 0.6 & 1 & 4 \\
\hline Sb & 2 & 3 & 1 & 2 & 1.0 & 0 & 4 & 0 & 1 & 0 & 0 & 0.6 & -1 & 2 \\
\hline
\end{tabular}




\begin{tabular}{|c|c|c|c|c|c|c|c|c|c|c|c|c|c|c|}
\hline Label & 6-3 A Top & 6-3 A Mid & 6-3 A Bot & & & & & 6-3 B Top & 6-3 B Mid & 6-3 B Bot & & & & \\
\hline Store & \multicolumn{3}{|c|}{ Lowes } & & & & & \multicolumn{3}{|c|}{ Lowes } & & & & \\
\hline Brand & \multicolumn{3}{|c|}{ Mueller Pro-line } & & & & & \multicolumn{3}{|c|}{ Mueller Proline } & & & & \\
\hline Location & \multicolumn{3}{|c|}{ Robinson, PA } & & & & & \multicolumn{3}{|c|}{ Robinson, PA } & & & & \\
\hline Slice & \multicolumn{3}{|c|}{ end } & & & & & \multicolumn{3}{|c|}{ middle } & & & & \\
\hline Spot & top & middle & bottom & Average & StdDev & \multicolumn{2}{|c|}{ 95\% Conf Inter } & top & middle & bottom & Average & StdDev & \multicolumn{2}{|c|}{ 95\% Conf Inter } \\
\hline $\mathbf{P}$ & 7 & 9 & 7 & 8 & 1.2 & 5 & 11 & 11 & 6 & 7 & 8 & 2.6 & 1 & 15 \\
\hline $\mathrm{Ti}$ & 20 & 27 & 21 & 23 & 3.8 & 13 & 32 & 27 & 36 & 28 & 30 & 4.9 & 18 & 43 \\
\hline V & 76 & 74 & 123 & 91 & 27.7 & 22 & 160 & 96 & 79 & 80 & 85 & 9.5 & 61 & 109 \\
\hline $\mathrm{Cr}$ & 158 & 187 & 149 & 165 & 19.9 & 115 & 214 & 140 & 152 & 178 & 157 & 19.4 & 108 & 205 \\
\hline Mn & 364 & 345 & 371 & 360 & 13.5 & 327 & 393 & 376 & 356 & 399 & 377 & 21.5 & 324 & 430 \\
\hline $\mathrm{Fe}$ & 50349 & 50773 & 49935 & 50352 & 419.0 & 49311 & 51393 & 50784 & 50820 & 50642 & 50749 & 94.1 & 50515 & 50982 \\
\hline Co & 1811 & 1772 & 1960 & 1848 & 99.2 & 1601 & 2094 & 1928 & 1886 & 1841 & 1885 & 43.5 & 1777 & 1993 \\
\hline $\mathrm{Ni}$ & 9 & 11 & 11 & 10 & 1.2 & 7 & 13 & 17 & 14 & 14 & 15 & 1.7 & 11 & 19 \\
\hline $\mathrm{Cu}$ & 10 & 5 & 7 & 7 & 2.5 & 1 & 14 & 7 & 10 & 9 & 9 & 1.5 & 5 & 12 \\
\hline Ge & 11 & 7 & 12 & 10 & 2.6 & 3 & 17 & 3 & 7 & 6 & 5 & 2.1 & 0 & 11 \\
\hline Mo & 5 & 6 & 8 & 6 & 1.5 & 3 & 10 & 6 & 6 & 8 & 7 & 1.2 & 4 & 10 \\
\hline Sn & 0 & 2 & 1 & 1 & 1.0 & -1 & 3 & 3 & 4 & 1 & 3 & 1.5 & -1 & 6 \\
\hline Sb & 0 & 4 & 1 & 2 & 2.1 & -4 & 7 & 1 & 2 & 2 & 2 & 0.6 & 0 & 3 \\
\hline
\end{tabular}




\begin{tabular}{|c|c|c|c|c|c|c|c|c|c|c|c|c|c|c|}
\hline Label & 7-1 A Top & 7-1 A Mid & 7-1 A Bot & & & & & 7-1 B Top & 7-1 B Mid & 7-1 B Bot & & & & \\
\hline Store & \multicolumn{3}{|c|}{ Lowes } & & & & & \multicolumn{3}{|c|}{ Lowes } & & & & \\
\hline Brand & \multicolumn{3}{|c|}{ Mueller Proline } & & & & & \multicolumn{3}{|c|}{ Mueller Proline } & & & & \\
\hline Location & \multicolumn{3}{|c|}{ Wheeling, WV } & & & & & \multicolumn{3}{|c|}{ Wheeling, WV } & & & & \\
\hline Slice & \multicolumn{3}{|c|}{ end } & & & & & \multicolumn{3}{|c|}{ middle } & & & & \\
\hline Spot & top & middle & bottom & Average & StdDev & $95 \%$ Con & f Inter & top & middle & bottom & Average & StdDev & $95 \%$ Con & If Inter \\
\hline $\mathbf{P}$ & 8 & 8 & 6 & 7 & 1.2 & 4 & 10 & 6 & 5 & 19 & 10 & 7.8 & -9 & 29 \\
\hline $\mathrm{Ti}$ & 21 & 30 & 27 & 26 & 4.6 & 15 & 37 & 36 & 30 & 24 & 30 & 6.0 & 15 & 45 \\
\hline $\mathbf{v}$ & 68 & 83 & 69 & 73 & 8.4 & 53 & 94 & 64 & 100 & 47 & 70 & 27.1 & 3 & 138 \\
\hline $\mathrm{Cr}$ & 99 & 90 & 114 & 101 & 12.1 & 71 & 131 & 91 & 95 & 91 & 92 & 2.3 & 87 & 98 \\
\hline Mn & 334 & 382 & 402 & 373 & 34.9 & 286 & 459 & 311 & 307 & 359 & 326 & 28.9 & 254 & 398 \\
\hline $\mathrm{Fe}$ & 50736 & 50497 & 50317 & 50517 & 210.2 & 49995 & 51039 & 50649 & 50419 & 50766 & 50611 & 176.5 & 50173 & 51050 \\
\hline Co & 1930 & 1868 & 1860 & 1886 & 38.3 & 1791 & 1981 & 1952 & 1968 & 1846 & 1922 & 66.3 & 1757 & 2087 \\
\hline $\mathrm{Ni}$ & 3 & 7 & 11 & 7 & 4.0 & -3 & 17 & 10 & 5 & 7 & 7 & 2.5 & 1 & 14 \\
\hline $\mathrm{Cu}$ & 10 & 10 & 4 & 8 & 3.5 & -1 & 17 & 13 & 7 & 14 & 11 & 3.8 & 2 & 21 \\
\hline Ge & 6 & 10 & 8 & 8 & 2.0 & 3 & 13 & 6 & 12 & 9 & 9 & 3.0 & 2 & 16 \\
\hline Mo & 8 & 9 & 9 & 9 & 0.6 & 7 & 10 & 8 & 6 & 4 & 6 & 2.0 & 1 & 11 \\
\hline Sn & 1 & 5 & 3 & 3 & 2.0 & -2 & 8 & 1 & 1 & 3 & 2 & 1.2 & -1 & 5 \\
\hline Sb & 3 & 1 & 2 & 2 & 1.0 & 0 & 4 & 0 & 1 & 1 & 1 & 0.6 & -1 & 2 \\
\hline
\end{tabular}




\begin{tabular}{|c|c|c|c|c|c|c|c|c|c|c|c|c|c|c|}
\hline Label & 7-2 A Top & 7-2 A Mid & 7-2 A Bot & & & & & 7-2 B Top & 7-2 B Mid & 7-2 B Bot & & & & \\
\hline Store & \multicolumn{3}{|c|}{ Lowes } & & & & & \multicolumn{3}{|c|}{ Lowes } & & & & \\
\hline Brand & \multicolumn{3}{|c|}{ Mueller Pro-line } & & & & & \multicolumn{3}{|c|}{ Mueller Proline } & & & & \\
\hline Location & \multicolumn{3}{|c|}{ Wheeling, WV } & & & & & \multicolumn{3}{|c|}{ Wheeling, WV } & & & & \\
\hline Slice & \multicolumn{3}{|c|}{ end } & & & & & \multicolumn{3}{|c|}{ middle } & & & & \\
\hline Spot & top & middle & bottom & Average & StdDev & $95 \%$ Cor & nf Inter & top & middle & bottom & Average & StdDev & \multicolumn{2}{|c|}{ 95\% Conf Inter } \\
\hline $\mathbf{P}$ & 11 & 11 & 7 & 10 & 2.3 & 4 & 15 & 8 & 4 & 12 & 8 & 4.0 & -1.9 & 17.9 \\
\hline $\mathrm{Ti}$ & 32 & 41 & 22 & 32 & 9.5 & 8 & 55 & 35 & 19 & 37 & 30 & 9.9 & 5.8 & 54.8 \\
\hline V & 86 & 116 & 82 & 95 & 18.6 & 49 & 141 & 66 & 52 & 81 & 66 & 14.5 & 30.3 & 102.4 \\
\hline $\mathrm{Cr}$ & 76 & 102 & 84 & 87 & 13.3 & 54 & 120 & 100 & 87 & 89 & 92 & 7.0 & 74.6 & 109.4 \\
\hline$M n$ & 370 & 399 & 382 & 384 & 14.6 & 347 & 420 & 340 & 326 & 379 & 348 & 27.5 & 280.1 & 416.6 \\
\hline $\mathrm{Fe}$ & 50233 & 50273 & 50420 & 50309 & 98.5 & 50064 & 50553 & 50287 & 50708 & 50867 & 50621 & 299.7 & 49876.2 & 51365.2 \\
\hline Co & 1877 & 1792 & 1816 & 1828 & 43.8 & 1719 & 1937 & 1850 & 1963 & 1843 & 1885 & 67.4 & 1718.0 & 2052.6 \\
\hline $\mathrm{Ni}$ & 6 & 8 & 7 & 7 & 1.0 & 5 & 9 & 9 & 8 & 8 & 8 & 0.6 & 6.9 & 9.8 \\
\hline $\mathrm{Cu}$ & 8 & 7 & 9 & 8 & 1.0 & 6 & 10 & 8 & 8 & 9 & 8 & 0.6 & 6.9 & 9.8 \\
\hline Ge & 11 & 9 & 3 & 8 & 4.2 & -3 & 18 & 6 & 5 & 10 & 7 & 2.6 & 0.4 & 13.6 \\
\hline Mo & 10 & 6 & 12 & 9 & 3.1 & 2 & 17 & 3 & 6 & 13 & 7 & 5.1 & -5.4 & 20.1 \\
\hline Sn & 4 & 3 & 1 & 3 & 1.5 & -1 & 6 & 2 & 2 & 2 & 2 & 0.0 & 2.0 & 2.0 \\
\hline Sb & 7 & 2 & 2 & 4 & 2.9 & -4 & 11 & 3 & 3 & 4 & 3 & 0.6 & 1.9 & 4.8 \\
\hline
\end{tabular}




\begin{tabular}{|c|c|c|c|c|c|c|c|c|c|c|c|c|c|c|}
\hline Label & 7-3 A Top & 7-3 A Mid & 7-3 A Bot & & & & & 7-3 B Top & 7-3 B Mid & 7-3 B Bot & & & & \\
\hline Store & \multicolumn{3}{|c|}{ Lowes } & & & & & \multicolumn{3}{|c|}{ Lowes } & & & & \\
\hline Brand & \multicolumn{3}{|c|}{ Mueller Proline } & & & & & \multicolumn{3}{|c|}{ Mueller Proline } & & & & \\
\hline Location & \multicolumn{3}{|c|}{ Wheeling, WV } & & & & & \multicolumn{3}{|c|}{ Wheeling, WV } & & & & \\
\hline Slice & \multicolumn{3}{|c|}{ end } & & & & & \multicolumn{3}{|c|}{ middle } & & & & \\
\hline Spot & top & middle & bottom & Average & StdDev & \multicolumn{2}{|c|}{$95 \%$ Conf Inter } & top & middle & bottom & Average & StdDev & \multicolumn{2}{|c|}{ 95\% Conf Inter } \\
\hline $\mathbf{P}$ & 7 & 12 & 4 & 8 & 4.0 & -2 & 18 & 15 & 16 & 9 & 13 & 3.8 & 4 & 23 \\
\hline $\mathrm{Ti}$ & 29 & 22 & 24 & 25 & 3.6 & 16 & 34 & 25 & 30 & 33 & 29 & 4.0 & 19 & 39 \\
\hline V & 50 & 63 & 99 & 71 & 25.4 & 8 & 134 & 67 & 58 & 131 & 85 & 39.8 & -14 & 184 \\
\hline $\mathrm{Cr}$ & 69 & 52 & 85 & 69 & 16.5 & 28 & 110 & 62 & 71 & 73 & 69 & 5.9 & 54 & 83 \\
\hline Mn & 245 & 286 & 262 & 264 & 20.6 & 213 & 316 & 256 & 226 & 278 & 253 & 26.1 & 188 & 318 \\
\hline $\mathrm{Fe}$ & 50444 & 50725 & 50476 & 50548 & 153.8 & 50166 & 50930 & 50642 & 50701 & 50998 & 50780 & 190.8 & 50306 & 51254 \\
\hline Co & 1854 & 1835 & 1838 & 1842 & 10.2 & 1817 & 1868 & 1849 & 1826 & 1880 & 1852 & 27.1 & 1784 & 1919 \\
\hline $\mathrm{Ni}$ & 7 & 13 & 4 & 8 & 4.6 & -3 & 19 & 11 & 7 & 9 & 9 & 2.0 & 4 & 14 \\
\hline $\mathrm{Cu}$ & 14 & 17 & 9 & 13 & 4.0 & 3 & 23 & 16 & 11 & 10 & 12 & 3.2 & 4 & 20 \\
\hline Ge & 9 & 8 & 13 & 10 & 2.6 & 3 & 17 & 9 & 7 & 20 & 12 & 7.0 & -5 & 29 \\
\hline Mo & 6 & 10 & 17 & 11 & 5.6 & -3 & 25 & 6 & 8 & 12 & 9 & 3.1 & 1 & 16 \\
\hline Sn & 1 & 2 & 0 & 1 & 1.0 & -1 & 3 & 1 & 5 & 2 & 3 & 2.1 & -3 & 8 \\
\hline Sb & 2 & 1 & 3 & 2 & 1.0 & 0 & 4 & 4 & 4 & 3 & 4 & 0.6 & 2 & 5 \\
\hline
\end{tabular}




\begin{tabular}{|c|c|c|c|c|c|c|c|c|c|c|c|c|c|c|}
\hline Label & 8-1 A Top & 8-1 A Mid & 8-1 A Bot & & & & & 8-1 B Top & 8-1 B Mid & 8-1 B Bot & & & & \\
\hline Store & \multicolumn{3}{|c|}{ Northern Panhandle } & & & & & \multicolumn{3}{|c|}{ Northern Panhandle } & & & & \\
\hline Brand & \multicolumn{3}{|c|}{ Wheaton } & & & & & \multicolumn{3}{|c|}{ Wheaton } & & & & \\
\hline Location & \multicolumn{3}{|c|}{ Wheeling, WV } & & & & & \multicolumn{3}{|c|}{ Wheeling, WV } & & & & \\
\hline Slice & \multicolumn{3}{|c|}{ end } & & & & & \multicolumn{3}{|c|}{ middle } & & & & \\
\hline Spot & top & middle & bottom & Average & StdDev & \multicolumn{2}{|c|}{$\mathbf{9 5 \%}$ Conf Inter } & top & middle & bottom & Average & StdDev & \multicolumn{2}{|c|}{ 95\% Conf Inter } \\
\hline $\mathbf{P}$ & 14 & 9 & 6 & 10 & 4.0 & 0 & 20 & 11 & 10 & 11 & 11 & 0.6 & 9 & 12 \\
\hline $\mathrm{Ti}$ & 25 & 33 & 31 & 30 & 4.2 & 19 & 40 & 25 & 32 & 32 & 30 & 4.0 & 20 & 40 \\
\hline $\mathbf{V}$ & 78 & 47 & 66 & 64 & 15.6 & 25 & 102 & 59 & 73 & 37 & 56 & 18.1 & 11 & 101 \\
\hline $\mathrm{Cr}$ & 81 & 76 & 77 & 78 & 2.6 & 71 & 85 & 75 & 56 & 62 & 64 & 9.7 & 40 & 88 \\
\hline Mn & 369 & 340 & 405 & 371 & 32.6 & 290 & 452 & 332 & 357 & 398 & 362 & 33.3 & 280 & 445 \\
\hline $\mathrm{Fe}$ & 50637 & 50570 & 50488 & 50565 & 74.6 & 50380 & 50750 & 50374 & 50321 & 50805 & 50500 & 265.5 & 49841 & 51159 \\
\hline Co & 1847 & 1996 & 1808 & 1884 & 99.2 & 1637 & 2130 & 1990 & 1721 & 1808 & 1840 & 137.3 & 1499 & 2181 \\
\hline $\mathrm{Ni}$ & 8 & 5 & 7 & 7 & 1.5 & 3 & 10 & 7 & 3 & 4 & 5 & 2.1 & -1 & 10 \\
\hline $\mathrm{Cu}$ & 13 & 9 & 14 & 12 & 2.6 & 5 & 19 & 12 & 12 & 16 & 13 & 2.3 & 8 & 19 \\
\hline Ge & 7 & 7 & 5 & 6 & 1.2 & 3 & 9 & 6 & 10 & 7 & 8 & 2.1 & 2 & 13 \\
\hline Mo & 8 & 9 & 5 & 7 & 2.1 & 2 & 13 & 9 & 16 & 6 & 10 & 5.1 & -2 & 23 \\
\hline Sn & 1 & 2 & 1 & 1 & 0.6 & 0 & 3 & 3 & 2 & 4 & 3 & 1.0 & 1 & 5 \\
\hline $\mathrm{Sb}$ & 1 & 1 & 2 & 1 & 0.6 & 0 & 3 & 3 & 2 & 2 & 2 & 0.6 & 1 & 4 \\
\hline
\end{tabular}




\begin{tabular}{|c|c|c|c|c|c|c|c|c|c|c|c|c|c|c|}
\hline Label & 8-2 A Top & 8-2 A Mid & 8-2 A Bot & & & & & 8-2 В Top & 8-2 B Mid & 8-2 B Bot & & & & \\
\hline Store & \multicolumn{3}{|c|}{ Northern Panhandle } & & & & & \multicolumn{3}{|c|}{ Northern Panhandle } & & & & \\
\hline Brand & \multicolumn{3}{|c|}{ China } & & & & & \multicolumn{3}{|c|}{ China } & & & & \\
\hline Location & \multicolumn{3}{|c|}{ Wheeling, WV } & & & & & \multicolumn{3}{|c|}{ Wheeling, WV } & & & & \\
\hline Slice & \multicolumn{3}{|c|}{ end } & & & & & \multicolumn{3}{|c|}{ middle } & & & & \\
\hline Spot & top & middle & bottom & Average & StdDev & $95 \%$ Cor & ff Inter & top & middle & bottom & Average & StdDev & \multicolumn{2}{|c|}{ 95\% Conf Inter } \\
\hline $\mathbf{P}$ & 12 & 7 & 12 & 10 & 2.9 & 3 & 18 & 7 & 5 & 7 & 6 & 1.2 & 3 & 9 \\
\hline $\mathrm{Ti}$ & 28 & 25 & 31 & 28 & 3.0 & 21 & 35 & 33 & 23 & 41 & 32 & 9.0 & 10 & 55 \\
\hline V & 120 & 82 & 70 & 91 & 26.1 & 26 & 156 & 67 & 63 & 52 & 61 & 7.8 & 41 & 80 \\
\hline $\mathrm{Cr}$ & 68 & 68 & 55 & 64 & 7.5 & 45 & 82 & 59 & 54 & 59 & 57 & 2.9 & 50 & 65 \\
\hline Mn & 249 & 307 & 289 & 282 & 29.7 & 208 & 355 & 305 & 267 & 252 & 275 & 27.3 & 207 & 343 \\
\hline $\mathrm{Fe}$ & 50629 & 50558 & 50647 & 50611 & 47.1 & 50494 & 50728 & 50889 & 50569 & 50864 & 50774 & 178.0 & 50332 & 51216 \\
\hline Co & 1829 & 1882 & 1804 & 1838 & 39.8 & 1739 & 1937 & 1762 & 1999 & 1835 & 1865 & 121.4 & 1564 & 2167 \\
\hline $\mathbf{N i}$ & 11 & 10 & 6 & 9 & 2.6 & 2 & 16 & 13 & 11 & 16 & 13 & 2.5 & 7 & 20 \\
\hline $\mathrm{Cu}$ & 22 & 20 & 29 & 24 & 4.7 & 12 & 35 & 18 & 19 & 21 & 19 & 1.5 & 16 & 23 \\
\hline Ge & 13 & 9 & 8 & 10 & 2.6 & 3 & 17 & 9 & 7 & 10 & 9 & 1.5 & 5 & 12 \\
\hline Mo & 10 & 6 & 8 & 8 & 2.0 & 3 & 13 & 7 & 12 & 6 & 8 & 3.2 & 0 & 16 \\
\hline Sn & 4 & 2 & 1 & 2 & 1.5 & -1 & 6 & 3 & 2 & 4 & 3 & 1.0 & 1 & 5 \\
\hline $\mathrm{Sb}$ & 4 & 3 & 3 & 3 & 0.6 & 2 & 5 & 1 & 0 & 2 & 1 & 1.0 & -1 & 3 \\
\hline
\end{tabular}




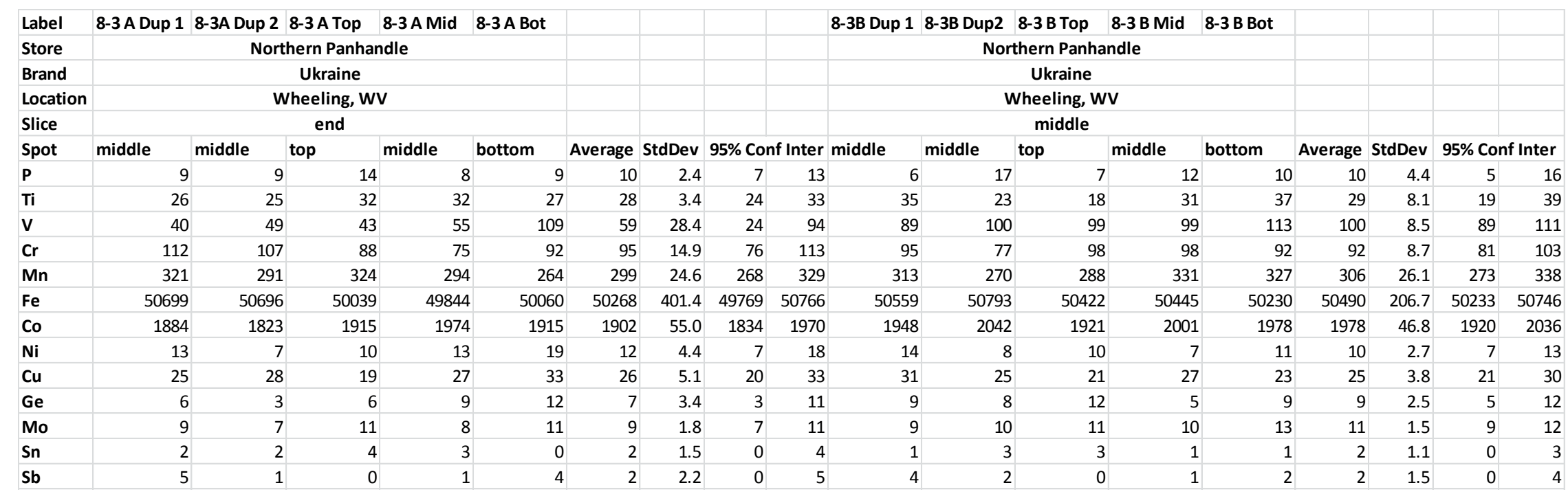




\begin{tabular}{|c|c|c|c|c|c|c|c|c|c|c|c|c|c|c|}
\hline Label & 9-1A Top & 9-1 A Mid & 9-1 A Bot & & & & & 9-1 B Top & 9-1 B Mid & 9-1 B Bot & & & & \\
\hline Store & \multicolumn{3}{|c|}{ Lowes } & & & & & \multicolumn{3}{|c|}{ Lowes } & & & & \\
\hline Brand & \multicolumn{3}{|c|}{ Mueller Proline } & & & & & \multicolumn{3}{|c|}{ Mueller Proline } & & & & \\
\hline Location & \multicolumn{3}{|c|}{ Morgantown, WV } & & & & & \multicolumn{3}{|c|}{ Morgantown, WV } & & & & \\
\hline Slice & \multicolumn{3}{|c|}{ end } & & & & & \multicolumn{3}{|c|}{ middle } & & & & \\
\hline Spot & top & middle & bottom & Average & StdDev & \multicolumn{2}{|c|}{$95 \%$ Conf Inter } & top & middle & bottom & Average & StdDev & \multicolumn{2}{|c|}{ 95\% Conf Inter } \\
\hline $\mathbf{P}$ & 6 & 5 & 9 & 7 & 2.1 & 1 & 12 & 8 & 10 & 3 & 7 & 3.6 & -2 & 16 \\
\hline $\mathrm{Ti}$ & 30 & 37 & 28 & 32 & 4.7 & 20 & 43 & 33 & 31 & 35 & 33 & 2.0 & 28 & 38 \\
\hline V & 45 & 69 & 47 & 54 & 13.3 & 21 & 87 & 50 & 73 & 83 & 69 & 16.9 & 27 & 111 \\
\hline $\mathrm{Cr}$ & 62 & 45 & 58 & 55 & 8.9 & 33 & 77 & 65 & 51 & 69 & 62 & 9.5 & 38 & 85 \\
\hline Mn & 275 & 268 & 323 & 289 & 29.9 & 214 & 363 & 317 & 288 & 310 & 305 & 15.1 & 267 & 343 \\
\hline $\mathrm{Fe}$ & 51202 & 50417 & 50222 & 50614 & 518.8 & 49325 & 51902 & 51151 & 50962 & 50927 & 51013 & 120.5 & 50714 & 51313 \\
\hline Co & 1833 & 1850 & 1829 & 1837 & 11.2 & 1810 & 1865 & 1939 & 1995 & 1767 & 1900 & 118.8 & 1605 & 2195 \\
\hline $\mathrm{Ni}$ & 4 & 4 & 2 & 3 & 1.2 & 0 & 6 & 4 & 4 & 6 & 5 & 1.2 & 2 & 8 \\
\hline $\mathrm{Cu}$ & 11 & 7 & 8 & 9 & 2.1 & 3 & 14 & 5 & 7 & 9 & 7 & 2.0 & 2 & 12 \\
\hline Ge & 3 & 12 & 7 & 7 & 4.5 & -4 & 19 & 6 & 6 & 6 & 6 & 0.0 & 6 & 6 \\
\hline Mo & 14 & 9 & 13 & 12 & 2.6 & 5 & 19 & 13 & 12 & 9 & 11 & 2.1 & 6 & 17 \\
\hline Sn & 0 & 2 & 1 & 1 & 1.0 & -1 & 3 & 3 & 0 & 1 & 1 & 1.5 & -2 & 5 \\
\hline Sb & 2 & 3 & 1 & 2 & 1.0 & 0 & 4 & 1 & 2 & 2 & 2 & 0.6 & 0 & 3 \\
\hline
\end{tabular}




\begin{tabular}{|c|c|c|c|c|c|c|c|c|c|c|c|c|c|c|}
\hline Label & 9-2 A Top & 9-2 A Mid & 9-2 A Bot & & & & & 9-2 В Top & 9-2 B Mid & 9-2 B Bot & & & & \\
\hline Store & \multicolumn{3}{|c|}{ Lowes } & & & & & \multicolumn{3}{|c|}{ Lowes } & & & & \\
\hline Brand & \multicolumn{3}{|c|}{ Mueller Proline } & & & & & \multicolumn{3}{|c|}{ Mueller Proline } & & & & \\
\hline Location & \multicolumn{3}{|c|}{ Morgantown, WV } & & & & & \multicolumn{3}{|c|}{ Morgantown, WV } & & & & \\
\hline Slice & \multicolumn{3}{|c|}{ end } & & & & & \multicolumn{3}{|c|}{ middle } & & & & \\
\hline Spot & top & middle & bottom & Average & StdDev & $95 \%$ Cor & nf Inter & top & middle & bottom & Average & StdDev & \multicolumn{2}{|c|}{ 95\% Conf Inter } \\
\hline $\mathbf{P}$ & 7 & 5 & 2 & 5 & 2.5 & -2 & 11 & 9 & 7 & 5 & 7 & 2.0 & 2 & 12 \\
\hline Ti & 34 & 27 & 35 & 32 & 4.4 & 21 & 43 & 14 & 30 & 42 & 29 & 14.0 & -6 & 64 \\
\hline V & 61 & 37 & 79 & 59 & 21.1 & 7 & 111 & 75 & 97 & 60 & 77 & 18.6 & 31 & 124 \\
\hline $\mathrm{Cr}$ & 45 & 70 & 61 & 59 & 12.7 & 27 & 90 & 60 & 73 & 56 & 63 & 8.9 & 41 & 85 \\
\hline Mn & 279 & 347 & 348 & 325 & 39.6 & 226 & 423 & 317 & 279 & 268 & 288 & 25.7 & 224 & 352 \\
\hline $\mathrm{Fe}$ & 50465 & 50578 & 50646 & 50563 & 91.4 & 50336 & 50790 & 50550 & 50483 & 50888 & 50640 & 217.1 & 50101 & 51180 \\
\hline Co & 1974 & 1855 & 1850 & 1893 & 70.2 & 1719 & 2067 & 2055 & 1879 & 1912 & 1949 & 93.6 & 1716 & 2181 \\
\hline $\mathbf{N i}$ & 12 & 1 & 8 & 7 & 5.6 & -7 & 21 & 7 & 7 & 5 & 6 & 1.2 & 3 & 9 \\
\hline $\mathrm{Cu}$ & 7 & 8 & 10 & 8 & 1.5 & 5 & 12 & 10 & 7 & 10 & 9 & 1.7 & 5 & 13 \\
\hline Ge & 7 & 2 & 7 & 5 & 2.9 & -2 & 13 & 12 & 11 & 8 & 10 & 2.1 & 5 & 16 \\
\hline Mo & 9 & 8 & 6 & 8 & 1.5 & 4 & 11 & 9 & 10 & 10 & 10 & 0.6 & 8 & 11 \\
\hline Sn & 1 & 2 & 2 & 2 & 0.6 & 0 & 3 & 0 & 2 & 1 & 1 & 1.0 & -1 & 3 \\
\hline Sb & 3 & 0 & 2 & 2 & 1.5 & -2 & 5 & 0 & 3 & 2 & 2 & 1.5 & -2 & 5 \\
\hline
\end{tabular}




\begin{tabular}{|c|c|c|c|c|c|c|c|c|c|c|c|c|c|c|}
\hline Label & 9-3 A Top & 9-3 A Mid & 9-3 A Bot & & & & & 9-3 B Top & 9-3 B Mid & 9-3 B Bot & & & & \\
\hline Store & \multicolumn{3}{|c|}{ Lowes } & & & & & \multicolumn{3}{|c|}{ Lowes } & & & & \\
\hline Brand & \multicolumn{3}{|c|}{ Mueller Proline } & & & & & \multicolumn{3}{|c|}{ Mueller Proline } & & & & \\
\hline Location & \multicolumn{3}{|c|}{ Morgantown, WV } & & & & & \multicolumn{3}{|c|}{ Morgantown, WV } & & & & \\
\hline Slice & \multicolumn{3}{|c|}{ end } & & & & & \multicolumn{3}{|c|}{ middle } & & & & \\
\hline Spot & top & middle & bottom & Average & StdDev & \multicolumn{2}{|c|}{ 95\% Conf Inter } & top & middle & bottom & Average & StdDev & \multicolumn{2}{|c|}{ 95\% Conf Inter } \\
\hline $\mathbf{P}$ & 2 & 6 & 10 & 6 & 4.0 & -4 & 16 & 8 & 4 & 5 & 6 & 2.1 & 0 & 11 \\
\hline $\mathrm{Ti}$ & 27 & 34 & 31 & 31 & 3.5 & 22 & 39 & 27 & 26 & 34 & 29 & 4.4 & 18 & 40 \\
\hline V & 60 & 51 & 100 & 70 & 26.1 & 6 & 135 & 46 & 114 & 137 & 99 & 47.3 & -19 & 217 \\
\hline $\mathrm{Cr}$ & 99 & 93 & 100 & 97 & 3.8 & 88 & 107 & 73 & 88 & 98 & 86 & 12.6 & 55 & 118 \\
\hline Mn & 307 & 339 & 347 & 331 & 21.2 & 278 & 384 & 314 & 408 & 404 & 375 & 53.2 & 243 & 507 \\
\hline $\mathrm{Fe}$ & 50826 & 50897 & 50572 & 50765 & 170.9 & 50341 & 51189 & 50437 & 50369 & 51033 & 50613 & 365.3 & 49706 & 51520 \\
\hline Co & 1782 & 1790 & 1989 & 1854 & 117.3 & 1562 & 2145 & 1905 & 1933 & 1926 & 1921 & 14.6 & 1885 & 1958 \\
\hline $\mathrm{Ni}$ & 10 & 11 & 4 & 8 & 3.8 & -1 & 18 & 8 & 8 & 8 & 8 & 0.0 & 8 & 8 \\
\hline $\mathrm{Cu}$ & 12 & 11 & 9 & 11 & 1.5 & 7 & 14 & 9 & 8 & 7 & 8 & 1.0 & 6 & 10 \\
\hline Ge & 5 & 8 & 4 & 6 & 2.1 & 0 & 11 & 7 & 13 & 10 & 10 & 3.0 & 3 & 17 \\
\hline Mo & 9 & 7 & 13 & 10 & 3.1 & 2 & 17 & 8 & 7 & 14 & 10 & 3.8 & 0 & 19 \\
\hline Sn & 0 & 2 & 1 & 1 & 1.0 & -1 & 3 & 2 & 0 & 1 & 1 & 1.0 & -1 & 3 \\
\hline Sb & 2 & 0 & 1 & 1 & 1.0 & -1 & 3 & 2 & 1 & 1 & 1 & 0.6 & 0 & 3 \\
\hline
\end{tabular}




\begin{tabular}{|c|c|c|c|c|c|c|c|c|c|c|c|c|c|c|}
\hline Label & 10-1 A Top & 10-1 A Mid & 10-1 A Bot & & & & & 10-1 B Top & 10-1 B Mid & 10-1 B Bot & & & & \\
\hline Store & \multicolumn{3}{|c|}{ Ace } & & & & & \multicolumn{3}{|c|}{ Ace } & & & & \\
\hline Brand & \multicolumn{3}{|c|}{ Wheatland } & & & & & \multicolumn{3}{|c|}{ Wheatland } & & & & \\
\hline Location & \multicolumn{3}{|c|}{ Morgantown, WV } & & & & & \multicolumn{3}{|c|}{ Morgantown, WV } & & & & \\
\hline Slice & \multicolumn{3}{|c|}{ end } & & & & & \multicolumn{3}{|c|}{ middle } & & & & \\
\hline Spot & top & middle & bottom & Average & StdDev & \multicolumn{2}{|c|}{ 95\% Conf Inter } & top & middle & bottom & Average & StdDev & \multicolumn{2}{|c|}{ 95\% Conf Inter } \\
\hline $\mathbf{P}$ & 7 & 8 & 8 & 8 & 0.6 & 6 & 9 & 6 & 4 & 7 & 6 & 1.5 & 2 & 9 \\
\hline $\mathrm{Ti}$ & 39 & 38 & 18 & 32 & 11.8 & 2 & 61 & 28 & 29 & 31 & 29 & 1.5 & 26 & 33 \\
\hline $\mathbf{V}$ & 49 & 53 & 57 & 53 & 4.0 & 43 & 63 & 47 & 27 & 118 & 64 & 47.8 & -55 & 183 \\
\hline $\mathrm{Cr}$ & 79 & 90 & 86 & 85 & 5.6 & 71 & 99 & 63 & 79 & 76 & 73 & 8.5 & 52 & 94 \\
\hline$M n$ & 797 & 344 & 315 & 485 & 270.3 & -186 & 1157 & 376 & 397 & 314 & 362 & 43.2 & 255 & 470 \\
\hline $\mathrm{Fe}$ & 49949 & 51009 & 50187 & 50382 & 556.2 & 49000 & 51763 & 50362 & 50695 & 50560 & 50539 & 167.5 & 50123 & 50955 \\
\hline Co & 1792 & 1861 & 1889 & 1847 & 49.9 & 1723 & 1971 & 1869 & 1870 & 1875 & 1871 & 3.2 & 1863 & 1879 \\
\hline $\mathrm{Ni}$ & 5 & 7 & 8 & 7 & 1.5 & 3 & 10 & 4 & 6 & 10 & 7 & 3.1 & -1 & 14 \\
\hline $\mathrm{Cu}$ & 11 & 12 & 9 & 11 & 1.5 & 7 & 14 & 9 & 15 & 5 & 10 & 5.0 & -3 & 22 \\
\hline Ge & 9 & 3 & 8 & 7 & 3.2 & -1 & 15 & 3 & 6 & 8 & 6 & 2.5 & -1 & 12 \\
\hline Mo & 10 & 21 & 9 & 13 & 6.7 & -3 & 30 & 9 & 13 & 13 & 12 & 2.3 & 6 & 17 \\
\hline Sn & 2 & 4 & 1 & 2 & 1.5 & -1 & 6 & 0 & 2 & 2 & 1 & 1.2 & -2 & 4 \\
\hline Sb & 2 & 4 & 1 & 2 & 1.5 & -1 & 6 & 0 & 2 & 2 & 1 & 1.2 & -2 & 4 \\
\hline
\end{tabular}




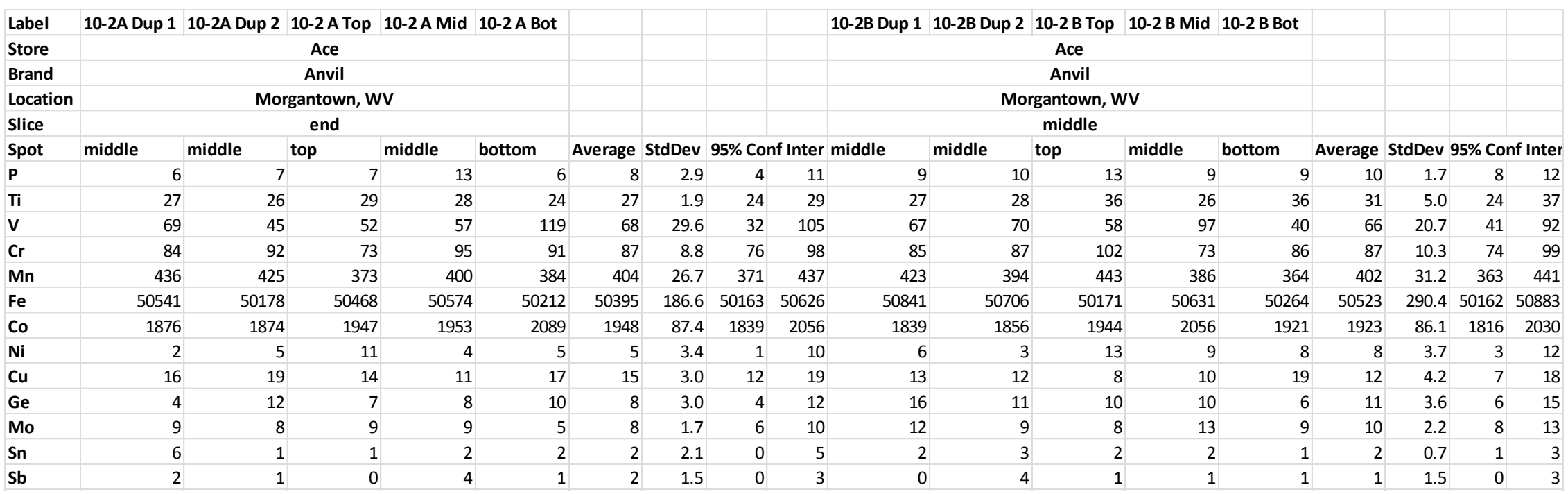




\begin{tabular}{|c|c|c|c|c|c|c|c|c|c|c|c|c|c|c|}
\hline Label & 10-3 A Top & 10-3 A Mid & 10-3 A Bot & & & & & 10-3 B Top & 10-3 B Mid & 10-3 B Bot & & & & \\
\hline Store & \multicolumn{3}{|c|}{ Ace } & & & & & & Ace & & & & & \\
\hline Brand & \multicolumn{3}{|c|}{ Anvil } & & & & & & Anvil & & & & & \\
\hline Location & \multicolumn{3}{|c|}{ Morgantown, WV } & & & & & Mo & organtown, V & WV & & & & \\
\hline Slice & \multicolumn{3}{|c|}{ end } & & & & & & middle & & & & & \\
\hline Spot & top & middle & bottom & Average & StdDev & $95 \%$ Cor & nf Inter & top & middle & bottom & Average & StdDev & 95\% Con & f Inter \\
\hline $\mathbf{P}$ & 10.0000 & 7 & 10 & 9 & 1.7 & 5 & 13 & 8 & 7 & 7 & 7 & 0.6 & 6 & 9 \\
\hline $\mathrm{Ti}$ & 31.0000 & 34 & 37 & 34 & 3.0 & 27 & 41 & 31 & 24 & 35 & 30 & 5.6 & 16 & 44 \\
\hline V & 33.0000 & 23 & 60 & 39 & 19.1 & -9 & 86 & 27 & 38 & 161 & 75 & 74.4 & -109 & 260 \\
\hline $\mathrm{Cr}$ & 90.0000 & 94 & 96 & 93 & 3.1 & 86 & 101 & 77 & 80 & 79 & 79 & 1.5 & 75 & 82 \\
\hline$M n$ & 411.0000 & 396 & 423 & 410 & 13.5 & 376 & 444 & 412 & 348 & 423 & 394 & 40.5 & 294 & 495 \\
\hline $\mathrm{Fe}$ & 50585.0000 & 50972 & 50695 & 50751 & 199.4 & 50255 & 51246 & 50900 & 51241 & 50907 & 51016 & 194.9 & 50532 & 51500 \\
\hline Co & 2014.0000 & 1975 & 1820 & 1936 & 102.6 & 1681 & 2191 & 1924 & 1859 & 1877 & 1887 & 33.6 & 1803 & 1970 \\
\hline $\mathrm{Ni}$ & 3.0000 & 7 & 9 & 6 & 3.1 & -1 & 14 & 3 & 6 & 3 & 4 & 1.7 & 0 & 8 \\
\hline $\mathrm{Cu}$ & 9.0000 & 17 & 10 & 12 & 4.4 & 1 & 23 & 14 & 11 & 12 & 12 & 1.5 & 9 & 16 \\
\hline Ge & 7.0000 & 7 & 9 & 8 & 1.2 & 5 & 11 & 3 & 12 & 18 & 11 & 7.5 & -8 & 30 \\
\hline Mo & 6.0000 & 5 & 18 & 10 & 7.2 & -8 & 28 & 10 & 11 & 8 & 10 & 1.5 & 6 & 13 \\
\hline Sn & 2.0000 & 4 & 1 & 2 & 1.5 & -1 & 6 & 4 & 3 & 1 & 3 & 1.5 & -1 & 6 \\
\hline Sb & 1.0000 & 2 & 2 & 2 & 0.6 & 0 & 3 & 3 & 1 & 2 & 2 & 1.0 & 0 & 4 \\
\hline
\end{tabular}




\begin{tabular}{|c|c|c|c|c|c|c|c|c|c|c|c|c|c|c|}
\hline Label & 11-1 A Top & 11-1 A Mid & 11-1 A Bot & & & & & 11-1 B Top & 11-1 B Mid & 11-1 B Bot & & & & \\
\hline Store & \multicolumn{3}{|c|}{ Home Depot } & & & & & \multicolumn{3}{|c|}{ Home Depot } & & & & \\
\hline Brand & \multicolumn{3}{|c|}{ Mueller B\&K } & & & & & \multicolumn{3}{|c|}{ Mueller B\&K } & & & & \\
\hline Location & \multicolumn{3}{|c|}{ Cleveland,Oh } & & & & & \multicolumn{3}{|c|}{ Cleveland,Oh } & & & & \\
\hline Slice & \multicolumn{3}{|c|}{ end } & & & & & \multicolumn{3}{|c|}{ middle } & & & & \\
\hline Spot & top & middle & bottom & Average & StdDev & \multicolumn{2}{|c|}{ 95\% Conf Inter } & top & middle & bottom & Average & StdDev & \multicolumn{2}{|c|}{ 95\% Conf Inter } \\
\hline $\mathbf{P}$ & 8 & 10 & 9 & 9 & 1.0 & 7 & 11 & 13 & 12 & 11 & 12 & 1.0 & 10 & 14 \\
\hline $\mathrm{Ti}$ & 23 & 27 & 35 & 28 & 6.1 & 13 & 44 & 27 & 30 & 28 & 28 & 1.5 & 25 & 32 \\
\hline V & 50 & 61 & 85 & 65 & 17.9 & 21 & 110 & 134 & 53 & 95 & 94 & 40.5 & -7 & 195 \\
\hline $\mathrm{Cr}$ & 116 & 105 & 104 & 108 & 6.7 & 92 & 125 & 118 & 97 & 112 & 109 & 10.8 & 82 & 136 \\
\hline$M n$ & 213 & 227 & 246 & 229 & 16.6 & 188 & 270 & 237 & 214 & 220 & 224 & 11.9 & 194 & 253 \\
\hline $\mathrm{Fe}$ & 50353 & 50692 & 50494 & 50513 & 170.3 & 50090 & 50936 & 50388 & 50337 & 50895 & 50540 & 308.5 & 49774 & 51306 \\
\hline Co & 1702 & 1662 & 1611 & 1658 & 45.6 & 1545 & 1772 & 1700 & 1568 & 1562 & 1610 & 78.0 & 1416 & 1804 \\
\hline $\mathrm{Ni}$ & 9 & 6 & 7 & 7 & 1.5 & 4 & 11 & 8 & 12 & 13 & 11 & 2.6 & 4 & 18 \\
\hline $\mathrm{Cu}$ & 6 & 8 & 5 & 6 & 1.5 & 3 & 10 & 6 & 13 & 11 & 10 & 3.6 & 1 & 19 \\
\hline Ge & 7 & 6 & 10 & 8 & 2.1 & 2 & 13 & 13 & 10 & 4 & 9 & 4.6 & -2 & 20 \\
\hline Mo & 6 & 8 & 8 & 7 & 1.2 & 4 & 10 & 9 & 5 & 4 & 6 & 2.6 & -1 & 13 \\
\hline Sn & 1 & 1 & 3 & 2 & 1.2 & -1 & 5 & 1 & 3 & 0 & 1 & 1.5 & -2 & 5 \\
\hline Sb & 1 & 0 & 2 & 1 & 1.0 & -1 & 3 & 2 & 2 & 2 & 2 & 0.0 & 2 & 2 \\
\hline
\end{tabular}




\begin{tabular}{|c|c|c|c|c|c|c|c|c|c|c|c|c|c|c|}
\hline Label & 11-2 A Top & 11-2 A Mid & 11-2 A Bot & & & & & 11-2 B Top & 11-2 B Mid & 11-2 B Bot & & & & \\
\hline Store & \multicolumn{3}{|c|}{ Home Depot } & & & & & \multicolumn{3}{|c|}{ Home Depot } & & & & \\
\hline Brand & \multicolumn{3}{|c|}{ Mueller B\&K } & & & & & \multicolumn{3}{|c|}{ Mueller B\&K } & & & & \\
\hline Location & \multicolumn{3}{|c|}{ Cleveland,Oh } & & & & & \multicolumn{3}{|c|}{ Cleveland,Oh } & & & & \\
\hline Slice & \multicolumn{3}{|c|}{ end } & & & & & \multicolumn{3}{|c|}{ middle } & & & & \\
\hline Spot & top & middle & bottom & Average & StdDev & \multicolumn{2}{|c|}{ 95\% Conf Inter } & top & middle & bottom & Average & StdDev & \multicolumn{2}{|c|}{ 95\% Conf Inter } \\
\hline $\mathbf{P}$ & 4 & 9 & 3 & 5 & 3.2 & -3 & 13 & 13 & 12 & 8 & 11 & 2.6 & 4 & 18 \\
\hline $\mathrm{Ti}$ & 30 & 29 & 26 & 28 & 2.1 & 23 & 34 & 24 & 27 & 33 & 28 & 4.6 & 17 & 39 \\
\hline V & 82 & 68 & 101 & 84 & 16.6 & 43 & 125 & 86 & 55 & 55 & 65 & 17.9 & 21 & 110 \\
\hline $\mathrm{Cr}$ & 102 & 120 & 141 & 121 & 19.5 & 73 & 169 & 102 & 95 & 126 & 108 & 16.3 & 67 & 148 \\
\hline$M n$ & 227 & 232 & 230 & 230 & 2.5 & 223 & 236 & 280 & 304 & 235 & 273 & 35.0 & 186 & 360 \\
\hline $\mathrm{Fe}$ & 50724 & 50586 & 50697 & 50669 & 73.1 & 50487 & 50851 & 51028 & 50886 & 50570 & 50828 & 234.4 & 50246 & 51410 \\
\hline Co & 1603 & 1576 & 1632 & 1604 & 28.0 & 1534 & 1673 & 1749 & 1992 & 1999 & 1913 & 142.4 & 1560 & 2267 \\
\hline $\mathrm{Ni}$ & 10 & 7 & 10 & 9 & 1.7 & 5 & 13 & 11 & 6 & 7 & 8 & 2.6 & 1 & 15 \\
\hline $\mathrm{Cu}$ & 5 & 13 & 7 & 8 & 4.2 & -2 & 19 & 9 & 7 & 7 & 8 & 1.2 & 5 & 11 \\
\hline Ge & 9 & 6 & 9 & 8 & 1.7 & 4 & 12 & 6 & 6 & 7 & 6 & 0.6 & 5 & 8 \\
\hline Mo & 9 & 6 & 6 & 7 & 1.7 & 3 & 11 & 15 & 8 & 11 & 11 & 3.5 & 3 & 20 \\
\hline Sn & 2 & 2 & 3 & 2 & 0.6 & 1 & 4 & 2 & 1 & 1 & 1 & 0.6 & 0 & 3 \\
\hline $\mathrm{Sb}$ & 2 & 2 & 1 & 2 & 0.6 & 0 & 3 & 2 & 3 & 0 & 2 & 1.5 & -2 & 5 \\
\hline
\end{tabular}




\begin{tabular}{|c|c|c|c|c|c|c|c|c|c|c|c|c|c|c|}
\hline Label & 11-3 A Top & 11-3 A Mid & 11-3 A Bot & & & & & 11-3 B Top & 11-3 B Mid & 11-3 B Bot & & & & \\
\hline Store & \multicolumn{3}{|c|}{ Home Depot } & & & & & \multicolumn{3}{|c|}{ Home Depot } & & & & \\
\hline Brand & \multicolumn{3}{|c|}{ Mueller B\&K } & & & & & \multicolumn{3}{|c|}{ Mueller B\&K } & & & & \\
\hline Location & \multicolumn{3}{|c|}{ Cleveland,Oh } & & & & & \multicolumn{3}{|c|}{ Cleveland,Oh } & & & & \\
\hline Slice & \multicolumn{3}{|c|}{ end } & & & & & \multicolumn{3}{|c|}{ middle } & & & & \\
\hline Spot & top & middle & bottom & Average & StdDev & $95 \%$ Con & f Inter & top & middle & bottom & Average & StdDev & \multicolumn{2}{|c|}{ 95\% Conf Inter } \\
\hline $\mathbf{P}$ & 8 & 7 & 7 & 7 & 0.6 & 6 & 9 & 6 & 11 & 12 & 10 & 3.2 & 2 & 18 \\
\hline Ti & 33 & 39 & 37 & 36 & 3.1 & 29 & 44 & 23 & 34 & 30 & 29 & 5.6 & 15 & 43 \\
\hline V & 79 & 95 & 80 & 85 & 9.0 & 62 & 107 & 57 & 69 & 61 & 62 & 6.1 & 47 & 78 \\
\hline $\mathrm{Cr}$ & 101 & 107 & 103 & 104 & 3.1 & 96 & 111 & 82 & 114 & 106 & 101 & 16.7 & 59 & 142 \\
\hline Mn & 213 & 251 & 225 & 230 & 19.4 & 181 & 278 & 216 & 242 & 296 & 251 & 40.8 & 150 & 353 \\
\hline Fe & 50818 & 51063 & 50792 & 50891 & 149.5 & 50520 & 51262 & 50952 & 51177 & 50776 & 50968 & 201.0 & 50469 & 51468 \\
\hline Co & 1914 & 2126 & 1814 & 1951 & 159.3 & 1556 & 2347 & 1854 & 1866 & 2070 & 1930 & 121.4 & 1628 & 2232 \\
\hline $\mathrm{Ni}$ & 8 & 4 & 5 & 6 & 2.1 & 0 & 11 & 8 & 5 & 8 & 7 & 1.7 & 3 & 11 \\
\hline $\mathrm{Cu}$ & 7 & 7 & 6 & 7 & 0.6 & 5 & 8 & 7 & 9 & 8 & 8 & 1.0 & 6 & 10 \\
\hline Ge & 6 & 12 & 10 & 9 & 3.1 & 2 & 17 & 7 & 9 & 9 & 8 & 1.2 & 5 & 11 \\
\hline Mo & 14 & 12 & 5 & 10 & 4.7 & -1 & 22 & 6 & 4 & 14 & 8 & 5.3 & -5 & 21 \\
\hline Sn & 3 & 2 & 2 & 2 & 0.6 & 1 & 4 & 4 & 1 & 1 & 2 & 1.7 & -2 & 6 \\
\hline Sb & 2 & 1 & 2 & 2 & 0.6 & 0 & 3 & 3 & 1 & 4 & 3 & 1.5 & -1 & 6 \\
\hline
\end{tabular}




\begin{tabular}{|c|c|c|c|c|c|c|c|c|c|c|c|c|c|c|}
\hline Label & 12-1 A Top & 12-1 A Mid & 12-1 A Bot & & & & & 12-1 B Top & 12-1 B Mid & 12-1 B Bot & & & & \\
\hline Store & \multicolumn{3}{|c|}{ Lowes } & & & & & \multicolumn{3}{|c|}{ Lowes } & & & & \\
\hline Brand & \multicolumn{3}{|c|}{ Mueller Proline } & & & & & \multicolumn{3}{|c|}{ Mueller Proline } & & & & \\
\hline Location & \multicolumn{3}{|c|}{ Cleveland,Oh } & & & & & \multicolumn{3}{|c|}{ Cleveland,Oh } & & & & \\
\hline Slice & \multicolumn{3}{|c|}{ end } & & & & & \multicolumn{3}{|c|}{ middle } & & & & \\
\hline Spot & top & middle & bottom & Average & StdDev & \multicolumn{2}{|c|}{ 95\% Conf Inter } & top & middle & bottom & Average & StdDev & \multicolumn{2}{|c|}{ 95\% Conf Inter } \\
\hline $\mathbf{P}$ & 7 & 10 & 12 & 10 & 2.5 & 3 & 16 & 3 & 9 & 8 & 7 & 3.2 & -1 & 15 \\
\hline $\mathrm{Ti}$ & 29 & 25 & 27 & 27 & 2.0 & 22 & 32 & 33 & 40 & 34 & 36 & 3.8 & 26 & 45 \\
\hline V & 83 & 82 & 94 & 86 & 6.7 & 70 & 103 & 89 & 68 & 42 & 66 & 23.5 & 8 & 125 \\
\hline $\mathrm{Cr}$ & 60 & 54 & 53 & 56 & 3.8 & 46 & 65 & 65 & 74 & 55 & 65 & 9.5 & 41 & 88 \\
\hline Mn & 345 & 294 & 251 & 297 & 47.1 & 180 & 414 & 304 & 265 & 363 & 311 & 49.3 & 188 & 433 \\
\hline $\mathrm{Fe}$ & 50504 & 50998 & 50873 & 50792 & 256.8 & 50154 & 51430 & 50048 & 50366 & 49230 & 49881 & 586.1 & 48425 & 51337 \\
\hline Co & 1918 & 1861 & 1923 & 1901 & 34.4 & 1815 & 1986 & 1942 & 1932 & 1962 & 1945 & 15.3 & 1907 & 1983 \\
\hline $\mathrm{Ni}$ & 9 & 2 & 12 & 8 & 5.1 & -5 & 20 & 8 & 9 & 12 & 10 & 2.1 & 4 & 15 \\
\hline $\mathrm{Cu}$ & 11 & 5 & 13 & 10 & 4.2 & -1 & 20 & 8 & 16 & 7 & 10 & 4.9 & -2 & 23 \\
\hline Ge & 13 & 6 & 21 & 13 & 7.5 & -5 & 32 & 6 & 6 & 9 & 7 & 1.7 & 3 & 11 \\
\hline Mo & 13 & 7 & 10 & 10 & 3.0 & 3 & 17 & 6 & 6 & 9 & 7 & 1.7 & 3 & 11 \\
\hline Sn & 1 & 1 & 2 & 1 & 0.6 & 0 & 3 & 1 & 4 & 0 & 2 & 2.1 & -4 & 7 \\
\hline $\mathrm{Sb}$ & 1 & 1 & 1 & 1 & 0.0 & 1 & 1 & 1 & 0 & 1 & 1 & 0.6 & -1 & 2 \\
\hline
\end{tabular}




\begin{tabular}{|c|c|c|c|c|c|c|c|c|c|c|c|c|c|c|}
\hline Label & 12-2 A Top & 12-2 A Mid & 12-2 A Bot & & & & & 12-2 B Top & 12-2 B Mid & 12-2 B Bot & & & & \\
\hline Store & \multicolumn{3}{|c|}{ Lowes } & & & & & \multicolumn{3}{|c|}{ Lowes } & & & & \\
\hline Brand & \multicolumn{3}{|c|}{ Mueller Proline } & & & & & \multicolumn{3}{|c|}{ Mueller Proline } & & & & \\
\hline Location & \multicolumn{3}{|c|}{ Cleveland,Oh } & & & & & \multicolumn{3}{|c|}{ Cleveland,Oh } & & & & \\
\hline Slice & \multicolumn{3}{|c|}{ end } & & & & & \multicolumn{3}{|c|}{ middle } & & & & \\
\hline Spot & top & middle & bottom & Average & StdDev & \multicolumn{2}{|c|}{ 95\% Conf Inter } & top & middle & bottom & Average & StdDev & \multicolumn{2}{|c|}{ 95\% Conf Inter } \\
\hline $\mathbf{P}$ & 8 & 9 & 11 & 9 & 1.5 & 6 & 13 & 13 & 7 & 9 & 10 & 3.1 & 2 & 17 \\
\hline $\mathrm{Ti}$ & 27 & 26 & 31 & 28 & 2.6 & 21 & 35 & 26 & 26 & 28 & 27 & 1.2 & 24 & 30 \\
\hline V & 50 & 127 & 65 & 81 & 40.8 & -21 & 182 & 79 & 54 & 59 & 64 & 13.2 & 31 & 97 \\
\hline $\mathrm{Cr}$ & 67 & 81 & 68 & 72 & 7.8 & 53 & 91 & 77 & 72 & 65 & 71 & 6.0 & 56 & 86 \\
\hline Mn & 376 & 302 & 294 & 324 & 45.2 & 212 & 436 & 324 & 367 & 304 & 332 & 32.2 & 252 & 412 \\
\hline $\mathrm{Fe}$ & 51057 & 50827 & 50733 & 50872 & 166.7 & 50458 & 51286 & 50903 & 50701 & 50658 & 50754 & 130.8 & 50429 & 51079 \\
\hline Co & 1892 & 1952 & 1935 & 1926 & 30.9 & 1850 & 2003 & 1906 & 1908 & 1869 & 1894 & 22.0 & 1840 & 1949 \\
\hline $\mathrm{Ni}$ & 8 & 11 & 11 & 10 & 1.7 & 6 & 14 & 7 & 8 & 6 & 7 & 1.0 & 5 & 9 \\
\hline $\mathrm{Cu}$ & 10 & 7 & 8 & 8 & 1.5 & 5 & 12 & 9 & 8 & 8 & 8 & 0.6 & 7 & 10 \\
\hline Ge & 8 & 14 & 10 & 11 & 3.1 & 3 & 18 & 4 & 4 & 6 & 5 & 1.2 & 2 & 8 \\
\hline Mo & 6 & 14 & 9 & 10 & 4.0 & 0 & 20 & 5 & 4 & 8 & 6 & 2.1 & 0 & 11 \\
\hline Sn & 1 & 1 & 3 & 2 & 1.2 & -1 & 5 & 3 & 0 & 1 & 1 & 1.5 & -2 & 5 \\
\hline $\mathrm{Sb}$ & 3 & 3 & 1 & 2 & 1.2 & -1 & 5 & 0 & 1 & 1 & 1 & 0.6 & -1 & 2 \\
\hline
\end{tabular}




\begin{tabular}{|c|c|c|c|c|c|c|c|c|c|c|c|c|c|c|}
\hline Label & 12-3 A Top & 12-3 A Mid & 12-3 A Bot & & & & & 12-3 B Top & 12-3 B Mid & 12-3 B Bot & & & & \\
\hline Store & \multicolumn{3}{|c|}{ Lowes } & & & & & \multicolumn{3}{|c|}{ Lowes } & & & & \\
\hline Brand & \multicolumn{3}{|c|}{ Mueller Proline } & & & & & \multicolumn{3}{|c|}{ Mueller Proline } & & & & \\
\hline Location & \multicolumn{3}{|c|}{ Cleveland,Oh } & & & & & \multicolumn{3}{|c|}{ Cleveland,Oh } & & & & \\
\hline Slice & \multicolumn{3}{|c|}{ end } & & & & & \multicolumn{3}{|c|}{ middle } & & & & \\
\hline Spot & top & middle & bottom & Average & StdDev & 95\% Cont & f Inter & top & middle & bottom & Average & StdDev & \multicolumn{2}{|c|}{ 95\% Conf Inter } \\
\hline $\mathbf{P}$ & 6 & 4 & 3 & 4 & 1.5 & 1 & 8 & 6 & 7 & 8 & 7 & 1.0 & 5 & 9 \\
\hline $\mathrm{Ti}$ & 26 & 33 & 28 & 29 & 3.6 & 20 & 38 & 24 & 31 & 30 & 28 & 3.8 & 19 & 38 \\
\hline V & 65 & 94 & 61 & 73 & 18.0 & 29 & 118 & 49 & 59 & 68 & 59 & 9.5 & 35 & 82 \\
\hline $\mathrm{Cr}$ & 58 & 62 & 64 & 61 & 3.1 & 54 & 69 & 60 & 60 & 70 & 63 & 5.8 & 49 & 78 \\
\hline$M n$ & 372 & 351 & 289 & 337 & 43.2 & 230 & 445 & 312 & 301 & 311 & 308 & 6.1 & 293 & 323 \\
\hline $\mathrm{Fe}$ & 50600 & 50701 & 50732 & 50678 & 69.0 & 50506 & 50849 & 51208 & 50716 & 50758 & 50894 & 272.7 & 50216 & 51572 \\
\hline Co & 1904 & 1969 & 1835 & 1903 & 67.0 & 1736 & 2069 & 1782 & 1968 & 1880 & 1877 & 93.0 & 1646 & 2108 \\
\hline $\mathrm{Ni}$ & 8 & 7 & 11 & 9 & 2.1 & 3 & 14 & 8 & 4 & 3 & 5 & 2.6 & -2 & 12 \\
\hline $\mathrm{Cu}$ & 3 & 5 & 8 & 5 & 2.5 & -1 & 12 & 15 & 9 & 10 & 11 & 3.2 & 3 & 19 \\
\hline Ge & 7 & 9 & 9 & 8 & 1.2 & 5 & 11 & 5 & 11 & 8 & 8 & 3.0 & 1 & 15 \\
\hline Mo & 7 & 5 & 8 & 7 & 1.5 & 3 & 10 & 15 & 13 & 8 & 12 & 3.6 & 3 & 21 \\
\hline Sn & 2 & 3 & 1 & 2 & 1.0 & 0 & 4 & 2 & 3 & 1 & 2 & 1.0 & 0 & 4 \\
\hline $\mathrm{Sb}$ & 1 & 1 & 3 & 2 & 1.2 & -1 & 5 & 1 & 3 & 2 & 2 & 1.0 & 0 & 4 \\
\hline
\end{tabular}




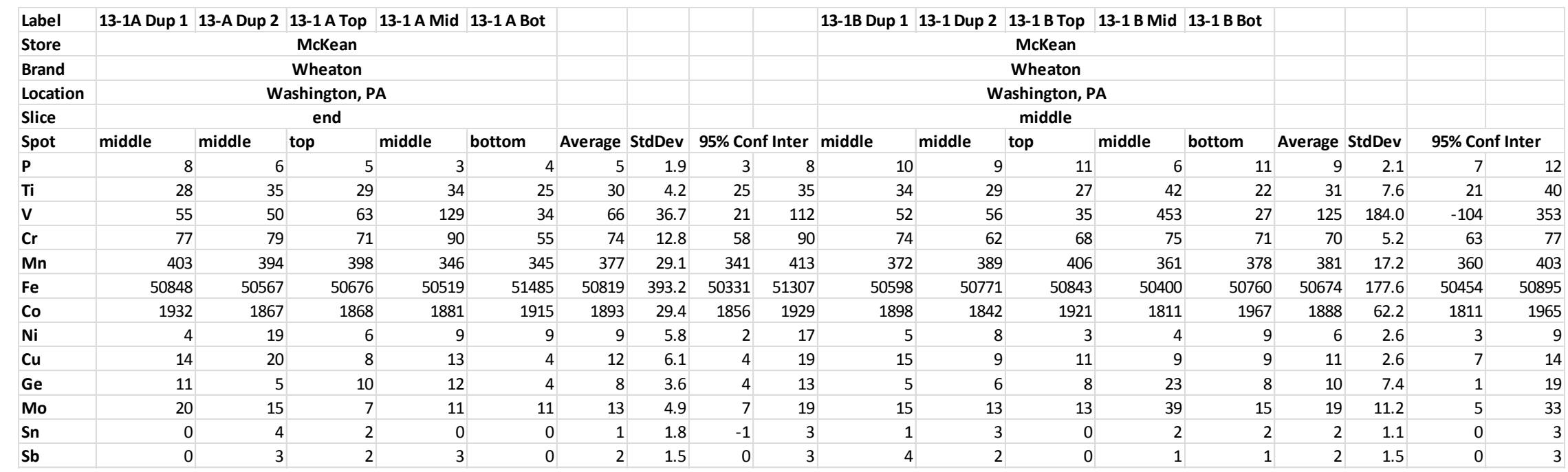


Appendix 8

Pair-wise Comparison Tables

(Groups are pipe numbers, i.e. Group 11 is Pipe 1-1) 


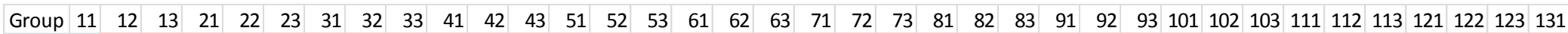
$11 \times$ Yes Yes Yes Yes Yes Yes Yes Yes Yes Yes Yes Yes Yes Yes Yes Yes Yes Yes Yes Yes Yes Yes Yes Yes Yes Yes Yes Yes Yes Yes Yes Yes Yes Yes Yes Yes $12 \quad \mathrm{x}$ Yes Yes Yes Yes Yes Yes Yes Yes Yes Yes Yes Yes Yes Yes Yes Yes Yes Yes Yes Yes Yes Yes Yes Yes Yes Yes Yes Yes Yes Yes Yes Yes Yes Yes Yes x Yes Yes Yes Yes Yes Yes Yes Yes Yes Yes Yes Yes Yes Yes Yes Yes Yes Yes Yes Yes Yes Yes Yes Yes Yes Yes Yes Yes Yes Yes Yes Yes Yes Yes $\mathbf{x}$ Yes Yes Yes Yes Yes Yes Yes Yes Yes Yes Yes Yes Yes Yes Yes Yes Yes Yes Yes Yes Yes Yes Yes Yes Yes Yes Yes Yes Yes Yes Yes Yes Yes $\mathrm{x}$ Yes Yes Yes Yes Yes Yes Yes Yes Yes Yes Yes Yes Yes Yes Yes Yes Yes Yes Yes Yes Yes Yes Yes Yes Yes Yes Yes Yes Yes Yes Yes Yes $\mathrm{x}$ Yes Yes Yes Yes Yes Yes Yes Yes Yes Yes Yes Yes Yes Yes Yes Yes Yes Yes Yes Yes Yes Yes Yes Yes Yes Yes Yes Yes Yes Yes Yes $\mathbf{x}$ Yes Yes Yes Yes Yes Yes Yes Yes Yes Yes Yes Yes Yes Yes Yes Yes Yes Yes Yes Yes Yes Yes Yes Yes Yes Yes Yes Yes Yes Yes $\mathbf{x}$ Yes Yes Yes Yes Yes Yes Yes Yes Yes Yes Yes Yes Yes Yes Yes Yes Yes Yes Yes Yes Yes Yes Yes Yes Yes Yes Yes Yes Yes $\mathbf{x}$ Yes Yes Yes Yes Yes Yes Yes Yes Yes Yes Yes Yes Yes Yes Yes Yes Yes Yes Yes Yes Yes Yes Yes Yes Yes Yes Yes Yes $x$ Yes Yes Yes Yes Yes Yes Yes Yes Yes Yes Yes Yes Yes Yes Yes Yes Yes Yes Yes Yes Yes Yes Yes Yes Yes Yes Yes $x$ Yes Yes Yes Yes Yes Yes Yes Yes Yes Yes Yes Yes Yes Yes Yes Yes Yes Yes Yes no Yes Yes Yes Yes Yes Yes $\mathbf{x}$ Yes Yes Yes Yes Yes Yes Yes Yes Yes Yes Yes Yes Yes Yes Yes Yes Yes Yes Yes Yes Yes Yes Yes Yes Yes $x$ Yes Yes Yes Yes Yes Yes Yes Yes Yes Yes Yes Yes Yes Yes Yes Yes Yes Yes Yes Yes Yes Yes Yes Yes $\mathbf{x}$ Yes Yes Yes Yes Yes Yes Yes Yes Yes Yes Yes Yes Yes Yes Yes Yes Yes Yes Yes Yes Yes Yes Yes x Yes Yes Yes Yes Yes Yes Yes Yes Yes Yes Yes Yes Yes Yes Yes Yes Yes Yes Yes Yes Yes Yes $x$ Yes Yes Yes Yes Yes Yes Yes Yes Yes Yes Yes Yes Yes Yes Yes Yes Yes Yes Yes Yes Yes $x$ Yes Yes Yes Yes Yes Yes Yes Yes Yes Yes Yes Yes Yes Yes Yes Yes Yes Yes Yes Yes $x$ Yes Yes Yes Yes Yes Yes Yes Yes Yes Yes Yes Yes Yes Yes Yes Yes Yes Yes Yes $\boldsymbol{x}$ Yes Yes Yes Yes Yes Yes Yes Yes Yes Yes Yes Yes Yes Yes Yes Yes Yes Yes $x$ Yes Yes Yes Yes Yes Yes Yes Yes Yes Yes Yes Yes Yes Yes Yes Yes Yes $\boldsymbol{x}$ Yes Yes Yes Yes Yes Yes Yes Yes Yes Yes Yes Yes Yes Yes Yes Yes $x$ Yes Yes Yes Yes Yes Yes Yes Yes Yes Yes Yes Yes Yes Yes Yes $x$ Yes Yes Yes Yes Yes Yes Yes Yes Yes Yes Yes Yes Yes Yes $x$ Yes Yes Yes Yes Yes Yes Yes Yes Yes Yes Yes Yes Yes $x$ Yes Yes Yes Yes Yes Yes Yes Yes Yes Yes Yes Yes $x$ Yes Yes Yes Yes no Yes Yes Yes Yes Yes Yes $\boldsymbol{x}$ Yes Yes Yes Yes Yes Yes Yes Yes Yes Yes $x$ Yes Yes No Yes Yes Yes Yes Yes Yes $x$ Yes Yes Yes Yes Yes Yes Yes Yes $x$ Yes Yes Yes Yes Yes Yes Yes $x$ Yes Yes Yes Yes No Yes $x$ Yes Yes Yes Yes Yes $x$ Yes Yes Yes Yes $x$ Yes Yes Yes $x$ Yes Yes $x$ Yes

Phosphorus - 4 samples differentiated 


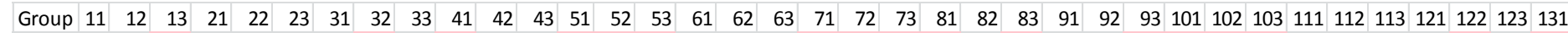
$11 \mathrm{x}$ No Yes No No No No Yes No Yes No No Yes Yes Yes No No No Yes Yes Yes Yes No Yes No No Yes Yes Yes Yes No No No No Yes No Yes $12 \quad x \quad$ No no Yes no no no no no no no no no no no Yes Yes no no no no no no no no no no no no no no no no no no no $x$ No no no no Yes no Yes no no Yes Yes no no no no Yes Yes Yes Yes no Yes no no Yes Yes Yes Yes no no no no Yes no Yes $x$ No Yes Yes no Yes no Yes Yes no Yes Yes Yes no no no no Yes Yes Yes no Yes Yes no no no no no no no Yes no Yes no $x$ No no no no no no no Yes no no no Yes yes no no no no no no no no no no no no no no no no no no no $x$ No no no no Yes no no no no Yes no no no no no no Yes no Yes Yes no no no no no no no Yes no no no $x$ Yes Yes no Yes Yes no Yes Yes Yes no no no no Yes Yes Yes no Yes Yes no Yes no no no no no Yes Yes Yes Yes $x$ Yes no Yes Yes Yes Yes Yes no no no no Yes Yes Yes Yes no Yes Yes no Yes Yes Yes no no no Yes Yes Yes Yes $x$ no Yes Yes no Yes Yes Yes no no no no Yes Yes Yes no Yes Yes no Yes no no no no no Yes Yes Yes Yes $x$ no no Yes no no no no no Yes Yes no no no Yes no no Yes Yes Yes Yes no Yes Yes no no no no $x$ Yes no Yes Yes Yes no no no no Yes Yes Yes no Yes Yes no Yes no no no no no Yes Yes Yes Yes $x$ no Yes Yes Yes no no no no Yes Yes Yes no Yes Yes no Yes no no no no no Yes Yes Yes Yes $x$ Yes no no Yes Yes Yes Yes Yes Yes no Yes no no Yes Yes Yes Yes Yes Yes Yes no Yes no Yes $x$ Yes Yes no no no no Yes Yes Yes no Yes Yes no Yes no Yes no no no Yes Yes Yes Yes $x$ no no no no no Yes Yes Yes no Yes Yes no Yes no no no no No Yes Yes Yes Yes $x$ No no no no Yes no Yes no Yes Yes no no no no no no no Yes no Yes no $x$ Yes no no no no no no no no no no no no no no no no No no No $x$ No no no no no no no no no no no no no no no no no no No $x$ yes no no no Yes no no Yes Yes Yes Yes Yes Yes yes no no no No $x$ Yes Yes no Yes no no Yes Yes Yes Yes Yes Yes Yes no no No Yes

$x$ Yes Yes no Yes Yes no Yes Yes Yes no no no Yes Yes Yes Yes $x$ Yes no Yes Yes Yes Yes Yes Yes no no no Yes Yes Yes Yes $x$ No Yes Yes no no no no no no No Yes Yes Yes Yes $x$ No no Yes Yes Yes Yes Yes Yes Yes no No No No

$x$ Yes no no no no no no no Yes Yes Yes Yes $x$ No Yes no no no no no Yes Yes Yes Yes $x$ Yes Yes Yes Yes Yes Yes no no No No $x$ Yes Yes no no no Yes Yes no Yes $x$ Yes no no Yes no no no No $x$ No no Yes no Yes no Yes $x$ Yes Yes no No No No $x$ Yes no no No No

$x$ No No No No $x$ Yes Yes Yes $x$ Yes Yes $x$ Yes

\section{Chromium - 382 samples differentiated, $57 \%$}




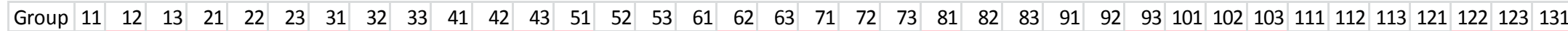
$11 \mathrm{x}$ Yes Yes Yes Yes Yes Yes Yes Yes Yes Yes Yes Yes No No No Yes Yes Yes Yes No Yes no no No No Yes Yes Yes Yes No No No No Yes Yes Yes $x$ Yes Yes Yes Yes Yes Yes Yes Yes Yes Yes Yes no No No Yes Yes Yes Yes no Yes No no no Yes Yes Yes Yes Yes No No No Yes Yes Yes Yes $x$ Yes Yes no Yes Yes Yes Yes Yes Yes no no no no Yes Yes Yes Yes no Yes no no no no Yes Yes Yes Yes no no no No no no Yes $x$ Yes Yes Yes Yes Yes Yes Yes Yes Yes no No No Yes Yes Yes Yes No Yes No no No No Yes Yes Yes Yes No No No No Yes Yes Yes $x$ Yes Yes Yes Yes Yes Yes Yes Yes no no No Yes Yes Yes Yes no Yes no no No No Yes Yes Yes Yes no no No No Yes no Yes $x$ Yes Yes Yes Yes Yes Yes Yes no Yes No Yes Yes Yes Yes no Yes no no No Yes Yes Yes no no No No No Yes Yes Yes Yes $x$ Yes Yes Yes Yes Yes Yes no no no Yes Yes Yes Yes no Yes No No No Yes Yes Yes Yes Yes No No No Yes Yes Yes Yes $x$ Yes Yes Yes Yes Yes no Yes no Yes Yes Yes Yes no Yes no no no Yes Yes Yes Yes Yes no No No Yes Yes Yes Yes $x$ Yes Yes Yes Yes no no No Yes Yes Yes Yes no Yes no no No Yes Yes Yes no Yes no no No Yes Yes Yes Yes $x$ Yes Yes Yes no No No Yes Yes Yes Yes No Yes no no No No Yes Yes Yes Yes no no no No Yes No Yes $x$ Yes Yes no Yes no Yes Yes Yes Yes No Yes no no No Yes Yes Yes Yes Yes No no no Yes Yes Yes Yes $x$ Yes no no no Yes Yes Yes Yes no Yes no no no no Yes Yes Yes Yes no no no no Yes No Yes $x$ No No no Yes Yes Yes Yes no Yes no no no Yes Yes Yes no no no no no Yes Yes Yes Yes $x$ No Yes no No no no Yes no Yes Yes Yes Yes no Yes no no No Yes Yes Yes Yes Yes No $x$ Yes no no Yes no no no no Yes Yes Yes Yes Yes no no No no No Yes Yes Yes No $x$ No No Yes no no no Yes Yes Yes Yes Yes Yes no no no no no Yes Yes Yes No $x$ Yes Yes Yes no Yes no no No Yes Yes Yes no Yes no no no Yes Yes Yes Yes $x$ Yes Yes no Yes no no no no Yes Yes Yes Yes no no no Yes Yes Yes Yes $x$ Yes no Yes no Yes Yes Yes Yes Yes Yes Yes no no no Yes Yes Yes Yes $x$ No Yes no no no Yes Yes Yes Yes Yes no no no Yes Yes Yes Yes $x \quad$ No Yes no Yes Yes no Yes no no Yes Yes Yes Yes no no no $x$ No no no Yes Yes Yes Yes Yes no No No Yes Yes Yes Yes $x$ Yes Yes Yes no Yes no No No Yes Yes Yes Yes Yes No $x$ Yes Yes Yes Yes no no No Yes no Yes Yes Yes no $x$ Yes Yes Yes no No No Yes Yes Yes Yes Yes No $x$ Yes Yes no no no Yes Yes Yes Yes Yes No $x$ Yes Yes Yes no no No Yes Yes Yes Yes $x$ Yes Yes Yes Yes Yes Yes Yes Yes Yes $x$ Yes no No No No No No Yes $x$ No No No No No No Yes $x$ Yes Yes no No No No $x$ Yes Yes no No No $x$ Yes No No No $x$ Yes Yes No $x$ Yes Yes $x$ No

Manganese - 272 samples differentiated, $41 \%$ 


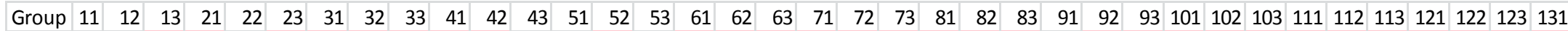
$11 \mathrm{x}$ No Yes Yes no Yes Yes Yes Yes Yes Yes no no Yes No Yes Yes Yes Yes Yes Yes Yes Yes Yes No Yes Yes Yes Yes Yes Yes Yes Yes Yes Yes Yes Yes $x$ No No Yes no no no no no no no Yes no no no no no no no no no no no no no no no no no no no no no no no no $x$ Yes no Yes Yes Yes Yes Yes Yes Yes no Yes no Yes Yes Yes Yes Yes Yes Yes Yes Yes Yes Yes Yes Yes Yes Yes Yes Yes Yes Yes Yes Yes Yes $x$ No Yes Yes Yes Yes Yes Yes Yes no Yes No Yes Yes no Yes Yes Yes Yes Yes Yes Yes Yes Yes Yes Yes Yes Yes Yes Yes Yes Yes Yes Yes

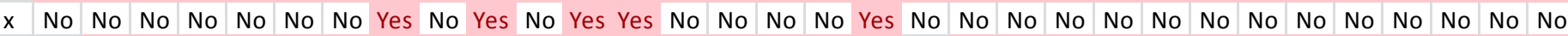
x Yes Yes Yes Yes Yes Yes no Yes no Yes Yes no Yes Yes Yes Yes Yes No Yes Yes Yes Yes Yes Yes Yes Yes Yes Yes Yes Yes Yes $x$ Yes Yes Yes no no no no no Yes Yes Yes Yes Yes Yes Yes Yes Yes No Yes Yes Yes Yes Yes Yes Yes Yes Yes Yes Yes Yes x Yes Yes Yes Yes no Yes no Yes Yes Yes Yes Yes Yes Yes Yes Yes no Yes Yes Yes Yes Yes Yes Yes Yes Yes Yes Yes Yes $x$ Yes Yes Yes no Yes no Yes Yes No Yes Yes Yes Yes Yes no no Yes Yes Yes Yes Yes Yes Yes Yes Yes Yes Yes Yes $x$ Yes no no Yes no Yes Yes Yes Yes Yes Yes Yes Yes Yes no Yes Yes Yes Yes Yes Yes Yes Yes Yes Yes Yes Yes $x$ Yes no Yes no Yes no no Yes Yes Yes Yes no no Yes Yes Yes Yes Yes Yes Yes Yes Yes Yes Yes Yes Yes $x$ No Yes no Yes no no Yes no Yes Yes no no Yes Yes Yes Yes Yes Yes Yes Yes Yes Yes Yes Yes Yes $x$ No No No No no no no no no no no no no no no no no no no no no no no no $x$ No Yes no no Yes Yes Yes Yes no no Yes Yes Yes Yes Yes Yes Yes Yes Yes Yes Yes Yes Yes $x$ No Yes Yes no no no No Yes Yes no no no no no no No no No Yes no no No $\boldsymbol{x}$ Yes no Yes Yes Yes Yes Yes Yes Yes Yes Yes Yes Yes Yes Yes Yes Yes Yes Yes Yes Yes $x$ Yes Yes Yes Yes Yes Yes Yes no Yes Yes Yes Yes Yes Yes Yes Yes Yes Yes Yes Yes $x$ Yes no Yes no Yes Yes no Yes Yes no no no Yes Yes no Yes Yes Yes Yes $\boldsymbol{x}$ Yes Yes Yes Yes Yes Yes Yes Yes Yes Yes Yes Yes Yes Yes Yes Yes Yes Yes $x$ Yes Yes Yes Yes no Yes Yes Yes Yes Yes Yes Yes Yes Yes Yes Yes Yes $x$ Yes Yes Yes Yes Yes Yes Yes Yes Yes Yes Yes Yes Yes Yes Yes Yes $\boldsymbol{x}$ Yes No Yes Yes Yes Yes Yes Yes Yes Yes Yes Yes Yes Yes Yes $x$ Yes no Yes Yes Yes Yes Yes Yes Yes Yes Yes Yes Yes Yes $x$ No Yes Yes Yes Yes no Yes Yes no Yes Yes Yes Yes $x$ Yes no Yes Yes Yes No No Yes Yes no Yes Yes $\boldsymbol{x}$ Yes Yes Yes Yes Yes Yes Yes Yes Yes Yes Yes $\boldsymbol{x}$ Yes Yes Yes Yes Yes Yes Yes Yes Yes Yes $x$ Yes Yes Yes Yes Yes Yes Yes Yes Yes $x$ Yes Yes Yes Yes Yes Yes Yes Yes $x$ Yes Yes Yes Yes Yes Yes Yes $x$ Yes Yes Yes Yes Yes Yes $x$ Yes Yes Yes Yes Yes $\boldsymbol{x}$ Yes Yes Yes Yes $x$ Yes Yes Yes $x$ Yes Yes $x$ Yes

Nickel - 173 samples differentiated, $26 \%$ 


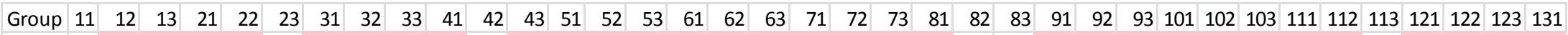
$x$ Yes Yes Yes Yes No Yes Yes Yes Yes No Yes Yes Yes Yes Yes Yes Yes Yes Yes Yes Yes No No Yes Yes Yes Yes Yes Yes Yes Yes No Yes Yes Yes Yes $\mathbf{x}$ Yes Yes Yes Yes Yes Yes Yes Yes Yes Yes Yes Yes Yes Yes Yes Yes Yes Yes Yes Yes no no Yes Yes Yes Yes Yes Yes Yes Yes Yes Yes Yes Yes Yes $x$ Yes Yes Yes Yes Yes Yes Yes no Yes Yes Yes Yes Yes Yes Yes Yes Yes Yes Yes Yes No Yes Yes Yes Yes Yes Yes Yes Yes Yes Yes Yes Yes Yes $x$ Yes Yes Yes Yes Yes Yes Yes Yes no Yes no Yes Yes Yes Yes Yes Yes Yes no No Yes Yes Yes Yes No Yes Yes Yes Yes Yes Yes Yes Yes $x$ Yes Yes Yes Yes Yes Yes Yes no Yes no Yes Yes Yes Yes Yes Yes Yes no No Yes Yes Yes Yes No Yes Yes Yes Yes Yes Yes Yes Yes $x$ Yes Yes Yes Yes Yes Yes no no no Yes Yes Yes Yes Yes no no no no Yes Yes Yes Yes no No Yes Yes Yes Yes Yes Yes Yes $\mathbf{x}$ Yes Yes Yes Yes Yes no Yes Yes Yes Yes Yes Yes Yes Yes Yes no no Yes Yes Yes Yes Yes Yes Yes Yes Yes Yes Yes Yes Yes $x$ Yes Yes Yes Yes no Yes no Yes Yes Yes Yes Yes Yes Yes no no Yes Yes Yes Yes no Yes Yes Yes Yes Yes Yes Yes Yes $x$ Yes no Yes no Yes Yes Yes Yes Yes Yes Yes Yes Yes no No Yes Yes Yes Yes Yes Yes Yes Yes Yes Yes Yes Yes Yes $x$ Yes Yes no Yes no Yes Yes Yes Yes Yes Yes Yes no no Yes Yes Yes Yes no Yes Yes Yes Yes Yes Yes Yes Yes $x$ Yes no no no Yes Yes Yes Yes Yes no no no No Yes Yes Yes Yes No no Yes Yes Yes Yes Yes Yes No $x$ No Yes no Yes Yes Yes Yes Yes Yes no no no Yes Yes Yes Yes No Yes Yes Yes Yes Yes Yes Yes Yes $x$ No Yes no no no Yes no Yes Yes Yes Yes no no no Yes Yes Yes no no no Yes no no Yes $x$ Yes Yes Yes Yes Yes Yes Yes Yes no no Yes Yes Yes Yes Yes Yes Yes Yes no Yes Yes Yes Yes $x$ No Yes no Yes no Yes Yes Yes Yes no no no Yes Yes Yes Yes no No Yes no Yes Yes $\mathbf{x}$ Yes Yes Yes Yes Yes Yes no No Yes Yes Yes Yes Yes Yes Yes Yes Yes Yes Yes Yes Yes $x$ Yes Yes Yes Yes Yes no no Yes Yes Yes Yes Yes Yes Yes Yes Yes Yes Yes Yes Yes $x$ Yes Yes Yes Yes no no Yes Yes Yes Yes no Yes Yes Yes Yes Yes Yes Yes Yes $x$ Yes Yes Yes no no Yes Yes Yes Yes Yes Yes Yes Yes Yes Yes Yes Yes Yes $x$ Yes no no no Yes Yes Yes Yes no Yes Yes Yes Yes Yes Yes Yes Yes $\boldsymbol{x}$ Yes no no Yes Yes Yes Yes Yes Yes Yes Yes no Yes Yes Yes Yes $x$ No No Yes Yes Yes Yes Yes Yes Yes Yes No Yes No Yes Yes $x$ Yes no No No No Yes no no no no no No No No $x$ No no no no no no no no no no no no No $x$ Yes Yes Yes no Yes Yes Yes Yes Yes Yes Yes Yes $\boldsymbol{x}$ Yes Yes no Yes Yes Yes Yes Yes Yes Yes Yes $x$ Yes Yes Yes Yes Yes Yes Yes Yes Yes Yes $\boldsymbol{x}$ Yes Yes Yes Yes Yes Yes Yes Yes Yes $x$ Yes Yes Yes no Yes No Yes Yes $\boldsymbol{x}$ Yes Yes no Yes Yes Yes Yes

$x$ Yes Yes Yes Yes Yes Yes $x$ Yes Yes Yes Yes Yes

$x$ Yes Yes Yes Yes $x$ Yes Yes Yes $x$ Yes Yes

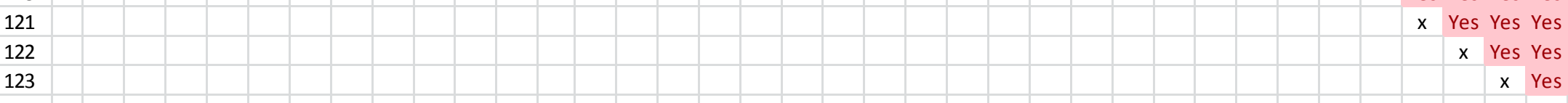

Copper - 136 samples differentiated, 20\% 


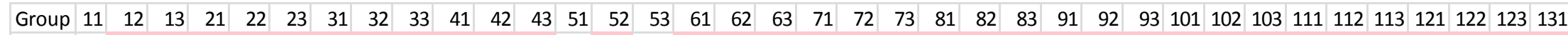
$11 \mathrm{x}$ Yes Yes Yes Yes Yes Yes Yes Yes Yes Yes Yes No Yes no Yes Yes Yes Yes Yes Yes Yes Yes Yes Yes Yes Yes Yes Yes Yes Yes Yes Yes Yes Yes Yes Yes $12 \quad \mathrm{x}$ Yes Yes Yes Yes Yes Yes Yes Yes Yes Yes no Yes no Yes Yes Yes Yes Yes Yes Yes Yes Yes Yes Yes Yes Yes Yes Yes Yes Yes Yes Yes Yes Yes Yes $\mathbf{x}$ Yes Yes Yes Yes Yes Yes Yes Yes Yes no Yes no Yes Yes Yes Yes Yes Yes Yes Yes Yes Yes Yes Yes Yes Yes Yes Yes Yes Yes Yes Yes Yes Yes

$x$ Yes Yes Yes Yes Yes Yes Yes Yes no Yes No Yes Yes Yes Yes Yes Yes Yes Yes Yes Yes Yes Yes Yes Yes Yes Yes Yes Yes Yes Yes Yes Yes $\mathbf{x}$ Yes Yes Yes Yes Yes Yes Yes no Yes no Yes Yes Yes Yes Yes Yes Yes Yes Yes Yes Yes Yes Yes Yes Yes Yes Yes Yes Yes Yes Yes Yes $x$ Yes Yes Yes Yes Yes Yes no Yes no Yes Yes Yes Yes Yes Yes Yes Yes Yes Yes Yes Yes Yes Yes Yes Yes Yes Yes Yes Yes Yes Yes $x$ Yes Yes Yes Yes Yes no Yes no Yes Yes Yes Yes Yes Yes Yes Yes Yes Yes Yes Yes Yes Yes Yes Yes Yes Yes Yes Yes Yes Yes $x$ Yes Yes Yes Yes no Yes no Yes Yes Yes Yes Yes Yes Yes Yes Yes Yes Yes Yes Yes Yes Yes Yes Yes Yes Yes Yes Yes Yes $\mathbf{x}$ Yes Yes Yes no Yes no Yes Yes Yes Yes Yes Yes Yes Yes Yes Yes Yes Yes Yes Yes Yes Yes Yes Yes Yes Yes Yes Yes $x$ Yes Yes no Yes no Yes Yes Yes Yes Yes Yes Yes Yes Yes Yes Yes Yes Yes Yes Yes Yes Yes Yes Yes Yes Yes Yes $x$ Yes no Yes no Yes Yes Yes Yes Yes Yes Yes Yes Yes Yes Yes Yes Yes Yes Yes Yes Yes Yes Yes Yes Yes Yes

$x$ No Yes no Yes Yes Yes Yes Yes Yes Yes Yes Yes Yes Yes Yes Yes Yes Yes Yes Yes Yes Yes Yes Yes Yes $x$ No Yes no no no no no no no no no no no no no no no no no no no no no no $x$ No Yes Yes Yes Yes Yes Yes Yes Yes Yes Yes Yes Yes Yes Yes Yes Yes Yes Yes Yes Yes Yes Yes $x$ No no no no no no no no no no no no no no no no no no no no no No $\mathbf{x}$ Yes Yes Yes Yes Yes Yes Yes Yes Yes Yes Yes Yes Yes Yes Yes Yes Yes Yes Yes Yes Yes

$\boldsymbol{x}$ Yes Yes Yes Yes Yes Yes Yes Yes Yes Yes Yes Yes Yes Yes Yes Yes Yes Yes Yes Yes $x$ Yes Yes Yes Yes Yes Yes Yes Yes Yes Yes Yes Yes Yes Yes Yes Yes Yes Yes Yes $x$ Yes Yes Yes Yes Yes Yes Yes Yes Yes Yes Yes Yes Yes Yes Yes Yes Yes Yes $x$ Yes Yes Yes Yes Yes Yes Yes Yes Yes Yes Yes Yes Yes Yes Yes Yes Yes $x$ Yes Yes Yes Yes Yes Yes Yes Yes Yes Yes Yes Yes Yes Yes Yes Yes $x$ Yes Yes Yes Yes Yes Yes Yes Yes Yes Yes Yes Yes Yes Yes Yes $\boldsymbol{x}$ Yes Yes Yes Yes Yes Yes Yes Yes Yes Yes Yes Yes Yes Yes $\boldsymbol{x}$ Yes Yes Yes Yes Yes Yes Yes Yes Yes Yes Yes Yes Yes $\boldsymbol{x}$ Yes Yes Yes Yes Yes Yes Yes Yes Yes Yes Yes Yes $x$ Yes Yes Yes Yes Yes Yes Yes Yes Yes Yes Yes $x$ Yes Yes Yes Yes Yes Yes Yes Yes Yes Yes $x$ Yes Yes Yes Yes Yes Yes Yes Yes Yes $\boldsymbol{x}$ Yes Yes Yes Yes Yes Yes Yes Yes $\boldsymbol{x}$ Yes Yes Yes Yes Yes Yes Yes $x$ Yes Yes Yes Yes Yes Yes $\boldsymbol{x}$ Yes Yes Yes Yes Yes $x$ Yes Yes Yes Yes $x$ Yes Yes Yes $x$ Yes Yes

Titanium - 70 samples differentiated, $11 \%$ 


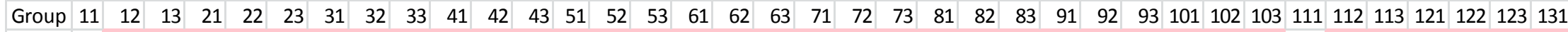
$11 \mathrm{x}$ Yes Yes Yes Yes Yes Yes Yes Yes Yes Yes Yes Yes Yes Yes Yes Yes Yes Yes Yes Yes Yes Yes Yes Yes Yes Yes Yes Yes Yes No Yes Yes Yes Yes Yes Yes $\mathbf{x}$ Yes Yes Yes Yes Yes Yes Yes Yes Yes Yes Yes Yes Yes Yes Yes Yes Yes Yes Yes Yes Yes Yes Yes Yes Yes Yes Yes Yes No Yes Yes Yes Yes Yes Yes $\mathbf{x}$ Yes Yes Yes Yes Yes Yes Yes Yes Yes Yes Yes Yes Yes Yes Yes Yes Yes Yes Yes Yes Yes Yes Yes Yes Yes Yes Yes No Yes Yes Yes Yes Yes Yes $x$ Yes Yes Yes Yes Yes Yes Yes Yes Yes Yes Yes Yes Yes Yes Yes Yes Yes Yes Yes Yes Yes Yes Yes Yes Yes Yes No Yes Yes Yes Yes Yes Yes $\mathbf{x}$ Yes Yes Yes Yes Yes Yes Yes Yes Yes Yes Yes Yes Yes Yes Yes Yes Yes Yes Yes Yes Yes Yes Yes Yes Yes No Yes Yes Yes Yes Yes Yes $x$ Yes Yes Yes Yes Yes Yes Yes Yes Yes Yes Yes Yes Yes Yes Yes Yes Yes Yes Yes Yes Yes Yes Yes Yes No Yes Yes Yes Yes Yes Yes $x$ Yes Yes Yes Yes Yes Yes Yes Yes Yes Yes Yes Yes Yes No Yes Yes Yes Yes Yes Yes Yes Yes Yes No Yes Yes Yes Yes Yes Yes $\mathbf{x}$ Yes Yes Yes Yes Yes Yes Yes Yes Yes Yes Yes Yes Yes Yes Yes Yes Yes Yes Yes Yes Yes Yes No Yes Yes Yes Yes Yes Yes $x$ Yes Yes Yes Yes Yes Yes Yes Yes Yes Yes Yes Yes Yes Yes No Yes Yes Yes Yes Yes Yes no Yes Yes No Yes Yes Yes $\mathbf{x}$ Yes Yes Yes Yes Yes Yes Yes Yes Yes Yes Yes Yes Yes Yes Yes Yes Yes Yes Yes Yes No Yes Yes Yes Yes Yes Yes $x$ Yes Yes Yes Yes Yes Yes Yes Yes Yes Yes Yes Yes Yes Yes Yes Yes Yes Yes Yes No Yes Yes Yes Yes Yes Yes $x$ Yes Yes Yes Yes Yes Yes Yes Yes Yes Yes Yes Yes Yes Yes Yes Yes Yes Yes no Yes Yes Yes Yes Yes Yes $\mathbf{x}$ Yes Yes Yes Yes Yes Yes Yes Yes Yes Yes Yes Yes Yes Yes Yes Yes Yes No Yes Yes Yes Yes Yes Yes x Yes Yes Yes Yes Yes Yes Yes Yes Yes Yes Yes Yes Yes Yes Yes Yes No Yes Yes Yes Yes Yes Yes $x$ Yes Yes Yes Yes Yes Yes Yes Yes Yes Yes Yes Yes Yes Yes Yes no Yes Yes Yes Yes Yes Yes $x$ Yes Yes Yes Yes Yes Yes Yes Yes Yes Yes Yes Yes Yes Yes No Yes Yes Yes Yes Yes Yes $x$ Yes Yes Yes Yes Yes Yes Yes Yes Yes Yes Yes Yes Yes no Yes Yes Yes Yes Yes Yes $x$ Yes Yes Yes Yes Yes Yes Yes Yes Yes Yes Yes Yes No Yes Yes Yes Yes Yes Yes $\boldsymbol{x}$ Yes Yes Yes Yes Yes Yes Yes Yes Yes Yes Yes No Yes Yes Yes Yes Yes Yes $x$ Yes Yes Yes Yes Yes Yes Yes Yes Yes Yes no Yes Yes Yes Yes Yes Yes $x$ Yes Yes no Yes Yes Yes Yes no Yes no Yes Yes no no Yes Yes $x$ Yes Yes Yes Yes Yes Yes Yes Yes no Yes Yes Yes Yes Yes Yes

$x$ Yes Yes Yes Yes Yes Yes Yes no Yes Yes Yes Yes Yes Yes $x$ Yes Yes Yes Yes Yes Yes No Yes Yes Yes Yes Yes Yes $x$ Yes Yes Yes Yes Yes no Yes Yes Yes Yes Yes Yes $x$ Yes Yes Yes Yes no Yes Yes Yes Yes Yes Yes $x$ Yes Yes Yes no Yes Yes Yes Yes Yes Yes $x$ Yes Yes no Yes Yes Yes Yes Yes Yes $\boldsymbol{x}$ Yes no Yes Yes Yes Yes Yes Yes $x$ No Yes Yes Yes Yes Yes Yes $x$ Yes no no No No No $\mathrm{x}$ Yes Yes Yes Yes Yes $x$ Yes Yes Yes Yes $x$ Yes Yes Yes $x$ Yes Yes

Cobalt - 42 samples differentiated, $6.3 \%$ 


\begin{tabular}{|c|c|c|c|c|c|c|c|c|c|c|c|c|c|c|c|c|c|c|c|c|c|c|c|c|c|c|c|c|c|c|c|c|c|c|c|c|}
\hline Group & 12 & 213 & $3 \quad 21$ & 22 & 23 & 31 & 32 & 33 & 41 & 42 & 43 & 51 & 52 & 53 & 61 & 62 & 63 & 71 & 72 & 73 & 81 & 82 & 83 & 91 & 92 & 931 & 1011 & 1021 & 1031 & 1111 & 1121 & 1131 & 1211 & 1221 & 1231 & 131 \\
\hline $11 x$ & $x$ No & Yes & No & No & No & No & Yes & No & Yes & No & No & No & No & No & No & No 1 & No $Y$ & Yes Y & Yes 1 & No $Y$ & Yes & No & No $N$ & No 1 & No & Yes Y & Yes Y & Yes Y & Yes $\mathrm{N}$ & No $\mathrm{N}$ & No $N$ & No $\mathrm{N}$ & No $Y$ & Yes $N$ & No $Y$ & Yes \\
\hline 12 & $x$ & No & No & Yes & No & No & No & No 1 & No & No & No & No & No 1 & No $N$ & No 1 & No 1 & No $N$ & No $\mathrm{N}$ & No 1 & No $\uparrow$ & No $\Gamma$ & No & No $N$ & No 1 & No 1 & No $N$ & No $\wedge$ & No $N$ & No $\mathrm{N}$ & No $\mathrm{N}$ & No $\mathrm{N}$ & No $\mathrm{N}$ & No $\mathrm{N}$ & No $N$ & No & No \\
\hline 13 & & $x$ & No & No & No & No & Yes & No & Yes & No & No & No & No 1 & No 1 & No 1 & No 1 & No $Y$ & Yes Y & Yes 1 & No $Y$ & Yes $N$ & No $\wedge$ & No $N$ & No 1 & No & Yes $Y$ & Yes Y & Yes $Y$ & Yes $\mathrm{N}$ & No $\mathrm{N}$ & No $\mathrm{N}$ & No $N$ & No $N$ & No $N$ & No $Y$ & Yes \\
\hline 21 & & & $x$ & No & Yes & Yes & No & Yes 1 & No & Yes & Yes & No & No 1 & No 1 & No 1 & No 1 & No $\mathrm{N}$ & No $\mathrm{N}$ & No 1 & No $Y$ & Yes $N$ & No $\wedge$ & No $N$ & No 1 & No 1 & No $N$ & No $\wedge$ & No $N$ & No $\mathrm{N}$ & No $\mathrm{N}$ & No $\mathrm{N}$ & No $N$ & No $\mathrm{N}$ & No $Y$ & Yes $\Lambda$ & No \\
\hline 22 & & & & $x$ & Yes & No & No & No & No & No & No & Yes & No & No & No & Yes & Yes $\mathrm{N}$ & No $\mathrm{N}$ & No 1 & No & No & No & No $N$ & No 1 & No & No $N$ & No & No $N$ & No $\mathrm{N}$ & No $\mathrm{N}$ & No $\mathrm{N}$ & No $\mathrm{N}$ & No $\mathrm{N}$ & No $N$ & No $\wedge$ & No \\
\hline 23 & & & & & $x$ & No & No & No & No & Yes & No & No & No & No & No & No & No $N$ & No $\mathrm{N}$ & No 1 & No & No & No & No $N$ & No & Yes 1 & No $N$ & No & No $N$ & No $\mathrm{N}$ & No $\mathrm{N}$ & No $\mathrm{N}$ & No $Y$ & Yes $\mathrm{N}$ & No $N$ & No & No \\
\hline 31 & & & & & & $x$ & Yes & Yes 1 & No & No & No & No & No 1 & No 1 & No 1 & No 1 & No $N$ & No $N$ & No 1 & No $Y$ & Yes $N$ & No $\wedge$ & No $N$ & No $Y$ & Yes 1 & No $Y$ & Yes $\wedge$ & No $N$ & No $\mathrm{N}$ & No $\mathrm{N}$ & No $\mathrm{N}$ & No $Y$ & Yes Y & Yes $Y$ & Yes $Y$ & Yes \\
\hline 32 & & & & & & & $x$ & Yes 1 & No & Yes & Yes & No & No 1 & No 1 & No 1 & No 1 & No $\mathrm{N}$ & No $Y$ & Yes 1 & No $Y$ & Yes $N$ & No $\wedge$ & No $N$ & No & Yes 1 & No $Y$ & Yes Y & Yes Y & Yes $\mathrm{N}$ & No $\mathrm{N}$ & No $N$ & No $Y$ & Yes $Y$ & Yes Y & Yes Y & Yes \\
\hline 33 & & & & & & & & $x$ & No & Yes & Yes & No & No & No 1 & No & No 1 & No $\mathrm{N}$ & No $\mathrm{N}$ & No 1 & No $Y$ & Yes 1 & No & No $N$ & No & Yes & No $Y$ & Yes $N$ & No $N$ & No $\mathrm{N}$ & No $\mathrm{N}$ & No $N$ & No $Y$ & Yes Y & Yes Y & Yes Y & Yes \\
\hline 41 & & & & & & & & & $x$ & No & No & No & No & No 1 & No & No 1 & No $Y$ & Yes Y & Yes 1 & No & No & No & No $N$ & No 1 & No $Y$ & Yes Y & Yes Y & Yes Y & Yes $\mathrm{N}$ & No $\mathrm{N}$ & No $N$ & No $N$ & No $\mathrm{N}$ & No $N$ & No 1 & No \\
\hline 42 & & & & & & & & & & $x$ & Yes & No & No & No 1 & No 1 & No 1 & No $\mathrm{N}$ & No $\mathrm{N}$ & No 1 & No $Y$ & Yes 1 & No & No $N$ & No & Yes 1 & No $Y$ & Yes $N$ & No $N$ & No $\mathrm{N}$ & No $\mathrm{N}$ & No $N$ & No $Y$ & Yes Y & Yes Y & Yes Y & Yes \\
\hline 43 & & & & & & & & & & & $x$ & No & No & No & No & No & No $N$ & No $\mathrm{N}$ & No 1 & No $Y$ & Yes & No & No $N$ & No 1 & No & No $Y$ & Yes $N$ & No $N$ & No $\mathrm{N}$ & No $\mathrm{N}$ & No $N$ & No $N$ & No $Y$ & Yes $N$ & No $Y$ & Yes \\
\hline 51 & & & & & & & & & & & & $x$ & No & No & No 1 & No & No $N$ & No $\mathrm{N}$ & No 1 & No & No & No & No $N$ & No 1 & No & No & No & No $N$ & No $\mathrm{N}$ & No $\mathrm{N}$ & No $\mathrm{N}$ & No $N$ & No $\mathrm{N}$ & No $N$ & No & No \\
\hline 52 & & & & & & & & & & & & & $x$ & No $Y$ & Yes 1 & No 1 & No $N$ & No $\mathrm{N}$ & No & Yes & No & No & No $Y$ & Yes Y & Yes & No $Y$ & Yes $N$ & No $N$ & No $\mathrm{N}$ & No $\mathrm{N}$ & No $\mathrm{N}$ & No $Y$ & Yes $Y$ & Yes Y & Yes & No \\
\hline 53 & & & & & & & & & & & & & & $x$ & No & No & No $N$ & No $\mathrm{N}$ & No 1 & No & No & No & No $N$ & No & No & No & No & No $N$ & No $\mathrm{N}$ & No $\mathrm{N}$ & No $\mathrm{N}$ & No $Y$ & Yes $\mathrm{N}$ & No $N$ & No & No \\
\hline 61 & & & & & & & & & & & & & & & $x$ & No 1 & No $\mathrm{N}$ & No $\mathrm{N}$ & No 1 & No 1 & No $Y$ & Yes $\Lambda$ & No $Y$ & Yes Y & Yes $N$ & No $N$ & No $\wedge$ & No $N$ & No $\mathrm{N}$ & No $\mathrm{N}$ & No $\mathrm{N}$ & No $Y$ & Yes $\mathrm{N}$ & No $Y$ & Yes $N$ & No \\
\hline 62 & & & & & & & & & & & & & & & & $x$ & Yes $\mathrm{N}$ & No $\mathrm{N}$ & No 1 & No & No 1 & No & No $N$ & No 1 & No 1 & No $N$ & No & No $N$ & No $\mathrm{N}$ & No $\mathrm{N}$ & No $N$ & No $N$ & No $\mathrm{N}$ & No $N$ & No 1 & No \\
\hline 63 & & & & & & & & & & & & & & & & $x$ & $\mathrm{~N}$ & No $\mathrm{N}$ & No 1 & No 1 & No 1 & No & No $N$ & No 1 & No 1 & No $N$ & No & No $N$ & No $\mathrm{N}$ & No $\mathrm{N}$ & No $N$ & No $N$ & No $\mathrm{N}$ & No $N$ & No 1 & No \\
\hline 71 & & & & & & & & & & & & & & & & & $x$ & Y & Yes 1 & No & No 1 & No $Y$ & Yes $\mathrm{N}$ & No 1 & No $Y$ & Yes Y & Yes Y & Yes Y & Yes $\mathrm{N}$ & No $\mathrm{N}$ & No $N$ & No $N$ & No $\mathrm{N}$ & No $N$ & No 1 & No \\
\hline 72 & & & & & & & & & & & & & & & & & & $x$ & $x$ & No $Y$ & Yes & No & No $N$ & No & No $Y$ & Yes Y & Yes Y & Yes Y & Yes $\mathrm{N}$ & No $\mathrm{N}$ & No $N$ & No $N$ & No $\mathrm{N}$ & No $N$ & No $Y$ & Yes \\
\hline 73 & & & & & & & & & & & & & & & & & & & & $x$ & No $Y$ & Yes $\Lambda$ & No $Y$ & Yes $Y$ & Yes & No $Y$ & Yes $N$ & No $N$ & No $\mathrm{N}$ & No $\mathrm{N}$ & No $N$ & No $Y$ & Yes $\mathrm{N}$ & No $N$ & No & No \\
\hline 81 & & & & & & & & & & & & & & & & & & & & & $x$ & No $\wedge$ & No $N$ & No $Y$ & Yes Y & Yes Y & Yes Y & Yes Y & Yes $\mathrm{N}$ & No $\mathrm{N}$ & No $N$ & No $Y$ & Yes $Y$ & Yes Y & Yes Y & Yes \\
\hline 82 & & & & & & & & & & & & & & & & & & & & & & $x$ & No $N$ & No $Y$ & Yes & No $N$ & No & No $N$ & No $\mathrm{N}$ & No $\mathrm{N}$ & No $N$ & No $Y$ & Yes Y & Yes Y & Yes 1 & No \\
\hline 83 & & & & & & & & & & & & & & & & & & & & & & $\mathrm{x}$ & $x$ & No & No $Y$ & Yes Y & Yes $N$ & No $N$ & No $\mathrm{N}$ & No $Y$ & es $N$ & No $N$ & No $\mathrm{N}$ & No $N$ & No 1 & No \\
\hline 91 & & & & & & & & & & & & & & & & & & & & & & & $\mathrm{x}$ & Y & Yes 1 & No & No & No $N$ & No $\mathrm{N}$ & No $\mathrm{N}$ & No $N$ & No Y & Yes $\mathrm{N}$ & No $Y$ & Yes 1 & No \\
\hline 92 & & & & & & & & & & & & & & & & & & & & & & & & & $x$ & No $Y$ & Yes $N$ & No $N$ & No $\mathrm{N}$ & No $\mathrm{N}$ & No $N$ & No Y & Yes Y & Yes Y & Yes 1 & No \\
\hline 93 & & & & & & & & & & & & & & & & & & & & & & & & & & $x$ & Yes Y & Yes Y & Yes $\mathrm{N}$ & No $\mathrm{N}$ & No $N$ & No $N$ & No $\mathrm{N}$ & No $N$ & No & No \\
\hline 101 & & & & & & & & & & & & & & & & & & & & & & & & & & & $x$ & Yes Y & Yes $\mathrm{N}$ & No $\mathrm{N}$ & No $N$ & No $Y$ & Yes $Y$ & Yes $N$ & No $Y$ & Yes \\
\hline 102 & & & & & & & & & & & & & & & & & & & & & & & & & & & $\mathrm{x}$ & $x$ & Yes $\mathrm{N}$ & No $\mathrm{N}$ & No $N$ & No & No $\mathrm{N}$ & No $N$ & No & No \\
\hline 103 & & & & & & & & & & & & & & & & & & & & & & & & & & & & $\mathrm{x}$ & $\mathrm{N}$ & No $\mathrm{N}$ & No $N$ & No & No $\mathrm{N}$ & No $N$ & No & Yes \\
\hline 111 & & & & & & & & & & & & & & & & & & & & & & & & & & & & & $x$ & Y & les Y & Yes $\Lambda$ & No $\mathrm{N}$ & No $N$ & No 1 & No \\
\hline 112 & & & & & & & & & & & & & & & & & & & & & & & & & & & & & & $x$ & & Yes $~$ & No $\mathrm{N}$ & No $N$ & No 1 & No \\
\hline 113 & & & & & & & & & & & & & & & & & & & & & & & & & & & & & & & & $x$ & No $N$ & No $N$ & No 1 & No \\
\hline 121 & & & & & & & & & & & & & & & & & & & & & & & & & & & & & & & & $\mathrm{x}$ & $Y$ & Yes Y & Yes 1 & No \\
\hline 122 & & & & & & & & & & & & & & & & & & & & & & & & & & & & & & & & & $x$ & $x$ & Yes & Yes \\
\hline 123 & & & & & & & & & & & & & & & & & & & & & & & & & & & & & & & & & & & $x$ & No \\
\hline 131 & & & & & & & & & & & & & & & & & & & & & & & & & & & & & & & & & & & & \\
\hline
\end{tabular}

Chromium, Manganese, and Nickel - 508 samples differentiated, 76\% 


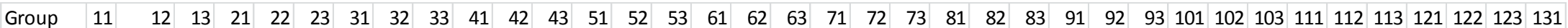

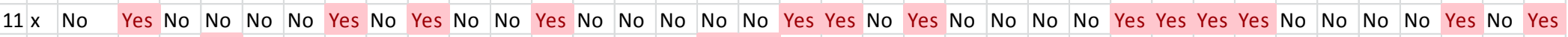

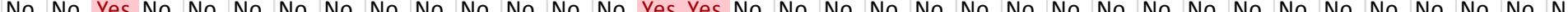

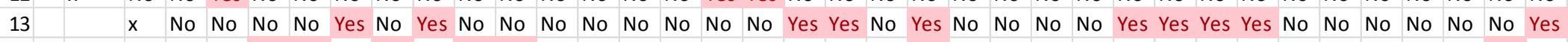
$21 \quad x \quad$ No Yes Yes no Yes no Yes Yes no no no no no no no no no Yes no no no no no no no no no no no no no Yes no $22 \quad x \quad$ No no no no no no no Yes no no no Yes Yes no no no no no no no no no no no no no no no no no no no

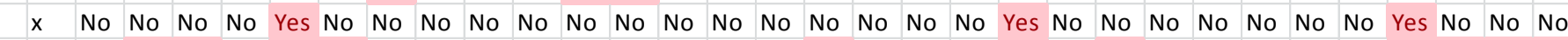
$x$ Yes Yes no Yes Yes no no no no no no no no no Yes no no No Yes no Yes no no no No No Yes Yes Yes Yes $x$ Yes no Yes Yes Yes no Yes no no no no Yes no Yes no no no Yes No Yes Yes Yes no No No Yes Yes Yes Yes $x \quad$ No Yes Yes no no no no no no no no no Yes no no no Yes no Yes no no no no no No Yes Yes Yes $x$ No no Yes no no no no no Yes Yes no no no no no no Yes Yes Yes Yes no No no no no No No $x$ Yes no no Yes no no no no no no Yes no no no Yes no Yes no no no no no Yes Yes Yes Yes $x \quad$ No No no no no no no no no Yes no no no no no Yes no no no no no no Yes No Yes $x \quad$ No no no Yes Yes Yes Yes no Yes no no no no Yes Yes no no no no no No Yes no Yes $x \quad$ No Yes no no no no Yes no Yes no Yes Yes no Yes No No no No No Yes Yes Yes no $x \quad$ No no no no no no No no No Yes Yes no Yes no No No No No Yes Yes Yes No $x \quad$ No no no no no no Yes no Yes Yes no no no no no no no Yes No Yes no $x$ Yes no no no no no No no no no no no no no no no No No No No $x \quad$ No no no no no No no no no no no no no no no no no No No $x$ Yes no no no Yes no no Yes Yes Yes Yes no no no no no no No $x \quad$ No Yes no no no No Yes Yes Yes Yes no no no No No No Yes $x \quad$ No Yes no Yes Yes no Yes no no no no no no no No No $x \quad$ No no no Yes Yes Yes Yes Yes no No No Yes Yes Yes Yes $x \quad$ No Yes Yes no no no No No No No Yes Yes Yes No $x \quad$ No No Yes Yes no no no Yes no no no no no $x$ Yes no no no no no No No Yes Yes Yes no $x \quad$ No Yes no No No No No Yes Yes Yes No $x$ Yes Yes Yes no no no No No No No $x$ Yes Yes no no No Yes Yes No Yes $x$ Yes No No No No No No No $x$ No No No No No No Yes $x$ Yes no No No No No $x$ Yes no No No No $x$ No No No No $x$ Yes Yes No

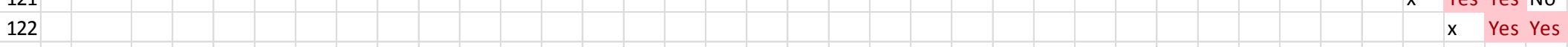
123 131 $x \quad$ No

Chromium, Manganese, Cobalt - 486 samples differentiated, $73 \%$ 
\begin{tabular}{|l|l|l|l|l|l|l|l|l|l|l|l|l|l|l|l|l|l|l|l|l|l|l|l|l|l|l|l|l|l|l|l|l|l|l|l|l|l} 
Group & 11 & 12 & 13 & 21 & 22 & 23 & 31 & 32 & 33 & 41 & 42 & 43 & 51 & 52 & 53 & 61 & 62 & 63 & 71 & 72 & 73 & 81 & 82 & 83 & 91 & 92 & 93 & 101 & 102 & 103 & 111 & 112 & 113 & 121 & 122 & 123 & 131
\end{tabular}

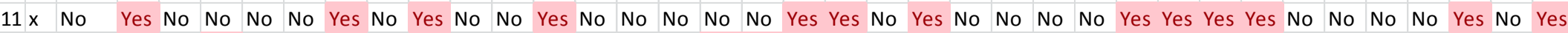

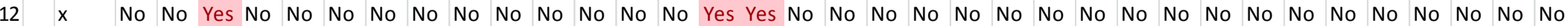
$13 \quad x \quad$ No No no no Yes no Yes no no no no no no no No Yes Yes no Yes no no no No Yes Yes Yes Yes no no No No No No Yes

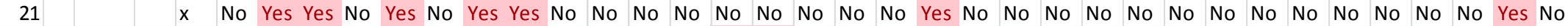

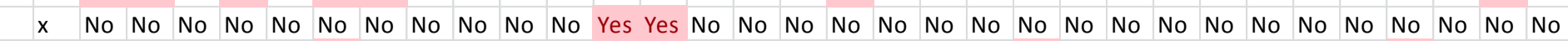

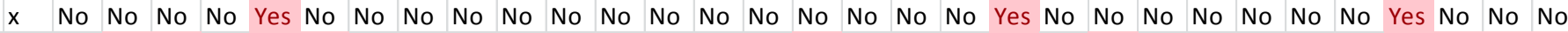
$x$ Yes Yes no Yes Yes no no no no no no no no no Yes no no No Yes no Yes no No No No No Yes Yes Yes Yes $x$ Yes no Yes Yes no no no no no no no Yes no Yes no no no Yes no Yes No Yes no No No Yes Yes Yes Yes $x$ No no Yes no no no no no no no no no Yes no no no Yes no Yes no no no no No Yes Yes Yes Yes

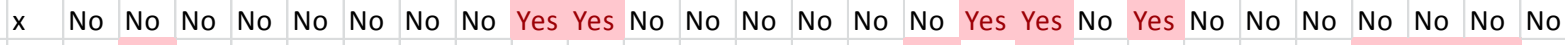
$x$ Yes no no no no no No no no no no no no no Yes no Yes no no no no no Yes Yes Yes no $x \quad$ No No no no no no no no no no no no no no no Yes no no no no no No Yes no Yes $x \quad$ No No No no no Yes No No Yes no no No no no Yes no No No no no no No No Yes $x \quad$ No Yes no no no no Yes no no no Yes Yes no Yes no no No No No Yes Yes Yes No $x \quad$ No no no no no no no no no No No No Yes No No No No No Yes No Yes No $x \quad$ No no no no no no no no Yes Yes no no no no no no no Yes no Yes no $x$ Yes no no no no no no no no no no no no No No no no no no No $x \quad$ No No No No No No No No No No No No no No No No No No No $x$ Yes no no no no no No Yes Yes Yes Yes no no no no no No No $x \quad$ No no no no no No Yes Yes no Yes no No no no No No Yes $x \quad$ No No No Yes Yes No Yes no No No No No Yes No No No $x \quad$ No no no Yes Yes Yes Yes Yes no no no Yes no Yes Yes $x \quad$ No no no no no no No no no no no no no No $x \quad$ No No No No No No No No No No No No No $x$ Yes no no no no No No No Yes Yes Yes No $x$ No Yes no no No No No Yes Yes Yes No $x \quad$ Yes Yes Yes no No No No No No No $x$ Yes Yes no No No Yes Yes no Yes $x$ Yes no no No No No No No $x$ No No No No No No Yes $x$ Yes Yes no No No No $x$ Yes No No No No $x$ No No No No $x$ Yes Yes no $x$ Yes Yes

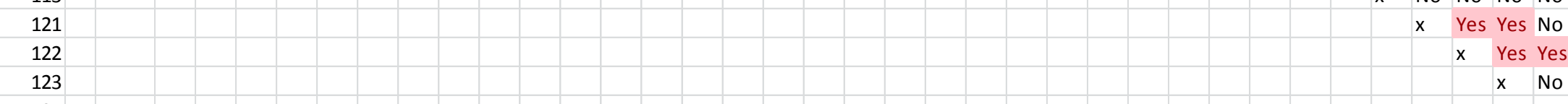

131

Chromium, Manganese, Copper - 517 samples differentiated, 78\% 


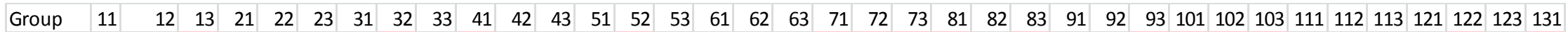
11 x No Yes no no no no Yes no Yes no no no Yes no no no No Yes Yes Yes Yes no Yes No No Yes Yes Yes Yes no no No No Yes No Yes

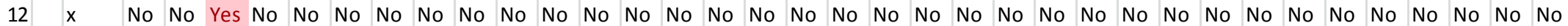

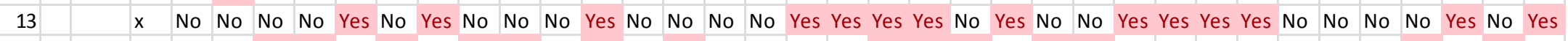
$21 \quad x \quad$ No Yes Yes no Yes no Yes Yes no Yes no Yes no No No no Yes Yes Yes No Yes Yes no No No No No No No Yes No Yes No

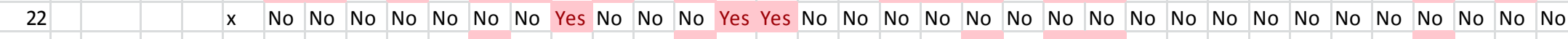

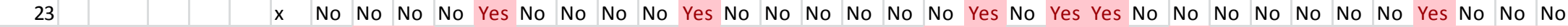
$31 \quad x \quad$ Yes Yes no no no no No No Yes No no No No No Yes Yes No No Yes No Yes No No No No No Yes Yes Yes Yes $x$ Yes no Yes Yes no Yes no no no no no Yes Yes Yes Yes no no Yes No Yes Yes Yes No No No Yes Yes Yes Yes $x$ No Yes Yes no Yes no Yes no no no no Yes Yes Yes no no Yes no Yes no no No no no No Yes Yes Yes $x$ No no no no no no no no Yes Yes no no no Yes no no Yes Yes Yes Yes no Yes Yes no no no no $x$ Yes no Yes no Yes no no no no Yes Yes no no Yes Yes no Yes no no no no no Yes Yes Yes Yes $x \quad$ No Yes no Yes no no no no Yes Yes no no Yes Yes no Yes no no no no No Yes Yes Yes Yes $x \quad$ No No no no no No no no no no no no no no no no no no no no no no no No $x \quad$ No Yes no no no no Yes Yes no no Yes Yes no Yes no Yes no no no Yes Yes Yes Yes

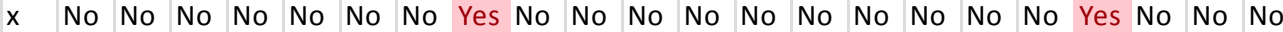
$x \quad$ No No no no Yes no Yes no Yes Yes no No no No No No No Yes No Yes No $x$ Yes no No No No No no no no No No No No No No No No No No No $x \quad$ No No No No No No No no no no no no no No No No No No No $x$ Yes no no no Yes no no Yes Yes Yes Yes no Yes Yes no No No No $x$ Yes Yes no Yes no no Yes Yes Yes Yes no Yes Yes no no no Yes $x$ Yes Yes no Yes Yes no Yes no Yes no no no no No Yes Yes x Yes no Yes Yes Yes Yes Yes Yes no no No Yes Yes Yes Yes $x \quad$ No no Yes no no no no no no No Yes Yes Yes Yes $x \quad$ No No Yes Yes Yes no no Yes no no No No No $x$ Yes no No No No No No No Yes No Yes Yes $x \quad$ No Yes no no No No No Yes Yes Yes Yes $x$ Yes Yes Yes no Yes Yes No No No No $x$ Yes Yes no no no Yes Yes no Yes $x$ Yes no no Yes No No No No $x \quad$ No No Yes no Yes No Yes $x$ Yes No No No No No $x$ Yes no No No No $x$ No No No No

$x$ Yes Yes Yes $x$ Yes Yes $x$ Yes

Chromium, Nickel, Cobalt -444 samples, $67 \%$ 


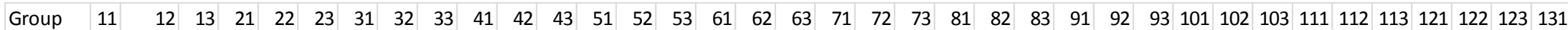
11 x no Yes no no no no Yes no Yes no no no Yes no no no no Yes Yes Yes Yes no no No No Yes Yes Yes Yes no no no no Yes no Yes

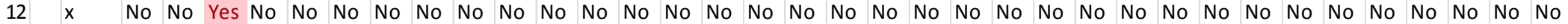

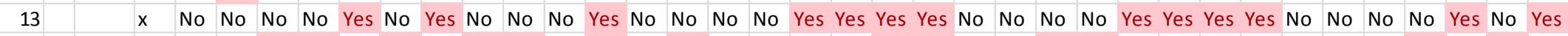
$21 \quad x \quad$ No Yes Yes no Yes no Yes Yes no Yes no Yes no no No no Yes Yes no no Yes Yes No No No No No No No Yes no Yes No

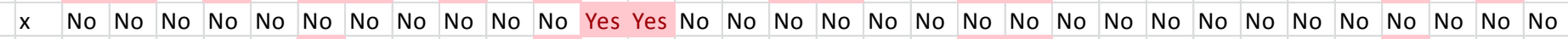

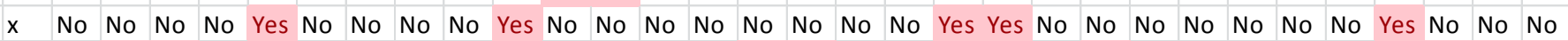
$x$ Yes Yes no no no no no no Yes no no No No Yes Yes no No No Yes No Yes no no No No No Yes Yes Yes Yes $x$ Yes no Yes Yes no Yes no no no no no Yes Yes Yes no no no Yes no Yes no Yes no No No Yes Yes Yes Yes x No no Yes no Yes no Yes no no no no Yes Yes no No no Yes no Yes no no no no No Yes Yes Yes Yes $x \quad$ No no no no no no no no Yes Yes no no no no no no Yes Yes no Yes no Yes Yes no no No No $x$ Yes no no no Yes no no no no no no no no Yes Yes no Yes no no no no no Yes Yes Yes no $x \quad$ no Yes no Yes no no no no Yes no no no Yes Yes no Yes no no no no No Yes Yes Yes Yes

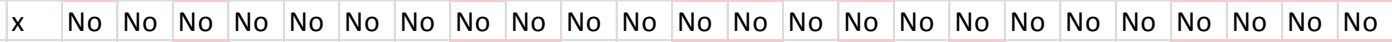
$x \quad$ No Yes no no no no Yes Yes no no Yes Yes no Yes no Yes no No No Yes Yes Yes Yes $x \quad$ No No No no no No No Yes no no no no no no No No no No Yes no no No $x \quad$ No No no no Yes no no no Yes Yes no no no no no no no Yes No Yes no $x$ Yes no no no no No No No No No No No no no no no no no No No $x \quad$ No No No No No No No No no no no no no No No No No No No $x$ Yes no no no no no no Yes Yes Yes Yes Yes Yes Yes no No No No $x$ Yes no no no no no Yes Yes no Yes Yes Yes Yes no No No Yes $x$ Yes no no Yes Yes no Yes Yes Yes no no No Yes Yes Yes Yes $x \quad$ No No Yes Yes Yes Yes Yes Yes no no no Yes no Yes Yes $x \quad$ No No No No No No no no no no no No No No $x$ No No No No No No No No No No No No No $x$ Yes no no no No No No No Yes No Yes Yes $x \quad$ No Yes no no no no no Yes Yes Yes Yes $x$ Yes Yes Yes Yes Yes Yes no No No No $x$ Yes Yes no no no Yes Yes no Yes $x$ Yes no no no no No No No $x \quad$ No No No No Yes No Yes $x$ Yes Yes no no no No $x$ Yes no No No No $x$ No No No No $x$ Yes Yes Yes $x$ Yes Yes 123 $x$ Yes

Chromium, Nickel, and Copper - 471 samples, $71 \%$ 


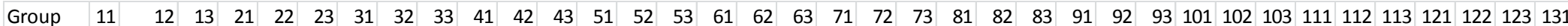
$11 \times$ No Yes no no no no Yes no Yes no no no no no no no no Yes Yes no Yes no no no no Yes Yes Yes Yes no no no no Yes no Yes

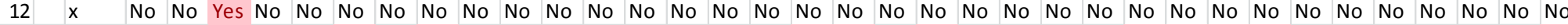
$13 \quad x \quad$ No No No No Yes No Yes No No No No No No No No Yes Yes No Yes No No No No Yes Yes Yes Yes No No No No No No Yes

$x \quad$ No Yes Yes no Yes no Yes Yes no no no no no no no no no Yes no no no no no no no No no no No no no Yes no

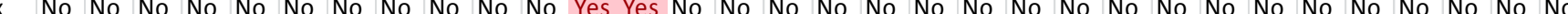
$x$ No no no no Yes no no no no no no no no no no no no no no Yes no no no no no no no Yes no No no $x$ Yes Yes no no no no no no no no no no no no Yes no no no Yes no Yes no no no no no Yes Yes Yes Yes $x$ Yes no Yes Yes no no no no no no no Yes no Yes no no no Yes no Yes no Yes no no No Yes Yes Yes Yes $x \quad$ No No Yes no no no no no no no no no Yes no No no Yes no Yes no no no no No No Yes Yes Yes $x$ No no no no no no no no Yes Yes no no no no no no Yes Yes no Yes no no no no no no No $x$ Yes no no no no no no no no no no no no no Yes no Yes no no no no no Yes Yes Yes no $x$ No no no no no no no no no no no no no no no Yes no no no no no no Yes no Yes

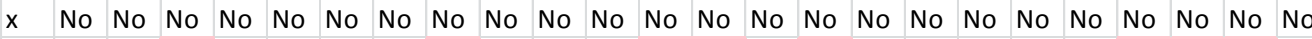
$x \quad$ No Yes no no no no Yes no no no Yes Yes no Yes no no no no no Yes Yes Yes No $x$ No no no no no no no no no no no no no no no no no no Yes no no No $x$ No no no no no no no no Yes Yes no no no no no No no Yes no Yes no $x$ Yes no no no no no no no no no no no no no no no No No No No $x \quad$ No No no no no no no no no no no no no no no no no No No $x$ Yes no no no no no no Yes Yes Yes Yes no no no no no no No $x \quad$ no no no no no no Yes Yes no Yes no no no no No No Yes $x \quad$ No No No Yes Yes no Yes no no no no no no no No No $x \quad$ No No no Yes Yes Yes Yes Yes no no no Yes no Yes Yes $x \quad$ No No no no No No No no No No no No No No $x$ No No No No No No No No No No No No No $x$ Yes no no no no no No No Yes no Yes No * No Yes no no no no No Yes Yes Yes no $x$ Yes Yes Yes no no no No No No No $x$ Yes Yes no no No Yes Yes no Yes $x$ Yes no No No No No No No $x$ No No No No No No Yes $x$ Yes no No No No No $x$ Yes no No No No $x$ No No No No $x$ Yes Yes no $x$ Yes Yes $x \quad$ No

Chromium, Manganese, Copper, Nickel, and Cobalt - 532 samples, 80\% 
